\title{
Metagenombasierte Isolierung und biochemische Charakterisierung neuartiger stereospezifischer Lipasen für biokatalytische Anwendungen
}

\author{
Dissertation \\ zur Erlangung des Doktorgrades \\ der Mathematisch-Naturwissenschaftlichen Fakultäten \\ der Georg-August-Universität zu Göttingen
}

vorgelegt von

Christian Elend

aus Göttingen 
D7

Referent: Prof. Dr. Wolfgang Streit

Korreferent: Prof. Dr. Wolfgang Liebl

Tag der mündlichen Prüfung: 01.11.2006 
Abkürzungen ................................................................................... vii

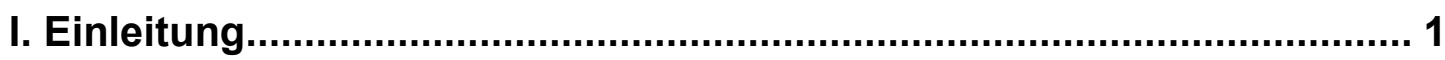

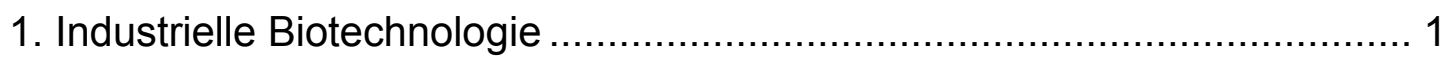

2. Lipasen und Esterasen als Biokatalysatoren .......................................... 2

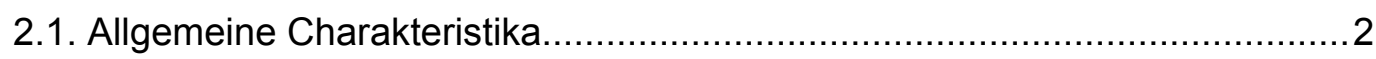

2.2. Praktische Beispiele für den Einsatz von Lipasen......................................... 4

3. Metagenomik als Quelle neuer Biokatalysatoren ..................................... 5

3.1. Unkultivierbare Organismen und der Begriff "Metagenom“.......................... 5

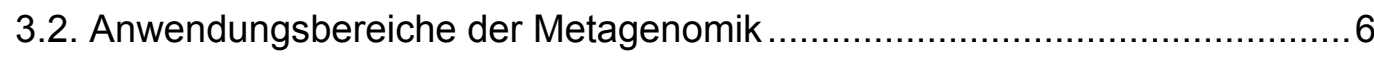

3.3. Neue Enzyme aus dem Metagenom ...................................................... 8

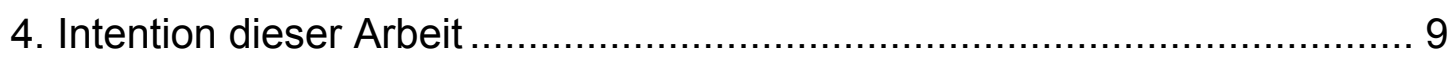

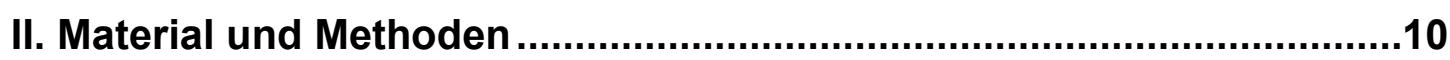

1. Verwendete Organismen, Plasmide und Oligonukleotide .....................10

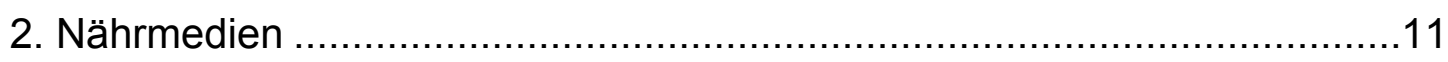

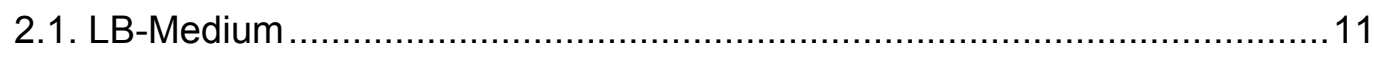

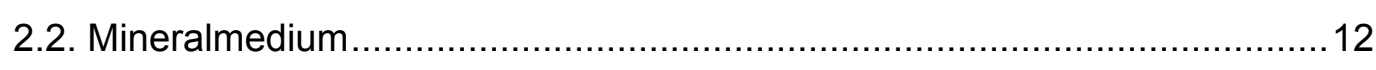

2.3. Antibiotika und sonstige Medienzusätze ................................................. 12

3. Wachstumsbedingungen und Stammhaltung......................................12

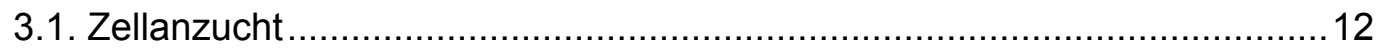

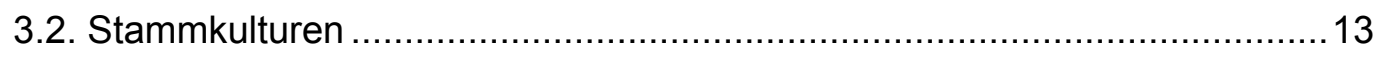

3.3. Messung der optischen Dichte ............................................................... 13

4. Standardtechniken für das Arbeiten mit Nukleinsäuren ...........................13

4.1. Behandlung von Geräten und Lösungen ............................................... 13

4.2. Reinigung und Konzentrierung von Nukleinsäuren ...................................13

4.2.1. Phenol/Chloroform-Extraktion ..........................................................13

4.2.2. Fällung von DNA mit Ethanol oder Isopropanol ...................................13

4.2.3. Dialyse von Gesamt-DNA ..........................................................14

4.2.4. Konzentrationsbestimmung von DNA ........................................... 14

4.3. Gelelektrophorese, Ethidiumbromid-Färbung und Größenbestimmung von

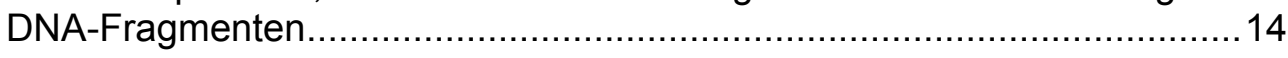

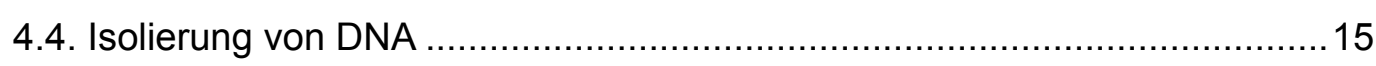

4.4.1. Isolierung von Gesamt-DNA aus Bodenproben .................................. 15

4.4.2. Isolierung von DNA aus Anreicherungskulturen ……..........................16

4.4.3. Isolierung von Plasmid-DNA durch alkalische Lyse.............................17

4.4.4. Isolierung hochreiner Plasmid- und Cosmid-DNA ............................. 17

4.4.5. Isolierung genomischer DNA mit dem „AquaPure Genomic DNA Kit“. 18

4.4.6. Elution von DNA-Fragmenten aus Agarosegelen ………………........ 18

4.5. Enzymatische Modifikationen von DNA ……………........................... 18 
4.5.1. DNA-Verdau durch Restriktionsendonukleasen .............................. 18

4.5.2. Partieller Verdau von Gesamt-DNA .............................................. 19

4.5.3. Dephosphorylierung von DNA-Enden ........................................... 19

4.5.4. Ligation von DNA-Fragmenten ................................................ 19

4.6. Amplifikation von DNA durch Polymerase-Kettenreaktion (PCR) .............. 19

4.7. Ligation von PCR-Produkten in den Klonierungsvektor pDrive ...................21

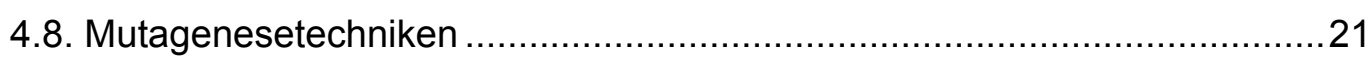

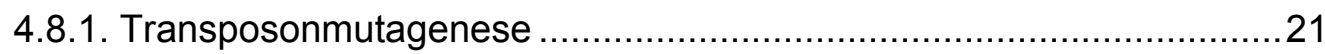

4.8.2. Gezielter Aminosäureaustausch ................................................... 21

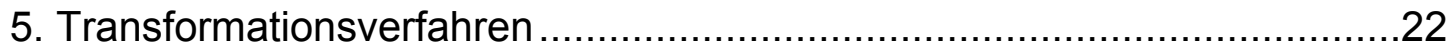

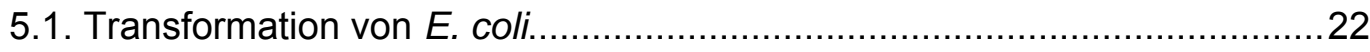

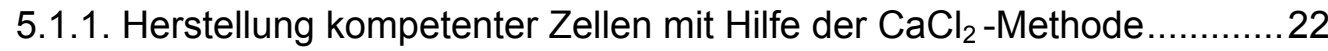

5.1.2. Transformation von E. coli mittels Hitzeschock ................................22

5.1.3. Herstellung kompetenter Zellen für die Elektroporation......................22

5.1.4. Transformation von E. coli mittels Elektroporation............................23

5.1.5. Selektion rekombinanter E. coli-Klone durch X-Gal-Test....................23

5.2. Transformation von Pseudomonas aeruginosa......................................23

5.2.1. Herstellung kompetenter Zellen....................................................23

5.2.2. Transformation von $P$. aeruginosa mittels Hitzeschock .....................24

5.3. Transduktion mit dem "Gigapack III Gold Packaging Extract".....................24

6. Standardtechniken für das Arbeiten mit Proteinen..............................24

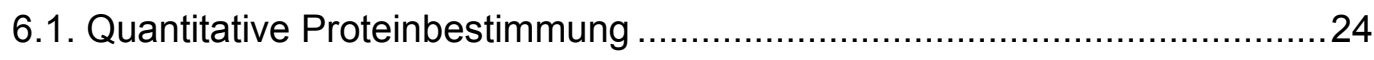

6.2. SDS-Polyacrylamidgelelektrophorese (SDS-PAGE) ............................25

6.3. Molekularmassenbestimmung von Proteinen in SDS-Gelen ....................26

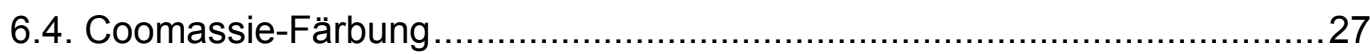

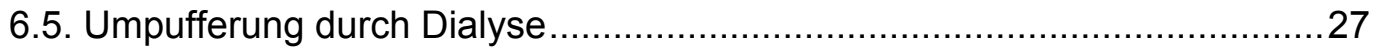

6.6. Konzentration von Proteinlösungen ..................................................2 27

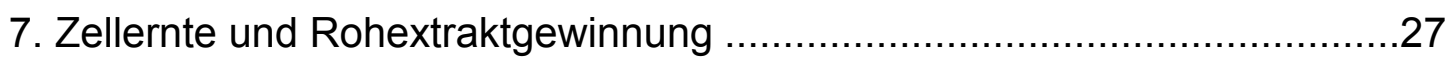

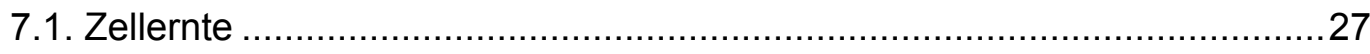

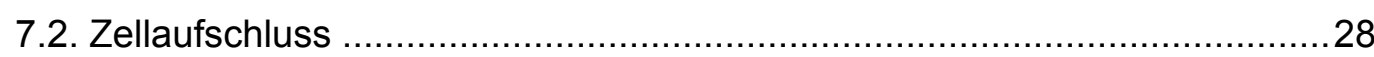

7.2.1. Zellaufschluss mit der „French Pressure Cell“ ...................................28

7.2.2. Zellaufschluss durch Ultraschall ................................................. 28

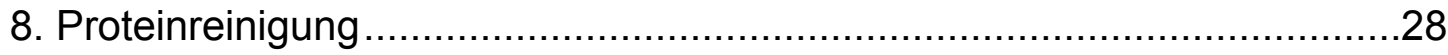

8.1. Rückfaltung von Proteinen aus Einschlusskörpern ...............................28

8.2. Proteinreinigung durch Metall-Ionen-Affinitäts-Chromatographie ..............29

8.3. Proteinreinigung durch FPLC und Gelfiltration.....................................29

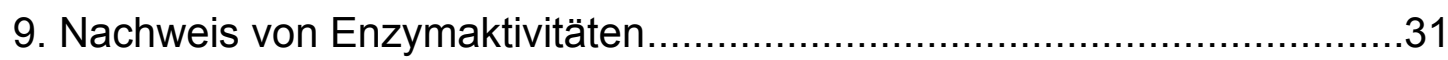

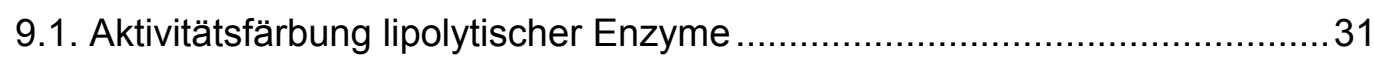

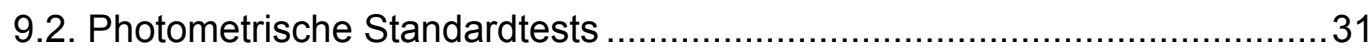


9.2.1. Bestimmung der Esteraseaktivität .................................................... 31

9.2.2. Bestimmung der Lipaseaktivität .................................................. 32

9.3. Bestimmung der Esterase-/Lipaseaktivität mittels Titration.........................33

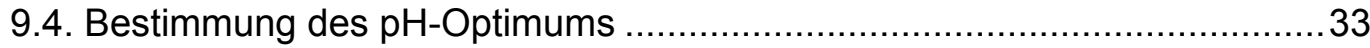

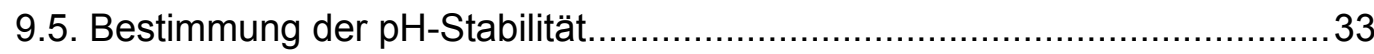

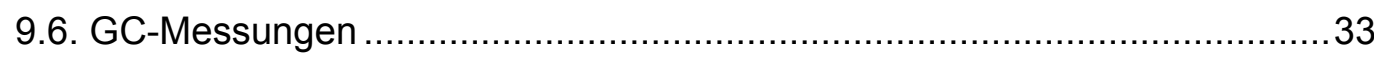

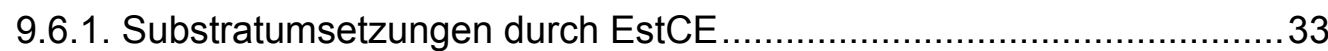

9.6.2. Substratumsetzungen durch LipCE ............................................ 34

9.6.3. Berechnungen von ee-Werten und Enantioselektivität (E) .................35

9.7. Erstellung eines „enzymatischen Fingerabdruckes“...................................36

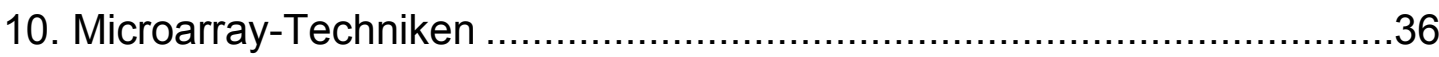

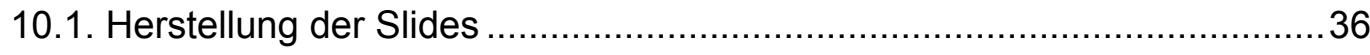

10.2. Visualisierung immobilisierter PCR-Produkte durch VistraGreen ..............37

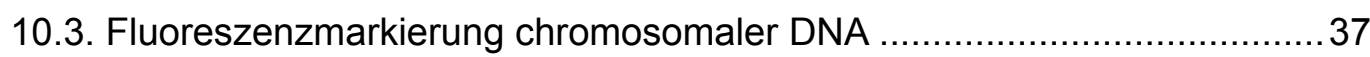

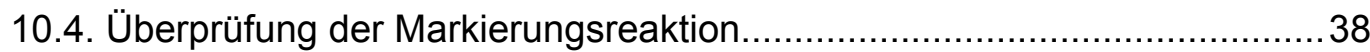

10.5. Hybdrisierung der markierten DNA mit den Microarrayslides ...................38

10.6. Scannen der hybridisierten Slides......................................................... 40

III. Ergebnisse...................................................................................... 41

1. Erstellung einer Cosmidbank und Charakterisierung des Standortes ........41

1.1. Entnahme von Bodenproben ........................................................ 41

1.2. Anlegen von Anreicherungskulturen ................................................ 42

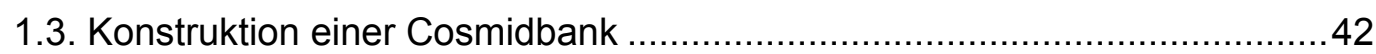

1.4. Analyse der phylogenetischen Diversität ..................................................4 43

1.4.1. Klonierung der bakteriellen 16S rRNA-Gene ..................................... 43

1.4.2. Analyse der $16 \mathrm{~S}$ rRNA-Gensequenzen .........................................4

2. Identifizierung und Charakterisierung der Esterase EstCE .....................45

2.1. Isolation des Cosmides pCosCE1 .......................................................... 45

2.2. Identifizierung des lipolytischen ORFs mittels Sequenzierung und Transposonmutagenese ...................................................................4 46

2.3. Genetische Analyse des Cosmidteilstückes RV1 ....................................46

2.4. Genetische Charakterisierung des estCE-Gens ...................................4 47

2.5. Heterologe Expression des estCE-Gens in E. coli ....................................49

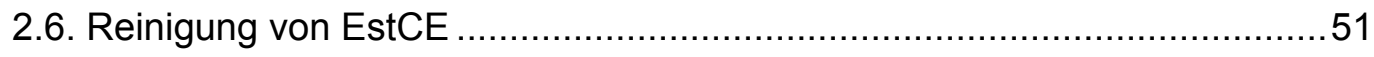

2.6.1. Reinigung mittels Ni-TED-Affinitätschromatographie.......................51

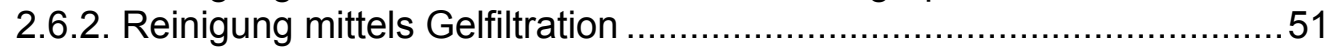

2.7. Biochemische Charakterisierung der Esterase EstCE ...........................53

2.7.1. Aktivitätsbasierter Nachweis von EstCE ...........................................53

2.7.2. Temperaturabhängigkeit der Aktivität von EstCE ............................54

2.7.3. Temperaturstabilität von EstCE ............................................... 54 
2.7.4. pH-Abhängigkeit der Aktivität und Stabilität von EstCE......................55

2.7.5. Aktivität von EstCE in Abhängigkeit von der Substratkettenlänge .......56

2.7.6. Einfluss von Lösungsmitteln und Detergenzien auf die Aktivität von EstCE

2.7.7. Einfluss verschiedener Kationen sowie EDTA auf die Aktivität von EstCE

2.7.8. Stereospezifische Umsetzung biotechnologisch relevanter Substrate 59

2.7.9. „Enzymatischer Fingerabdruck“ von EstCE .....................................61

2.7.10. Enzymkinetik von EstCE ............................................................64

2.7.11. Untersuchungen auf $\beta$-Laktamase-Aktivität von EstCE ..................64

2.7.12. Ortsspezifische Mutagenese im katalytischen Zentrum....................66

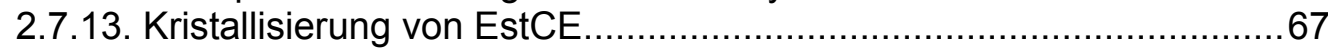

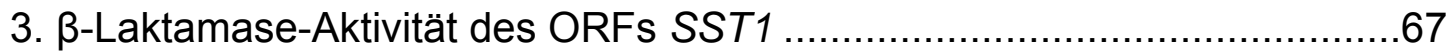

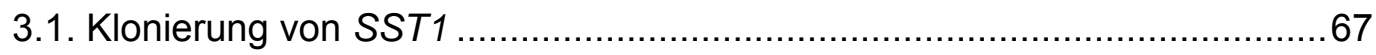

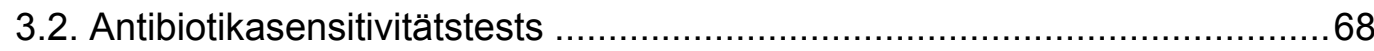

4. Identifizierung und Charakterisierung der Lipase LipCE .......................69

4.1. Isolation des Cosmides pCosCE2 .....................................................69

4.2. Identifizierung des lipolytischen ORFs mittels Transposonmutagenese .....69

4.3. Genetische Charakterisierung des lipCE-Gens.......................................70

4.4. Klonierung und heterologe Expression des lipCE-Gens ..........................73

4.4.1. Heterologe Expression in E. coli .....................................................73

4.4.2. Heterologe Expression in Pseudomonas aeruginosa ....................... 74

4.5. Rückfaltung aus Einschlusskörpern und Reinigung von LipCE .................74

4.5.1. Rückfaltung aus Einschlußkörpern ............................................. 74

4.5.2. Reinigung mittels Ni-TED-Affinitäts-Chromatographie.......................74

4.5.3. Reinigung mittels Gelfiltration ............................................... 74

4.6. Biochemische Charakterisierung von LipCE ....................................... 76

4.6.1. Aktivitätsbasierter Nachweis von LipCE ........................................76

4.6.2. Temperaturabhängigkeit der Aktivität von LipCE...........................76

4.6.3. $\mathrm{pH}$-Abhängigkeit der Aktivität von LipCE ......................................77

4.6.4. Aktivität von LipCE in Abhängigkeit von der Substratkettenlänge .......78

4.6.5. Temperaturstabilität von LipCE.................................................... 79

4.6.6. Einfluss von Lösungsmitteln auf die Aktivität von LipCE ....................79

4.6.7. Einfluss verschiedener Kationen, EDTA und PMSF auf die Aktivität von LipCE

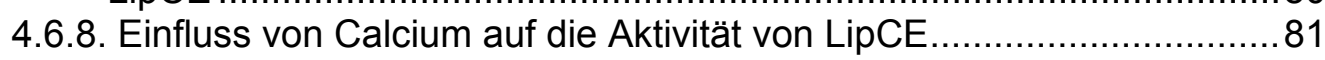

4.6.9. Einfluss von Calcium auf die Stabilität von LipCE ........................... 82

4.6.10. Untersuchungen zum Einfluss von Calcium auf die Sekundärstruktur

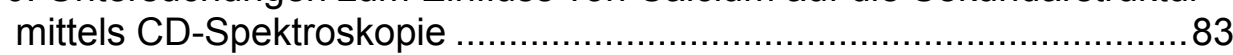

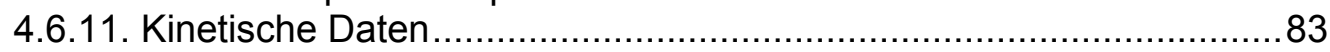

4.6.12. Stereospezifische Umsetzungen biotechnologisch relevanter Substrate

4.6.13. „Enzymatischer Fingerabdruck“ von LipCE ..................................... 85

5. Sequenzbasiertes Screening nach neuen Lipasen .............................87

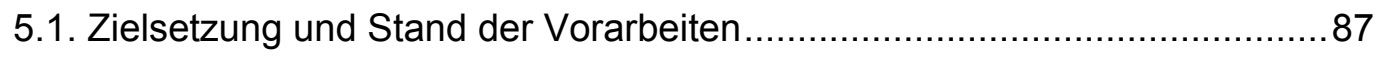

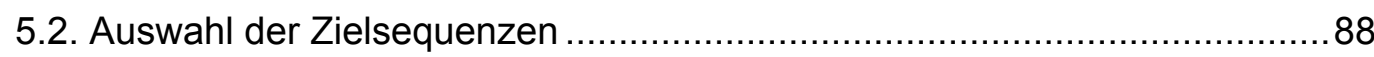




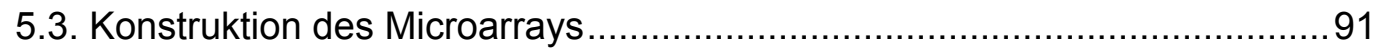

5.4. Präparation und Markierung genomischer DNA .....................................91

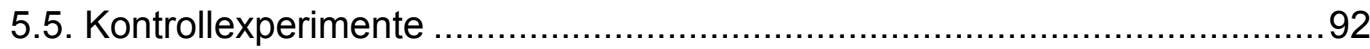

5.5.1. Hybridisierung mit markierten PCR-Produkten ................................92

5.5.2. Hybridisierung mit genomischer DNA aus Reinkulturen ....................93

5.6. Hybridisierung mit Umwelt-DNA....................................................... 95

5.7. Identifizierung der Gene in den Umweltproben mittels PCR .....................97

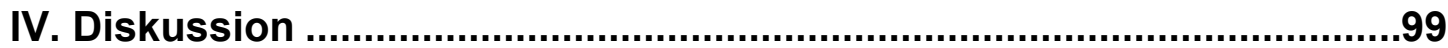

1. Phylogenetische Charakterisierung des Standortes ..............................99

2. Isolierung neuer Biokatalysatoren..................................................101

2.1. Neue Lipasen aus dem Metagenom ....................................................101

2.2. Sequenzneuheit der gefundenen Metagenomenzyme..........................102

2.3. Erweiterung der Familie VIII durch Metagenomlipasen............................104

3. Probleme der Metagenomik ....................................................... 104

3.1. Heterologe Expression der gefundenen Metagenomenzyme ..................104

3.2. Alternative Expressionssysteme für die Metagenomik .......................... 107

4. Herkunft der klonierten metagenomischen DNA ..............................107

5. Biochemische Charakterisierung der Enzyme ..................................109

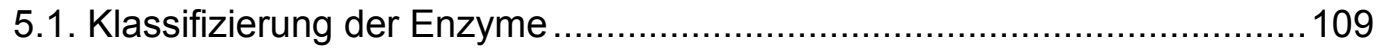

5.2. Identifizierung des katalytischen Nukleophils in EstCE - Hinweise auf den Reaktionsmechanismus.............................................................. 110

5.3. Aktivität der Enzyme ................................................................. 111

5.4. $\mathrm{pH}$-Optimum und Stabilität der Enzyme ........................................... 112

5.5. Thermische Eigenschaften von EstCE und LipCE ................................113

5.5.1. EstCE, eine Esterase mit mesophilen Eigenschaften......................113

5.5.2. LipCE, eine neue kälteaktive Lipase ............................................. 113

5.5.3. Molekulare Gründe für die Kälteaktivität .......................................113

5.5.4. Kälteaktive Enzyme aus dem Metagenom.................................. 115

5.6. Substratspezifität der beiden Enzyme ............................................... 116

5.6.1. Enantioselektive Umsetzungen durch EstCE ................................116

5.6.2. Enantioselektive Umsetzungen durch LipCE...............................118

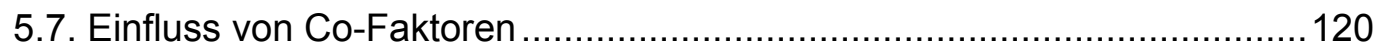

5.7.1. LipCE und der Einfluss von Calcium..........................................120

6. Microarray-Entwicklung zur Detektion neuer Lipasen .........................123

6.1. Microarrays in der Metagenomik ....................................................... 123

6.2. Identifizierung neuartiger Lipasegene ................................................ 125

V. Zusammenfassung ...................................................................127 


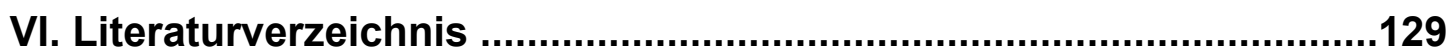

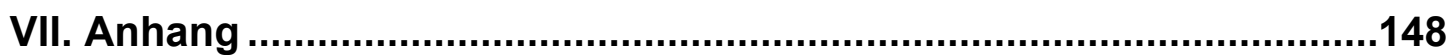

Danksagung

Lebenslauf 


\section{Abkürzungen}

a

A

Abb.

Amp

APS

AS

bp

bzw.

C

${ }^{\circ} \mathrm{C}$

$\mathrm{Cm}$

$\mathrm{Da}$

dCTP

dest

DMF

DMSO

DNA

dNTP

ds

E.

EDTA

E-Cup

et al.

FPLC

$g$

G

GC

h

$\mathrm{Hz}$

IAA

IPTG

Kann

$\mathrm{k}$

$\mathrm{kb}$

I

LB

$\mathrm{m}$

$M$

MKS

$\mu$

max.

$\min$

n.b.

$\mathrm{Nr}$.

OD

ORF

$p$

$P$.

PAGE

PCR

$P f u$

PEG

$\mathrm{pH}$
Jahr (lat. annum)

Adenin

Abbildung

Ampicillin

Ammoniumpersulfat

Aminosäure(n)

Basenpaare

beziehungsweise

Cytosin

Grad Celsius

Chloramphenicol

Dalton

Desoxyribocytosin-5'-triphosphat

bidestiliert

Dimethylformamid

Dimethylsulfoxid

Desoxyribonukleinsäure (engl. desoxyribonucleic acid)

Desoxyribonukleosid-5'-triphosphat

doppelsträngig, Doppelstrang

Escherichia

Ethylendiamintetraacetat

Eppendorfreaktionsgefäß

und andere (lat. et alii)

Fast Protein Liquid Chromatography

Gramm

Guanin

Gaschromatograph

Stunde(n)

Hertz

Isoamylalkohol

Isopropyl- $\beta$-D-thiogalactopyranosid

Kanamycin

kilo- $\left(1 * 10^{3}\right)$

Kilobasen

Liter

Luria-Bertani

milli- $\left(1 * 10^{-3}\right)$

Molar $(\mathrm{mol} / \mathrm{l})$

Multi-Klonierungs-Stelle

mikro- $\left(1 * 10^{-6}\right)$

maximal

Minute

nicht bestimmt

Nummer

Optische Dichte

offener Leserahmen (engl. open reading frame)

para

Pseudomonas

Polyacrylamid-Gelelektrophorese

Polymerase Kettenreaktion (engl. polymerase chain reaction)

Pyrococcus furiosus

Polyethylenglycol

$\mathrm{pH}$-Wert 


$\begin{array}{ll}r & \text { resistent/Resistenz } \\ \text { RNA } & \text { Ribonukleinsäure (engl. ribonucleic acid) } \\ \text { RNase } & \text { Ribonuklease } \\ \text { rRNA } & \text { ribosomale Ribonukleinsäure } \\ \text { RT } & \text { Raumtemperatur } \\ \text { S } & \text { Sekunde(n) } \\ \text { SDS } & \text { Natrium-Dodecylsulfat (engl. Sodium-Dodecylsulfate) } \\ \text { SG } & \text { Sammelgel } \\ \text { SSC } & \text { Standard-Saline-Citrat } \\ \text { T } & \text { Thymin } \\ \text { t } & \text { Tonne } \\ \text { Tab. } & \text { Tabelle } \\ \text { TAE } & \text { Tris-Acetat-EDTA-Puffer } \\ \text { Taq } & \text { Thermus aquaticus } \\ \text { TE } & \text { Tris-EDTA-Puffer } \\ \text { TED } & \text { Tris-(carboxymethyl)-ethylendiamin } \\ \text { Tet } & \text { Tetracyclin } \\ \text { TG } & \text { Trenngel } \\ \text { Tm } & \text { Schmelztemperatur } \\ \text { Tris } & \text { Tris-(hydroxymethyl)-aminoethan } \\ \text { U } & \text { unit (Einheit) } \\ \text { üN } & \text { über Nacht } \\ \text { Upm } & \text { Umdrehungen pro minute } \\ \text { UV } & \text { Ultraviolett } \\ \text { V } & \text { Volt } \\ \text { Vol. } & \text { Volumen } \\ \text { v/v } & \text { Volumen pro Volumen } \\ \text { w/v } & \text { Masse pro Volumen } \\ \text { W } & \text { Watt } \\ \text { X-Gal } & \text { 5-Brom-4-chlor-3-indolyl-ß-D-galactopyranosid } \\ \text { z.B. } & \text { zum Beispiel } \\ & \end{array}$

Abkürzungsverzeichnis Aminosäuren
A Ala Alanin
M Met Methionin
C Cys Cystein
$\mathrm{N}$ Asn Asparagin
D Asp Aspartat
P Pro Prolin
E Glu Glutamat
Q Gin Glutamin
F Phe Phenylalanin
$\mathrm{R}$ Arg Arginin
G Gly Glycin
S Ser Serin
$\mathrm{H}$ His Histdin
$\mathrm{T}$ Thr Threonin
I Ile Isoleucin
V Val Valin
$\mathrm{K}$ Lys Lysin
W Trp Tryptophan
L Leu Leucin
Y Tyr Tyrosin 


\section{Einleitung}

\section{Industrielle Biotechnologie}

Der Einsatz von Mikroorganismen in Produktionsprozessen, insbesondere der Lebensmittelherstellung, reicht bereits Jahrtausende zurück, auch wenn dies meist ohne Kenntnis der Organismen geschah. Aus heutigen industriellen Produktionsprozessen sind Mikroorganismen oder Enzyme nicht mehr wegzudenken. Für die industrielle Biotechnologie wurde im Jahr 2003 von der Europäischen Gesellschaft der Bioindustrie „EuropaBio“ (www.europabio.com) der Begriff „Weiße Biotechnologie“ zur Abgrenzung gegenüber der roten (medizinischer) und grünen (pflanzlicher) Biotechnologie eingeführt. Er bezeichnet den „Einsatz biotechnischer Methoden in industriellen Prozessen“ (Zinke, 2004). Die industrielle Biotechnologie spielt eine wichtige Rolle bei der Herstellung von Lebensmitteln, Futterzusätzen, Pharmazeutika, Enzymen, in der Waschmittelindustrie oder in chemischen Verfahren bei der Herstellung von Bulk- und Feinchemikalien. Sie hat bei vielen Großunternehmen wie BASF, Degussa oder Henkel in den unterschiedlichsten Feldern Einzug gehalten (Tab. 1).

Die Verdrängung etablierter chemischer Herstellungsprozesse durch biotechnologische Prozesse geschieht, obwohl häufig möglich, bislang jedoch noch sehr zögerlich, was meist auf ökonomische Gründe zurückzuführen ist (Flaschel und Sell, 2006). Da jedoch die Zeit für die Optimierung von Enzymen, die einen wichtigen Kostenfaktor darstellt, in den letzten Jahren um den Faktor 10 bis 100 gesunken ist, sollte sich auch dies in Zukunft ändern (Bachmann et al., 2004).

Tab. 1: Anwendungsgebiete industrieller Biotechnologie (nach Zinke, 2004)

\begin{tabular}{ll}
\hline Unternehmen & Produkte \\
\hline BASF (D) & Vitamine, Zwischenprodukte \\
Cargill Dow (USA) & Biopolymere, chemische Produkte \\
Degussa (D) & Aminosäuren, Pharmaintermediate \\
DSM (NL) & Antibiotika, Feinchemikalien \\
Dupont (USA) & Biopolymere \\
Genencor (USA) & Enzyme \\
Henkel (D) & Waschmittelenzyme \\
Novozymes (DK) & Enzyme \\
Lonza (CH) & Feinchemikalien \\
Sandoz (A) & Antibiotika \\
\hline
\end{tabular}


Ein erfolgreiches Beispiel für die Verdrängung traditioneller chemischer Synthesen durch biotechnologische Verfahren unter nachhaltigen Bedingungen und gleichzeitiger Reduktion von Kosten ist die Synthese von Vitamin B2 (Futterzusatz) der Firma BASF. Hier wurde eine Sechs-Schritt-Synthese durch eine Fermentation mit der Hefe Ashbya gossypii abgelöst, was zu einer Kostenreduktion von 40\% und einer wesentlich geringeren Umweltbelastung führte (Frazzetto, 2003). Noch bilden solche Vorgänge aber eher die Ausnahme.

Der größte Einfluss in den kommenden Jahren wird im Segment der Feinchemikalien $(<10.000$ t/a) prognostiziert, da dort die Vorteile von Enzymen wie hohe Spezifität und Selektivität am stärksten zum Tragen kommen (Flaschel und Sell, 2006). In der Feinchemikalienherstellung werden allein 134 Prozesse im industriellen Maßstab aufgelistet, in denen biotechnologische Verfahren involviert sind. Deren Anzahl hat sich allein im letzten Jahrzehnt mehr als verdoppelt (Straathof et al., 2002). Die Unternehmensberatung McKinsey (www.mckinsey.com) prognostizierte 2003, dass bis zum Jahre 2010 bei $30-60 \%$ aller Produktionen von Feinchemikalien wenigstens ein biokatalytischer Schritt beteiligt sein wird. Allgemein wird dort eine biotechnologische Beteiligung an der Produktion von 10-20\% aller Chemikalien bis 2010 (Stand 2003: $5 \%$ ) als möglich vorhergesagt (Sijbesma, 2003). Auch wenn diese Zahlen inzwischen etwas relativiert gesehen werden, verdeutlichen sie doch das große Potential, welches die weiße Biotechnologie für die Zukunft besitzt (Herrera, 2004) und warum in die Isolierung neuer Stämme und Enzyme auch zukünftig noch viel Arbeit investiert werden muss.

\section{Lipasen und Esterasen als Biokatalysatoren}

\subsection{Allgemeine Charakteristika}

Lipolytische Enzyme, d.h. Lipasen [E.C. 3.1.1.3] und Carboxylesterasen [3.1.1.1], die in der Lage sind, die Hydrolyse oder Synthese von Esterbindungen zu katalysieren, bilden eine wichtige Gruppe biokatalytischer Enzyme (Jäger und Eggert, 2002; Bornscheuer, 2002b). Als drittes gehört die Familie der Phospholipasen [E.C. 3.1.1.2] dazu, die an dieser Stelle jedoch nicht weiter behandelt werden soll. Lipasen und Esterasen gehören zur Superfamilie der $\alpha / \beta$-Hydrolasen (Ollis et al., 1992), deren wichtiges Merkmal die katalytische Triade Ser-His-Asp ist, wie sie typisch für Serinhydrolasen ist. Der katalytische Serinrest (Brady et al., 1990) findet sich gewöhnlich eingebettet in ein Motiv der Form G-x-S-x-G (Arpigny und Jäger, 1999), wobei $x$ für eine beliebige Aminosäure steht und das erste Glycin teilweise durch andere kleine Aminosäuren ersetzt sein kann (Jäger et al., 1999). Zudem finden sich 
auch Strukturmotive wie G-D-S-L (Wei et al., 1995) oder Ähnlichkeiten zu $\beta$ Laktamasen (Petersen et al., 2001). Der Reaktionsmechanismus besteht im Wesentlichen aus vier Schritten (Abb. 1). Im ersten wird das Substrat durch einen nukleophilen Angriff des katalytischen Serins (1) an dieses gebunden und es kommt zur Bildung eines tetrahedralen Übergangszustandes. Dieser wird durch die beiden Reste Histidin und Aspartat sowie Wasserstoffbrücken der Proteinhauptkette stabilisiert (2). Der Alkoholrest wird abgespalten und es entsteht ein Acyl-Enzym-Komplex. Durch einen nukleophilen Angriff eines Wassermoleküls (Hydrolyse) (3) kommt es erneut zur Bildung eines tetrahedralen Übergangszustandes, aus welchem schließlich das Enzym und das Produkt wieder freigesetzt werden (4). Fungiert beim Angriff auf den AcylEnzym-Komplex ein Alkohol oder anderer Ester statt des Wassermoleküls als Nukleophil, kommt es statt zur Hydrolyse zur einer Umesterung, die insbesondere für chemische Synthesen von Bedeutung sein kann.
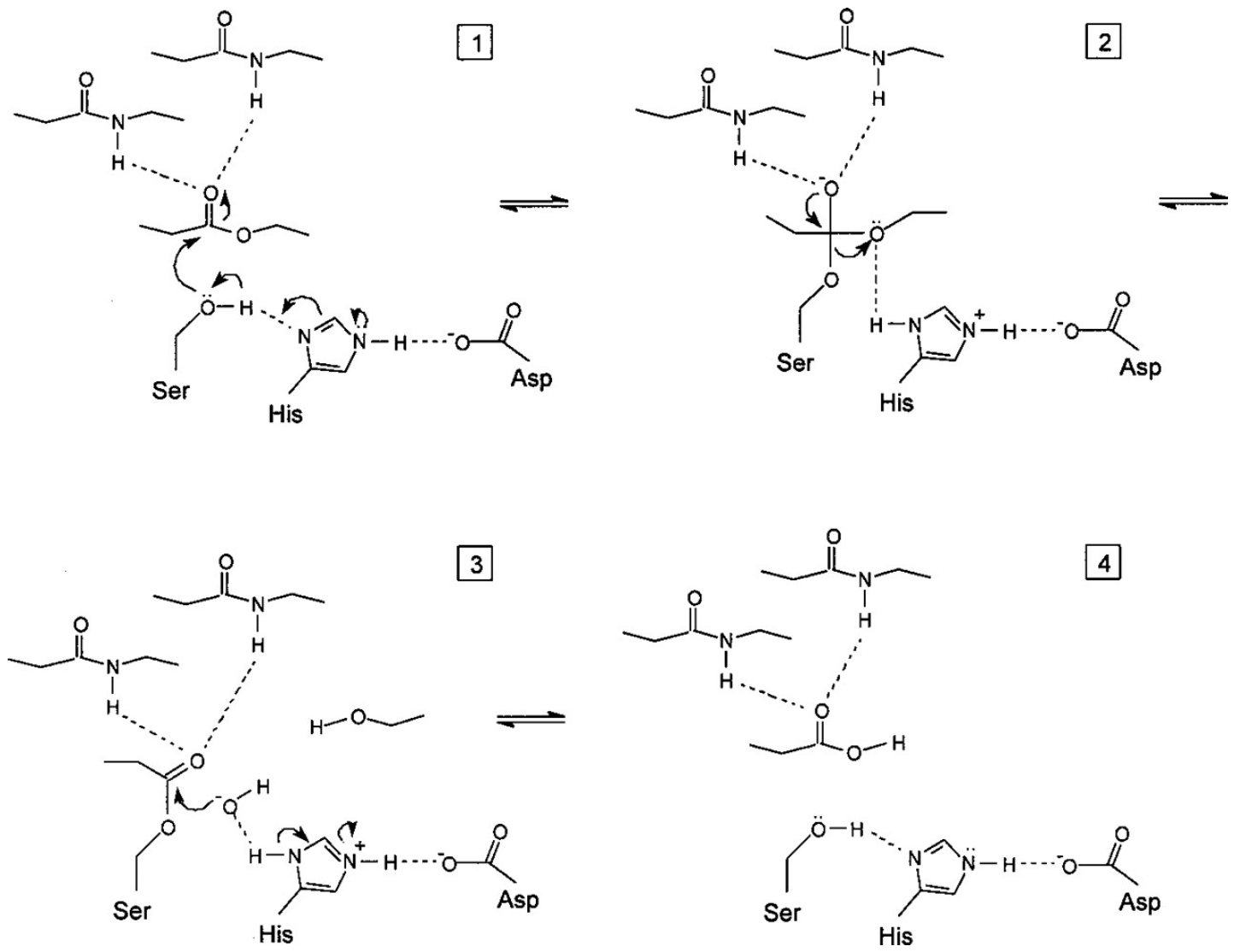

4

Abb. 1: Reaktionsmechanismus der hydrolytischen Esterspaltung durch Esterasen und Lipasen

Die Details zum Reaktionsmechanismus sind im Text erläutert (nach Jäger et al., 1999). 
Unterschieden werden Lipasen und Esterasen im Wesentlichen anhand ihrer Fähigkeit, langkettige, wasserunlösliche Estersubstrate (Lipasen), oder eher kurzkettige, wasserlösliche Substrate (Esterasen) umzusetzen (Chahinian et al., 2005). Zu den bevorzugten Substraten von Lipasen gehören im Gegensatz zu Esterasen die Ester sekundärer Alkohole, während Esterasen eher einfache Ester umsetzen (Bornscheuer, 2002b). Lipasen benötigen für ihre Aktivität eine Grenzfläche zwischen einer wässrigen Phase und dem wasserunlöslichen Substrat, welches eine Emulsion bildet. Man spricht hier auch vom Phänomen der Grenzflächenaktivierung (Sarda und Desnuelle, 1958). Auf molekularer Ebene lässt sich dies durch das Vorhandensein eines „Deckels“ (lid) erklären, der häufig aus ein bis zwei $\alpha$-Helices besteht und erst in Anwesenheit der Grenzfläche zum Substrat den Zugang zum aktiven Zentrum freigibt (Grochulski et al., 1993; Jäger et al., 1999). Dadurch können die Umsetzungen durch Esterasen durch einfache Michaelis-Menten-Kinetiken beschrieben werden, während Lipasen zunächst eine bestimmte Substratkonzentration benötigen, bevor es zu einem starken Anstieg der Aktivität kommt (Verger, 1997; Nini et al., 2001).

Ihre biochemischen Eigenschaften machen Lipasen und Esterasen zu attraktiven Enzymen für die biotechnologische Anwendung, insbesondere als Biokatalysatoren in der organischen Chemie. Sie benötigen meist keine Co-Faktoren, zeigen hohe Toleranz und Stabilität gegenüber Lösungsmitteln und weisen eine hohe Chemo-, Regio- und Stereoselektivität auf. Von vielen Lipasen sind inzwischen die Kristallstrukturen bekannt, was ein molekulares Modellieren hinsichtlich der gewünschten Substratspezifität erlaubt (Jäger und Eggert, 2002).

\subsection{Praktische Beispiele für den Einsatz von Lipasen}

Inzwischen ist eine Vielzahl stereospezifischer Umsetzungen von Lipasen bekannt, die Einzug in biotechnologische Verfahren zur Herstellung von Pharmazeutika, Kosmetika und Agrochemikalien erhalten haben (Jäger und Eggert, 2002; Liese et al., 2005). Sie kommen in der Lebensmittelherstellung bei der Umsetzung von Fetten und Ölen oder in der Biodieselproduktion zum Einsatz (Fukuda et al., 2001; Jäger und Eggert, 2002). Weiterhin kommen sie in der Synthese von Feinchemikalien wie enantiomerenreiner Alkohole sowie chiraler Amine und Amide ausgehend von racemischen Ausgangssubstanzen zum Einsatz (Schmid et al., 2001; Straathof et al., 2002; Ghanem und Aboul-Enein, 2005).

Ein erfolgreiches Beispiel für den Einsatz von Lipasen ist die Herstellung von optisch reinen 2-Arylpropionsäurederivaten, wozu Wirkstoffe wie Naproxen und Ibuprofen (Abb. 2) gehören. Letzteres ist z.B. in Schmerzmitteln wie Dolormin ${ }^{\circledR}$ enthalten. Die 
Schwierigkeiten liegen hierbei in der Herstellung des chiralen Endproduktes. Die Wirkung von (S)-Ibuprofen ist 160-fach stärker als die von $(R)$-lbuprofen, das quasi wirkungslos ist (Hutt und Caldwell, 1984). Es existieren zwar genügend Wege, das racemische Produkt auf chemischem Wege zu synthetisieren, die asymmetrische Synthese von reinem (S)-Ibuprofen gestaltet sich jedoch zu schwierig und unwirtschaftlich (Alcántara et al., 2000). Grundsätzlich sind hierbei zwei Möglichkeiten denkbar:

(1) die enantioselektive Hydrolyse des racemischen Esters bzw. Amides unter Bildung optisch reinen (S)-Ibuprofens

(2) die enantioselektive Veresterung der racemischen Säuren unter Bildung des $(R)$-Ibuprofen-Esters, wobei (S)-Ibuprofen zurückbleibt

Diese Reaktionen geschehen in Gegenwart verschiedener Lösungsmittel (Alcántara et al., 2000; Carvalho et al., 2006), gegenüber denen Lipasen eine hohe Stabilität und Aktivität zeigen. Seit neuestem wird auch von einem erfolgreichen Einsatz in ungewöhnlichen Lösungsmitteln wie ionischen Flüssigkeiten berichtet (Hongwei et al., 2005). Bei beiden Reaktionen wird deutlich, dass abhängig vom gewählten Weg sowohl Lipasen mit einer Stereopräferenz für das $(R)$ - als auch das (S)-Enantiomer zum Einsatz kommen können.<smiles>CC(C)Cc1ccc([C@@H](C)C(=O)O)cc1</smiles>

(S)-Ibuprofen<smiles>COc1ccc2cc([C@@H](C)C(=O)O)ccc2c1</smiles>

(S)-Naproxen

Abb. 2: Strukturformeln der Schmerzmittelwirkstoffe Ibuprofen (2-(4-Isobutyl-phenyl)propionsäure) und Naproxen (2-(6-Methoxy2-napthyl)-propionsäure)

\section{Metagenomik als Quelle neuer Biokatalysatoren}

\subsection{Unkultivierbare Organismen und der Begriff „Metagenom“}

Der erstmals durch Woese erstellte bakterielle Stammbaum (1987) umfasste zunächst 12 Linien (nach offizieller Nomenklatur „Phylum“ (Boone et al., 2002)). Durch 16S rRNA-Genanalysen unkultivierter Organismen wurde dieser Stammbaum inzwischen auf 56 Linien erweitert, von denen allein die Hälfte keine bis heute kultivierten Vertreter umfasst (Rappé und Giovannoni, 2003). Inzwischen gilt es als anerkannte Tatsache, 
dass nur etwa 1-5\% aller Mikroorganismen mit heute gängigen Methoden im Labor kultivierbar sind (Amann et al., 1995). Um sich dieses große, ungenutzte Potential nutzbar zu machen, wurden in letzter Zeit vermehrt Anstrengungen unternommen, wobei im Wesentlichen zwei Strategien verfolgt wurden. Zum einen wurde die Entwicklung neuer Kultivierungstechniken vorangetrieben (Käberlein et al., 2002; Zengler et al., 2002), zum anderen wurden Verfahren entwickelt, die sich die genetischen Ressourcen der nicht-kultivierbaren Mikroorganismen nutzbar machen sollen. Dieser zweite Ansatz wird auch als "Metagenomik“ bezeichnet, wobei der Begriff „Metagenom“ erstmals 1998 verwendet wurde. Er bezeichnet die genetische Information sämtlicher Organismen (Pro- und Eukaryonten) eines bestimmten Habitates, unabhängig davon, ob diese kultivierbar sind oder nicht (Handelsman et al., 1998).

\subsection{Anwendungsbereiche der Metagenomik}

Durch direktes Klonieren der aus Umweltproben gewonnen DNA in geeignete Vektorsysteme (Plasmide, Cosmide, BACs, YACs) steht diese Ressource im Labor leicht handhabbar zur Verfügung. Somit können neue Einblicke in die Ökologie der zu untersuchenden Standorte gewonnen werden (Steele und Streit, 2005), was zum Beispiel zur Entdeckung neuer, bis dahin völlig unbekannter bakterieller Photosysteme (Beja et al., 2000) geführt hat. Zudem können diese Genbanken für die Suche nach neuartigen Enzymen genutzt werden. Hierbei stehen im Wesentlichen drei Wege zur Verfügung (Abb. 3):

(1) Techniken wie Dot-Blot-Hybdridisierungen oder PCR mit degenerierten Primern für konservierte Enzymfunktionen können zur Isolierung neuer funktioneller Gene führen. Dies wurde erfolgreich z.B. für Lipasen (Bell et al., 2002) und Nitrilhydratasen (Liebeton und Eck, 2004) gezeigt. Auch die Anwendung von Microarrays zum Detektieren spezifischer Gene ist eine Möglichkeit (Gentry et al., 2006), wobei diese Technik bislang meist für Untersuchungen in der mikrobiellen Ökologie zum Einsatz kam (Dennis et el., 2003).

(2) Großangelegte Sequenzierprojekte ganzer Standorte haben zur Entdeckung einer Vielzahl neuer Gene geführt. Allein die Sequenzierung des Metagenoms einer Probe aus der Sargasso-See hat zum Auffinden von über 1,2 Millionen neuer Gene geführt, was die Anzahl bekannter Gene in den Datenbanken zum damaligen Zeitpunkt mit einem Mal verdoppelt hat (Venter et al., 2004). Aus anderen Standorten wie saurem Minenabwasser konnten komplette Genome unkultivierter Mikroorganismen rekonstruiert (Tyson et al., 2004) oder eine Vielzahl potentiell neuer Biokatalysatoren 
aus einem Trinkwasserbiofilm gefunden werden (Schmeißer et al., 2003). Letztendlich ist dieser Weg fast nicht limitiert und nur eine Frage von Arbeits- und Sequenzierkapazitäten (Schloss und Handelsmann, 2005).

Beide Wege haben hinsichtlich des Auffindens neuer Enzymaktivitäten aber den großen Nachteil, dass sie nur Ähnlichkeiten zu bekannten Enzymen detektieren können.

(3) Um völlig neuartige Enzymaktivitäten aufzufinden, sollte die aktivitätsbasierte Durchmusterung erstellter Metagenombanken gewählt werden. Voraussetzung hierfür ist ein geeignetes Nachweissystem (Plattentests, Mikrotiterplattensysteme), das zugleich eine Durchmusterung einer möglichst großen Zahl an Klonen erlaubt (high throughput screening). Des Weiteren muss die Expression der Gene in einem heterologen Wirt gewährleistet sein. Während die meisten Metagenomstudien Escherichia coli als Wirt nutzen, von dem geschätzt wird, dass er nur $40 \%$ aller Metagenomgene exprimiert (Gabor et al., 2004), werden auch andere Organismen wie Streptomyces lividans oder Pseudomonas putida hierfür herangezogen (Wang et al., 2000; Courtois et al., 2003; Martinez et al., 2004).

Probleme der Metagenomtechnik liegen nach wie vor noch in der Gewinnung sauberer DNA aus Standortproben (Streit et al., 2004) sowie bei der späteren Expression der gefundenen Gene. Hier sind es mangelnde Transkription, da z.B. Promotoren nicht erkannt werden, Toxizität der Produkte für den Wirt, fehlende Cofaktoren oder Faltungshelfer und somit unkorrekte Faltung der Proteine im heterologen Wirt, sowie fehlende Sekretionssysteme, die ein großes Problem darstellen können (Streit und Schmitz, 2004). 


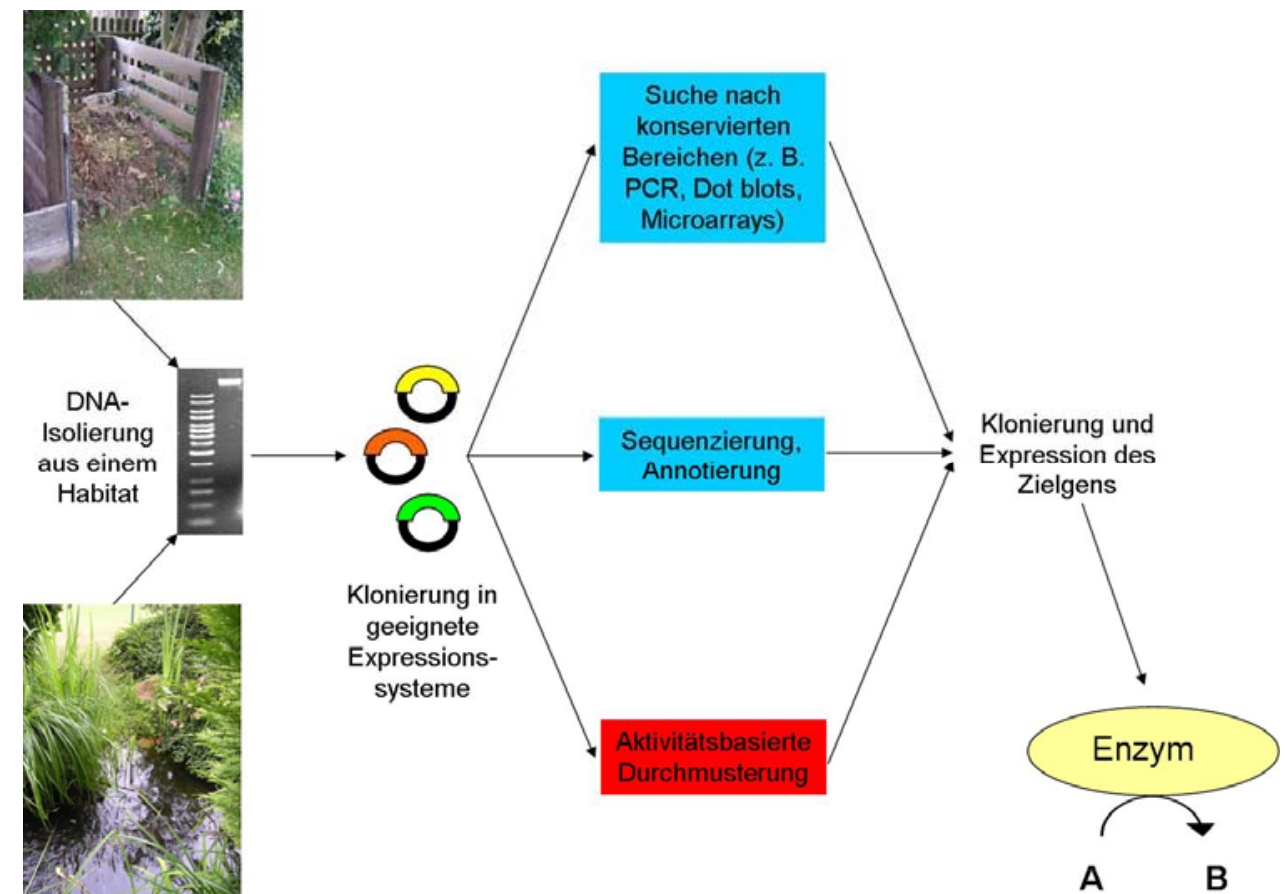

Abb. 3: Vorgehensweise bei der Isolierung neuer Enzyme aus dem Metagenom

\subsection{Neue Enzyme aus dem Metagenom}

Die oben beschriebenen Strategien haben zur Entdeckung einer Großzahl neuer Sekundärmetabolite und neuartiger Enzyme aus den verschiedensten Klassen mit einem weiten Anwendungsspektrum geführt. Als Auswahl seien an dieser Stelle Proteasen (Santosa, 2001; Gupta et al., 2002), Cellulasen (Healy et al., 1995; Voget et al., 2006), Amylasen (Voget et al., 2003; Yun et al., 2004), Nitrilasen (DeSantis et al., 2002), Lipasen (Lee et al., 2004; Ferrer et al., 2005a/b; Jiang et al., 2006, Kim et al., 2006), Polyketidsynthasen (Courtois et al., 2003) oder verschiedene antimikrobielle Wirkstoffe (Gillespie et al., 2002; Piel, 2002; Riesenfeld et al., 2004) genannt.

Viele dieser genannten Enzyme weisen interessante biotechnologische Eigenschaften auf. So wurden Lipasen und Esterasen (Lorenz et al., 2002) oder Nitrilasen (DeSantis et al., 2002) mit hoher Stereospezifität gegenüber biotechnologisch relevanten Substraten gefunden. Weitere interessante Charakteristika, die diese Enzyme aufweisen sind Aktivität bei extremen Bedingungen, wie z.B. thermophile Esterasen (Rhee et al., 2005), kälteaktive Xylanasen (Lee et al., 2006) oder extrem druckbeständige Lipasen (Ferrer et al., 2005a).

Einzug in die Industrie hat die Metagenomtechnologie bereits vielfältig gefunden (Cowan et al., 2005). Firmen wie der Marktführer „Diversa Corporation“ (San Diego, USA, www.diversa.com) sind auf diesem Feld seit Ende der 1990er Jahre in Zusammenarbeit mit Großunternehmen wie BASF oder DSM aktiv. In Deutschland 
existieren Kooperationen zwischen der B.R.A.I.N. AG (www.brain-biotech.de) und Chemiekonzernen wie Degussa oder Henkel (Lorenz, 2006). Der kommerzielle Vertrieb aus dem Metagenom gewonnener Enzyme ist bislang jedoch eher die Ausnahme. Die isländische Firma Prokaria (www.prokaria.is) beispielsweise vertreibt thermophile Enzyme wie Ligasen für die Anwendung in der Forschung (Zinke, 2004; Cowan et al., 2005).

\section{Intention dieser Arbeit}

Zielsetzung dieser Arbeit war das Auffinden neuer lipolytischer Enzyme aus Metagenomproben. Diese Enzyme sollten biochemisch charakterisiert und mit einem besonderen Augenmerk auf biotechnologische Verwertbarkeit hin untersucht werden. Besondere Charakteristika von Lipasen und Esterasen, nämlich ihre Stabilität gegenüber Lösungsmitteln und ihre oft hohe Stereoselektiviät sollten dabei vorrangig von Interesse sein. Dies sollte an einer breiten Palette von Modellsubstraten sowie für die pharmazeutische oder chemische Industrie relevanten Substraten gezeigt werden. $\mathrm{Zu}$ diesen Substraten gehörten unter anderem Schmerzmittelwirkstoffe (2Arylpropionsäurederivate), die von Lipasen stereospezifisch umgesetzt werden können.

Weiterhin sollte die Entwicklung neuer Techniken zur Detektion von industriell relevanten Genen aus Metagenomproben unabhängig von der Klonierung der Standort-DNA vorangebracht werden. Hierzu sollte ein DNA-Microarray entwickelt werden, um das Aufspüren von Lipasegenen aus Umweltproben zu ermöglichen. 


\section{Material und Methoden}

\section{Verwendete Organismen, Plasmide und Oligonukleotide}

Die im Rahmen dieser Arbeit verwendeten Organismen sind in Tab. 2, die Plasmide in Tab. 3 aufgeführt. Tab. 4 gibt eine Übersicht über die verwendeten Oligonukleotide.

Tab. 2: Verwendete Bakterienstämme

\begin{tabular}{|c|c|c|}
\hline Bakterienstamm & Eigenschaften $^{1)}$ & Herkunft/Referenz \\
\hline Escherichia coli XL1-blue & 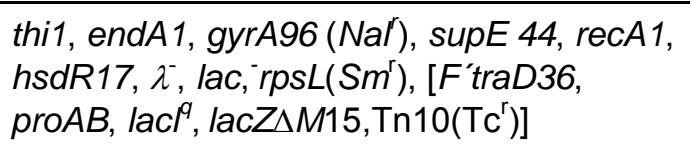 & Bullock et al., 1987 \\
\hline Escherichia coli BL21 (DE3) & $\mathrm{F}^{-}, o m p T, h s d S_{\mathrm{B}}\left(\mathrm{r}_{\mathrm{B}}^{-} \mathrm{m}_{\mathrm{B}}^{-}\right) \mathrm{gal}, \mathrm{dcm}, \lambda \mathrm{DE} 3$ & $\begin{array}{l}\text { Novagen/Merck } \\
\text { (Darmstadt) }\end{array}$ \\
\hline Escherichia coli M15 & $\begin{array}{l}\mathrm{Nal}^{\mathrm{s}}, \mathrm{Str}^{\mathrm{s}}, \mathrm{Rif}^{\mathrm{s}} \text {, } \mathrm{Thi}^{-}, \mathrm{Lac}^{-}, \mathrm{Ara}^{+}, \mathrm{Gal}^{+}, \mathrm{Mtl}^{-} \text {, } \\
\mathrm{F}^{-}, \mathrm{RecA}^{+}, \mathrm{Uvr}^{+}, \mathrm{Lon}^{+}, \mathrm{pREP} 4\end{array}$ & Qiagen (Hilden) \\
\hline Escherichia coli VCS257 & $\begin{array}{l}\text { DP50 Derivat: tonA53 dapD8 lacY1gInV44 } \\
\text { (supE44) (gal-uvrB)47 tyrT58 (supF58) } \\
\text { gyrA29 (thyA57) hsdS3(rk-mk-) mcrA }\end{array}$ & $\begin{array}{l}\text { Sambrook et al., } \\
1989\end{array}$ \\
\hline $\begin{array}{l}\text { Pseudomonas aeruginosa } \\
\text { PABST7.1 }\end{array}$ & 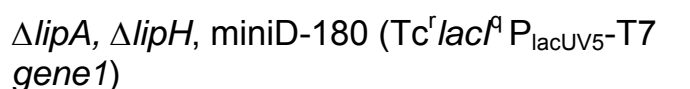 & Jäger et al., 1997 \\
\hline
\end{tabular}

1) Geno- und Phänotypbezeichnung siehe Bachmann (1987)

Tab. 3: Verwendete Vektoren und rekombinante Plasmide

\begin{tabular}{|c|c|c|}
\hline Plasmid & Eigenschaften & Herkunft/Referenz \\
\hline pBlueskript SK(+) & $A m p^{r}$, lacPOZ' & Stratagene (Heidelberg) \\
\hline pET19b & T7 Promotor, lacl, $\mathrm{Amp}^{\mathrm{r}}$ & Novagen/Merck (Darmstadt) \\
\hline pET24b & T7 Promotor, lacl, $\mathrm{Kan}^{\mathrm{r}}$ & Novagen/Merck (Darmstadt) \\
\hline pWE15 & $A m p^{r}, \mathrm{Kan}^{r}, \cos$ & Stratagene (Heidelberg) \\
\hline pBR22b & rep mob lacZ' (MKS: pET22b), $\mathrm{Cm}^{\mathrm{r}}$ & Rosenau und Jäger, 2003 \\
\hline pDrive & oriEc, $\mathrm{P}_{\mathrm{lac}} \mathrm{lacZ}, \mathrm{Kan}^{\mathrm{r}}, \mathrm{Amp}^{\mathrm{r}}$ & Qiagen (Hilden) \\
\hline pCosCE1 & $\begin{array}{l}27 \text { kb-Insert aus Anreicherung } \\
\text { „Wietze2“ in pWE15 }\end{array}$ & diese Arbeit \\
\hline pCosCE2 & $\begin{array}{l}13 \text { kb-Insert aus Anreicherung } \\
\text { „Wietze2“ in pWE15 }\end{array}$ & diese Arbeit \\
\hline pET19b::lipCE & $\begin{array}{l}\text { pET19b mit lipCE, N-terminaler } \\
\text { 10xHis-Tag }\end{array}$ & diese Arbeit \\
\hline pET19b::estCE & $\begin{array}{l}\text { pET19b mit estCE, N-terminaler } \\
\text { 10xHis-Tag }\end{array}$ & diese Arbeit \\
\hline pQE30::estCE & $\begin{array}{l}\text { pQE30 mit estCE, N-terminaler } \\
6 x \text { His-Tag }\end{array}$ & diese Arbeit \\
\hline pQE30::estCE_S65A & estCE mit Punktmutation S65A & diese Arbeit \\
\hline pET24c::estCE & pET24c mit estCE & diese Arbeit \\
\hline pET24c::SST1 & pET24c mit SST1 ( $\beta$-Laktamase) & diese Arbeit \\
\hline
\end{tabular}


1) Phänotypbezeichnungen: $\mathrm{Amp}^{r}$, Ampicillin-Resistenz; Kan ${ }^{r}$, Kanamycin-Resistenz; $\mathrm{Cm}^{r}$, Chloramphenicol-Resistenz; Genotypbezeichnungen: lacl, Repressor des Lactose-Operons; lacPOZ', Promotor-Operator-Region des Lactose-Operons und $\alpha$-Peptid der $\beta$-Galactosidase; oriEc, origin of replication in $E$. coli; $\mathrm{P}_{l a c}$, lac Promotor, cos, Erkennungssequenz für $\lambda$-Phagen.

Tab. 4: Verwendete Oligonukleotide

\begin{tabular}{|c|c|c|}
\hline Bezeichnung & Sequenz & Referenz \\
\hline Abi_for & 5'-ACGACGTTGTAAAACGACGGCCAG-3' & $\mathrm{G}_{2} \mathrm{~L}$, Göttingen \\
\hline Abi_rev & 5'-TTCACACAGGAAACAGCTATGACC-3' & $\mathrm{G}_{2} \mathrm{~L}$, Göttingen \\
\hline T7_for & 5'-TAGGGGAATTGTGAGCGGAT-3' & Voget, 2006 \\
\hline T7_rev & 5'-ATCCGGATATAGTTCCTCC-3' & Voget, 2006 \\
\hline $616 \mathrm{~V}$ & 5'AGAGTTTGATYMTGGCTCAG-3' & Brosius et al., 1981 \\
\hline $1492 R$ & 5'-CGGYTACCTTGTTACGAC-3' & Kane et al., 1993 \\
\hline GM1F & 5'-CCAGCAGCCGCGGTAAT-3' & Muyzer et al., 1993 \\
\hline LipCE_for & 5'-GGCATATGGGTATCTTTGACTATAA-3' & diese Arbeit \\
\hline LipCE_rev & 5'-GGGATCCTCAGCCGATGCTGACGCCGT-3' & diese Arbeit \\
\hline EstCE_for1 & 5'-GGATCCATGTCGATAGCGGATCAGTCA-3' & diese Arbeit \\
\hline EstCE_rev1 & 5'-AAGCTTTTACGAGTAGGTTCG TTTGTCC-3' & diese Arbeit \\
\hline EstCE_for2 & 5'-GGCATATGTCGATAGCGGATCAGTCA-3' & diese Arbeit \\
\hline EstCE_rev2 & 5'-GGATCCTTAGCGAGTAGGTTCGTTTG-3' & diese Arbeit \\
\hline S65A_for & 5'-TTCGGCTGTCGGCGGTGTCCAAGCC-3' & diese Arbeit \\
\hline S65A_rev & 5'-GGCTTGGACACCGCCGACAGCCGAA-3' & diese Arbeit \\
\hline SST1_for & 5'-GGATCCATGACGAAAATAAATCGCTT-3' & diese Arbeit \\
\hline SST1_rev & 5'-AAGCTTTCAGCGTTTGTCCAGCGCCT-3' & diese Arbeit \\
\hline
\end{tabular}

$\mathrm{Y}=\mathrm{C}$ oder $\mathrm{T} ; \mathrm{M}=\mathrm{A}$ oder $\mathrm{C}$; eingefügte Restriktionsstellen sind unterstrichen, zusätzliche Basenpaare zum Schutz der Primerenden sind kursiv. Mutierte Bereiche für Aminosäureaustausche sind fettgedruckt.

\section{Nährmedien}

Die angegebenen Mengen beziehen sich auf ein Endvolumen von $1 \mathrm{I}$ in demineralisiertem Wasser. Zur Herstellung von Festmedien wurde jeweils 1,5\% (w/v) Agar hinzugegeben. Alle Lösungen und Medien wurden, sofern nicht anders angegeben, autoklaviert. Die Lagerung erfolgte bei $4^{\circ} \mathrm{C}$.

2.1. LB-Medium (Sambrook et al., 1989)

$\begin{array}{lrl}\text { Trypton } & 10 \mathrm{~g} / \mathrm{l} \\ \text { Hefeextrakt } & 5 \mathrm{~g} / \mathrm{l} \\ \mathrm{NaCl} & 10 \mathrm{~g} / \mathrm{l}\end{array}$




\subsection{Mineralmedium}

Die Bestandteile wurden als 100fach konzentrierte Stammlösungen angesetzt und getrennt autoklaviert. Nach dem Abkühlen wurden die Lösungen zu sterilem $\mathrm{H}_{2} \mathrm{O}_{\text {dest }}$ (ad $1000 \mathrm{ml}$ ) gegeben. Zur Herstellung von Festmedium wurden Mineralmedium und Agar doppelt konzentriert angesetzt, autoklaviert und nach Abkühlen auf ca. $50^{\circ} \mathrm{C}$ vereinigt.

Zusammensetzung:

$$
\begin{aligned}
& \mathrm{NaNO}_{3} \times 3 \mathrm{H}_{2} \mathrm{O} \\
& \mathrm{K}_{2} \mathrm{HPO}_{4} \times 3 \mathrm{H}_{2} \mathrm{O} \\
& \mathrm{MgSO}_{4} \times 7 \mathrm{H}_{2} \mathrm{O} \\
& \mathrm{CaCl}_{2} \times 7 \mathrm{H}_{2} \mathrm{O} \\
& \mathrm{FeSO}_{4} \times 7 \mathrm{H}_{2} \mathrm{O} \\
& \text { EDTA } \\
& \text { Spurenelementlösung } \\
& \text { keine pH-Korrektur }
\end{aligned}
$$

$\begin{array}{rl}1,0 & \mathrm{~g} / \mathrm{l} \\ 1,01 & \mathrm{~g} / \mathrm{l} \\ 0,25 & \mathrm{~g} / \mathrm{l} \\ 0,015 & \mathrm{~g} / \mathrm{l} \\ 0,14 & \mathrm{~g} / \mathrm{l} \\ 0,02 & \mathrm{~g} / \mathrm{l} \\ 1 & \%(\mathrm{v} / \mathrm{v})\end{array}$

$\begin{array}{rl}15 & \mathrm{mg} / \mathrm{l} \\ 61,8 & \mathrm{mg} / \mathrm{l} \\ 198,0 & \mathrm{mg} / \mathrm{l} \\ 57,5 & \mathrm{mg} / \mathrm{l} \\ 47,5 & \mathrm{mg} / \mathrm{l} \\ 2,5 & \mathrm{mg} / \mathrm{l} \\ 2,4 & \mathrm{mg} / \mathrm{l} \\ 4,0 & \mathrm{mg} / \mathrm{l}\end{array}$

\subsection{Antibiotika und sonstige Medienzusätze}

Von den Medienzusätzen (Tab. 5) wurden Stammlösungen angesetzt, sterilfiltriert und bei $-20^{\circ} \mathrm{C}$ gelagert. Die Zugabe der Antibiotika und anderer hitzelabiler Medienbestandteile erfolgte nach Abkühlung der autoklavierten Medien auf ca. $50^{\circ} \mathrm{C}$.

Tab. 5: Konzentrationen der verwendeten Antibiotika und anderer Medienzusätze

\begin{tabular}{cccc}
\hline Medienzusatz & Lösungsmittel & $\begin{array}{c}\text { Stammlösung } \\
(\mathrm{mg} / \mathrm{ml})\end{array}$ & $\begin{array}{c}\text { Arbeitskonzentration } \\
(\mu \mathrm{g} / \mathrm{ml})\end{array}$ \\
\hline Ampicillin & $\mathrm{H}_{2} \mathrm{O}_{\text {dest }}$ & 100 & 100 \\
Kanamycin & $\mathrm{H}_{2} \mathrm{O}_{\text {dest }}$ & 20 & 20 \\
Tetracyclin & Ethanol & 10 & 10 \\
Chloramphenicol & Ethanol & 34 & $25($ E. coli $)$ \\
& & & $600(P$. aeruginosa $)$ \\
IPTG & $\mathrm{H}_{2} \mathrm{O}_{\text {dest }}$ & 24 & $1 \mu \mathrm{M}$ bis $1 \mathrm{mM}$ \\
X-Gal & DMF & 20 & $0,002 \%(\mathrm{v} / \mathrm{v})$ \\
\hline
\end{tabular}

\section{Wachstumsbedingungen und Stammhaltung}

\subsection{Zellanzucht}

E. coli- und $P$. aeruginosa-Stämme wurden üN bei $37^{\circ} \mathrm{C}$ in LB-Flüssigmedium in Reagenzgläsern $(5 \mathrm{ml})$ oder Erlenmeyerkolben $(30 \mathrm{ml}$ bis 1 I Kulturvolumen) 
angezogen. Plasmidhaltige Stämme wurden durch Zugabe des entsprechenden Antibiotikums unter Selektionsdruck gehalten. Hauptkulturen wurden mit 1-3\% (v/v) einer üN gewachsenen Vorkultur angeimpft. Bei der Verwendung von Expressionsstämmen wurde die Expression der Proteine mit IPTG bei einer OD $_{595}$ von etwa 0,5 induziert. Die Inkubation von E. coli- bzw. P. aeruginosa-Kulturen erfolgte bei $37^{\circ} \mathrm{C}$ auf einem Schüttler.

\subsection{Stammkulturen}

$E$. coli und $P$. aeruginosa konnten bis zu vier Wochen auf festem Komplexmedium mit dem entsprechenden Antibiotikum bei $4^{\circ} \mathrm{C}$ gelagert werden. Für eine längere Lagerung wurden Glycerinkulturen angelegt. Frische Übernachtkulturen wurden mit sterilem Glycerin $(87 \% \mathrm{v} / \mathrm{v})$ im Verhältnis $1: 1$ gemischt und bei $-70^{\circ} \mathrm{C}$ eingefroren.

\subsection{Messung der optischen Dichte}

Die optische Dichte wurde in Einmalküvetten mit einer Schichtdicke von $1 \mathrm{~cm}$ bei einer Wellenlänge von $595 \mathrm{~nm}$ gegen unbeimpftes Medium im Photometer Ultraspec 3000 (Pharmacia, Freiburg) bestimmt. Um Messungenauigkeiten zu vermeiden, wurden die Proben mit unbeimpftem Medium entsprechend verdünnt, sobald eine OD von 0,3 überschritten wurde.

\section{Standardtechniken für das Arbeiten mit Nukleinsäuren}

\subsection{Behandlung von Geräten und Lösungen}

Thermostabile Lösungen, Glaswaren und andere Geräte wurden zur Inaktivierung von Nukleasen für 30 min bei $121^{\circ} \mathrm{C}$ autoklaviert. Hitzelabile Lösungen wurden sterilfiltriert. Nicht autoklavierbare Materialien wurden mit $70 \%(\mathrm{v} / \mathrm{v})$ Ethanol gespült oder abgeflammt.

\subsection{Reinigung und Konzentrierung von Nukleinsäuren}

\subsubsection{Phenol/Chloroform-Extraktion}

Zur Extraktion von Proteinen wurden die DNA-Lösungen im Verhältnis 1:1 mit einem Phenol/Chloroform/IAA-Gemisch (25:24:1 (v/v/v)) versetzt und gründlich durchmischt. Zur Phasentrennung wurden die Ansätze $20 \mathrm{~min}$ bei $13.000 \mathrm{Upm}$ und $4^{\circ} \mathrm{C}$ zentrifugiert und die wässrige, DNA-haltige Oberphase vorsichtig abgehoben. Zur Entfernung von Phenolresten wurde noch eine Extraktion mit 1 Vol. Chloroform/IAA (24:1 (v/v)) durchgeführt. Anschließend erfolgte eine Fällung der DNA mit Ethanol [II.4.2.2]

\subsubsection{Fällung von DNA mit Ethanol oder Isopropanol}

Zum Fällen von DNA wurde die DNA-Lösung mit 0,1 Vol. einer $3 \mathrm{M}$ NatriumacetatLösung $(\mathrm{pH} \mathrm{5,5)}$ und 0,7 Vol. Isopropanol oder 2,5 Vol. eiskaltem, unvergälltem Ethanol $(96 \%(v / v))$ versetzt. Nach Durchmischung und Inkubation für 30 min auf Eis 
konnte die DNA durch Zentrifugation (13.000 Upm, $4^{\circ} \mathrm{C}, 15-30 \mathrm{~min}$ ) gefällt werden. Das Pellet wurde zweimal mit unvergälltem $70 \%(\mathrm{v} / \mathrm{v})$ Ethanol gewaschen und dann in der Vakuumzentrifuge (Concentrator 5301, Eppendorf, Hamburg) für 5-10 min getrocknet. Die DNA wurde nun im gewünschten Volumen $\mathrm{H}_{2} \mathrm{O}_{\text {dest }}$ Oder TE-Puffer resuspendiert.

\section{$\underline{\text { TE-Puffer }}$}

$\begin{array}{lrc}\text { Tris-Cl } & 10 & \mathrm{mM} \\ \text { EDTA } & 1 & \mathrm{mM} \\ \text { pH } & 7,4 & \end{array}$

\subsubsection{Dialyse von Gesamt-DNA}

Aus Umweltproben isolierte DNA [II.4.4.2] enthält oftmals zu hohe Salzkonzentrationen, die bei weiteren Anwendungen stören können. Sie muß daher zunächst einer Dialyse unterzogen werden. Dazu wurden Dialyseschlauch-Stücke (VISKING Dialysis Tubing, Serva, Heidelberg) in TE-Puffer [II.4.2.2] für $10 \mathrm{~min}$ aufgekocht. Anschließend konnte die DNA-Lösung in die Schlauchstücke eingefüllt werden, die an beiden Enden mit Dialyseschlauch-Klammern verschlossen wurden. Die Dialyse der DNA erfolgte bei $4^{\circ} \mathrm{C}$ üN gegen TE-Puffer, der nach den ersten $1-2 \mathrm{~h}$ ausgewechselt wurde.

\subsubsection{Konzentrationsbestimmung von DNA}

Zur Ermittlung der Konzentration wurde die $\mathrm{OD}_{260}$ einer DNA-Lösung in einer Quarzküvette gemessen. Bei dieser Wellenlänge entspricht eine $\mathrm{OD}_{260}$ von 1 einer Konzentration an dsDNA von $50 \mu \mathrm{g} / \mathrm{ml}$. Die Reinheit konnte durch die Bildung der Quotienten von Absorptionswerten bei verschiedenen Wellenlängen ermittelt werden. Für reine DNA-Lösungen gilt als Richtwert $\mathrm{OD}_{260}: \mathrm{OD}_{280} \geq 1,8$ (Sambrook et al., 1989), niedrigere Werte weisen auf Proteinverunreinigungen hin.

\subsection{Gelelektrophorese, Ethidiumbromid-Färbung und Größenbestimmung von DNA-Fragmenten}

Eine der am häufigsten angewandten Methoden zur Charakterisierung von DNA ist die Agarosegelelektrophorese. Mit Hilfe dieser Technik können DNA-Moleküle im Gel aufgetrennt werden. Dabei hängt die Laufgeschwindigkeit eines DNA-Fragments von mehreren Faktoren ab, wie z.B. der Größe des DNA-Moleküles, der Agarosekonzentration und der davon abhängigen Porengröße, der angelegten Spannung und den Salzkonzentrationen des Puffers. Es wurden 0,8\%ige (w/v) Gele für die Analyse von Restriktionsfragmenten und 1,6\%ige (w/v) Gele zur Auftrennung von PCR-Produkten kleiner als $1 \mathrm{~kb}$ in 1x TAE-Puffer, der auch als Laufpuffer verwendet wurde, gegossen. Vor Beladen der Geltaschen wurde die DNA mit 0,1 Vol. Ladepuffer 
vermischt, was der Beschwerung und der Markierung der Lauffront durch den enthaltenen Farbstoff Bromphenolblau (ca. 500 bp) diente. Die Auftrennung erfolgte im Minigel (Hoefer HE33 Mini Horizontal Submarine Unit) bei einer Spannung von 60$100 \mathrm{~V}$ und einer Laufzeit von 45-90 min. Nach Beendigung der Gelelektrophorese erfolgte die Färbung der DNA durch Überführung des Gels in ein Ethidiumbromidbad für ca. 10 min und anschließender Entfärbung im Wasserbad für ebenfalls $10 \mathrm{~min}$. Mit Hilfe der Dokumentationsanlage GelDoc1000 (BioRad, München) wurde die DNA bei UV-Licht durch das eingelagerte Ethidiumbromid sichtbar gemacht, fotografisch dokumentiert und eventuell bearbeitet. Die Bestimmung der Größen der jeweiligen DNA-Fragmente erfolgte durch Vergleich mit Markerbanden bekannter Größen zwischen 100 bp und 10 kb (Fermentas, St. Leon-Rot).

\section{$\underline{\text { 50x TAE-Puffer }}$}

Tris

Eisessig

$\mathrm{Na}_{2}$ EDTA $\times 2 \mathrm{H}_{2} \mathrm{O}$

$\mathrm{pH}$

$242 \mathrm{~g} / \mathrm{l}$

$5,71 \%(v / v)$

$32,1 \mathrm{~g} / \mathrm{l}$

8,4

10x DNA-Ladepuffer

Ficoll 400

$200 \mathrm{~g} / \mathrm{l}$

Bromphenolblau

SDS

EDTA (pH 8)

$2,5 \mathrm{~g} / \mathrm{l}$

$10 \mathrm{~g} / \mathrm{l}$

$0,1 \mathrm{M}$

Ethidiumbromid-Färbebad

$200 \mu \mathrm{l}$ einer $2 \mathrm{mg} / \mathrm{ml}$ Ethidiumbromidlösung wurden mit $500 \mathrm{ml} \mathrm{H} \mathrm{H}_{2} \mathrm{O}$ vermischt.

\subsection{Isolierung von DNA}

\subsubsection{Isolierung von Gesamt-DNA aus Bodenproben}

Diese Methode der DNA-Isolierung (Zhou et al., 1996) basiert auf der direkten Lyse der Zellen, damit diese vor dem Aufschluss nicht von den Bodenpartikeln abgetrennt werden müssen. Dadurch wird sowohl frei im Boden vorkommende als auch mikrobielle DNA isoliert.

Zur DNA-Isolierung wurden $50 \mathrm{~g}$ Bodenprobe mit $135 \mathrm{ml}$ DNA-Extraktionpuffer (DEP) und $1 \mathrm{ml}$ Proteinase $\mathrm{K}(10 \mathrm{mg} / \mathrm{ml})$ versetzt und für $30 \mathrm{~min}$ bei $37^{\circ} \mathrm{C}$ geschüttelt $(240$ Upm). Nach der Zugabe von $15 \mathrm{ml}$ 20\% (v/v) SDS wurde diese Suspension für $2 \mathrm{~h}$ bei $65^{\circ} \mathrm{C}$ inkubiert und dabei alle 15 min vorsichtig geschüttelt. Zur Trennung der gelösten DNA von Bodenpartikeln wurde das Gemisch zentrifugiert (10 min, 6.000 Upm, RT) und der Überstand abgenommen. Das Pellet wurde noch zweimal in je $45 \mathrm{ml}$ DEP und 
$5 \mathrm{ml} 20 \%(\mathrm{v} / \mathrm{v})$ SDS resuspendiert und nach einer Inkubation für $10 \mathrm{~min}$ bei $65^{\circ} \mathrm{C}$ wie oben beschrieben zentrifugiert.

Zur DNA-Extraktion wurden die gesammelten Überstände mit 1 Vol. Chloroform/IAA (24:1, v/v) gemischt und zentrifugiert (10 min, $5.000 \mathrm{Upm}, \mathrm{RT})$. Die DNA wurde durch Zugabe von 0,7 Vol. Isopropanol und Inkubation für $1 \mathrm{~h}$ bei RT gefällt. Nach der Zentrifugation (7.500 Upm, 20 min, RT) wurde das Pellet mit eiskaltem 70\%igem (v/v) Ethanol gewaschen, getrocknet und in 2 bis $3 \mathrm{ml}$ sterilem $\mathrm{H}_{2} \mathrm{O}_{\text {dest }}$ aufgenommen. Anschließend wurde eine Dialyse gegen TE-Puffer [II.4.2.2] bei $4^{\circ} \mathrm{C}$ üN durchgeführt.

\begin{tabular}{lrl} 
DNA-Extraktionspuffer (DEP) & & \\
\cline { 1 - 2 } Tris & 100 & $\mathrm{mM}$ \\
$\mathrm{Na}_{2}$-EDTA & $100 \mathrm{mM}$ \\
$\mathrm{Na}_{2} \mathrm{HPO}_{4}$ & 100 & $\mathrm{mM}$ \\
$\mathrm{NaCl}$ & 1,5 & $\mathrm{M}$ \\
$\mathrm{CTAB}$ & 1 & $\%$ \\
pH & 8,0 &
\end{tabular}

\subsubsection{Isolierung von DNA aus Anreicherungskulturen}

Die DNA-Isolierung aus Anreicherungskulturen (Entcheva et al., 2001) basiert auf einer bereits beschriebenen Methode (Streit et al., 1993). Gewisse Veränderungen waren notwendig, da hier ein Konsortium von Mikroorganismen vorlag, deren Lyse unter verschiedenen Bedingungen erfolgreich war.

Nachdem die Zellen aus einem Kulturvolumen von $200 \mathrm{ml}$ pelletiert waren, wurden diese in $4 \mathrm{ml} 1 \mathrm{M} \mathrm{NaCl}$ resuspendiert und für $1 \mathrm{~h}$ auf Eis inkubiert. Nach Zentrifugation $\left(4{ }^{\circ} \mathrm{C}, 20 \mathrm{~min}, 13.000 \mathrm{Upm}\right)$ wurde das Pellet in $2 \mathrm{ml}$ TE-Saccharose-Puffer $(20 \%$, w/v) aufgenommen und die Zellen in 1,6 ml DNA-Extraktionpuffer [II.4.4.1] mit 0,4 $\mathrm{ml} 10 \%$ SDS (w/v) (Endkonzentration 1\% (w/v)) für 2 bis $4 \mathrm{~h}$ bei einer Temperatur von $37^{\circ} \mathrm{C}$ lysiert. Die DNA-Extrakte wurden mit $400 \mu$ Sarkosyl-Proteinase K-Lösung versetzt und für $3 \mathrm{~h}$ bis üN bei $37^{\circ} \mathrm{C}$ inkubiert, wodurch ein Abbau der Zellproteine erfolgte.

Die Gesamt-DNA wurde anschließend mit 1 Vol. Phenol/Chloroform-Lösung (1:1, v/v) extrahiert. Diese Extraktion wurde 2-3mal wiederholt, bis eine klare viskose DNALösung in der wässrige Phase vorhanden war. Anschließend wurde eine ChloroformExtraktion durchgeführt. Die DNA wurde gegen 2 I TE-Puffer bei $4^{\circ} \mathrm{C}$ üN dialysiert [II.4.2.2]. Anschließend wurde ein Aliquot der DNA auf dem Agarosegel überprüft, um sicher zu stellen, dass diese nicht abgebaut war.

TE-Saccharose-Puffer

Saccharose

1x TE [II.4.2.2]
$20 \mathrm{~g}$

ad $100 \mathrm{ml}$ 
Sarkosyl-Proteinase K-Lösung

N-Lauryl-Sarkosyl $(5 \%(\mathrm{w} / \mathrm{v})) \quad 1 \mathrm{ml}$

ProteinaseK $(25 \%(w / v)) \quad 25 \mu l$

\subsubsection{Isolierung von Plasmid-DNA durch alkalische Lyse}

Diese Methode wurde eingesetzt, um eine große Anzahl von Klonen auf das Vorhandensein positiver rekombinanter Plasmide zu überprüfen.

Hierzu wurden $1,5 \mathrm{ml}$ einer Übernachtkultur $1 \mathrm{~min}$ im E-Cup bei 13.000 Upm und RT abzentrifugiert. Das Pellet wurde in $200 \mu \mathrm{l}$ Puffer P1 resuspendiert. Anschließend erfolgte die alkalische Lyse der Zellen durch Zugabe von $200 \mu \mathrm{l}$ Puffer P2, dreimaligem Invertieren des E-Cups und 5 min Inkubation bei RT. Durch Zugabe von $200 \mu$ Puffer P3 erfolgte die Fällung der Proteine. Nach Zentrifugation (13.000 Upm, $20 \mathrm{~min}, 4^{\circ} \mathrm{C}$ ) wurde der Überstand in ein neues E-Cup überführt. Zur Verminderung von Proteinkontaminationen wurde der Ansatz mit 1 Vol. Chloroform-IAA (24:1, v/v) versetzt, gevortext und nach Trennung der Phasen (13.000 Upm, $5 \mathrm{~min}, 4^{\circ} \mathrm{C}$ ) wurde der Überstand in ein neues Gefäß überführt. Durch Zugabe von 0,7 Vol. Isopropanol und 15 min Inkubation auf Eis wurde die DNA gefällt und durch Zentrifugation pelletiert (13.000 Upm, $30 \mathrm{~min}, 4^{\circ} \mathrm{C}$ ). Das Pellet wurde zweimal mit $1 \mathrm{ml} 70 \%$ igem (v/v) reinem Ethanol gewaschen, bei $37^{\circ} \mathrm{C}$ oder in der Vakuumzentrifuge getrocknet und in $50 \mu \mathrm{l}$ $\mathrm{H}_{2} \mathrm{O}_{\text {dest }}$ resuspendiert.

\section{Puffer P1}

\begin{tabular}{lrl}
\hline Tris-HCl & 50 & $\mathrm{mM}$ \\
EDTA & 10 & $\mathrm{mM}$ \\
RNAse & 1 & $\mathrm{mg} / \mathrm{ml}$ \\
pH & 8,0 &
\end{tabular}

Puffer P2

$\mathrm{NaOH}$

$0,2 \quad M$

SDS

$1 \%(w / v)$

Puffer P3

Eisessig

$\mathrm{pH}$

$2,95 \%(\mathrm{v} / \mathrm{v})$

4,8 (mit KOH-Plätzchen)

\subsubsection{Isolierung hochreiner Plasmid- und Cosmid-DNA}

Die Plasmidisolierungskits von Qiagen (Hilden) ermöglichten die Präparation kleinerer („QIAprep Spin Miniprep“) und größerer Mengen („QIAprep Spin Midiprep“) hochreiner DNA. Dabei wurde die Plasmid-DNA mit hoher Kopienzahl aus 3-5 ml E. coli-Kulturen gewonnen. Plasmide mit niedriger Kopienzahl und Cosmide wurden aus bis zu $500 \mathrm{ml}$ Kultur gewonnen. Die Durchführung erfolgte gemäß Anleitung des Herstellers. Die in $\mathrm{H}_{2} \mathrm{O}_{\text {dest }}$ eluierte DNA war für die PCR und Sequenzierungen verwendbar. 


\subsubsection{Isolierung genomischer DNA mit dem „AquaPure Genomic DNA Kit"} Zur Isolierung genomischer DNA aus Reinkulturen wurde das „AquaPure Genomic DNA Kit“ (BioRad, München) verwendet. Die Isolierung von DNA aus Gram-negativen Organismen erfolgte wie nach Anleitung des Herstellers für $E$. coli.

Zur Isolierung von DNA aus Gram-positiven Organismen wurde das Protokoll etwas modifiziert. Nach der Zellernte wurde das Pellet aus 1,5 ml Kultur zunächst in $100 \mu \mathrm{l}$ TE-Puffer [II.4.2.2], der $10 \mathrm{mg} / \mathrm{ml}(\mathrm{w} / \mathrm{v})$ Lysozym enthielt, resuspendiert. Zur Lyse der Peptidoglykanschicht wurde für $15 \mathrm{~min}$ bei $37^{\circ} \mathrm{C}$ inkubiert und anschließend mit dem Protokoll nach Anleitung fortgefahren.

\subsubsection{Elution von DNA-Fragmenten aus Agarosegelen}

Nach PCR oder Restriktionsverdau und Überprüfung der Ergebnisse auf einem Agarosegel konnten DNA-Fragmente, die für eine Ligation benötigt wurden, unter Verwendung des "Wizard SV Gel and PCR Clean up Kit“ (Promega, Madison, USA) nach Angaben des Herstellers aus dem Gel eluiert werden. PCR-Reaktionen, die keine Nebenprodukte lieferten, konnten ohne Auftrennung im Agarosegel direkt gereinigt werden.

\subsection{Enzymatische Modifikationen von DNA}

\subsubsection{DNA-Verdau durch Restriktionsendonukleasen}

Diese Methode beruht auf der hohen Spezifität der aus verschiedenen Prokaryonten isolierten Typ II-Restriktionsendonukleasen zu ihrer meist palindromischen Erkennungssequenz in einem DNA-Doppelstrang. Nach Bindung an diese palindromische Sequenz hydrolysieren die Enzyme an definierter Stelle die Phosphodiesterbindung zwischen je zwei Basen in beiden Strängen, wobei überhängende oder glatte Enden entstehen können. Es wurden Restriktionsenzyme und die mitgelieferten Inkubationspuffer der Firmen Fermentas (St. Leon-Rot) oder New England Biolabs (Ipswich, USA) verwendet. In der Regel hatten analytische Restriktionssansätze ein Gesamtvolumen von $10 \mu \mathrm{l}$, präparative Ansätze ein Gesamtvolumen von $50 \mu \mathrm{l}$.

\begin{tabular}{|c|c|c|}
\hline Restriktionsansatz & analytischer Verdau & präparativer Verdau \\
\hline$\overline{D N A}$ & $x \mu g$ & $x \mu g$ \\
\hline 10x Puffer & $1 \mu l$ & $5 \mu l$ \\
\hline Restriktionsenzym $(10 \mathrm{U} / \mu \mathrm{l})$ & $0,5 \mu \mathrm{l}$ & $1 \mu l$ \\
\hline $\mathrm{H}_{2} \mathrm{O}_{\text {dest }}$ & ad $10 \mu \mathrm{l}$ & ad $50 \mu \mathrm{l}$ \\
\hline
\end{tabular}

Die Inkubation erfolgte bei analytischen Ansätzen für $1 \mathrm{~h}$, bei präparativen Ansätzen für $3 \mathrm{~h}$ bis üN, bei der für das Restriktionsenzym optimalen Temperatur. Zur Inaktivierung der Restriktionsenzyme wurden die Ansätze 20 min je nach Herstellerangabe inkubiert. 


\subsubsection{Partieller Verdau von Gesamt-DNA}

Der partielle Verdau von Gesamt-DNA aus Umweltproben wurde in einer Verdünnungsreihe durch das Enzym Bsp143l durchgeführt. Die verschiedenen Verdünnungsstufen wurden zunächst im analytischen Maßstab angesetzt. Die eingesetzte DNA-Menge sollte nicht mehr als $250 \mathrm{ng}$ DNA betragen. Nach $20 \mathrm{~min}$ Inkubation bei $37^{\circ} \mathrm{C}$ wurde der Verdau gestoppt und auf einem $0,8 \%$ igem Agarosegel überprüft. Nach Ermittlung der optimalen Verdünnungsstufe wurde der Verdau im präparativen Maßstab wiederholt.

\subsubsection{Dephosphorylierung von DNA-Enden}

Zur Vermeidung von Selbstligationen konnten die 5'-Phosphatgruppen restriktionsverdauter DNA enzymatisch durch alkalische Phosphatase abgespalten werden. Hierfür wurden 0,1 Volumen des 10x Puffers zu $1 \mu \mathrm{g}$ DNA gegeben. Nach Hinzufügen von $1 \mu \mathrm{l}$ „Antarctic Phosphatase“ (New England Biolabs, Ipswich, USA) wurde der Ansatz gemischt. Handelte es sich um 5'-Überhänge oder gerade Enden wurde für $15 \mathrm{~min}$ bei $37^{\circ} \mathrm{C}$ inkubiert, bei 3'-Überhängen für $60 \mathrm{~min}$. Die Inaktivierung erfolgte durch fünf Minuten Inkubation bei $65^{\circ} \mathrm{C}$.

\subsubsection{Ligation von DNA-Fragmenten}

DNA-Ligasen katalysieren die Bildung von Phosphodiester-Bindungen zwischen einem 5'-Phosphat- und einem 3'-OH-Ende in doppelsträngiger DNA. Mit Hilfe der T4-DNALigase (Fermentas, St-Leon-Rot) wurden DNA-Fragmente ligiert. Die Ligationen wurden mit einem Überschuss an Insert-DNA durchgeführt. Dieser sollte bei glatten Enden etwa 5:1, bei kohäsiven Enden etwa 3:1 gegenüber der Vektor-DNA liegen. Für die Ligation von DNA-Fragmenten mit glatten Enden wurde dem Ansatz 0,1 Vol. Polyethylenglykol $(50 \%(\mathrm{v} / \mathrm{v}))$ zugegeben, die Inkubation erfolgte bei $16^{\circ} \mathrm{C}$ üN. Die Ligationsansätze konnten ohne weitere Behandlung zur Transformation [II.5.1.2] eingesetzt werden.

\subsection{Amplifikation von DNA durch Polymerase-Kettenreaktion (PCR)}

Die PCR wurde zur Herstellung spezifischer DNA-Fragmente für Klonierungen oder Sequenzierungen verwendet. Als Enzyme wurden Taq-oder Pfu-DNA-Polymerase (Fermentas, St. Leon-Rot) eingesetzt. Aufgrund ihrer Korrekurlesefunktion wurde die Pfu-Polymerase insbesondere für die Amplifikation von Genen zur späteren Proteinexpression eingesetzt, um evtl. Mutationen durch Fehler in der PCR-Reaktion zu unterbinden. Die Reaktionen wurden entsprechend den Herstellerempfehlungen in einem Volumen von $50 \mu$ durchgeführt und enthielten folgende Bestandteile: 


Oligonukleotide (100 mM)
dNTP-Gemisch (je $10 \mathrm{mM}$ )
DNA-Polymerase
$10 x$ Reaktionspuffer
[MgCl
[DMSO
DNA
$\mathrm{H}_{2} \mathrm{O}_{\text {dest }}$

$\begin{array}{rl}\text { je } 0,5 & \mu \mathrm{l} \\ 0,5 & \mu \mathrm{l} \\ 1 & \mathrm{U} \\ 5 & \mu \mathrm{l} \\ 1,5 & \mathrm{mM}] \\ 2-5 & \%(\mathrm{v} / \mathrm{v})] \\ \mathrm{x} & \mu \mathrm{l} \\ \text { ad } 50 & \mu \mathrm{l}\end{array}$

Die Temperaturzyklen wurden den jeweiligen Anforderungen in Bezug auf die Hybridisierungstemperatur $(x)$ und die Dauer der Kettenverlängerung $(y)$ angepasst. Sie wurden nach folgendem Schema durchgeführt:

\begin{tabular}{|c|c|c|}
\hline \multirow{2}{*}{\multicolumn{3}{|c|}{$\begin{array}{l}\text { Denaturierung } \\
\text { 30-35 Zyklen }\end{array}$}} \\
\hline & & \\
\hline Denaturierung & $95^{\circ} \mathrm{C}$ & $1 \min$ \\
\hline Hybridisierung & $\mathrm{x}^{\circ} \mathrm{C}$ & $1 \mathrm{~min}$ \\
\hline Kettenverlängerung & $72^{\circ} \mathrm{C}$ & $y \min$ \\
\hline Zyklus Ende & & \\
\hline Kettenverlängerung & $72^{\circ} \mathrm{C}$ & $10 \mathrm{~min}$ \\
\hline
\end{tabular}

Für die Einstellung der Parameter waren die zu erwartende Fragmentlänge und die Schmelztemperatur $\mathrm{T}_{\mathrm{m}}$ der verwendeten Oligonukleotide entscheidend. Für die Elongation wurde entsprechend der zu erwartenden Fragmentlänge eine Zeit von ca. 2 kb/min (Taq-Polymerase) bzw. 1 kb/min (Pfu-Polymerase) gewählt. Die optimale Hybridisierungstemperatur wurde nach der Schmelztemperatur $T_{m}$ der Oligonukleotide festgelegt, die über Formel (1) errechnet wurde:

$$
\mathrm{T}_{\mathrm{m}}=69,3+0,41(\% \mathrm{GC})-650 / \mathrm{L}
$$

Hierbei sind L die Länge des Oligonukleotids und \% GC der prozentuale GC-Gehalt des Oligonukleotids.

Durch Verkürzung der Hybridisierungsdauer, Variation der Hybridisierungstemperatur und Verringerung der Oligonukleotidkonzentration, DMSO- oder $\mathrm{MgCl}_{2}$-Konzentration konnte die Spezifität der PCR optimiert werden.

Bei der 16S rRNA-Gen spezifischen PCR wurden etwa 3fach verlängerte Zeiten für die Kettenverlängerung verwendet, um die Entstehung von chimeren Sequenzen zu minimieren (Meyerhans et al., 1990).

Die Temperaturzyklen wurden mit dem "Thermocycler Primus" (MWG Biotech, Ebersberg) durchgeführt. Die PCR-Produkte wurden durch Agarose-Gelelektrophorese [II.4.3] analysiert. 


\subsection{Ligation von PCR-Produkten in den Klonierungsvektor pDrive}

Der pDrive Klonierungs-Vektor (Qiagen, Hilden) wird in einer linearen Form geliefert und enthält an jedem Ende einen U-Überhang, der eine spezifische Bindung mit dem PCR-Produkt möglich macht. Für die PCR wurde die Taq-Polymerase verwendet, da diese A-Überhänge an den Enden des PCR-Produkts erzeugt, die für eine anschließende Ligation in den pDrive Vektor benötigt werden. Die Ligation erfolgte nach Angabe des Herstellers.

\subsection{Mutagenesetechniken}

\subsubsection{Transposonmutagenese}

Um funktionelle Gene zu identifizieren, wurde das EZ::TN ${ }^{\mathrm{TM}}<\mathrm{KAN}-2>$ oder das EZ::TN ${ }^{\mathrm{TM}}<\mathrm{TET}-1>$ Transposon der Firma Epicentre (Madison, USA) verwendet. Das Transposon inserierte in vitro zufällig in die Ziel-DNA. Mittels einer durch das Transposon vermittelten Resistenz konnte die mutagenisierte DNA selektioniert werden. Die Mutagenese erfolgte nach Angaben des Herstellers. Das Transposon enthielt ebenfalls Primerbindestellen für die in Tab. 6 aufgelisteten Primer, die eine bidirektionale Sequenzierung des DNA-Abschnitts, in den das Transposon inseriert hatte, ermöglichten.

Tab. 6: EZ::TN ${ }^{\mathrm{TM}}<\mathrm{KAN}-2>$ und $<\mathrm{TET}-1>$ Transposon Primer

\begin{tabular}{llc}
\hline Primer & Sequenz & $\mathrm{T}_{\mathrm{m}}$ [ $\left.^{\circ} \mathrm{C}\right]$ \\
\hline KAN-2 FP-1 & 5'-ACCTACAACAAAGCTCTCATCAACC-3' & 55 \\
KAN-2 RP-1 & 5'-GCAATGTAACATCAGAGATTTTGAG-3' & 55 \\
TET-1 FP-1 & 5'-GGGTGCGCATGATCCTCTAGAGT-3' & 67 \\
TET-1 RP-2 & 5'-TAAATTGCACTGAAATCTAGAAATA-3' & 57 \\
\hline
\end{tabular}

\subsubsection{Gezielter Aminosäureaustausch}

Zum gezielten Austausch von Aminosäuren wurde der "QuikChange Mutagenesis Kit" (Stratagene, Heidelberg) verwendet. Das Design der für die Mutagenese verwendeten Primer und die Mutagenese erfolgten nach Anleitung des Herstellers. 


\section{Transformationsverfahren}

\subsection{Transformation von E. coli}

\subsubsection{Herstellung kompetenter Zellen mit Hilfe der $\mathbf{C a C l}_{2}-\mathbf{M e t h o d e}$}

$200 \mathrm{ml}$ LB-Medium [II.2.1] wurden 1\%ig (v/v) mit einer Übernachtkultur angeimpft und bis zu einer $\mathrm{OD}_{595}$ von ca. 0,4 angezogen. Nach 10 min Inkubation auf Eis erfolgte die Pelletierung der Zellen (4.000 Upm, $7 \mathrm{~min}, 4^{\circ} \mathrm{C}$ ). Das Pellet wurde in $10 \mathrm{ml}$ eiskalter $\mathrm{CaCl}_{2}$-Lösung resuspendiert und anschließend zentrifugiert (4.000 Upm, $5 \mathrm{~min}, 4^{\circ} \mathrm{C}$ ). Die Pellets wurden in $2 \mathrm{ml}$ eiskalter $\mathrm{CaCl}_{2}$-Lösung resuspendiert und in Aliquots $\mathrm{zu}$ $200 \mu \mathrm{l}$ in vorgekühlte E-Cups portioniert. Die Zellen konnten direkt für eine Transformation verwendet werden oder wurden sofort bei $-70^{\circ} \mathrm{C}$ schockgefroren.

$\mathrm{CaCl}_{2}$-Lösung

$\begin{array}{lrl}\mathrm{CaCl}_{2} & 60 \mathrm{mM} \\ \text { Glycerin } & 15 \%(\mathrm{w} / \mathrm{v}) \\ \text { PIPES } & 10 \mathrm{mM} \\ \mathrm{pH} & 7,0 & \end{array}$

\subsubsection{Transformation von E. coli mittels Hitzeschock}

Eingefrorene kompetente Zellen wurden $10 \mathrm{~min}$ auf Eis aufgetaut. Nach Zugabe von 10-150 ng DNA und vorsichtigem Mischen erfolgte eine Adsorption der DNA an die Zellen durch 30 min Inkubation auf Eis. Durch einen Hitzeschock für $90 \mathrm{sec}$ bei $42^{\circ} \mathrm{C}$ sollte die DNA in die Zellen aufgenommen werden. Anschließend wurden die Zellen für 3-5 min auf Eis inkubiert. Nach Zugabe von $800 \mu$ LB-Medium [II.2.1] wurden die Zellen zur Ausbildung der Antibiotikaresistenz $1 \mathrm{~h}$ bei $37^{\circ} \mathrm{C}$ inkubiert. $100 \mu \mathrm{l}$ des Transformationsansatzes wurden auf vorgewärmte Agarplatten mit entsprechendem Antibiotikazusatz zur Selektion plattiert und üN bei $37^{\circ} \mathrm{C}$ inkubiert.

\subsubsection{Herstellung kompetenter Zellen für die Elektroporation}

Alle Lösungen und Gefäße mußten eisgekühlt verwendet werden. Vornehmliche Aufgabe der Zellpräparation war die Beseitigung von Salzen, um die Ionenstärke der Suspension zu verringern. Die Zellpellets sollten nur äußerst vorsichtig resuspendiert werden.

$500 \mathrm{ml}$ LB-Medium [II.2.1] wurden mit 2,5 ml einer üN gewachsenen Kultur angeimpft und bis zu einer $\mathrm{OD}_{595}$ von etwa 0,6 unter starkem Schütteln bei $37^{\circ} \mathrm{C}$ inkubiert. Anschließend wurden die Zellen 10-15 min auf Eis gelagert. Die Ernte der Zellen erfolgte durch Zentrifugation (5.000 Upm, $20 \mathrm{~min}, 4^{\circ} \mathrm{C}$ ). Das Pellet wurde in der verbleibenden Flüssigkeit resuspendiert. Die Zellen wurden mit $500 \mathrm{ml}$ sterilem $\mathrm{H}_{2} \mathrm{O}_{\text {dest }}$ gewaschen und erneut zentrifugiert (5.000 Upm, $20 \mathrm{~min}, 4^{\circ} \mathrm{C}$ ). Das Pellet wurde mitm40 ml 10\% (v/v) Glycerin gut gemischt und abermals zentrifugiert (4.000 Upm, 10 
$\min , 4^{\circ} \mathrm{C}$ ). Die Zellen wurden in $1 \mathrm{Vol} .10 \%$ igem Glycerin resuspendiert, aliquotiert (60 $\mu \mathrm{l})$ und entweder direkt verwendet oder bei $-70^{\circ} \mathrm{C}$ gelagert.

\subsubsection{Transformation von E. coli mittels Elektroporation}

In einer Elektroporationsküvette wurden 0,1-1 $\mu$ DNA mit $60 \mu$ Zellsuspension gemischt. Die Elektroporation erfolgte bei 2.500 V, $25 \mu \mathrm{F}$ und $200 \Omega$ (2 mm Elektrodenabstand) im GenePulser Xcell ${ }^{\mathrm{TM}}$ (BioRad, München). Die Entladungszeit sollte bei $5 \mathrm{~ms}$ liegen. Nach der Elektroporation erfolgte die Zugabe von $1 \mathrm{ml}$ LB-Medium [II.2.1] und sofortiges Umfüllen des Ansatzes in ein E-Cup. Die Zellen wurden für $1 \mathrm{~h}$ bei $37^{\circ} \mathrm{C} \mathrm{im}$ Schüttler inkubiert, jeweils $25-50 \mu \mathrm{l}$ auf Selektionsmedium ausplattiert und bei $37^{\circ} \mathrm{C}$ üN inkubiert.

\subsubsection{Selektion rekombinanter E. coli-Klone durch X-Gal-Test}

Der verwendete E. coli Stamm XL1-blue ist durch eine Deletion im lacZ-Gen gekennzeichnet und kann daher keine aktive $\beta$-Galaktosidase mehr bilden. Durch Transformation mit Plasmiden wie pBlueskriptSK(+), die über die $\alpha$-Untereinheit der $\beta$-Galaktosidase verfügen, in der sich wiederum die MKS befindet, kommt es zur Bildung eines aktiven Enzyms. Dies kann dadurch auf X-Gal- und IPTG-haltigen Platten sichtbar gemacht werden, dass das lacZ-Gen durch IPTG induziert wird und die $\beta$-Galaktosidase das Glucoseanalogon X-Gal spaltet, wonach durch Luftoxidation ein blauer Farbstoff entsteht. Soll in die MKS des Plasmids ein DNA-Fragment ligiert werden, kann der Erfolg der Insertion nach Transformation anhand der Koloniefarbe sichtbar gemacht werden. Plasmide mit einer Insertion in der Multiklonierungsstelle können keine aktive $\beta$-Galaktosidase mehr bilden und erscheinen weiß.

\subsection{Transformation von Pseudomonas aeruginosa}

\subsubsection{Herstellung kompetenter Zellen}

$20 \mathrm{ml}$ LB-Medium [II.2.1] wurden mit 0,4 ml Mg${ }^{2+}-\mathrm{Mix}$ (150 mM MgCl $2,150 \mathrm{mM} \mathrm{MgSO}_{4}$ ) versehen und mit 0,2 $\mathrm{ml}$ einer $P$. aeruginosa üN-Kultur beimpft. Die Kultur wurde in einem $100 \mathrm{ml}$-Erlenmeyerkolben bei $37^{\circ} \mathrm{C}$ und $200 \mathrm{Upm}$ bis zur logarithmischen Wuchsphase $\left(\mathrm{OD}_{580}=0,5-0,8\right)$ inkubiert. Pro Transformationsansatz wurden $2 \mathrm{ml}$ Kultur durch Zentrifugation ( $1 \mathrm{~min}, 10.000 \mathrm{Upm}$, RT) geerntet, in $2 \mathrm{ml}$ eiskaltem $\mathrm{MgCl}_{2}$ (150 $\mathrm{mM}$ ) resuspendiert und $5 \mathrm{~min}$ auf Eis inkubiert. Die Zellen wurden durch eine weitere Zentrifugation ( $1 \mathrm{~min}, 10.000 \mathrm{Upm}, \mathrm{RT}$ ) pelletiert, in $1 \mathrm{ml}$ eiskaltem $\mathrm{MgCl}_{2}$ (150 mM) resuspendiert und für 20 min auf Eis inkubiert. Nach der Inkubation wurden die Zellen erneut durch Zentrifugation (1 min, 10.000 Upm, RT) sedimentiert und das Pellet in $0,2 \mathrm{ml}$ eiskaltem $\mathrm{MgCl}_{2}(150 \mathrm{mM})$ resuspendiert. Die Zellen wurden über Nacht bei $4^{\circ} \mathrm{C}$ gelagert, bevor sie in einer Transformation eingesetzt werden konnten. 
Nach Zugabe von Glycerin (Endkonzentration 20\% (v/v)) konnten die Ansätze bei $70^{\circ} \mathrm{C}$ eingefroren und gelagert werden.

\subsubsection{Transformation von $P$. aeruginosa mittels Hitzeschock}

Zur Transformation wurden ca. 0,5 $\mu$ g Plasmid-DNA mit $\mathrm{MgCl}_{2}(150 \mathrm{mM})$ auf ein Volumen von $100 \mu \mathrm{l}$ aufgefüllt. Die DNA wurde mit einem transformationskompetenten Ansatz $P$. aeruginosa-Zellen vermischt und für $1 \mathrm{~h}$ auf Eis inkubiert. Es folgte ein Hitzeschock von $3 \mathrm{~min}$ bei $50^{\circ} \mathrm{C}$ und nach Zugabe von $1 \mathrm{ml}$ LB-Medium [II.2.1] die Expression der Antibiotikaresistenz für 2 bis $3 \mathrm{~h}$ bei $37^{\circ} \mathrm{C}$ in einem Schüttler. Nach Zentrifugation des Ansatzes (2 min, 8.000 Upm, RT) wurde das Pellet in 0,2 ml LBMedium [II.2.1] aufgenommen, resuspendiert und anschließend auf entsprechenden Selektivagarplatten ausplattiert.

\subsection{Transduktion mit dem "Gigapack III Gold Packaging Extract"}

Um Genbanken mit relativ großen Fragmenten ( $\sim 30 \mathrm{~kb})$ herzustellen, wurden Cosmidvektoren verwendet. Diese konnten, falls sie dementsprechend große Inserts trugen, in vitro in $\lambda$-Phagen Köpfe verpackt und in dafür geeignete $E$. coli-Stämme transduziert werden.

Hierfür wurde der "Gigapack III Gold Packaging Extract" (Stratagene, Heidelberg) mit E. coli VCS257 als Wirt verwendet. Die Durchführung erfolgte nach Anleitung des Herstellers.

\section{Standardtechniken für das Arbeiten mit Proteinen}

\subsection{Quantitative Proteinbestimmung (Bradford, 1976)}

Für eine quantitative Proteinbestimmung wurde der „Protein Assay Kit“ (BioRad, München) verwendet, der auf der colorimetrischen Methode von Bradford (1976, mod.) basiert. Der anionisch vorliegende Farbstoff Coomassie Brilliant Blue G250 bindet dabei an positiv geladene Aminosäuren der Proteine. Maximal können Proteinmengen von $10 \mu \mathrm{g}$ bestimmt werden. Die untere Nachweisgrenze liegt bei $1 \mu \mathrm{g}$.

Hierfür wurde die Proteinlösung mit $1 \mathrm{ml}$ der nach Angaben des Herstellers (Konzentrat-Verdünnung 1:5 mit $\mathrm{H}_{2} \mathrm{O}$ ) angesetzten Färbelösung versetzt, der Ansatz gut gemischt und für $10 \mathrm{~min}$ bei RT im Dunkeln inkubiert. Nach nochmaligem Durchmischen erfolgte die Messung der $\mathrm{OD}_{595}$ gegen eine Nullprobe ohne Protein. Die Quantifizierung erfolgte mit Hilfe einer Eichgeraden, die mit BSA im Bereich von 0-10 $\mu$ g Protein/Ansatz erstellt wurde. 


\subsection{SDS-Polyacrylamidgelelektrophorese (SDS-PAGE) (Laemmli, 1970)}

Bei der SDS-PAGE werden alle Proteine durch Einlagerung des amphipatischen, negativ geladenen SDS denaturiert und mit einer identischen Ladungsdichte versehen. Dies folgt aus der Einlagerung eines SDS-Moleküls pro 2 Aminosäuren, so dass die negative Gesamtladung der Größe des Proteins proportional ist. Durch die identische Ladungsdichte ist nun eine Auftrennung der Proteine nach der Masse in einem Polyacrylamid-Netzwerk möglich. Für die Elektrophorese wurde eine „Mini Protean 3“Apparatur (BioRad, München) verwendet. Es wurden ausschließlich diskontinuierliche Gele gegossen, die aus einem Trenngel und einem darüber liegenden Sammelgel bestanden, was zu einer besseren Auftrennung der Proben führte. Für die Trennleistung in einem bestimmten Molekularmassenbereich ist der Vernetzungsgrad des SDS-Gels entscheidend. Für die in dieser Arbeit untersuchten Proteine wurden 12\%ige Trenngele verwendet.

\section{Herstellung der Gele:}

Für ein Gel wurden je eine große und eine kleine Glasplatte mit 70\%igem (v/v) Ethanol gereinigt, zusammengesetzt und in die Gelapparatur eingesetzt. Danach wurde das Trenngel zwischen die senkrecht stehenden Glasplatten gegossen und vorsichtig mit $\mathrm{H}_{2} \mathrm{O}$ überschichtet, um eine gerade Geloberfläche zu erhalten und die Polymerisation des Acrylamids unter Luftabschluß zu gewährleisten. Nach Polymerisation des Trenngels für 30 min wurde das Wasser mit saugfähigem Papier entfernt und das Sammelgel darüber gegossen. Das Pipettierschema für die Zusammensetzung von Trenn- und Sammelgel findet sich in Tab. 7. Sofort danach wurde der Kamm luftblasenfrei eingesetzt und das Gel konnte nach dem Auspolymerisieren und Ziehen des Kammes für die Elektrophorese verwendet werden.

Tab. 7: Pipettierschema für 2 Acrylamidgele

\begin{tabular}{lll}
\hline Stammlösung & Trenngel (12\%) & Sammelgel (4\%) \\
\hline $\mathrm{AA}(40 \%, \mathrm{w} / \mathrm{v})$ & $2,4 \mathrm{ml}$ & $0,4 \mathrm{ml}$ \\
$\mathrm{TG}$ & $2 \mathrm{ml}$ & -- \\
$\mathrm{SG}$ & -- & $0,96 \mathrm{ml}$ \\
$\mathrm{H}_{2} \mathrm{O}_{\text {dest }}$ & $3,6 \mathrm{ml}$ & $2,64 \mathrm{ml}$ \\
\hline TEMED & $6 \mu \mathrm{l}$ & $4 \mu \mathrm{l}$ \\
APS & $60 \mu \mathrm{l}$ & $30 \mu \mathrm{l}$ \\
\hline
\end{tabular}




\begin{tabular}{|c|c|c|}
\hline Stammlösungen & Trenngel (TG) & Sammelgel (SG) \\
\hline $\begin{array}{l}\text { Tris } \\
\text { SDS } \\
\mathrm{pH}\end{array}$ & $\begin{array}{rr}182 & \mathrm{~g} / \mathrm{l} \\
4 & \mathrm{~g} / \mathrm{l} \\
8,8 & \end{array}$ & $\begin{array}{rr}61 & \mathrm{~g} / \mathrm{l} \\
4 & \mathrm{~g} / \mathrm{l} \\
6,8 & \end{array}$ \\
\hline \multicolumn{2}{|c|}{ Acrylamid-Stammlösung (AA) } & $40 \%$ (w/v) Fertiglösung (BioRad) \\
\hline \multicolumn{2}{|c|}{$\underline{\text { Ammoniumpersulfat (APS) }}$} & $10 \%(w / v)$ in $\mathrm{H}_{2} \mathrm{O}_{\text {dest }}$ \\
\hline \multicolumn{2}{|c|}{$\underline{\mathrm{N}, \mathrm{N}, \mathrm{N}^{\prime}, \mathrm{N}^{\prime}-\text {-Tetramethylendiamin (TEMED) }}$} & Fertiglösung (BioRad, München) \\
\hline
\end{tabular}

\section{Probenvorbereitung und Durchführung der Elektrophorese:}

Die Proben wurden, sofern nicht anders angegeben, 1:4 mit 4x SDS-Probenpuffer versetzt, vor dem Auftragen mindestens $5 \mathrm{~min}$ bei $95^{\circ} \mathrm{C}$ denaturiert und anschließend kurz abzentrifugiert. Nach dem Auftragen wurden die Proben zunächst für etwa 20 min bei einer konstanten Stromstärke von $20 \mathrm{~mA}$ pro Gel in das Sammelgel eingezogen, danach wurde die Elektrophorese bei $30 \mathrm{~mA}$ pro Gel durchgeführt bis die Bromphenolblaubande das Ende des Gels erreicht hatte. Als Laufpuffer diente 1x SDSElektrophorese-Puffer.

\section{4x Probenpuffer}

\begin{tabular}{lrl}
\hline Glycerin & 7,5 & $\mathrm{ml}$ \\
$\beta$ - Mercaptoethanol & 2,5 & $\mathrm{ml}$ \\
$\mathrm{SDS}$ & 1,2 & $\mathrm{~g}$ \\
Bromphenolblau (2\%) & 0,5 & $\mathrm{ml}$ \\
Tris & 0,4 & $\mathrm{~g}$ \\
$\mathrm{H}_{2} \mathrm{O}_{\text {dest }}$ & ad 50 & $\mathrm{ml}$
\end{tabular}

\section{0x Elektrophorese-Puffer}

$\begin{array}{lrl}\text { Tris } & 30,3 & \mathrm{~g} / \mathrm{l} \\ \text { Glycin } & 144,1 & \mathrm{~g} / \mathrm{l} \\ \text { SDS } & 10,0 & \mathrm{~g} / \mathrm{l} \\ \mathrm{pH} & 8,4 & \end{array}$

\subsection{Molekularmassenbestimmung von Proteinen in SDS-Gelen}

Bei der Elektrophorese von Proteinen wurden Marker mit definierten Molekularmassen auf ein SDS-Gel mit aufgetragen. Die Wanderungsstrecken der verschiedenen Proteine konnten gegen den dekadischen Logarithmus ihrer Molekularmassen aufgetragen werden. Aus der so erhaltenen Eichgerade wurde die Molekularmasse eines mit aufgetragenen, unbekannten Proteins ermittelt. Verwendet wurde der „Protein Molecular Weight Marker" (Fermentas, St. Leon-Rot) oder der „High Molecular Weight Marker" (Sigma, St. Louis, USA). 


\subsection{Coomassie-Färbung}

Nach Beendigung der Elektrophorese wurden die SDS-Gele mit Färbelösung versetzt und ca. 30 min auf einer Laborwippe leicht geschwenkt. Entfärbt wurden die Gele mit Entfärberlösung, die solange gewechselt wurde, bis der Hintergrund der Gele farblos war. Die Gele wurden bis zum Trocknen in $\mathrm{H}_{2} \mathrm{O}_{\text {dest }}$ aufbewahrt.

\section{Färbelösung}

\begin{tabular}{lr} 
Coomassie Blue R-250 & $0,1 \%(\mathrm{w} / \mathrm{v})$ \\
Methanol & $40 \%(\mathrm{v} / \mathrm{v})$ \\
Essigsäure & $10 \%(\mathrm{v} / \mathrm{v})$ \\
& \\
Entfärberlösung & $40 \%(\mathrm{v} / \mathrm{v})$ \\
\hline Methanol & $10 \%(\mathrm{v} / \mathrm{v})$ \\
Essigsäure & 10
\end{tabular}

\subsection{Umpufferung durch Dialyse}

Proteinlösungen wurden durch Dialyse in Dialyseschläuchen entsalzt und umgepuffert (VISKING Dialysis Tubing, Serva, Heidelberg). Zunächst wurde ein angemessen großes Schlauchstück abgeschnitten, wobei $1 \mathrm{~cm}$ Dialyseschlauch ca. 2,5 ml Flüssigkeit aufnehmen kann. Der Schlauch wurde in dem für die Dialyse benutzten Puffer für 10 min aufgekocht, anschließend mit der Proteinlösung befüllt und an beiden Enden mit Schlauchklammern verschlossen. Die Dialyse erfolgte unter leichtem Rühren gegen 2-5 I Puffer bei $4^{\circ} \mathrm{C}$ üN.

\subsection{Konzentration von Proteinlösungen}

Um Proteinlösungen zu konzentrieren, wurden Mikrokonzentratoren (Amicon Ultra/ Millipore, Cork, Irland) mit einer Ausschlussgröße von 10 kDa oder 30 kDa verwendet. Dabei konnten Proteinlösungen von $14 \mathrm{ml}$ auf bis zu $200 \mu \mathrm{l}$ eingeengt werden. Die Zentrifugation erfolgte in einer Kühlzentrifuge (Centrifuge 5804, Eppendorf, Hamburg) bei 3.000 Upm.

\section{Zellernte und Rohextraktgewinnung}

\subsection{Zellernte}

Zur Gewinnung von Rohextrakten wurden Zellen in Flüssigkultur angezogen [II.3.1] und geerntet. Das Pellet wurde entsprechend den weiteren Erfordernissen in Puffer aufgenommen. Dieser Puffer diente auch als Waschpuffer. Nach gegebenenfalls mehrmaligem Waschen durch Resuspendieren und Abzentrifugieren (15 min, 7.000 Upm, $4^{\circ} \mathrm{C}$ ) wurde das Naßgewicht des Pellets bestimmt und die Zellen in 2-3 ml Puffer pro Gramm Naßgewicht gründlich resuspendiert. 


\subsection{Zellaufschluss}

\subsubsection{Zellaufschluss mit der „French Pressure Cell““}

Der Aufschluss von Zellen in der „French Pressure Cell“ (American Instrument Company, Silver Spring, USA) erfolgt dadurch, dass die Zellsuspension zunächst einem Druck von 6,9 MPa ausgesetzt wird, der absinkt, wenn ein kleines Ventil geöffnet wird, und die Zellen hindurchgepreßt werden. Der plötzliche Druckabfall bewirkt das Platzen und somit die Lyse der Zellen. Das zähflüssige Lysat wird aufgefangen und zentrifugiert, wobei Zelltrümmer sedimentieren und von der cytoplasmatischen Fraktion getrennt werden. Der Überstand mit löslichen, intrazellulären Proteinen wird als Rohextrakt bezeichnet. Diese Methode wurde ausschließlich bei größeren Kulturvolumina eingesetzt.

Hierzu wurde die Zellsuspension durch dreimalige Passage durch die „French Pressure Cell“" aufgeschlossen. Das zähflüssige Lysat wurde in SS34-Röhrchen aufgefangen und zentrifugiert (13.000 Upm, $\left.30 \mathrm{~min}, 4^{\circ} \mathrm{C}\right)$.

\subsubsection{Zellaufschluss durch Ultraschall}

Kulturvolumina von $\leq 5 \mathrm{ml}$ wurden durch Ultraschallaufschluss unter Verwendung einer Ultraschall-Sonde (Ultraschallprozessor UP 200S, 24 kHz, 200 W, Dr. Hielscher $\mathrm{GmbH}$, Teltow) lysiert. Die Zellsuspension wurde in einem E-Cup 5 min beschallt (Amplitude 50\%, Cycle 0,5). Das Abtrennen der Zelltrümmer erfolgte durch Zentrifugation (13.000 Upm, $30 \mathrm{~min}, 4^{\circ} \mathrm{C}$ ). Der Überstand wurde in ein neues E-Cup überführt.

\section{Proteinreinigung}

\subsection{Rückfaltung von Proteinen aus Einschlusskörpern}

Da die Lipase LipCE bei der Expression stets unlösliche Einschlusskörper bildete, wurde das Protein aus diesen Einschlusskörpern isoliert. Hierzu erfolgte zunächst ein Lösen der Einschlusskörper und deren Denaturierung in Gegenwart des chaotrophen Reagenz Harnstoff (8 M) und eine anschließende Rückfaltung. Hierzu wurde wie folgt vorgegangen (alle Angaben beziehen sich auf 1 I Kultur):

Nach Expression [II.3.1] und Zellaufschluß [II.7.2.1] wurde der cytoplasmatische Überstand verworfen und das Pellet zunächst in Na-Phosphatpuffer (50 mM, pH 8,0) gewaschen und erneut pelletiert (13.000 Upm, $\left.10 \mathrm{~min}, 4^{\circ} \mathrm{C}\right)$. Das Pellet wurde dann in $8 \mathrm{ml}$ Denaturierungspuffer resuspendiert, was durch eine Ultraschallbehandlung [II.7.2.2] von 2 min unterstützt wurde. Die komplette Denaturierung des inkorrekt gefalteten Proteins erfolgte dann für $3 \mathrm{~h}$ bei $37^{\circ} \mathrm{C}$.

Danach erfolgten alle weiteren Schritte bei $4^{\circ} \mathrm{C}$. Zur Rückfaltung wurde der Harnstoff schrittweise aus der Lösung entfernt. Zunächst wurde die Lösung mit 
Rückfaltungspuffer auf $50 \mathrm{ml}$ aufgefüllt und anschließend üN gegen 2 । Rückfaltungspuffer dialysiert. Zur Abtrennung verbliebener unlöslicher Bestandteile wurde die Lösung zentrifugiert (13.000 Upm, $30 \mathrm{~min}, 4^{\circ} \mathrm{C}$ ) und $\mathrm{NaCl} \mathrm{zu}$ einer Endkonzentration von $300 \mathrm{mM}$ hinzugegeben. Somit entspricht die Pufferzusammensetzung den Äquilibrationsbedingungen der fertig gepackten Protino ${ }^{\circledR}$ Säulen [II.9.2]. Die Lösung wurde filtriert und dann direkt zur Reinigung mittels Ni-TEDSäulen eingesetzt.

\section{Denaturierungspuffer}

$\begin{array}{lrl}\text { Harnstoff } & 8 & \mathrm{M} \\ \text { Glycerin } & 5 & \%(\mathrm{v} / \mathrm{v}) \\ \text { Na-Phosphatpuffer } & 50 & \mathrm{mM} \\ \text { pH } & 8,0 & \end{array}$

Rückfaltungspuffer

\begin{tabular}{lrl}
\hline Glycerin & 5 & $\%(\mathrm{v} / \mathrm{v})$ \\
Na-Phosphatpuffer & 50 & $\mathrm{mM}$ \\
$\mathrm{pH}$ & 8,0 &
\end{tabular}

\subsection{Proteinreinigung durch Metall-Ionen-Affinitäts-Chromatographie}

Zur Reinigung der rekombinanten Enzyme mittels ihrer $\mathrm{N}$-terminal angefügten Histidinreste wurden fertig gepackte Protino-Einwegsäulen (Macherey\&Nagel, Düren) verwendet. Diese Säulen sind mit einem TED-basierten (Tris(carboxymethyl)ethylendiamin) Resin gepackt, welcher $\mathrm{Ni}^{2+}$-Ionen komplexiert und dabei fünf der sechs Komplexierungsstellen besetzt. Die sechste Stelle ist zunächst von Wassermolekülen besetzt, diese werden jedoch durch die freien Elektronenpaare des Stickstoffs der Histdinreste verdrängt, wodurch das rekombinante Protein an die Matrix gebunden wird. Die Elution erfolgte nach Waschen der Säulen zur Entfernung ungebundener Proteine mittels Imidazol, welches die Histidinreste des Proteins wieder aus der Matrix verdängte.

Die Durchführung erfolgte nach Anleitung des Herstellers zur Reinigung cytoplasmatischer Proteine unter nativen Bedingungen.

\subsection{Proteinreinigung durch FPLC und Gelfiltration}

Bei einer säulenchromatographischen Proteinreinigung mittels FPLC wird das zu trennende Substanzgemisch in Lösung (mobile Phase) über eine Säule aus einer festen, porösen Matrix (stationäre Phase) geschickt.

Alle Puffer und Proben wurden vor dem Auftragen filtriert, um eine Verunreinigung des Säulenmaterials mit Staubpartikeln zu vermeiden. Die Filtration der Proben erfolgte durch Einweg-Sterilfilter (Minisart 0,2 $\mu \mathrm{m}$, Sartorius, Göttingen). Die Puffer wurden mit $\mathrm{H}_{2} \mathrm{O}_{\text {dest }}$ hergestellt und anschließend mit einer Vakuumpumpe durch Cellulosenitrat- 
Filter $(0,45 \mu \mathrm{m}$, Schleicher \& Schuell, Dassel) filtriert. Um das Eindringen von Luftblasen in das Säulenmaterial zu verhindern, wurden alle Anschlüsse drop to drop verbunden. Die Säulen wurden in $20 \%$ igem (v/v) Ethanol gelagert. Direkte Umpufferung der Säulen von Ethanol zu einem salzhaltigen Puffer oder umgekehrt sollte durch Spülen mit $\mathrm{H}_{2} \mathrm{O}_{\text {dest }}$ vermieden werden.

Die verwendete ÄKTA-FPLC-Anlage (GE Healthcare, Freiburg) besteht aus folgenden Komponenten:

\author{
Monitor UPC-900 \\ Pumpe P-920 \\ In-line Mixer M-925 \\ Motor-Ventil INV-907 \\ Fraktionssammler Frac-900 \\ $1 \mathrm{ml}, 250 \mu \mathrm{l}$ und $100 \mu \mathrm{l}$ Probenschleifen
}

Bei der nicht adsorptiven Methode der Gelfiltration erfolgt die Trennung der Proteine aufgrund ihrer Größe. Größeren Molekülen steht ein vergleichsweise kleines Verteilungsvolumen in der jeweiligen Gelmatrix zur Verfügung, so dass sie früher als kleinere Proteine eluieren. Für die Gelfiltration wurde eine Superdex 200 High Load 16/60 Säule (GE Healthcare, Freiburg) unter Beachtung der Herstellerempfehlungen verwendet.

Da das Elutionsvolumen mit der Größe des jeweiligen Proteins korreliert, kann die Gelfiltration nicht nur als Reinigungsschritt, sondern auch zur Molekülmassenbestimmung herangezogen werden. Hierzu wurde der Verteilungskoeffizient $\mathrm{K}_{\mathrm{av}}$ eines Proteins ermittelt

$$
\begin{aligned}
& \mathbf{K}_{\mathrm{av}}=\left(\mathbf{V}_{\mathrm{e}}-\mathbf{V}_{\mathrm{o}}\right) /\left(\mathbf{V}_{\mathbf{t}}-\mathbf{V}_{\mathrm{o}}\right) \\
& \mathrm{V}_{\mathrm{t}}=\text { gesamtes Säulenvolumen } \\
& \mathrm{V}_{\mathrm{o}}=\text { Ausschlussvolumen der Säule } \\
& \mathrm{V}_{\mathrm{e}}=\text { Elutionsvolumen des Proteins }
\end{aligned}
$$

Durch Kalibrierung der Gelfiltrationssäule mit Eichproteinen, Ermittlung des jeweiligen Verteilungskoeffizienten und Auftragung des dekadischen Logarithmus der Molekularmasse gegen den $\mathrm{K}_{\mathrm{av}}$-Wert, konnte eine Eichgerade erstellt werden, aus der die Molekularmasse eines beliebigen Proteins anhand seines Verteilungskoeffizienten errechnet wurde. 


\section{Nachweis von Enzymaktivitäten}

\subsection{Aktivitätsfärbung lipolytischer Enzyme (Sommer et al., 1997)}

Der Nachweis der lipolytischen Aktivität rekombinanter Proteine erfolgte nach Auftrennung im SDS-Polyacrylamidgel. Das Testsystem beruht auf der Umsetzung des in den Testagar emulgierten Triglycerids (Tributyrin) zu Glycerin und freien Fettsäuren. Die Substrathydrolyse führte zur Aufklarung des weißlichen Testagars.

Die Proben wurden jeweils denaturiert in denaturierendem SDS-Auftragspuffer und nicht denaturiert in nativem SDS-Auftragspuffer auf ein SDS-Gel aufgetragen. Nach der SDS-PAGE [II.6.2] wurde das SDS-Gel $20 \mathrm{~min}$ in $20 \%(\mathrm{v} / \mathrm{v})$ Isopropanol und zweimal 10 min in $\mathrm{H}_{2} \mathrm{O}_{\text {dest }}$ gewaschen, um SDS zu entfernen und die enzymatische Aktivität zu gewährleisten. Anschließend wurde es auf dem Lipaseaktivität-Testagar üN bei RT inkubiert.

\begin{tabular}{lrl} 
Lipaseaktivitäts-Testagar & & \\
\hline Tris- $\mathrm{HCl}$ & 20 & $\mathrm{mM}$ \\
$\mathrm{CaCl}_{2}$ & 5 & $\mathrm{mM}$ \\
Tributyrin & 1 & $\%(\mathrm{v} / \mathrm{v})$ \\
Agar & 1,5 & $\%(\mathrm{w} / \mathrm{v})$ \\
$\mathrm{pH}$ & 8,0 &
\end{tabular}

4x Probenpuffer, nativ

\begin{tabular}{lrl}
\hline Glycerin & 7,5 & $\mathrm{ml}$ \\
Bromphenolblau $(2 \%,(\mathrm{w} / \mathrm{v}))$ & 0,5 & $\mathrm{ml}$ \\
$\mathrm{Tris}$ & 0,4 & $\mathrm{~g}$ \\
$\mathrm{H}_{2} \mathrm{O}_{\text {dest }}$ & ad 25 & $\mathrm{ml}$ \\
$\mathrm{pH}$ & 6,8 &
\end{tabular}

\subsection{Photometrische Standardtests}

\subsubsection{Bestimmung der Esteraseaktivität}

Zur Bestimmung der Esteraseaktivität wurden pNP-Acylester bis zu einer Kettenlänge von C8 verwendet. Die Reaktion beruht auf der enzymatischen Abspaltung von p-Nitrophenol, welches photometrisch bei einer Wellenlänge von $410 \mathrm{~nm}$ bestimmt werden kann. Exemplarisch ist diese Reaktion in Abb. 4 für die Reaktion mit pNPCaproat als Substrat gezeigt.<smiles>CCCCCC(=O)Oc1ccc([N+](=O)[O-])cc1</smiles>

pNP-Caproat

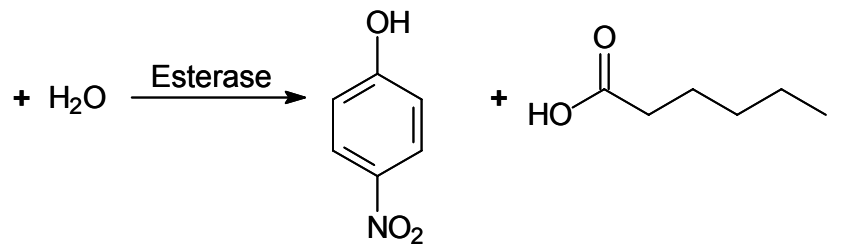

p-Nitrophenol
n-Hexansäure (Capronsäure)

Abb. 4: Hydrolytische Spaltung von pNP-Caproat durch eine Esterase 
Unmittelbar vor dem Gebrauch wurden Lösung A und Lösung B im Verhältnis 20:1 gemischt. Die Substratemulsion war bis zu zwei Stunden stabil und wurde lichtgeschützt auf Eis gelagert. Pro Reaktionsansatz wurden $1,5 \mathrm{ml}$ der Substratemulsion kurz vorgewärmt und mit Enzym bei der für das Enzym optimalen bzw. bei der zu bestimmenden Temperatur für 10 min inkubiert. Anschließend wurden die Ansätze kurz abzentrifugiert und die $\mathrm{OD}_{410}$ gegen einen Ansatz ohne Enzym als Kontrolle bestimmt. Eine Unit (U) Enzymaktivität ist hierbei als die Menge Enzym definiert, die pro Minute $1 \mu$ mol p-Nitrophenol freisetzt. Als molarer Extinktionskoeffizient von p-Nitrophenol zur Berechnung der Aktivität wurde $10.400 \mathrm{M}^{-1}$ $\mathrm{cm}^{-1}$ verwendet.

Zur Bestimmung des Einflusses von Salzen, EDTA und Lösungsmitteln auf die Enzymaktivität wurde der Kaliumphosphatpuffer durch Trispuffer (100 mM, pH 7,2) ersetzt, um das Ausfallen unlöslicher Phosphatsalze zu verhindern.

\section{Lösung A}

Kaliumphosphatpuffer $\quad 100 \mathrm{mM}$

$\mathrm{Mg}_{2} \mathrm{SO}_{4}$

$\mathrm{pH} \quad 7,2$

Lösung B

pNP-Acylester $\quad 40 \mathrm{mM}$

(in $96 \%(v / v)$ Ethanol)

9.2.2. Bestimmung der Lipaseaktivität (Winkler und Stuckmann, 1979)

Die Bestimmung der Lipaseaktivität erfolgte analog der Bestimmung der Esteraseaktivität [II.9.2.1] mit folgender Substratemulsion:

Lösung A

Gummi Arabicum

Na-Deoxycholat

Sörensenphosphatpuffer

a: $\mathrm{NaH}_{2} \mathrm{PO} 4$

b: $\mathrm{K}_{2} \mathrm{HPO} 4$

$\mathrm{pH}$

Lösung $B$

pNP-Acylester

(in $10 \mathrm{ml}$ DMSO, kurz über dem Bunsenbrenner erhitzen)
$100 \mathrm{mg}$

$207 \mathrm{mg}$

$90 \mathrm{ml}(\mathrm{a}: \mathrm{b}=17: 1)$

$8,9 \mathrm{~g} / \mathrm{l}$

$0,68 \mathrm{~g} / \mathrm{l}$

8,0

$20 \mathrm{mM}$ 


\subsection{Bestimmung der Esterase-/Lipaseaktivität mittels Titration}

Die Enzymaktivitäten gegen Triglyceride und Vinylester wurden mittels Titration durch einen so genannten „pH Stat“ (718 STAT Titrino, METROHM LTD., Herisau, Schweiz) bestimmt.

Hierzu wurden 20 ml Puffer (2,5 mM Tris/HCl; 100 mM NaCl; pH 6,9) unter Rühren konstant auf die gewünschte Temperatur gebracht. $5 \mathrm{ml}$ des ebenfalls vorgewärmten Puffers wurden mit dem jeweiligen Substrat versetzt (geschüttelt oder bei Bedarf emulgiert) und zum Gesamtansatz vereinigt. Der pH-Wert dieser Substratemulsion wurde auf einen konstanten Wert titriert. Die Autohydrolyse des Substrats und die Entstehung der entsprechenden Fettsäuren wurde durch die automatische Gegentitration von 0,1 M NaOH bei konstantem pH-Wert über 2 min dokumentiert und diente als Kontrolle. Anschließend wurde gereinigtes Enzym (etwa $5 \mu \mathrm{g}$ ) hinzugefügt und der Verbrauch von 0,1 M NaOH über einen Zeitraum von 4 min dokumentiert. Über den Verbrauch an $\mathrm{NaOH}$ ließ sich der Substratumsatz in $\mathrm{U} / \mathrm{mg}$ eingesetztes Enzym errechnen.

\subsection{Bestimmung des pH-Optimums}

Das pH-Optimum für EstCE wurde mittels Titration [II.9.3] bestimmt. Als Substrat wurde Tributyrin ( $2 \mathrm{mM}$ Endkonzentration) verwendet, welches erst bei $\mathrm{pH}-$ Werten über 11 oder unter $4 \mathrm{zu}$ einer extremen Autohydrolyse neigt, so dass eine Messung unmöglich wurde. Zur Messung der Aktivitäten in einem pH-Bereich von 4-11 wurden unterschiedliche Puffersysteme in einer Konzentration von jeweils 2,5 mM eingesetzt (pH 4-7: $\mathrm{Na}_{2} \mathrm{HPO}_{4} ; \mathrm{pH}$ 7-11 Tris/HCl; pH 9-11 Glycin).

Zur Bestimmung des optimalen pH-Wertes für LipCE wurden die gleichen Puffersysteme und pNP-Laurat als Substrat (2 mM Endkonzentration) eingesetzt und die Aktivität spektrophotometrisch [II.9.2.2] ermittelt.

\subsection{Bestimmung der pH-Stabilität}

Die pH-Stabilität wurde durch Inkubation in Puffern (50 mM Endkonzentration) bei unterschiedlichen $\mathrm{pH}-$ Werten $\left(\mathrm{pH}\right.$ 2-3: Glycin/ $\mathrm{HCl} ; \mathrm{pH}$ 4-6: $\mathrm{Na}_{2} \mathrm{HPO}_{4} ; \mathrm{pH}$ 7-9: Tris/HCl; pH 10-12: Glycin/NaOH) ermittelt. Hierzu wurde das Enzym zu einer Konzentration von ca. $2 \mu \mathrm{g} / \mathrm{ml}$ verdünnt und für $48 \mathrm{~h}$ bei Raumtemperatur inkubiert. Die Restaktivität wurde spektrophotometrisch mit pNP-Caproat als Substrat bestimmt [II.9.2].

\subsection{GC-Messungen}

\subsubsection{Substratumsetzungen durch EstCE}

Zur Messung der Substratumsetzung künstlicher Modellsubstrate durch EstCE wurden jeweils 0,1 M Stammlösungen der Substrate in DMSO angesetzt. Die GC-Proben setzten sich dann folgendermaßen zusammen: 
Tris $(1 \mathrm{M}, \mathrm{pH} 7,5)$

Substrat $(0,1 \mathrm{M}$ in DMSO) $\quad 100 \mu \mathrm{l}$

Enzym $5 \mu \mathrm{l}$

(ca. $2 \mu \mathrm{g}$ in $2 \mathrm{mM}$ Glycin/NaOH, pH 11)

Der pH-Wert des Puffers wurde im neutralen Bereich gewählt, um einer Autohydrolyse der Substrate vorzubeugen. Zur Bestimmung der Retentionszeiten der Substrate sowie zur Überprüfung der Substrate auf Autohydrolyse wurden gleichzeitig Proben ohne Lipase angesetzt, indem die Lipaselösung durch den entsprechenden Puffer ersetzt wurde.

Die Probenansätze wurden sorgfältig durchmischt und für $24 \mathrm{~h}$ bei RT inkubiert. Anschließend wurde die Reaktion durch Extraktion gestoppt. Das Ende der Reaktion ist dabei auf das Verbleiben der Lipase in der wässrigen Phase zurückzuführen, während die Alkohole und Substrate in die organische Phase übergehen. Dazu wurden $250 \mu \mathrm{l}$ der Ansätze in ein neues E-Cup überführt, $250 \mu \mathrm{l}$ Essigsäureethylester zugegeben und 1 min sorgfältig durchmischt. Anschließend wurden die Phasen durch Zentrifugation getrennt (5 min, 13.000 Upm, RT). $100 \mu \mathrm{l}$ der oberen, organischen Phase wurden abgenommen, in ein GC-Gefäß überführt und gaschromatographisch analysiert (Gaschromatograph Shimadzu GC-17A, Duisburg; GC-Säule CHROMAPACK WCOT fused silica $25 \mathrm{~m} \times 0,25 \mathrm{~mm}$, Coating: $P$ Chirasil-DEX CB DF = 0,25). Die freigesetzten Alkohole konnten anschließend mit Hilfe der Kalibrationsgeraden aus den erhaltenen Peakflächen quantifiziert werden.

Diese Arbeiten wurden in der Arbeitsgruppe von Prof. Jäger (Institut für Molekulare Enzymtechnologie im FZ Jülich, Heinrich-Heine-Universität Düsseldorf) durchgeführt.

\subsubsection{Substratumsetzungen durch LipCE}

Die Umsetzungen der 2-Arylpropionsäurederivate durch LipCE erfolgten in folgendem Reaktionsansatz für $2 \mathrm{~h}$ bei $20^{\circ} \mathrm{C}$ :

Tris $(100 \mathrm{mM}, \mathrm{pH} 7,5)$

Substrat $(10 \mathrm{mg} / \mathrm{ml}$ in DMSO)

Enzym

$\begin{array}{rl}4 & \mathrm{ml} \\ 100 & \mu \mathrm{l} \\ 10 & \mu \mathrm{g}\end{array}$

Anschließend erfolgte zunächst die Extraktion des nicht umgesetzten Esters durch Extraktion mit $2 \mathrm{ml}$ Methyl-tert-Butylether (MTBE). Es wurde kurz gevortext und die organische Phase verworfen. Anschließend wurden zur Ansäuerung der Lösung $100 \mu \mathrm{l}$ $\mathrm{HCl}(10 \%, v / v)$ zugegeben und erneut mit $2 \mathrm{ml}$ MTBE extrahiert. Diese Extraktion wurde wenigstens dreimal durchgeführt und die organischen Phasen, welche die Reaktionsprodukte enthielten, vereinigt. Unter Vakuum wurde der Ether komplett 
verdampft und die Reaktionsprodukte anschließend in $400 \mu \mathrm{l}$ MTBE resuspendiert und in ein GC-Gefäß überführt.

\section{GC-Analyse}

Die Analyse der Reaktionsprodukte mit Chiralitätszentrum in $\alpha$-Position (bis auf Naproxen- und Ketoprofenester) erfolgte mit einer IVADEX-1-Säule (IVA Analysentechnik, Meerbusch) $(25 \mathrm{~m} \times 0,25 \mathrm{~mm}$, Filmdicke $0,15 \mu \mathrm{m})$ in der Arbeitsgruppe von Prof. Reetz am Max-Planck-Institut für Kohlenforschung (Mülheim an der Ruhr).

\subsubsection{Berechnungen von ee-Werten und Enantioselektivität (E)}

Zur Berechnung des Enantiomerenüberschusses, welcher die optische Reinheit chiraler Komponenten ausdrückt, werden die Peakflächen der durch GC oder HPLC erhaltenen Elutionsprofile vermessen. Per Definition haben Racemate einen ee-Wert von $0 \%$, optisch reine Substanzen einen ee-Wert von 100\%. Die Berechnung erfolgt nach Formel (2):

$$
e e=\frac{X_{A}-X_{B}}{X_{A}+X_{B}} * 100 \%
$$

Wobei $X_{A}$ und $X_{B}$ die Konzentrationen von Enantiomer $A$ bzW. $B$ sind. Zur Berechnung der Enantioselektivität von Enzymen wird der E-Wert verwendet, um insbesondere kinetische Umsetzungen zu beschreiben. Er beschreibt die Fähigkeit eines Enzyms, zwischen verschiedenen Enantiomeren zu unterscheiden. Nicht-selektive Reaktionen haben einen E-Wert von 1, brauchbar für synthetische Zwecke sind E-Werte über 20, besser noch über 50. Hierbei ist darauf zu achten, dass E-Werte über 100 weniger genau zu bestimmen sind, da die Berechnung eine logarithmische Funktion ist. Zur Ermittlung des E-Wertes müssen zwei von drei Variablen bestimmt werden. Dies sind die enantiomere Reinheit des Startmaterials $\left(e_{s}\right)$, die enantiomere Reinheit des Produktes (ee $\mathrm{p}_{\mathrm{p}}$, bzw. der Substratumsatz (c). Hierfür stehen drei Gleichungen (3-5) zur Verfügung (Chen et al., 1982; Chen et al., 1987), die jedoch nur für irreversible Reaktionen gelten:

$$
\begin{array}{r}
E=\frac{\ln \left[1-c\left(1+e_{p}\right)\right]}{\ln \left[1-c\left(1-e_{p}\right)\right]} \\
E=\frac{\ln \left[(1-c)\left(1-e_{s}\right)\right]}{\ln \left[(1-c)\left(1+e e_{s}\right)\right]}
\end{array}
$$




$$
\mathrm{E}=\frac{\ln \left[\frac{1-\mathrm{ee}_{\mathrm{s}}}{1+\left(\mathrm{ee}_{\mathrm{s}} / \mathrm{ee}_{\mathrm{p}}\right)}\right]}{\ln \left[\frac{1+\mathrm{ee}_{\mathrm{s}}}{1+\left(\mathrm{ee}_{\mathrm{s}} / \mathrm{ee}_{\mathrm{p}}\right)}\right]}
$$

\subsection{Erstellung eines „enzymatischen Fingerabdruckes“}

Die Erstellung eines „enzymatischen Fingerabdruckes“ erfolgte durch den simultanen Umsatz eines Gemisches aus 10 verschiedenen Substraten (Abb. 25) in folgendem Ansatz:

$\begin{array}{lrl}\text { PBS-Puffer } & 75 \%(\mathrm{v} / \mathrm{v}) \\ \text { DMSO } & 25 \%(\mathrm{v} / \mathrm{v}) \\ \text { SDS } & 0,0025 & \%(\mathrm{w} / \mathrm{v}) \\ \text { Substratgemisch } & 150 \mathrm{mM} \\ \text { (15 mM/Substrat) } & & \\ \text { Enzym } & 0,25 \mathrm{mg} / \mathrm{ml}\end{array}$

Die Reaktionszeit betrug 15 min (LipCE) bzw. 30 min (EstCE). Die Reaktionsprodukte wurden anschließend in einem Schritt mittels HPLC untersucht, ein identischer Ansatz ohne Enzym diente dabei als Nullwert, der als Hintergrund abgezogen wurde. Der höchste beobachtete Umsatz wurde als $100 \%$ in einem Farbcode angegeben, sämtliche anderen Umsätze wurden relativ dazu wiedergegeben. Diese Arbeiten wurden komplett in der Arbeitsgruppe von Prof. J.-L. Reymond (Universität Bern) durchgeführt. Die exakten Bezeichnungen sämtlicher Substrate sowie deren Synthese finden sich im Zusatzmaterial zu der Veröffentlichung Goddard und Reymond, 2004.

\section{PBS-Puffer}

$\begin{array}{lrr}\mathrm{NaH}_{2} \mathrm{PO}_{4} & 10 & \mathrm{mM} \\ \mathrm{Na}_{2} \mathrm{HPO}_{4} & 10 & \mathrm{mM} \\ \mathrm{NaCl} & 150 & \mathrm{mM} \\ \mathrm{pH} & 7,4 & \end{array}$

\section{Microarray-Techniken}

\subsection{Herstellung der Slides}

Zur Herstellung der Microarrayslides wurden zunächst die zu spottenden PCRProdukte generiert [II.4.6] und gereinigt [II.4.4.6]. Die in $\mathrm{H}_{2} \mathrm{O}_{\text {dest }}$ eluierten PCR-Produkte wurden 1:1 mit DMSO versetzt und in eine 384 well-Mikrotiterplatte übertragen. 
Mit einem Lucidea Spotter (Amersham, Freiburg) wurden die PCR-Produkte im Verfahren des Kontaktdruckens auf Aminosilan (3-Aminopropyltrimethoxysilan) beschichtete Slides (Amersham, Freiburg) gespottet. Hierbei werden von der extrem feinen Nadel des Druckkopfs 100 pl pro Spot auf die Oberfläche des Slides aufgetragen. Die PCR-Produkte wurden in Reihen zu je 8 Spots auf den Slide aufgetragen, wobei jeder Spot in vierfacher Ausfertigung aufgebracht wurde.

Die aufgetragenen PCR-Produkte wurden schließlich mittels UV-Strahlung kovalent auf die speziell behandelte Oberfläche immobilisiert. Hierzu wurde der Slide 5 min mit einem UVC500 UV Crosslinker (Hoefer, San Francisco) und Licht mit einer Energie von $500 \mu \mathrm{J} / \mathrm{cm}^{2}$ bestrahlt. Da die fertigen Slides feuchtigkeitsempfindlich sind, wurden sie bei Unterdruck im Exsikkator bei Raumtemperatur gelagert.

\subsection{Visualisierung immobilisierter PCR-Produkte durch VistraGreen}

Zum Nachweis der erfolgreichen DNA-Immobilisierung auf der Oberfläche der Slides, wurde ein bedruckter Slide in einer Färbelösung (VistraGreen (Amersham, Freiburg) 1:10.000 in TE-Puffer) für 10 min inkubiert, zweimal kurz in $\mathrm{H}_{2} \mathrm{O}_{\text {dest }}$ gewaschen und nach dem Trocknen bei einer Wellenlänge von 532 nm gescannt [II.10.6].

\subsection{Fluoreszenzmarkierung chromosomaler DNA}

Zur Markierung mit Fluoreszenzfarbstoff wurde Cy5 (rot) markiertes dCTP (Amersham, Freiburg) benutzt. Da der Cyaninfarbstoff sehr lichtempfindlich ist, waren sämtliche Reaktionen und die Lagerung möglichst lichtgeschützt durchzuführen.

Die chromosomale DNA (5 $\mu \mathrm{g})$ wurde zunächst komplett mit einem Restriktionsenzym mit 4-bp-Erkennungssequenz (z.B. Alul, Bsp143I) komplett ( 3 h bis üN) verdaut, um reproduzierbar gleiche Fragmente zu erhalten. Der Restriktionsansatz (50 $\mu \mathrm{l})$ wurde thermisch inaktiviert, das Reaktionsvolumen auf $250 \mu \mathrm{l}$ mit $\mathrm{H}_{2} \mathrm{O}_{\text {dest }}$ aufgefüllt, der Ansatz mit Chloroform extrahiert [II.4.2.1] und anschließend mit Ethanol gefällt [II.4.2.2]. Die DNA wurde in $25 \mu \mathrm{H}_{2} \mathrm{O}_{\text {dest }}$ aufgenommen und der Verdau auf dem Agarosegel überprüft [II.4.3].

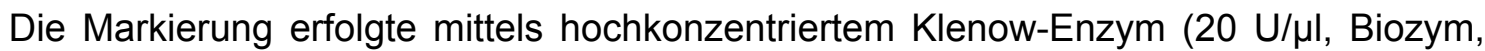
Hess. Oldendorf) mit einem Gemisch aus zufälligen Hexameren (Roche, Penzberg) als Primer. Es wurde möglichst lichtgeschützt folgender Ansatz zusammenpipettiert:

$\begin{array}{lrr}\text { DNA } & 18 & \mu \mathrm{l} \\ \text { Klenow-Puffer } & 3 & \mu \mathrm{l} \\ \text { Hexamer } & 3 & \mu \mathrm{l} \\ \text { Gesamt } & 24 & \mu \mathrm{l}\end{array}$


Der Ansatz wurde 5 min denaturiert $\left(95^{\circ} \mathrm{C}\right)$ und anschließend auf Eis abgekühlt. Anschließend wurden folgende Komponenten hinzupipettiert:

$\begin{array}{lrllll}\text { DNA-Gemisch (s.o.) } & 24 & \mu \mathrm{l} & \text { dNTP-Mix } & & \\ \text { dNTP-Mix } & 5 & \mu \mathrm{l} & \text { dATP, dTTP, dGTP } & \text { je } 1 & \mathrm{mM} \\ \text { Klenow }(20 \mathrm{U} / \mu \mathrm{l}) & 1 & \mu \mathrm{l} & \text { dCTP } & 0,65 & \mathrm{mM} \\ \text { Gesamt } & 30 & \mu \mathrm{l} & \text { Cy5-dCPT } & 0,35 & \mathrm{mM}\end{array}$

Der Ansatz wurde $3 \mathrm{~h}$ bis üN bei $37^{\circ} \mathrm{C}$ lichtgeschützt inkubiert, die Reaktion anschließend durch Zugabe von $3 \mu \mathrm{I}$ EDTA $(0,5 \mathrm{M}$, pH 8,0) gestoppt.

Der Markierungsansatz wurde anschließend mittels "CyScribe GFX Purification Kit" (Amersham, Freiburg) nach Anleitung des Herstellers gereinigt und in $60 \mu \mathrm{l}$ warmem $\mathrm{H}_{2} \mathrm{O}_{\text {dest }}\left(70^{\circ} \mathrm{C}\right)$ eluiert.

\section{4. Überprüfung der Markierungsreaktion}

Um festzustellen, wie viel Farbstoff in die markierte DNA eingebaut wurde, wurde die eluierte DNA einem Wellenlängenscan unterzogen. Das Absorptionsmaxium von eingebautem Farbstoff liegt bei $650 \mathrm{~nm}$ und das von freiem Farbstoff bei $600 \mathrm{~nm}$.

Hierzu wurden $10 \mu \mathrm{l}$ der gereinigten Probe 1:6 mit $\mathrm{H}_{2} \mathrm{O}_{\text {dest }}$ verdünnt und in einer Quarzküvette $(\mathrm{d}=1 \mathrm{~cm})$ im Spektralphotometer (Jasco V530, Groß Umstadt) ein Spektrum über einen Bereich von 700 bis 500 nm ermittelt. Hierbei wurde die Extinktion bei $650 \mathrm{~nm}$ gegenüber einem Nullwert bei $700 \mathrm{~nm}$ ermittelt, woraus anschließend die Menge eingebauten Farbstoffs nach folgender Formel (6) ermittelt werden konnte:

$$
\mathrm{n} \text { Cy } 5=(\mathrm{A} /(\mathrm{E} \cdot \mathrm{d})) \cdot \mathrm{z} \cdot \text { Verdünnungsfaktor } \cdot 10^{12}
$$

Hierbei sind A die Absorption von Cy5 bei 650 nm, E der Extinktionskoeffizient von Cy5 $\left(250.000 \mathrm{I} \cdot \mathrm{mol}^{-1} \cdot \mathrm{cm}^{-1}\right), \mathrm{z}$ das Volumen der markierten DNA $\left(10^{-6} \mathrm{I}\right)$ nach der Reinigung und d die Schichtdicke der Küvette.

\subsection{Hybdrisierung der markierten DNA mit den Microarrayslides}

Die restlichen $50 \mu \mathrm{l}$ der markierten DNA wurden zunächst in der Vakuumzentrifuge auf ein Volumen von $30 \mu \mathrm{l}$ konzentriert und anschließend für $5 \mathrm{~min}$ denaturiert $\left(95^{\circ} \mathrm{C}\right)$. Danach wurde der Hybridisierungsansatz wie folgt zusammenpipettiert:

$\begin{array}{lrr}\text { markierte, denaturierte DNA } & 30 & \mu \mathrm{l} \\ \text { 4x Hybridisierungspuffer } & 30 & \mu \mathrm{l} \\ \text { Formamid }(100 \%, \mathrm{v} / \mathrm{v}) & 60 & \mu \mathrm{l} \\ \text { Gesamt } & 120 & \mu \mathrm{l}\end{array}$


Bei dem Hybridisierungspuffer handelte es sich um eine Fertiglösung „ $4 x$ Microarray hybridization buffer" (Amersham, Freiburg).

Pro Hybridisierungsansatz wurde ein Slide in die Hybridisierungskammer HybStation4 (GenomicSolutions, Ann Arbor, USA) eingelegt und nach Anleitung des Herstellers zusammengebaut. Bis zu vier Slides konnten dabei gleichzeitig hybridisiert werden. Beim Zusammenbau der Apparatur war auf absolute Reinheit zu achten, insbesondere beim Einlegen der Slides in die Kammer und beim Anpassen der Dichtungsringe. Sämtliche benutzen Lösungen und Waschpuffer wurden mit $\mathrm{H}_{2} \mathrm{O}_{\text {dest }}$ hergestellt und anschließend mit einer Vakuumpumpe durch Cellulosenitrat-Filter $(0,45 \mu \mathrm{m}$, Schleicher \& Schuell, Dassel) filtriert um sie zu entgasen und von Partikeln zu befreien. Die Lösungen konnten bei Bedarf auf der Maschine auch temperiert gehalten werden. Für die Hybridisierung über Nacht wurde folgendes Programm verwendet:
- 1. Schritt
„O-ring conditioning“
$75^{\circ} \mathrm{C} \quad 2 \min$
Agitate: No

Dieser Schritt dient dem luftdichten Abschließen der Kammern durch die Dichtungsringe, bzw. deren ordentlichem Sitz. Sollten die Ringe porös erscheinen oder nicht mehr schließen waren sie auszutauschen.

\section{-2. Schritt „Introduce Sample“ $\quad 42^{\circ} \mathrm{C}$}

Hier wurde die Probe mit einer gelben Pipettenspitze möglichst luftblasenfrei (!) und komplett in die jeweilige Kammer injiziert.
-3. Schritt
„Hybridization“
$42^{\circ} \mathrm{C} \quad 16 \mathrm{~h}$
Agitate: Yes

Während der Hybridisierung wurde die Probe durch intervallartige Erzeugung eines leichten Unterdruckes durchmischt („Agitate“).

- 4. Schritt „Wash Slides Solution 1“ $45^{\circ} \mathrm{C} \quad$ Flow for $10 \mathrm{~s} \quad$ Hold for $20 \mathrm{~s}$

2 Zyklen

- 5. Schritt "Wash Slides Solution 2" $45^{\circ} \mathrm{C} \quad$ Flow for $10 \mathrm{~s} \quad$ Hold for $20 \mathrm{~s}$

$$
2 \text { Zyklen }
$$

- 6. Schritt "Wash Slides Solution 3" $45^{\circ} \mathrm{C} \quad$ Flow for $10 \mathrm{~s}$ Hold for $20 \mathrm{~s}$

$$
2 \text { Zyklen }
$$

• 7. Schritt "Drain Slides" $30 \mathrm{~s}$

Nach dem Trocknen wurden die Slides entnommen und restliche Flüssigkeitstropfen durch Zentrifugation (500 Upm, 4 min, RT) in einem 50 ml Falcon-Röhrchen in einer Eppendorf-Zentrifuge (Centrifuge 5804, Eppendorf, Hamburg) entfernt. Anschließend konnten die Slides ausgewertet werden. 
Nach Entnahme der Slides wurden diese in der Maschine durch Objektträger oder alte Slides ersetzt. Sämtliche Verschlusskappen wurden von den Lösungsbehältern entfernt und in ein Becherglas mit $\mathrm{H}_{2} \mathrm{O}_{\text {dest }}$ gehalten. Anschließend wurden sämtliche Schläuche der Maschine mit dem Reinigungsprogramm („Wash machine“) gespült. Danach wurden die Slides entnommen, die Aufsätze der Hybridisierungskammern auseinandergebaut, gereinigt und staubfrei bis zur nächsten Verwendung gelagert.

$\begin{array}{llll} & \text { Lösung 1 } & \text { Lösung 2 } & \text { Lösung 3 } \\ \text { SSC } & 1 \mathrm{x} & 0,1 \mathrm{x} & 0,1 \mathrm{x} \\ \text { SDS } & 0,2 \%(\mathrm{w} / \mathrm{v}) & 0,2 \%(\mathrm{w} / \mathrm{v}) & -\end{array}$

\begin{tabular}{|c|c|}
\hline $\mathrm{NaCl}$ & $3 \mathrm{M}$ \\
\hline $\mathrm{Na}_{3}-\mathrm{Citrat}$ & $0,3 \quad \mathrm{M}$ \\
\hline $\mathrm{pH}$ & 7,0 \\
\hline
\end{tabular}

\subsection{Scannen der hybridisierten Slides}

Um die hybridisierten Proben sichtbar zu machen, wurden die trockenen Slides nach der Hybridisierung in einen GenePix 4100A Scanner (Axon Instruments, Union City, USA) eingelegt und mit der Software GenePix Pro 6.0 eingelesen. Hierzu wurde zunächst in einem Vorscan die zu lesende Fläche festgelegt und anschließend in einem Hauptscan die beiden Wellenlängen $532 \mathrm{~nm}$ und $635 \mathrm{~nm}$ eingelesen. Die Einstellungen für den Scan betrugen:

$\begin{array}{ll}\text { Pixelsize } & 10 \mu \mathrm{m} \\ \text { Lines to average } & 1 \\ \text { Focus position } & 0 \mu \mathrm{m}\end{array}$

Die Scanstärke („PMT Gain“) der jeweiligen Kanäle wurde nach dem Vorscan manuell festgelegt.

Über die Bereiche der einzelnen Spots wurde anschließend eine Schablone gelegt und die Signalintensität vermessen. Für die Auswertung wurde der Wert „F635MedianB635“ herangezogen. Dieser Wert stellt Mittelwerte der Signalintensitäten abzüglich der umgebenden Hintergrundfluoreszenz außerhalb der Schablone dar. Da es vorrangig um qualitative Aussagen ging, wurden sämtliche anderen Werte nicht weiter betrachtet, da diese für andere Anwendungen, beispielsweise in der Transkriptionsanalyse eine Rolle spielen, für dieses Vorhaben aber nicht von Bedeutung waren. 


\section{Ergebnisse}

Aufgrund des stetig wachsenden Bedarfs an neuen Enzymen für die Biokatalyse wurde in den letzten Jahren verstärkte Aufmerksamkeit auf den Metagenomansatz gelegt. Durch direktes Klonieren von DNA aus Umweltproben oder Anreicherungskulturen konnten so bereits viele neue Enzyme mit interessanten Eigenschaften hinsichtlich Substratspektrum oder Aktivität bei extremen Bedingungen (Temperatur, pH, Druck) isoliert werden (Steele und Streit, 2005). Eine Enzymklasse, der in der industriellen Biotechnologie durch ihre speziellen Eigenschaften (hohe Stereospezifität und Enantioselektivität, Stabilität gegenüber organischen Lösungsmitteln, kein Bedarf an Co-Faktoren) große Aufmerksamkeit gewidmet wird, sind Lipasen (Jäger und Eggert, 2002). Diese spielen in vielen industriellen Prozessen heutzutage bereits eine wichtige Rolle (Gupta et al., 2004).

Ziel dieser Arbeit sollte es sein, aus Umweltproben neuartige Enzyme zu isolieren und detailliert zu charakterisieren und diese einer möglichen industriellen Verwertung zuzuführen. Ferner sollte die Entwicklung neuer Methoden zur Aufspürung von enzymkodierenden Genen in Metagenomen vorangetrieben werden. Der Fokus lag dabei auf lipolytischen Enzymen wie Lipasen und Esterasen.

\section{Erstellung einer Cosmidbank und Charakterisierung des Standortes}

\subsection{Entnahme von Bodenproben}

Als Probenmaterial für die Inokulation der Anreicherungskulturen sollte ölkontaminierter Boden dienen. Dieser wurde in der Nähe des Deutschen Erdölmuseums in Wietze (Landkreis Celle) (Abb. 5) entnommen. An diesem Standort wurde seit Ende der 60er Jahre des 19. Jahrhunderts bis 1963 Erdöl gefördert, 1910 stammten 80\% des gesamten deutschen Erdöls aus der Region Wietze (www.erdoelmuseum.de). Als Konsequenz dieses natürlichen Erdölvorkommens ist der Boden dort über Jahrzehnte hinweg Kontaminationen ausgesetzt gewesen, was zum Teil eine karge Vegetation zur Folge hat (Abb. 6), aber natürlich auch Mikroorganismen die Gelegenheit gegeben hat, sich dieser Umwelt anzupassen.

Bei Außentemperaturen von $5^{\circ} \mathrm{C}$ und in tieferen Schichten teils gefrorenem Boden sowie z.T. mit einer dünnen Eisschicht bedeckten Seen wurden insgesamt 6 Bodenund 3 Wasserproben (10.02.2003) von unterschiedlichen Standorten auf dem Gelände genommen, die alle mit Ölschlamm oder Ölfilmen bedeckt waren (Abb. 6) und mit „Wietze1-9“ bezeichnet wurden. 


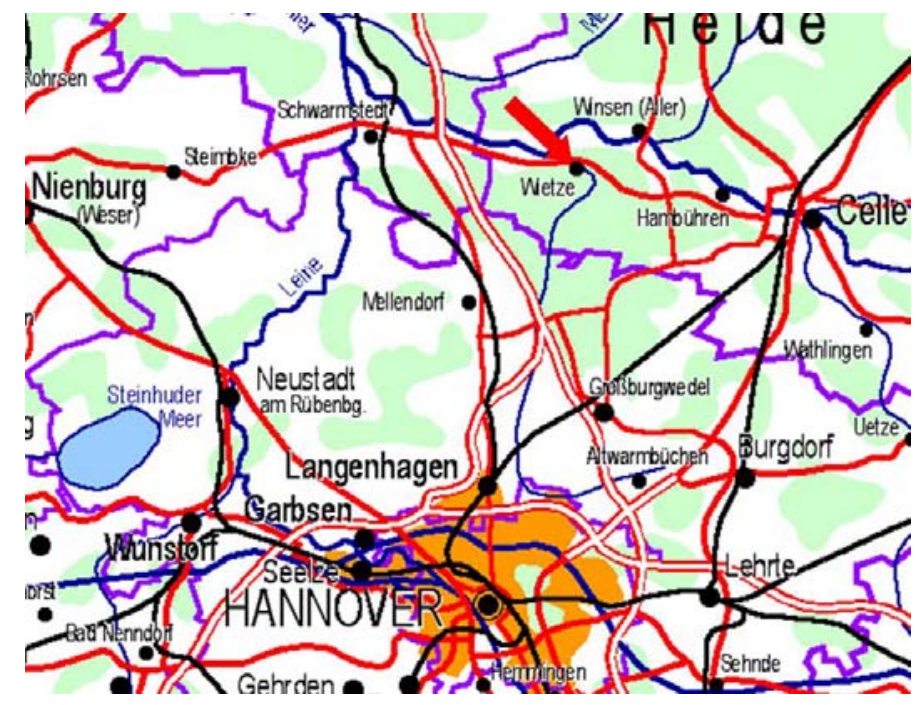

Abb. 5: Topographische Karte mit Lage des Standortes Wietze (roter Pfeil) (Quelle: www.niedersachsen.de)

\subsection{Anlegen von Anreicherungskulturen}

Von den genommenen Boden- und Wasserproben wurden mit einem Gramm Probenmaterial Anreicherungskulturen in $100 \mathrm{ml}$ Mineralmedium [II.2.2] mit 1\% (v/v) Mineralöl als alleiniger C-Quelle inokuliert. Diese wurden für 5-6 Tage bei Raumtemperatur bebrütet, bis eine ausreichende Trübung des Mediums festzustellen war. Um Hinweise auf lipolytische Aktivität und die Diversität der Anreicherung zu bekommen, erfolgten Ausstriche auf Mineralmediumsplatten mit Tributyrin als Indikator für lipolytische Aktivität. Nach einer weiteren Inokulation mit frisch überimpftem Medium wurde zum Anlegen einer Cosmidbank schließlich die Anreicherungskultur der Bodenprobe „Wietze2“ gewählt, da diese auf Plattentests eine hohe Diversität sowie die stärkste lipolytische Aktivität zeigte.

\subsection{Konstruktion einer Cosmidbank}

Aus der Anreicherungskultur wurde wie unter [II.4.4.2] beschrieben die Gesamt-DNA isoliert. Nach einem partiellen Verdau mit Bsp143I wurde die DNA in den mit BamHI geschnittenen Cosmidvektor pWE15 (Tab. 3) ligiert und mittels Phagen in E. coli VCS257 transduziert [II.5.3]. 2.400 der erhaltenen Klone wurden in Mikrotiterplatten gepickt, weitere ca. 4.000 Klone wurden von den Platten abgeschwämmt und als Pools bis zur weiteren Verwendung bei $-70^{\circ} \mathrm{C}$ gelagert. Bei 30 zufällig ausgewählten Klonen wurde eine Inserthäufigkeit von 63,3\% gefunden, wobei die Insertgröße nach Abschätzung auf dem Agarosegel zwischen 15 und 30 kb lag. 


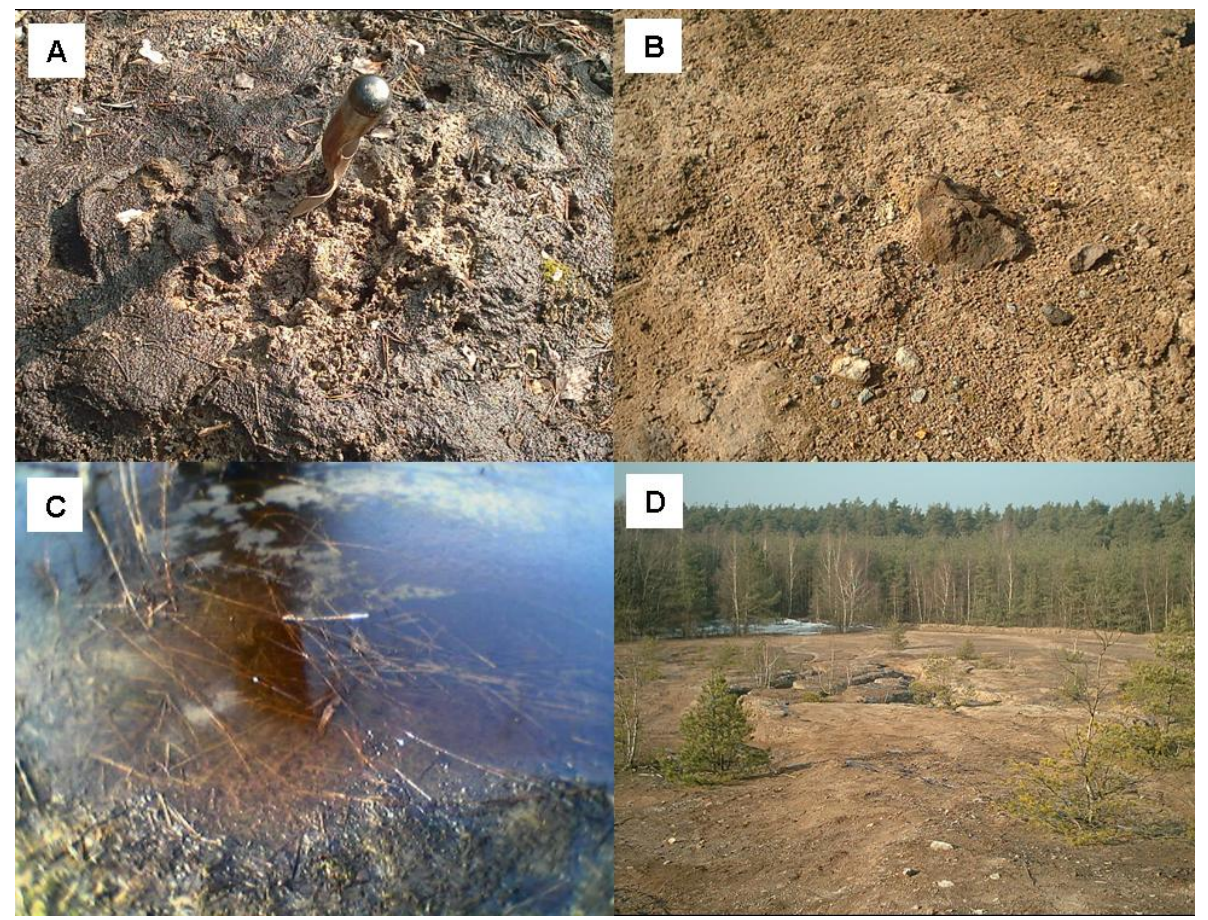

Abb. 6: Probeentnahmestellen am Standort Wietze

Als Folge der natürlichen Ölvorkommen und der damit verbundenen Kontamination treten Ölschlamm (A), Bitumenklumpen (B) und Ölfilme (C) auf. Die Bodenprobe „Wietze2“, aus deren Anreicherung die Cosmidbank erstellt wurde, wurde im Bereich (D) genommen.

\subsection{Analyse der phylogenetischen Diversität}

\subsubsection{Klonierung der bakteriellen $16 \mathrm{~S}$ rRNA-Gene}

Aus dem Originalboden der Probe „Wietze2“ wurde wie unter [II.4.4.1] beschrieben Gesamt-DNA isoliert und als Template für die PCR zur Amplifikation der 16S rRNAGene verwendet. Mit den degenerierten Primer 616V und 1492R (Tab. 4), welche spezifisch für die Domäne Bacteria sind, wurde die variable V3-Region des 16S rRNA Gens (Neefs et al., 1990) mittels Taq-Polymerase amplifiziert. Das erhaltene PCRProdukt, welches ein Gemisch aus verschiedenen 16S rRNA-Genen darstellt, wurde in den Vektor pDrive kloniert [II.4.7] und in E. coli XL1 blue transformiert. Es wurden insgesamt 480 Klone gepickt und mittels des Primers GM1F (Tab. 4) sequenziert.

Für die isolierte DNA konnten mit verschiedenen eukaryonten- und archeenspezifischen Primern keine 16S bzw. 18S rRNA-Gene von Archeen bzw. Eukaryonten nachgewiesen werden. 


\subsubsection{Analyse der 16S rRNA-Gensequenzen}

Nach Überprüfung auf chimere Sequenzen mit dem Programm "CHIMERA_CHECK" (Version 2.7), des ribosomalen Datenbank-Projektes (http://rdp.cme.msu.edu/cgis/ chimera.cgi) und Aussortierung identischer Sequenzen, konnten aus den 480 Sequenzen der Bodenprobe insgesamt 128 unterschiedliche Klone mit bakteriellen 16S rRNA-Gensequenzen identifiziert werden. Als identisch wurden hierbei Klone eingestuft, deren Ähnlichkeit über $97 \%$ lag. Diese wurden mit Sequenzen in der Datenbank des ribosomomalen Datenbankprojektes (http://rdp.cme.msu.edu/, Release-Version 9.41, Stand 07/2006) (Cole et al., 2005), verglichen. Parameter der Suche nach dem nächsten Nachbarn waren Sequenzen aus unkultivierten als auch kultivierten Isolaten und Größen sowohl kleiner als auch größer 1200 bp. Die überwiegende Mehrheit $(85,9 \%)$ fand hierbei einen nächsten Nachbarn in bislang unkultivierten Bakterien, wovon 14 Klone (10,9\%) als gänzlich unklassifiziert eingestuft wurden. Der Großteil der klassifizierbaren Organismen konnte den Proteobakterien (53,9\%) sowie den Acidobacteria (18,8\%) und Gram-positiven Organismen (10,9\%) zugeordnet werden. Innerhalb der Proteobakterien dominierte die Klasse der $\alpha$ Proteobakterien mit 48 Vertretern (37,5\% der Gesamtorganismen). Des Weiteren fanden sich Vertreter der Cyanobakterien (1,6\%) und der CFB-Gruppe (CytophagaFlexibacter-Bacteroides, 4,7\%). Die Verteilung der Sequenzen nach der Zuordnung zu den nächsten Nachbarn ist als Diagramm in Abbildung 7 wiedergegeben.

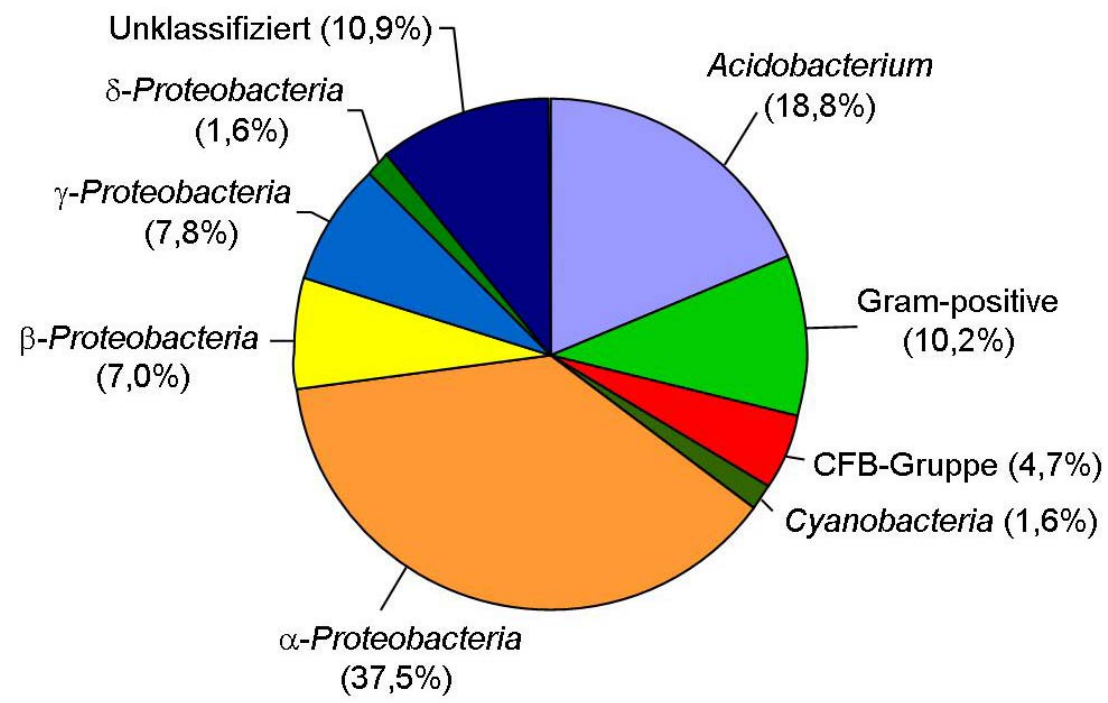

Abb. 7: Verteilung der sequenzierten 16S rRNA-Gene anhand ihrer nächsten Verwandten in phylogenetische Klassen. Insgesamt wurden 128 verschiedene Sequenzen für die Erstellung der Grafik einbezogen. 
Unter diesen Klonen waren viele Isolate, die hohe Ähnlichkeit zu Arten aufwiesen, die am biologischen Abbau von Erdöl und dessen Abbauprodukten beteiligt sind, so z.B. aus der Gattung Methylobacterium und Methylomicrobium. Weiterhin fanden sich viele Desulfurikanten, darunter die Gattungen Desulfosporosinus, Desulfobacterium, Desulfocapsa, Desulfotomaculum, Desulfuromonas oder die Art Geobacter sulfurreducens.

Aber auch „normale“ Bodenbakterien ohne besonderen Bezug zum ölkontaminierten Standort, wie Vertreter der Gattungen Agrobacterium und Burkholderia sowie diverse rhizobielle Arten wurden gefunden. Eine Übersicht über die nächsten Verwandten aller 128 identifizierten Klone ist im Anhang (Tab. 26) wiedergegeben.

\section{Identifizierung und Charakterisierung der Esterase EstCE}

\subsection{Isolation des Cosmides pCosCE1}

Die Cosmidbankerstellung war Voraussetzung für die anschließende Durchmusterung auf lipolytische Aktivität zum Auffinden neuer Biokatalysatoren. Die Detektion lipolytisch aktiver Klone erfolgte durch Ausstempeln der 25 Mikrotiterplatten der Cosmidbank auf LB-Platten [II.2.1] mit 1\% (v/v) Tributyrin (1,2,3-Glycerintributyrol, C4Fettsäurerest) als Indikator (Lawrence et al., 1967), wobei Aktivität an einer Hofbildung um die entsprechende Kolonie herum erkennbar war. Die Durchmusterung der 2400 Klone ergab einen positiven Treffer, der nach Isolierung und Retransformation des Cosmides, im folgenden pCosCE1 genannt, einen stabilen Phänotyp zeigte (Abb. 8). Neben der Aktivität auf Indikatorplatten mit Tributyrin konnte auf Indikatorplatten mit Triolein (C18) als Fettsäureester keine Aktivität nachgewiesen werden.

Durch Verdaue mit verschiedenen Restriktionsenzymen konnte eine Insertgröße von pCosCE1 von etwa $27 \mathrm{~kb}$ ermittelt werden. Durch Subklonierung des Cosmides mit EcoRV in den Vektor pSK+ konnte ein aktiver Subklon, pSK::RV1, mit einem 6,5 kb großen Insert erhalten werden.

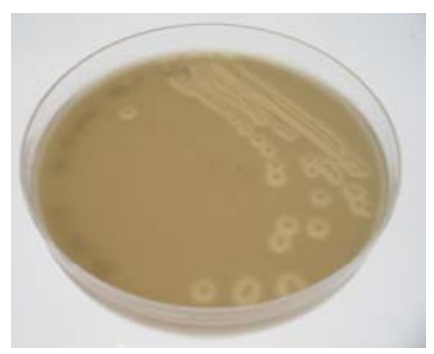

Abb. 8: Hydrolytische Aktivität von E. coli VCS257/pCosCE1 auf Tributyrinplatte Die lipolytische Aktivität ist an der Hofbildung um die Kolonien herum zu erkennen und beruht auf dem Abbau des emulgierten Tributyrins in den Platten. 


\subsection{Identifizierung des lipolytischen ORFs mittels Sequenzierung und Transposonmutagenese}

Das Insert des 6,5 kb großen DNA-Fragmentes in pSK::RV1 wurde mittels Standardprimern Abi_for und Abi_rev (Tab. 4) und anschließendem primer walking vollständig sequenziert, wobei eine Gesamtgröße von 6535 bp ermittelt wurde. Auf diesem Stück wurden insgesamt 6 ORFs identifiziert (Abb. 9). Die isolierte PlasmidDNA wurde einer Transposonmutagenese mit dem EZ::TN ${ }^{\mathrm{TM}}<\mathrm{KAN}-2>$ Transposon-Kit [II.4.8.1] unterzogen. Eine kanamycinresistente, lipolytisch nicht mehr aktive Kolonie wurde erhalten und die Plasmid-DNA mittels Standardprimern KAN-2 FP1 und KAN-2 RP1 (Tab. 6) sequenziert. Hierdurch wurde der 1167 bp umfassende ORF2, in welchen das Transposon zwischen den Basenpaaren 409 und 410 inseriert war, als verantwortlich für die lipolytische Aktivität identifiziert. Die Anordnung aller 6 auf dem Teilstück identifizierten ORFs ist in Abb. 9 wiedergegeben. Die Gesamtsequenz wurde bei GenBank unter der Accession-Nummer DQ0022079 hinterlegt.

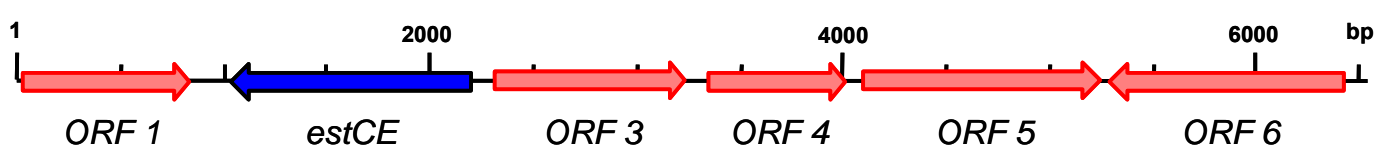

Abb. 9: Anordnung der 6 ORFs des Klons pSK::RV1

Die einzelnen ORFs sind als Pfeile in der jeweiligen Transkriptionsrichtung abgebildet. Der ORF, welcher die lipolytische Aktivität vermittelt, ist blau hervorgehoben und als estCE gekennzeichnet. Die Annotierung der anderen ORF ist in Tabelle 8 wiedergegeben. Die Gesamtgröße des abgebildeten Teilstücks beträgt 6535 bp.

\subsection{Genetische Analyse des Cosmidteilstückes RV1}

Die insgesamt 6 ORFs, welche auf dem sequenzierten Teilstück identifiziert wurden, wurden in der Datenbank des National Center for Biotechnological Information (NCBI, www.ncbi.nlm.nih.gov, Realease-Nummer 2.2.14, Stand 03.07.2006) einem Vergleich (blastp) mit bekannten Proteinen unterzogen, um Aussagen über die wahrscheinliche Funktion machen zu können. Die Resultate für jeden einzelnen ORF sind in Tabelle 8 wiedergegeben. Auffallend sind die nur relativ geringen Identitäten zu bekannten Proteinen, die mit Ausnahme von ORF6 alle deutlich unter $60 \%$ liegen. Weiterhin erwähnenswert ist die Ähnlichkeit von $56 \%$ von ORF5 zu einem ChloramphenicolResistenzprotein aus Streptomyces coelicolor A3(2) (Accession-Nr. NP_631570). Da sie nicht der Treffer mit der höchsten Ähnlichkeit war, ist sie in Tabelle 8 jedoch nicht aufgeführt. Somit werden wenigsten drei der sechs ORFs (estCE, ORF5, ORF6) mit möglichen Antibiotikaresistenzproteinen in Zusammenhang gebracht. Für den als lipolytische Aktivität vermittelnden identifizierten ORF2 finden sich im Weiteren Treffer 
zu einer funktionellen Esterase EstB aus Burkholderia gladioli (Accession-Nr. AAF59826), wobei die Werte für Identität und Ähnlichkeit mit $45 \%$ bzw. $66 \%$ in einem ähnlichen Bereich lagen wie bei der als erstem Treffer zugeordneten $\beta$-Laktamase.

Tab. 8: Annotation der identifizierten ORFs des Cosmidteilstückes RV1

${ }^{1}$ Die Identitätswerte beziehen sich auf die Anzahl der verglichenen AS der beiden Proteine (in Klammern angegeben), AS: Aminosäuren

\begin{tabular}{|c|c|c|c|c|c|c|}
\hline ORF & $\begin{array}{l}\text { Position } \\
\text { (bp) }\end{array}$ & $\begin{array}{l}\text { GC- } \\
\text { Gehalt } \\
(\%)\end{array}$ & AS & $\begin{array}{c}\text { Funktion des nächsten Treffers - } \\
\text { Mikroorganismus }\end{array}$ & $\begin{array}{l}\text { Accesion-Nr., } \\
\text { nächster Treffer }\end{array}$ & $\begin{array}{l}\text { Identität/ } \\
\text { Anzahl } \\
\text { AS }^{1}\end{array}$ \\
\hline 1 & $25-837$ & 51,7 & 271 & $\begin{array}{l}\text { Uncharakt., konserv. Protein - } \\
\text { Yersinia intermedia ATCC } 29909\end{array}$ & ZP00834850 & $\begin{array}{l}56 \% \\
(257)\end{array}$ \\
\hline $\begin{array}{l}\text { est } \\
C E\end{array}$ & $\begin{array}{c}2203- \\
1079\end{array}$ & 58,2 & 388 & $\begin{array}{c}\text { } \text {-Laktamase, Klasse C - } \\
\text { Burkholderia pseudomallei } 668\end{array}$ & ZP00486659 & $\begin{array}{l}51 \% \\
(378)\end{array}$ \\
\hline 3 & $\begin{array}{l}2305- \\
3234\end{array}$ & 57,9 & 309 & $\begin{array}{c}\text { wahrsch. Transkriptionsregulator } \\
\text { - Mesorhizobium loti } \\
\text { MAFF303099 }\end{array}$ & BA000012 & $\begin{array}{l}42 \% \\
(293)\end{array}$ \\
\hline 4 & $\begin{array}{l}3338- \\
4009\end{array}$ & 51,3 & 223 & $\begin{array}{c}\text { wahrsch. Transkriptionsregulator } \\
\text { - Bacillus cereus G9241 }\end{array}$ & ZP00235387 & $\begin{array}{l}40 \% \\
(191)\end{array}$ \\
\hline 5 & $\begin{array}{l}4086- \\
5240\end{array}$ & 51,4 & 384 & $\begin{array}{c}\text { Arabinose Efflux Permease - } \\
\text { Pseudomonas aeruginosa } \\
\text { UCBPP-PA14 }\end{array}$ & ZP00136708 & $\begin{array}{l}45 \% \\
(380)\end{array}$ \\
\hline 6 & $\begin{array}{l}6422- \\
5286\end{array}$ & 56,3 & 378 & $\begin{array}{c}\text { SST1 }(\beta \text {-Laktamase, Klasse C) - } \\
\text { Serratia marcescens }\end{array}$ & AB008455 & $\begin{array}{l}79 \% \\
(378)\end{array}$ \\
\hline
\end{tabular}

\subsection{Genetische Charakterisierung des estCE-Gens}

Das estCE Gen umfasste 1167 bp mit einem GC-Gehalt von 58,2\% und kodierte für ein Protein mit 388 AS, einer theoretisch errechneten Größe von 42,1 kDa und einem isoelektrischen Punkt von 5,31 (www.expasy.org). Die komplette Nukleotid- und Aminosäuresequenz ist in Abb. 10 dargestellt. Beim Datenbankvergleich fielen nicht sofort Ähnlichkeit mit Esterasen oder Lipasen auf, sondern vielmehr mit $\beta$-Laktamasen. So fand sich bei einem Datenbankabgleich in der Conserved Domain Database (Marchler-Bauer et al., 2005) des National Center for Biotechnology Information (NCBI) ein typisches $\beta$-Laktamase-Strukturmotiv, aber kein Lipasestrukturmotiv. Die Kernregion dieses $\beta$-Laktamase-Motives bilden beim EstCE-Protein die Aminosäuren Phe61 bis Arg77, wobei der Serin-Rest an Position 65 wahrscheinlich das katalytische Nukleophil ist. Bei $\beta$-Laktamasen findet sich dieses in der Konsensussequenz S-X-x-K innerhalb des konservierten Bereiches wieder. Bei einem Vergleich mit der 
biochemisch gut charakterisierten Esterase EstB aus B. gladioli (Petersen et al., 2001) lassen sich in einem Alignment ebenfalls die Aminosäuren 61 bis 77 als $\beta$-LaktamaseStrukturmotiv in EstCE mit Ser65 als katalytischem Nukleophil finden (Abb. 11).

1 atgtcgatag cggatcagtc attagcaaaa agagtgcagg gcgttagcca acaggcgatt $\begin{array}{lllllllllllllllllllllllllllll}M & S & I & A & D & Q & S & L & A & K & R & V & Q & G & V & S & Q & Q & A & I\end{array}$

61 gatgaagggc gtatcgttgg cagcgtggtg ctgatcgctc ggcacggtcg cgtgatttac $\begin{array}{llllllllllllllllllll}D & E & G & R & I & V & G & S & V & V & L & I & A & R & H & G & R & V & I & Y\end{array}$ 121 gccaatgcca gcggctatgc cgatcgtgaa cagaagaaac ctatggtgcg tgagacccaa $\begin{array}{llllllllllllllllllll}A & N & A & S & G & Y & A & D & R & E & Q & K & K & P & M & V & R & E & T & Q\end{array}$

181 tttcggctgt cgtcggtgtc caagccttat attacgctgg cggccatgcg tatgatcgaa

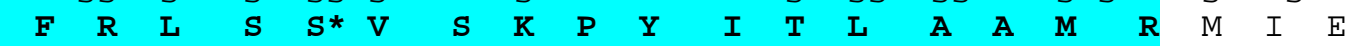

241 cagcagaagc tggggctgga tgataccgtc agccgttggt tgccgtggtt taccccggcg $\begin{array}{lllllllllllllllllllllllllll}Q & Q & K & L & G & L & D & D & T & V & S & R & W & L & P & W & F & T & P & A\end{array}$

301 ctggccgatg gggttcgccc gccaattaaa atccgtcact tgttgagcca cactgccggc $\begin{array}{llllllllllllllllllll}L & A & D & G & V & R & P & P & I & K & I & R & H & L & L & S & H & T & A & G\end{array}$

361 ctggattatc gtttgagcca acctgcggaa ggaccgtatc atcgactcgg tattaaagac $\begin{array}{llllllllllllllllllll}L & D & Y & R & L & S & Q & P & A & E & G & P & Y & H & R & L & G & I & K & D\end{array}$ 421 ggtatggaac tgtcgtcgtt aacgctggaa cagaatctgc gcctgttggc gcaggcggat $\begin{array}{lllllllllllllllllllllllllllll} & M & E & L & S & S & L & T & L & E & Q & N & L & R & L & L & A & Q & A & D\end{array}$ 481 ctgttggccg agccgggcag cgagtttcga tattcactgg caatcgatgt gctgggggcg $\begin{array}{lllllllllllllllllllllll}L & L & A & E & P & G & S & E & F & R & Y & S & L & A & I & D & V & L & G & A\end{array}$ 541 gtgctggaac aggtggcggg cgagccettg ccgcaggtgt tcaaccattg ggttgcccaa $\begin{array}{llllllllllllllllllll}V & L & E & Q & V & A & G & E & P & L & P & Q & V & F & N & H & W & V & A & Q\end{array}$

601 cctttggggt tgcgtaatac cggtttttac accaccgatg tcgataatct ggcaacggcg $\begin{array}{lllllllllllllllllllllllll}P & L & G & L & R & N & T & G & F & Y & T & T & D & V & D & N & L & A & T & A\end{array}$ 661 tatcacgaca ccgccgcgga gccggaacct atacgagatg gcatgttgct gaccctgccg

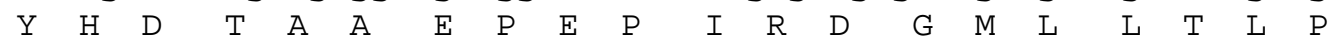

721 gaagggttcg gcttcgagat tgaactggca ccctcgcgcg cactggacgc tcaggcctat

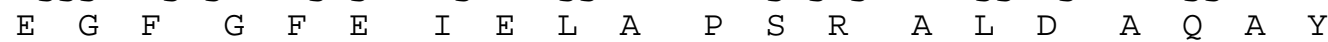
781 ccttctggcg gcgctggcat ggtcggcgat gcagacgatg tgttgcagtt ggtggaaacc $\begin{array}{llllllllllllllllllllllllll}P & S & G & G & A & G & M & V & G & D & A & D & D & V & L & Q & L & V & E & T\end{array}$

841 ttgcgcactg gcaaggaagg cattttacag ccggccaccg cagcgctgat gcgtcaagcg $\begin{array}{lllllllllllllllllllllllll} & R & T & G & K & E & G & I & L & Q & P & A & T & A & A & L & M & R & Q & A\end{array}$ 901 catgtcgggt cgcacgccga gactcagggg cccggctggg ggtttggttt cggcggtgcg $\begin{array}{lllllllllllllllllllllllll}H & V & G & S & H & A & E & T & Q & G & P & G & W & G & F & G & F & G & G & A\end{array}$ 961 gtactggaag atgcgcagtt ggcggcgacg cctcagcaca atggcactct gcagtggggc $\begin{array}{llllllllllllllllllll}V & L & E & D & A & Q & L & A & A & T & P & Q & H & N & G & T & L & Q & \text { W } & G\end{array}$

1021 ggtgtctatg gccacagttg gttttacgat ccgcaagcgg cgatcagcgt ggtagccttg $\begin{array}{llllllllllllllllllll}G & V & Y & G & H & S & W & F & Y & D & P & Q & A & A & I & S & V & V & A & L\end{array}$ 1081 accaatacgg cctttgaagg catgagtgga cgttatccac tgcaaatccg cgatgctgtt $\begin{array}{lllllllllllllllllllllllll}T & N & T & A & F & E & G & M & S & G & R & Y & P & L & Q & I & R & D & A & V\end{array}$

1141 tacgggacaa acgaacctac tcgctaa

Y G T N E P T R -

Abb. 10: Nukleotid- und daraus abgeleitete Aminosäuresequenz des estCE-Gens Aminosäuren sind im Ein-Buchstaben-Code dargestellt, das $\beta$-Laktamase-Strukturmotiv hellblau hinterlegt. 
EStCE 33 ARHGRVIYANASGYADREQKKPMVRETQFRLSSVSKPYITLAAMRMIEQQKLGLDDTVSR

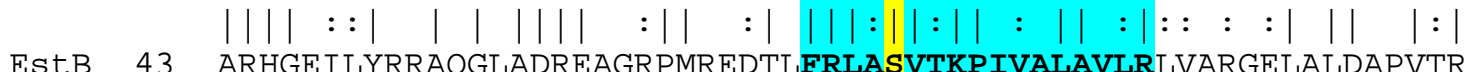
EStCE 93 WLPWFTPALADGVRPPIKIRHLLSHTAGLDYRLSQPAEGPYHRLGIKDGMELSSLTLEQN EstB 103 WLPEFRPRLADGSEPLVTIHHLLTHTSGLGYWLEGAGSVYDRLGISDGIDLRDFDLDEN

Abb. 11: Partieller Aminosäurevergleich der Esterase EstCE und EstB aus B. gladioli Identische Aminosäuren sind mit einem (|) gekennzeichnet, ähnliche Aminosäuren mit einem (:). Die Strukturmotive für $\beta$-Laktamasen sind hellblau, das für Lipasen in EstB rot hinterlegt. Der in beiden Proteinen als katalytisches Nukleophil identifizierte Serinrest ist gelb markiert.

\subsection{Heterologe Expression des estCE-Gens in E. coli}

Zur Expression und Reinigung mittels $\mathrm{N}$-terminal angehängtem His-Tag wurde das estCE-Gen mit den Primern EstCE_for1 und EstCE_rev1 (Tab. 4) amplifiziert, wobei eine 5'-BamHI- und eine 3'-HindIII-Schnittstelle eingefügt wurden. Das Pfu-amplifizierte PCR-Produkt wurde zunächst in den mit EcoRV linearisierten Vektor pSK+ kloniert, mit den Restriktionsendonukleasen BamHI und HindIII wieder herausgeschnitten und in den ebenso geschnittenen Vektor pQE30 (Qiagen, Hilden) kloniert. Somit wurden $\mathrm{N}$-terminal sechs zusätzliche Histidinreste zur späteren Aufreinigung angehängt. Der so konstruierte Expressionsvektor pQE30::estCE ist in Abb. 12 dargestellt. Das korrekte Vorhandensein des Inserts wurde durch Sequenzierung mittels Standardprimern überprüft und sichergestellt.

Zur Expression wurde dieses Plasmid in E. coli M15 transformiert. Aus Kulturen bis $50 \mathrm{ml}$ ließ sich die Esterase in einem Schritt als lösliches Protein aus dem Cytoplasma mittels Ni-TED-Affinitätschromatographie (Protino ${ }^{\circledR}$-Säulen, Machery\&Nagel) nach Anleitung des Herstellers in hoher Reinheit isolieren (Abb. 13).

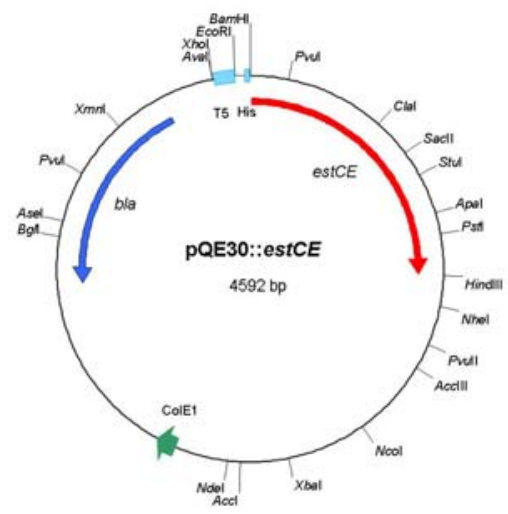

Abb. 12: Restriktionskarte des Expressionsvektors $p Q E 30:: e s t C E$

Das estCE-Gen ist in rot dargestellt, Vektorgene in blau, der Replikationsursprung ColE1 in Grün. bla= $\beta$-Laktamase $\left(A m p^{R}\right)$, T5=T5-Promotor, His= 6xHis-Tag 


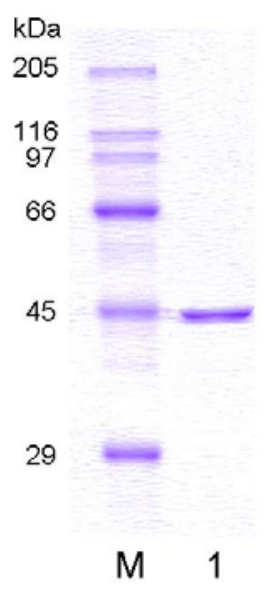

Abb. 13: Reinigung von EstCE mittels Ni-TED-Affinitätschromatographie nach Expression in E. coli M15/pQE30::estCE

$\mathrm{M}=$ „High Molecular Weight Marker“ (Sigma), Spur 1=EstCE, 2 $\mu \mathrm{g}$.

Bei einer Erhöhung des Kulturvolumens fand sich trotz unterschiedlichster Anzuchtbedingungen (Induktionsstärke, Wachstumstemperatur) der Großteil des Proteins in unlöslichen Einschlusskörpern wieder. Die Maximalausbeuten lagen bei etwa $500 \mu \mathrm{g}$ löslichem Protein aus 11 Kulturvolumen, weswegen zur weiteren Expression ein anderes Vektorsystem gewählt wurde.

Mit den Primern EstCE_for2 und EstCE_rev2 (Tab. 4) wurde das estCE-Gen amplifiziert und dabei eine 5'-Ndel- und eine 3'-BamHI-Schnittstelle eingefügt. Dieses PCR-Produkt wurde wie bereits beschrieben zunächst in $\mathrm{pSK}+$ kloniert, mittels Ndel und $\mathrm{BamHI}$ wieder herausgeschnitten und in den ebenso geschnittenen Vektor pET19b (Tab. 3) kloniert. Eine Karte dieses Plasmides pET19b::estCE ist in Abb. 14 dargestellt.

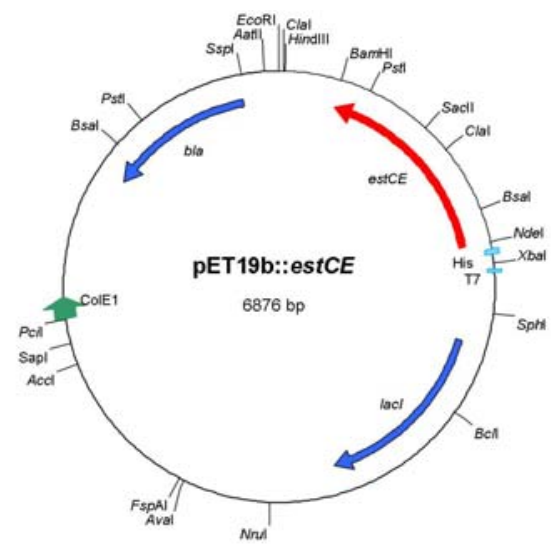

Abb. 14: Restriktionskarte des Expressionsvektors pET19b::estCE

Das estCE-Gen ist in rot dargestellt, Vektorgene in blau, der Replikationsursprung ColE1 in grün. lacl=Lac-Repressor, bla= $\beta$-Laktamase $\left(\mathrm{Amp}^{\mathrm{R}}\right)$, T7=T7-Promotor, His=10xHis-Tag 


\subsection{Reinigung von EstCE}

\subsubsection{Reinigung mittels $\mathrm{Ni}-\mathrm{TED}-$ Affinitätschromatographie}

Zur Expression wurde das Plasmid pET19b::estCE in E. coli BL21(DE3) transformiert. Nach Anzucht über Nacht bei $30^{\circ} \mathrm{C}$ und Induktion mit 0,5 mM IPTG konnten aus 1 I Kultur Zellen mit einem Feuchtgewicht von 10,7 g geerntet werden. Nach Zellaufschluss [II.7.2.1] und Abtrennung der unlöslichen Bestandteile durch Zentrifugation wurde EstCE zunächst aus der löslichen Fraktion mittels Ni-TEDAffinitätschromatographie über Protino ${ }^{\circledR}$ 2000-Säulen (Macherey \& Nagel) [II.8.2] gereinigt. Hierbei wurden 7,1 mg lösliches, aktives Protein erhalten, was noch leichte Verunreinigungen aufwies (Abb. 17). Das Eluat wurde zunächst gegen $10 \mathrm{mM}$ Tris, pH 7,5 dialysiert um restliches Imidazol zu entfernen und anschließend auf $1 \mathrm{ml}$ eingeengt.

\subsubsection{Reinigung mittels Gelfiltration}

Vor der Reinigung durch FPLC [II.8.3] unter Verwendung einer Gelfiltrationssäule wurde zunächst eine Eichgerade mit fünf bekannten Markerproteinen (Fa. BioRad) erstellt und dabei die in Tab. 9 dargestellten Elutionsvolumina ermittelt. Die Parameter der Läufe zur Ermittlung der Eichgerade und der Reinigung (s.u.) waren hierbei identisch:

$\begin{array}{ll}\text { Medium: } & \text { Supderdex 200 prep grade } \\ \text { Säule: } & \text { HiLoad } 16 / 60 \\ \text { Säulenvolumen: } & 121 \mathrm{ml} \\ \text { Laufmittel: } & 10 \mathrm{mM} \text { Tris, } \mathrm{pH} 7,5 \\ \text { Flussrate: } & 1 \mathrm{ml} / \mathrm{min} \\ \text { Fraktionsgröße: } & 1,5 \mathrm{ml}\end{array}$

Bei einer logarithmischen Auftragung des Molekulargewichtes gegen das Elutionsvolumen ergab sich die in Abb. 15 dargestellte Eichgerade.

Tab. 9: Für die Eichgerade ermittelte Elutionsvolumen mit der Superdex 200 pg HiLoad 16/60 Säule und zugehörige Eichproteine

\begin{tabular}{lcc}
\hline Protein & $\begin{array}{c}\text { Molekulargewicht } \\
{[\mathrm{Da}]}\end{array}$ & $\begin{array}{c}\text { Elutionsvolumen } \\
{[\mathrm{ml}]}\end{array}$ \\
\hline Thyroglobulin & 670.000 & 46,9 \\
$\gamma$-Globin (Pferd) & 158.000 & 60,9 \\
Ovalbumin (Huhn) & 44.000 & 78,7 \\
Myoglobin (Pferd) & 17.000 & 90,7 \\
Vitamin $\mathrm{B}_{12}$ & 1.350 & 116,6 \\
\hline
\end{tabular}




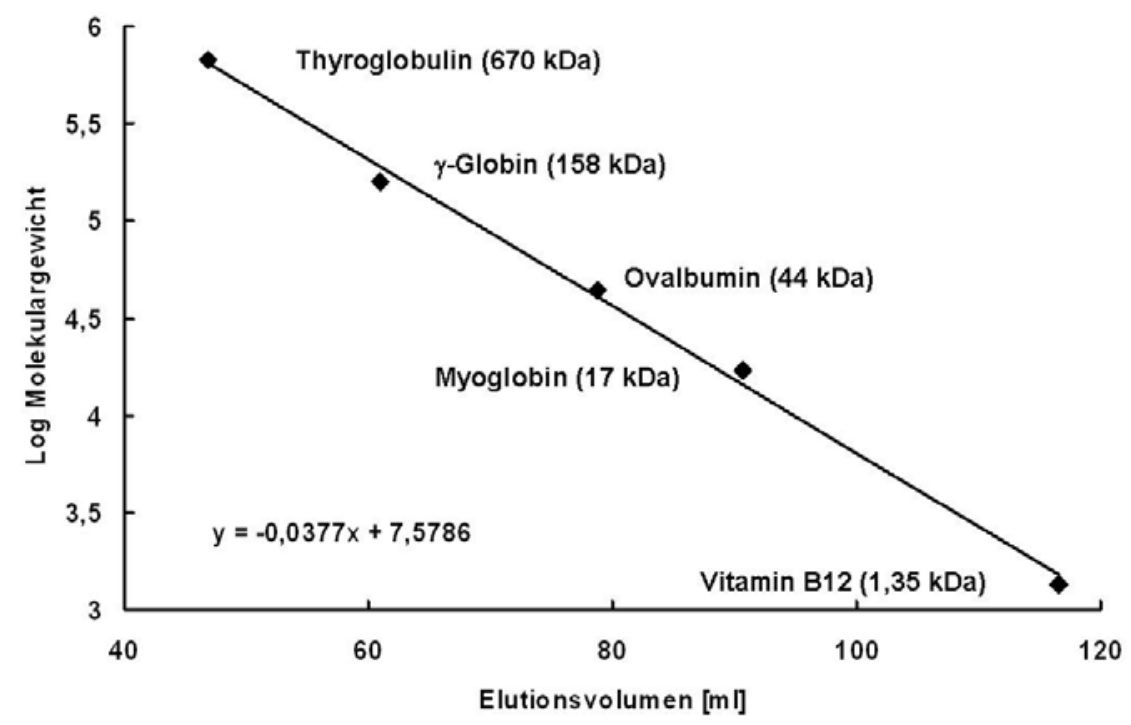

Abb. 15: Eichgerade für die Gelfiltration mit der Säule Superdex 200 pg HiLoad 16/60

Aufgetragen wurde $1 \mathrm{ml}$ Proteinlösung mit einer Konzentration von $7,1 \mathrm{mg} / \mathrm{ml}$, der Säulenlauf erfolgte unter identischen Bedingungen wie die Erstellung der Eichgerade.

Das EstCE-Protein eluierte nach $78 \mathrm{ml}$ (Abb. 16) von der Säule, wonach sich anhand der Eichgerade eine Größe von 43,5 kDa ermittelt, was im Einklang mit dem theoretisch ermittelten Molekulargewicht sowie dem Molekulargewicht von etwa $44 \mathrm{kDa}$ aus dem SDS-Gel steht (Abbildung 13 und 18). Die Aktivität enthaltenden Fraktionen wurden nach Überprüfung auf Tributyrinindikatorplatten vereinigt und konzentriert, so dass insgesamt $6 \mathrm{mg}$ sauberes Protein erhalten wurden. Der gesamte Reinigungsverlauf ist in Abbildung 17 zusammengefaßt.

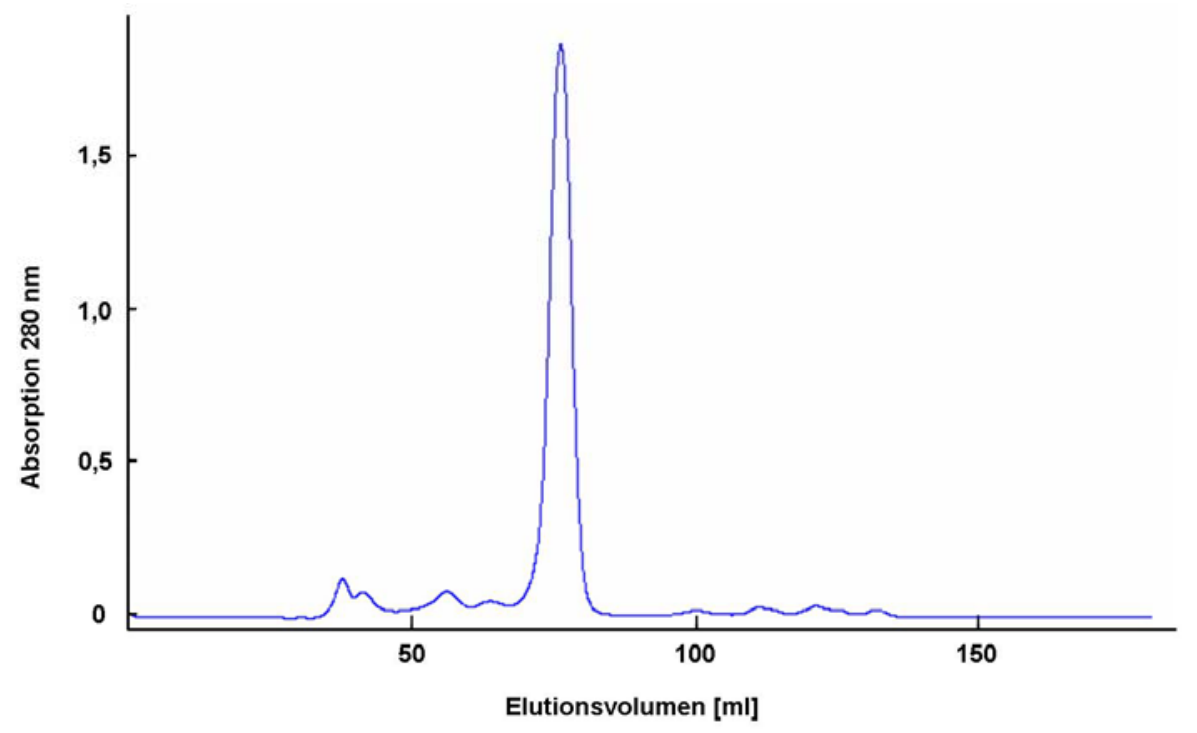

Abb. 16: Chromatogramm des Säulenlaufs der Gelfiltration mit der Säule Superdex 200 HiLoad 16/60 zur Reinigung von EstCE (Laufbedingungen siehe Text) 


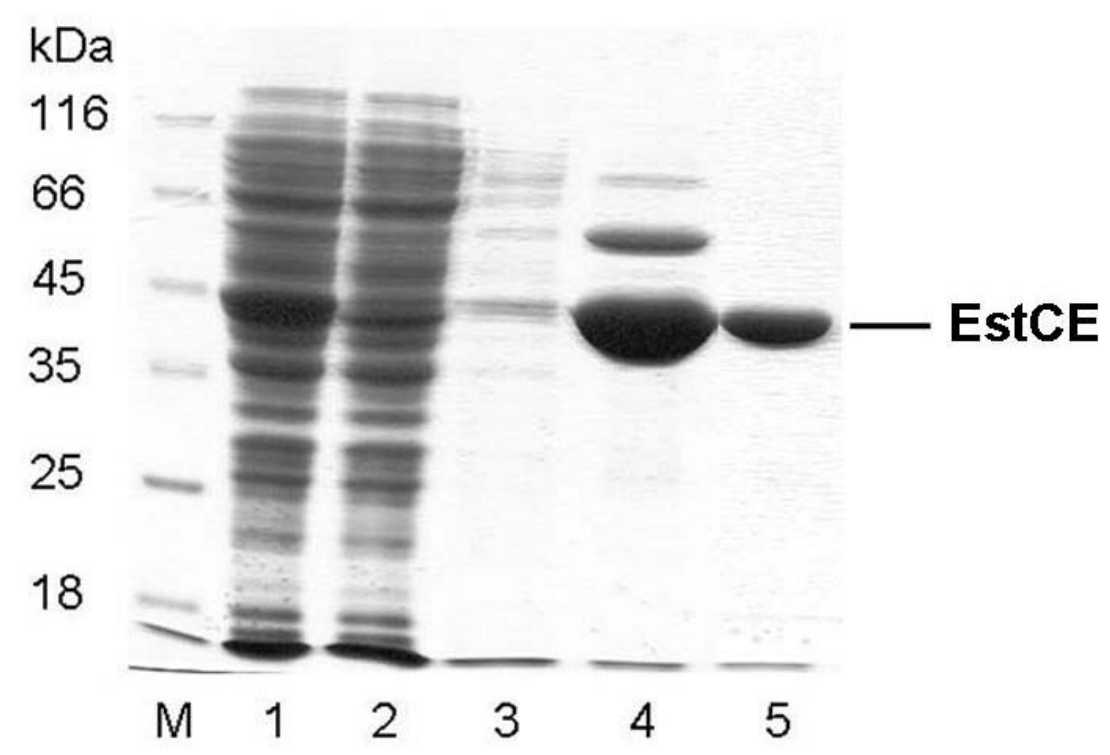

Abb. 17: SDS-PAGE des Reinigungsverlaufs der Esterase EstCE

Spur M: „Molecular Weight Marker“ (Fermentas), Spur 1: Rohextrakt, Spur 2: Durchlauf, Spur 3: Waschfraktion, Spur 4: 1. Elutionsfraktion der Ni-TED-Affinitätschromatographie $(20 \mu \mathrm{g})$, Spur 5: EstCE nach Gelfiltration $(4 \mu \mathrm{g})$.

\subsection{Biochemische Charakterisierung der Esterase EstCE}

\subsubsection{Aktivitätsbasierter Nachweis von EstCE}

Die Aktivität der gereinigten Esterase EstCE wurde zunächst im Aktivitätsgel [II.9.1] nachgewiesen. Hier fand sich Aktivität beim nicht-denaturierten Protein (Abb. 18), das Laufverhalten wich unter den Bedingungen allerdings etwas vom denaturierten Protein ab und ergab eine Bande bei etwa $30 \mathrm{kDa}$, der sich die Aktivität zuordnen ließ.

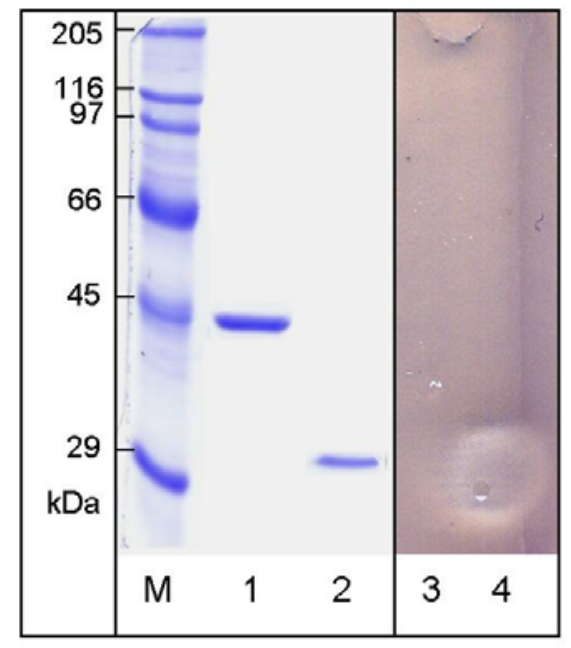

Abb. 18: Aktivitätsgel des gereinigten EstCE Proteins

Lipolytische Aktivität ist an einer Aufklarung des Tributyrins im Testagar zu erkennen. M: „Molecular Weight Marker" (Fermentas), Spur 1: EstCE, denaturiert (SDS-Gel), Spur 2: EstCE, nicht denaturiert in nativem Auftragspuffer (SDS-Gel), Spur 3 und 4: wie 1 und 2 (Aktivitätsgel), jeweils $3 \mu \mathrm{g}$. 


\subsubsection{Temperaturabhängigkeit der Aktivität von EstCE}

Unter Verwendung von pNP-Caproat als Substrat wurde über einen Temperaturbereich von $10^{\circ} \mathrm{C}$ bis $60^{\circ} \mathrm{C}$ wie unter [II.9.2.1] beschrieben die Esteraseaktivität bestimmt. Es zeigte sich Aktivität über einen relativ weiten Temperaturbereich mit einem Maximum bei $47^{\circ} \mathrm{C}$ und einer schnellen Inaktivierung bei höheren Temperaturen, also ein eher mesophiles Temperaturspektrum. Bei $60^{\circ} \mathrm{C}$ konnte bereits keine Aktivität mehr gemessen werden. Mindestens $50 \%$ der Maximalaktivität wurde in einem Temperaturbereich von $38^{\circ} \mathrm{C}$ bis $56^{\circ} \mathrm{C}$ gemessen. Der komplette Verlauf der Temperaturkurve ist in Abbildung 19 dargestellt.

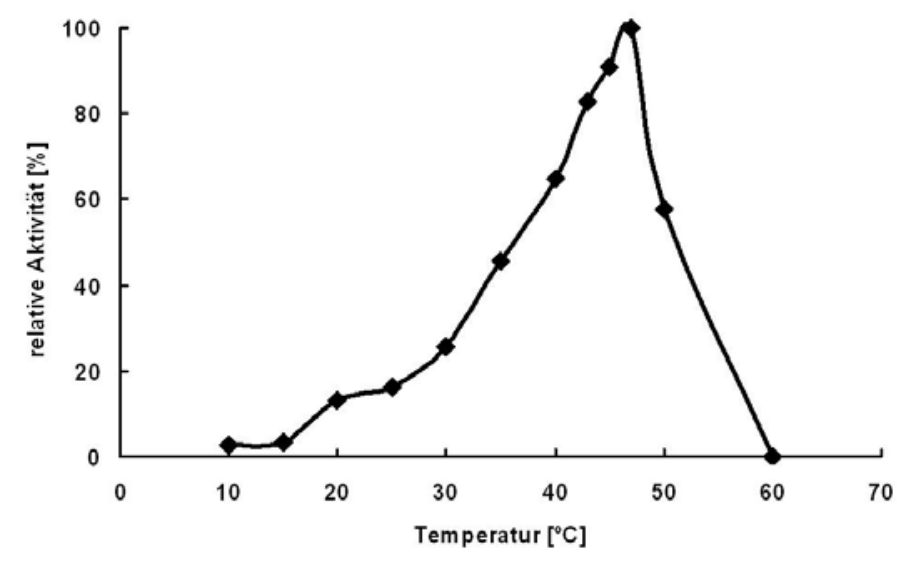

Abb. 19: Temperaturabhängigkeit der Aktivität von EstCE

Der höchste gemessene Wert bei $47^{\circ} \mathrm{C}$ wurde gleich $100 \%$ gesetzt. Reaktionsparameter: Substrat pNP-Caproat (2 mM), Puffer $100 \mathrm{mM}$ K-Phosphat $+10 \mathrm{mM} \mathrm{MgSO}$, pH 7,2, Inkubationsdauer $10 \mathrm{~min}$.

\subsubsection{Temperaturstabilität von EstCE}

Zur Bestimmung der thermischen Stabilität wurde das Enzym über einen Zeitraum von einer Stunde bei Temperaturen von $40^{\circ} \mathrm{C}$ bis $60^{\circ} \mathrm{C}$ vorinkubiert und in Abständen von 10 Minuten die Restaktivität mit pNP-Caproat als Substrat bei einer Temperatur von $40^{\circ} \mathrm{C}$ [II.9.2.1] bestimmt (Abb.20). Es zeigte sich, dass bei einer Inkubationstemperatur von $40^{\circ} \mathrm{C}$ über den gesamten Zeitraum kaum Aktivitätsverlust ( $\left.<5 \%\right)$ zu bemerken war. Erst mit steigenden Temperaturen kam es zu einer Inaktivierung des Enzyms. Bei $43^{\circ} \mathrm{C}, 45^{\circ} \mathrm{C}$ bzw. $47^{\circ} \mathrm{C}$ Vorinkubationstemperatur wurden $50 \%$ Restaktivität nach 30 , 20 bzw. 9 Minuten Vorinkubationszeit erreicht. Bei der Reaktionstemperatur, bei der die höchste Enzymaktivität vorliegt $\left(47^{\circ} \mathrm{C}\right)$, verliert das Enzym in 10 Minuten mehr als die Hälfte seiner Aktivität. Bei Vorinkubationstemperaturen von $50^{\circ} \mathrm{C}$ und höher war bereits nach 10 Minuten nur noch eine minimale Restaktivität zu verzeichnen. 


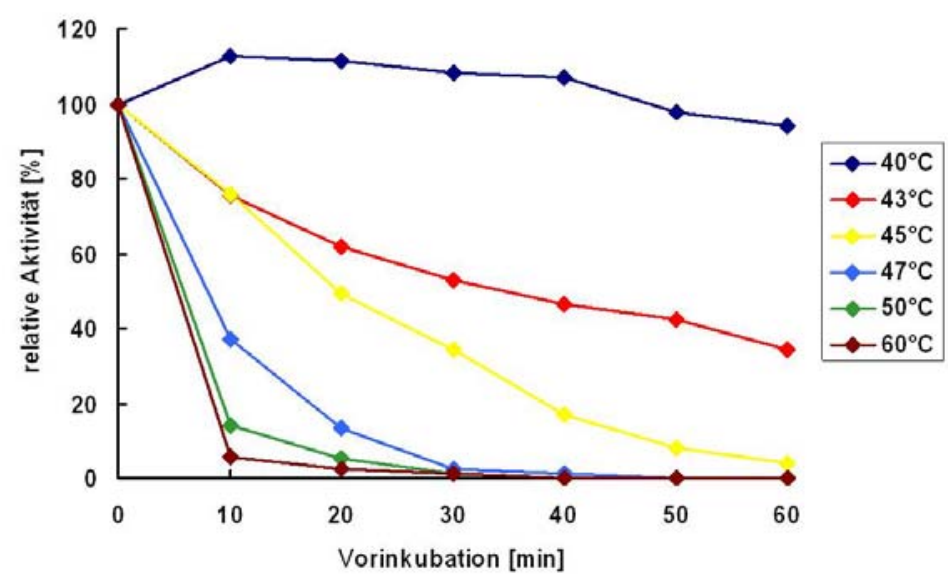

Abb. 20: Thermische Stabilität von EstCE

EstCE wurde bei verschiedenen Temperaturen (siehe Legende) vorinkubiert und die Restaktivität bestimmt. Reaktionsparameter: Substrat pNP-Caproat (2 mM), Puffer $100 \mathrm{mM} \mathrm{K-}$ Phosphat + $10 \mathrm{mM} \mathrm{MgSO}_{4}, \mathrm{pH} 7,2$, Inkubationsdauer 10 min, Inkubationstemperatur $40^{\circ} \mathrm{C}$.

\subsection{4. pH-Abhängigkeit der Aktivität und Stabilität von EstCE}

Unter Verwendung von Tributyrin als Substrat wurde wie unter [II.9.4] beschrieben mit drei verschiedenen Puffersystemen die Aktivität durch Titration bei einer Temperatur von $37^{\circ} \mathrm{C}$ bestimmt. Da weder pNP-Butyrat noch pNP-Caproat bei den zu messenden $\mathrm{pH}-$ Werten stabil sind, wurde hier Glycerin, welches zwischen $\mathrm{pH} 4$ und 11 relativ stabil ist, als Substrat benutzt. Es zeigte sich ein relativ hohes $\mathrm{pH}$-Optimum von $10 \mathrm{mit}$ wenigstens $50 \%$ der Aktivität von pH 6,5 an im alkalischen Bereich bis zum Ende des Messbereichs (Abb. 21). Im sauren Bereich wurde keine Aktivität gemessen.

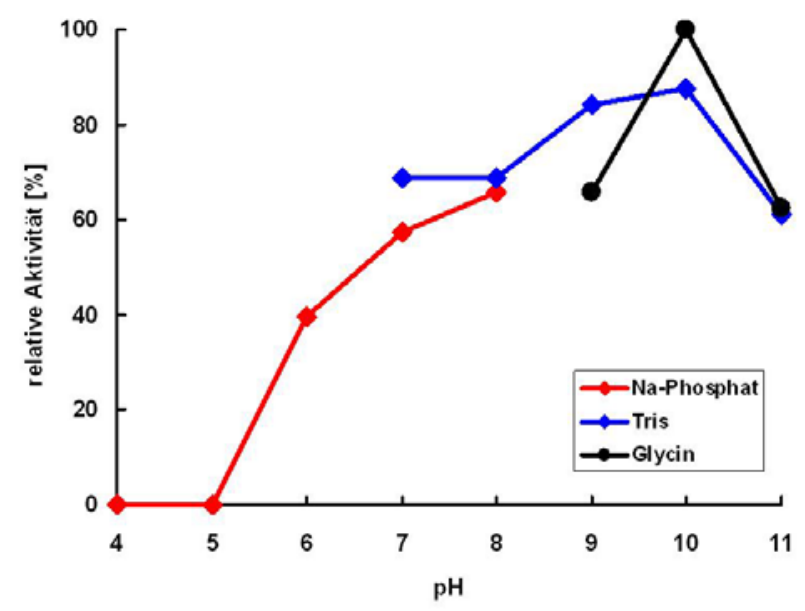

Abb. 21: pH-Abhängigkeit der Aktivität von EstCE

Die Aktivität wurde unter Verwendung drei verschiedener Puffersysteme bestimmt. Reaktionsparameter: Substrat Glycerin (2 mM), Puffer (Na-Phosphat, $\mathrm{pH}$ 4-8, Tris, $\mathrm{pH}$ 7-11 und Glycin, pH 9-11, je 2,5 mM, Inkubationstemperatur $37^{\circ} \mathrm{C}$, Meßdauer $4 \mathrm{~min}$. 
Zudem zeigte sich nach Inkubation für 48 Stunden in Puffern mit verschiedenen $\mathrm{pH}$ Werten (Abbildung 22) eine hohe Stabilität bei alkalischen $\mathrm{pH}-$ Werten, wo die Restaktivität selbst bei $\mathrm{pH} 12$ noch etwa $85 \%$ betrug. EstCE zeigte dafür aber keine Toleranz gegenüber sauren $\mathrm{pH}-$ Werten, unterhalb $\mathrm{pH} 7$ war keine bzw. kaum Stabilität mehr zu beobachten.

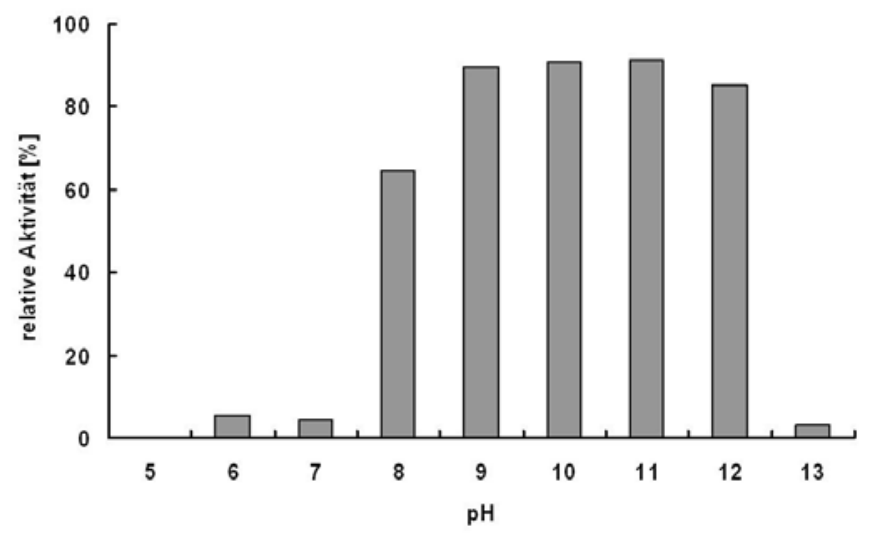

Abb. 22: Stabilität von EstCE nach Inkubation bei verschiedenen pH-Werten

Die Restaktivität wurde mit pNP-Caproat als Substrat nach 48 Stunden Inkubation bei RT gegen eine Kontrolle ohne Inkubationszeit in drei verschiedenen Puffersystemen (Na-Phosphat, pH 4-6 / Tris, pH 7-9 / Glycin, pH 11-13, je 50 mM) ermittelt.

\subsubsection{Aktivität von EstCE in Abhängigkeit von der Substratkettenlänge}

Unter Verwendung von pNP-Acylestern, Triglyceriden und Vinylsäureestern mit Säureresten verschiedener Kettenlänge wurde die Aktivität von EstCE spektrophotometrisch [II.9.2.1] bzw. über Titration [II.9.3] ermittelt. Die höchste Aktivität wurde jeweils bei Säureresten der Kettenlänge C4 (Butyrat) gefunden, bei längerkettigen Fettsäureresten $(\geq C 8)$ wurde keine bzw. nur noch sehr geringe Restaktivität von weniger als $1 \mathrm{U} / \mathrm{mg}$ gefunden. Dies ist ein weiteres Indiz dafür, dass es sich bei EstCE um eine Esterase und nicht um eine Lipase handelt. Sämtliche Daten sind in Tab. 10 zusammengefaßt. 
Tab. 10: Spezifische Aktivität von EstCE bei Substraten verschiedener Kettenlänge n.b.: nicht bestimmt - ${ }^{1}$ Die Werte für Triglyceride und Vinylester wurden von Dr. C. Leggewie, Institut für Molekulare Enzymtechnologie, FZ Jülich, bestimmt.

\begin{tabular}{lccc}
\hline & \multicolumn{3}{c}{ Spez. Aktivität [U/mg] unter Verwendung von } \\
Säurerest & pNP-Estern & Triglyceriden & Vinylestern \\
\hline Acetat (C2) & n.b. & 26,7 & 13,3 \\
Propionat (C3) & n.b. & 33,3 & 13,3 \\
Butyrat (C4) & 31,1 & 54,7 & 16,0 \\
Valerat (C5) & 22,9 & n.b. & n.b. \\
Caproat (C6) & 7,4 & n.b. & 0 \\
Caprylat (C8) & 1,0 & 0 & 0 \\
Caprat (C10) & 0,9 & n.b. & n.b. \\
\hline
\end{tabular}

\subsubsection{Einfluss von Lösungsmitteln und Detergenzien auf die Aktivität von EstCE}

Um die Stabilität gegenüber verschiedenen Lösungsmitteln zu bestimmen, wurde EstCE in Gegenwart verschiedener Lösungsmittel unterschiedlicher Konzentrationen (15\% bzw. 30\% (v/v)) für eine Stunde inkubiert und anschließend die Restaktivität mit pNP-Butyrat als Substrat bestimmt [II.9.2.1]. Stabilität gegenüber Lösungsmitteln ist ein häufig zu beobachtendes Charakteristikum von Lipasen und Esterasen (Jäger et al., 1994). Es zeigte sich jedoch nur eine moderate Stabilität gegenüber niedrigen Lösungsmittelkonzentrationen von 15\%. Die Gegenwart von DMSO hatte keinen Einfluss, Methanol und Isopropanol reduzierten die Aktivität gering auf $90 \%$ bzw. $75 \%$ Restaktivität. Sämtliche anderen Lösungsmittel beeinflussten die Aktivität sehr stark, häufig zeigte sich eine totale Inaktivierung. Sämtliche Daten sind in Tabelle 11 wiedergegeben.

Eine direkte Zugabe von Detergenzien (Triton X-100, Tween20, Tween80 und SDS, Endkonzentration $0,1 \%(\mathrm{v} / \mathrm{v})$ bzw. (w/v)) zum Reaktionsansatz beeinflusste die Aktivität weder hemmend noch steigernd $(<5 \%)$. Eine Vorinkubation mit SDS $(0,1 \%(w / v))$ für eine Stunde analog zu den Lösungsmittelversuchen führte zu einer kompletten Inaktivierung, so dass keine längerfristige Stabilität gegenüber Detergenzien vorhanden zu sein scheint. 
Tab. 11: Einfluss von Lösungsmitteln auf die Aktivität von EstCE

Bestimmt wurde die Restaktivität nach $1 \mathrm{~h}$ Inkubation in Gegenwart verschiedener Lösungsmittelkonzentrationen mit pNP-Butyrat als Substrat.

\begin{tabular}{lcc}
\hline Lösungsmittel & $\begin{array}{c}\text { Restaktivität [\%] in Gegenwart von } \\
15 \%(\mathrm{v} / \mathrm{v})\end{array}$ & $30 \%(\mathrm{v} / \mathrm{v})$ \\
\hline DMSO & 103 & 17 \\
Methanol & 90 & 0 \\
Isopropanol & 75 & 23 \\
Dimethylformamid & 34 & 0 \\
Aceton & 14 & 0 \\
Acetonitril & 0 & 0 \\
\hline
\end{tabular}

\subsubsection{Einfluss verschiedener Kationen sowie EDTA auf die Aktivität von EstCE}

Die Gegenwart verschiedener Kationen und EDTA auf die Aktivität von EstCE wurde mit pNP-Caproat als Substrat wie unter [II.9.2.1] beschrieben getestet. Die Konzentration der jeweiligen Additive, die als Chloridsalze hinzugegeben wurden, betrug jeweils $5 \mathrm{mM}$. Die meisten Kationen zeigten hierbei kaum Auswirkungen auf die Aktivität. Leichte Steigerungen wurden in Gegenwart von EDTA (120\%) und $\mathrm{Li}^{+}(112 \%)$ beobachtet. $\mathrm{Fe}^{3+}$ und $\mathrm{Cu}^{2+}$ inhibierten die Aktivität komplett, $\mathrm{Zn}^{2+}(56 \%), \mathrm{Cd}^{2+}(44 \%)$, $\mathrm{Ni}^{2+}(42 \%)$ und $\mathrm{Fe}^{2+}(21 \%)$ führten zu einem stärkeren Aktivitätsrückgang. Die Einflüsse von $\mathrm{Ba}^{2+}, \mathrm{Ca}^{2+}, \mathrm{Sr}^{2+}, \mathrm{Na}^{+}, \mathrm{Mg}^{2+}, \mathrm{Mn}^{2+}$ und $\mathrm{K}^{+}$wirkten sich kaum hemmend oder steigernd unter den getesteten Bedingungen aus. Diese Resultate sind in Abbildung 23 zusammengefaßt.

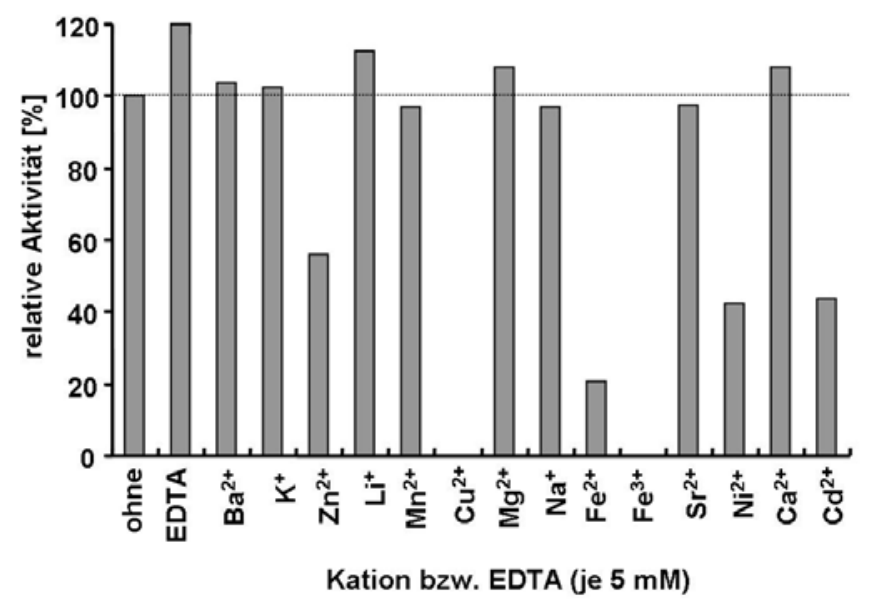

Abb. 23: Einfluss verschiedener Kationen und EDTA auf die Enzymaktivität In Gegenwart von $5 \mathrm{mM}$ der jeweiligen Chloridsalze bzw. EDTA wurde die Enzymaktivität mit pNP-Caproat als Substrat bestimmt und relativ zum Ansatz ohne Salz angegeben. 


\subsubsection{Stereospezifische Umsetzung biotechnologisch relevanter Substrate}

Bedeutung für die biotechnologische Industrie haben Lipasen und Esterasen durch ihre z.T. hohe Stereospezifität erlangt. An einigen chiralen Substraten (Essigsäureester) mit biotechnologischem Modellcharakter konnte dies auch für EstCE gezeigt werden. Wie unter [II.9.6.1] beschrieben, wurde die Umsetzung für $24 \mathrm{~h}$ bei Raumtemperatur, Extraktion der Alkohole und anschließende gaschromatographische Analyse in der Arbeitsgruppe von Prof. Jäger (Dr. C. Leggewie, Institut für Molekulare Enzymtechnologie, FZ Jülich) durchgeführt. Da nicht für alle Racemate enantiomerenreine Alkohole zum Vergleich zur Verfügung standen, konnte nicht allen die entsprechende Stereospezifität zugeordnet werden. Deswegen sind hier nur 1. und 2. Enantiomer in Tabelle 12 angegeben. Teilweise konnten die Enantiomere auch nicht getrennt werden, weswegen nur der Gesamtumsatz angegeben wurde. Nicht umgesetzt unter den getesteten Bedingungen wurden die Essigsäureester von Tetrahydronaphthylamin und Phenylethylamin. Die Strukturformeln sämtlicher verwendeten Substrate finden sich im Anhang (Abb. 66).

Tab. 12: Stereospezifische Umsetzung chiraler oder enantionmerenreiner Substrate Die freigesetzten Alkohole wurde nach 24 bzw. 12 Stunden Reaktion extrahiert und gaschromatographisch untersucht. Nicht für alle Modellsubstrate standen enantiomerenreine Alkohole als Referenz zur Verfügung, weswegen nur das 1. und 2. Enatiomer ohne nähere Angaben zur Stereospezifität gegeben sind. ( $\mathrm{E}=\mathrm{En}$ atiomer, ee=enantiomeric eccess) ${ }^{1}$ Substratumsatz nach $12 \mathrm{~h},{ }^{2}$ hier konnte nur der Gesamtumsatz gemessen werden, ${ }^{3}$ kein Essigsäureester

\begin{tabular}{|c|c|c|c|}
\hline \multirow[b]{2}{*}{ Essigsäureester von... } & \multicolumn{2}{|c|}{ Umsatz [\%] für das } & \multirow[b]{2}{*}{ ee $[\%]$} \\
\hline & 1.E & 2.E & \\
\hline$(+/-)-1-$ Octin-3-ol & 64 & 60 & 3 \\
\hline cis-1,2-Cyclohexandiol $^{1}$ & 100 & 100 & 0 \\
\hline trans-1,2-Cyclohexandiol & 100 & 45 & 38 \\
\hline rac-Isopropylidenglycerin ${ }^{1}$ & 100 & 100 & 0 \\
\hline $\begin{array}{l}R-(+)-3-C h l o r-1-P h e n y l-1- \\
\text { Propanol }^{2}\end{array}$ & \multicolumn{2}{|c|}{100} & - \\
\hline Trimethylsilylbutinol $^{2}$ & \multicolumn{2}{|c|}{100} & - \\
\hline Menthol (1.E (+), 2.E (-)) & 100 & 0 & $>99$ \\
\hline cis-3,5-Diacetoxy-1-Cyclopenten ${ }^{3}$ & 12 & 59 & 66 \\
\hline
\end{tabular}


Eine hohe Stereospezifität zeigte EstCE bei der Umsetzung von Menthylacetat, wo ausschließlich das (+)-Enantiomer mit einem Enantiomerenüberschuß (ee) von >99\% umgesetzt wurde (zur Berechnung siehe II.9.6.3). Unspezifisch wurden die Essigsäureester von cis-1,2-Cyclohexandiol, rac-Isopropylidenglycerin sowie (+/-)-1Octin-3-ol umgesetzt. Stereospezifität wurde zudem bei den Substraten cis-3,5Diacetoxy-1-Cyclopenten (66\% ee, 2. Enantiomer) sowie dem Essigsäureester von trans-1,2-Cyclohexandiol (38\% ee, 1. Enantiomer $(S, S)$ ) nachgewiesen, allerdings mit geringeren Enantiomerenüberschüssen als bei Menthylacetat. Auffallend waren auch die hohen Umsatzraten von oft $100 \%$, die z.T. in 12 h Reaktionszeit erreicht wurden.

Des Weiteren wurden Ester verschiedener Alkohole und Säuren getestet. Die erste Gruppe stellte eine Mischung aus 17 verschiedenen primäre, sekundären und tertiären Alkoholen sowie Alkoholen mit linearen aliphatischen, ringaliphatischen und aromatischen Systemen dar. Darunter befinden sich 10 chirale Substrate mit Chiralität sowohl am $\alpha$ - als auch $\beta$-Kohlenstoff. Die Umsetzungen erfolgten über $24 \mathrm{~h}$ bei $45^{\circ} \mathrm{C}$ [II.9.6], danach wurden die Proben mit Dichlormethan extrahiert und mittels GC untersucht (Tab. 13).

Tab. 13: Umsetzung von Estern verschiedener Alkohole durch EstCE

Die Umsätze sind relativ zum höchsten beobachteten Umsatz angegeben. n.b., nicht bestimmt

\begin{tabular}{llccc}
\hline Nr. & Substrat & rel. Aktivität [\%] & E-Wert & Präferenz \\
\hline 1 & 1-Oktylacetat & 20 & & \\
2 & $(R, S)-2-$ Oktylacetat & 5 & 3,8 & n.b. \\
3 & $(R, S)-3-$ Oktylacetat & 10 & 12 & n.b. \\
4 & $(R, S)$-1-Phenylethylacetat & 30 & $35-40$ & $(S)$ \\
5 & $(R, S)-1-(2-$ Naphtyl)-ethylacetat & 25 & 20 & n.b. \\
6 & $(R, S)-1-C y c l o h e x y l e t h y l a c e t a t$ & 1 & 19 & n.b. \\
7 & Phenylacetat & 100 & & \\
8 & Cyclohexylacetat & 1 & & \\
9 & $(R, S)$ - $\beta$-Citronollylacetat & 5 & n.b. & n.b. \\
10 & a-Terpinyl-Acetat & 0 & n.b & n.b. \\
11 & a-Terpinyl-Caprylat & 0 & n.b & n.b. \\
12 & 2,3-Glycerindibutylether-Acetat & 50 & 1,3 & n.b. \\
13 & $(R, S)-I P G-A c e t a t$ & 2,5 & 2,2 & n.b. \\
14 & Methyl-Caprylat & 0 & & \\
15 & Ethyl-Caprylat & 0 & & \\
16 & Isopropyl-Caprylat & 0 & & \\
17 & Tert-Butyl-Caprylat & 0 & & \\
\hline
\end{tabular}


EstCE setzte bevorzugt Ester mit aromatischen Resten im Alkoholteil um (Substrate 4 und 7), was aus direkten Vergleichen der Substrate 4 und 6 bzw. 7 und 8 ersichtlich ist, wo die aromatischen Reste durch aliphatische Ringe ersetzt sind (Strukturen im Anhang, Abb. 64). Grundsätzlich werden Ester primärer und sekundärer Alkohole umgesetzt, wohingegen Ester tertiärer Alkohole (Substrate 10, 11, und 17) und Kohlenstoffketten länger als C8 (Substrat 11, 14-17) nicht umgesetzt werden.

Eine moderat hohe Enantioselektivität wurde nur bei sekundären Estern (Substrate 36) mit der höchsten Selektivität bei 1-Phenylacetat gefunden, wo bevorzugt das (S)Enantiomer umgesetzt wurde. Primäre Ester hingegen wurden fast racemisch umgesetzt (E-Werte unter 4).

Es wurden 10 pNP-Ester sowie ein pNP-Amid mit verschiedenen Säureresten getestet (Anhang, Abb. 65). Hierbei handelt es sich um Substanzen, die der Klasse der nichtsteroiden, entzündungshemmenden Schmerzmittel angehören, wozu z.B. Ibuprofen und Naproxen gehören. Diese entfalten ihre medizinische Wirkung nur in optisch hochreiner Form (Hutt und Caldwell, 1984). Weitere Substrate sind Vorstufen dieser Substanzen sowie Gruppen, die ein chirales C-Atom in $\beta$-Position aufweisen (sonst $\alpha$ ) oder sehr sperrige Reste besitzen.

EstCE war in der Lage, pNP-Cyclohexanoat (16,8 U/mg), pNP-Benzoat (12,1 U/mg), sowie mit deutlich niedriegerer Aktivität pNP-3-Phenylbutanoat (1,0 U/mg, E-Wert n.b.) und pNP-2-(3-Benzoylphenyl)-propanoat (0,8 U/mg, E-Wert n.b.) umzusetzen. Sämtliche anderen Substrate wurden von EstCE nicht umgesetzt.

\subsection{9. „Enzymatischer Fingerabdruck“ von EstCE}

In Zusammenarbeit mit der Arbeitsgruppe von Prof. J.-L. Reymond (Universität Bern, Department Chemie und Biochemie) wurde für die Esterase EstCE ein sogenannter „enzymatischer Fingerabdruck" erstellt (Abb. 24). Hierbei wurde ein Substratgemisch aus 10 verschiedenen, in der Arbeitsgruppe synthetisierten Modellsubstraten primärer und sekundärer Oktansäureester (Abb. 25) gleichzeitig umgesetzt und in einem Schritt mittels HPLC analysiert (Goddard und Reymond, 2004). Der höchste gemessene Umsatz wurde dann in einen Farbcode übertragen und alle anderen Umsätze relativ dazu angegeben. Die höchste Aktivität wurde bei Substrat Nr. 7 (4-(4-Octylcarboxy-(3hydroxy-3-methyl-butyloxy))-coumarin) gemessen, der Umsatz lag bei 60\%. Gar nicht umgesetzt wurden die beiden sekundären Ester (Substrat 9 und 10), die aufgrund ihres sperrigen Restes auch von anderen Enzymen nur selten umgesetzt werden (Reymond, persönliche Mitteilung). 

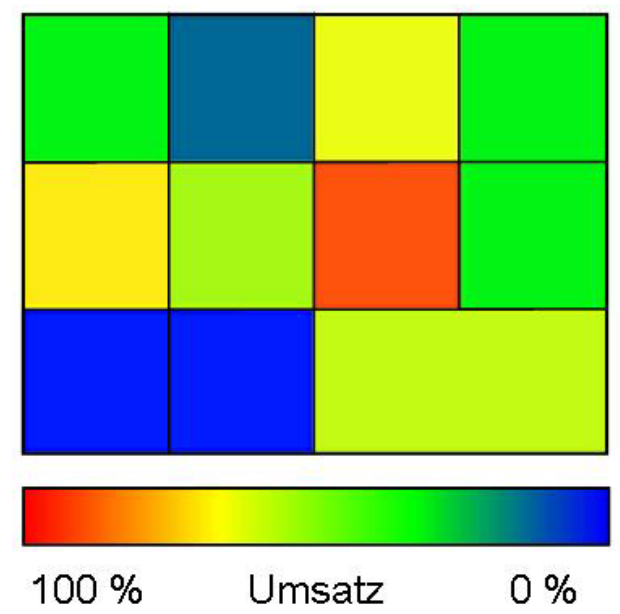

Abb. 24: „Enzymatischer Fingerabdruck“ der Esterase EstCE

Die Anordnung der Kästchen entspricht den Substraten in Abbildung 25. Die stärkste Umsetzung (Substrat 7) wurde rot gefärbt, alle anderen relativ dazu in den gezeigten Farbschattierungen der unten angegeben Farbskala. Der Umsatz des am stärksten umgesetzten Substrates ist in den unteren beiden Kästchen wiedergegeben und lag bei $60 \%$.

\begin{tabular}{|c|c|c|c|}
\hline $\mathrm{OH}_{1}$ & $\begin{array}{lllll} & \mathrm{OH} & & \end{array}$ & $\begin{array}{ll}\pi_{0} & \mathrm{OH} \text { OMeCoum } \\
3 & 3\end{array}$ & $\mathrm{O}_{7} \mathrm{H}_{15} \mathrm{O}_{\mathrm{OH}}{ }_{\mathrm{OPNP}}^{\mathrm{O}}$ \\
\hline$\underbrace{\mathrm{Me}}_{\mathrm{OH}}{ }_{5}$ & $\mathrm{C}_{7} \mathrm{H}_{15} \bigcirc$ & $\mathrm{C}_{7} \mathrm{H}_{15} \overbrace{\mathrm{OH}}{ }_{7}$ O4Coum & $\mathrm{C}_{7} \mathrm{H}_{15} \overbrace{\mathrm{OH}}^{\mathrm{O}} \overbrace{8}^{\mathrm{OMeCoun}}$ \\
\hline $\mathrm{C}_{7} \mathrm{H}_{15}{ }_{\mathrm{Me}}^{\mathrm{O}} \underbrace{\mathrm{OH}}_{\mathrm{Me}}$ & ${ }_{\mathrm{Me}}^{\mathrm{OH}}{ }_{\mathrm{Me}}^{\mathrm{O} \text { Coum }}$ & $\widehat{s}$ & $\pi$ \\
\hline
\end{tabular}

Abb. 25: Strukturformeln der für die Substratmischung verwendeten Substrate

Die Anordnung entspricht den Feldern in Abb. 24. Die erste Reihe zeigt primäre Ester, die zweite Reihe sterisch gehinderte Neopentylester und die dritte Reihe sterisch sehr stark gehinderte, sekundäre Ester. Die verwendeten Seitenketten sind unten rechts abgebildet.

Anhand des in Abbildung 24 gezeigten Farbschemas, das für viele kommerziell erhältliche Lipasen erstellt wurde, konnte eine Ähnlichkeitsmatrix berechnet und daraus ein Dendrogramm erstellt werden (Abb. 26). Dieses gibt Auskunft über die Ähnlichkeit der getesteten Enzyme anhand ihrer Substratumsetzungen.

Die Ähnlichkeiten vom Substratspektrum waren hierbei am größten zu einer weiteren Metagenomesterase EstA3, die wie EstCE hohe Ähnlichkeit zu $\beta$-Laktamasen aufweist (Schmeißer, 2004). Diese beiden Enzyme bilden dann einen Cluster zu einer Gruppe von 5 Enzymen, die allein vier eukaryontische Lipasen aus der Gattung Candida beinhaltet. 


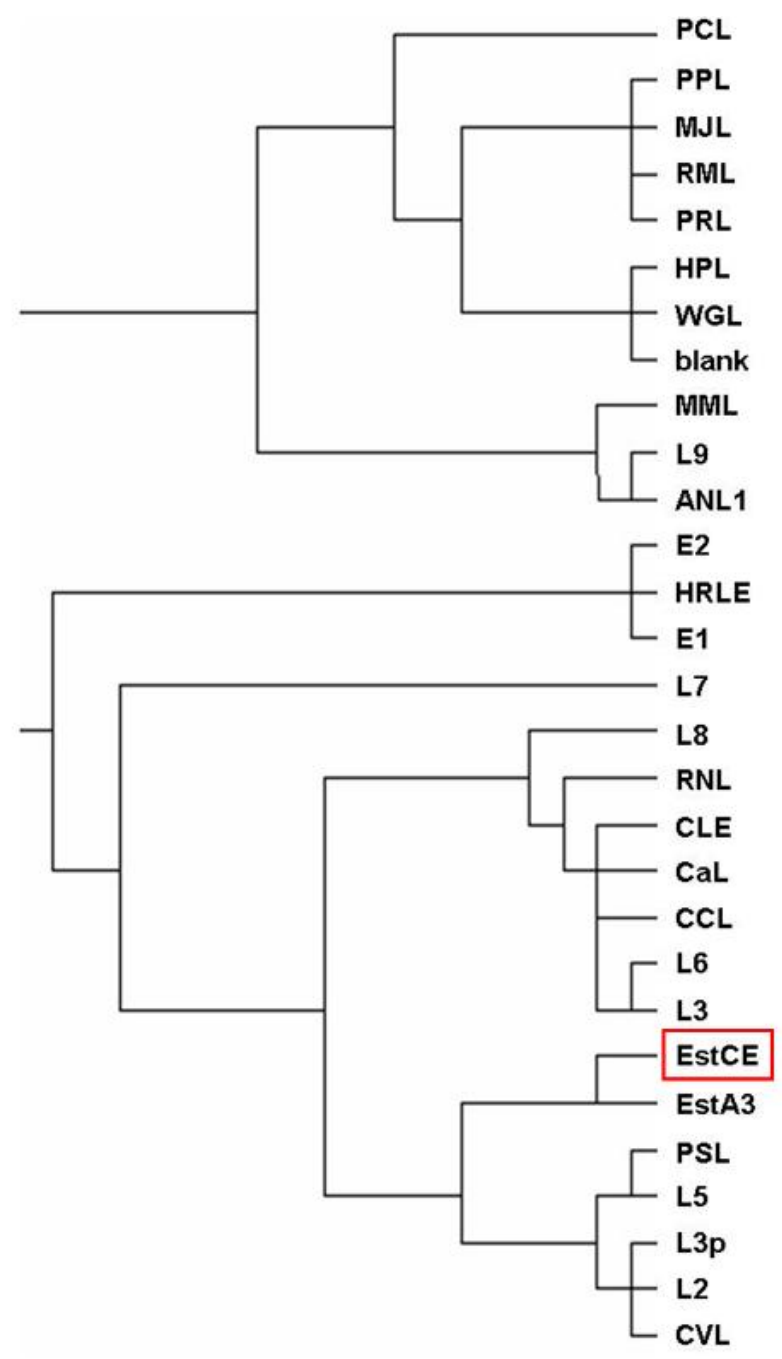

Abb. 26: Dendrogramm der Ähnlichkeit verschiedener Lipasen und Esterasen, erstellt anhand ihrer enzymatischen Fingerabdrücke

Das Dendrogramm wurde mit Hilfe der SPSS-Software (www.spss.com) erstellt. Die Kürzel stehen für Lipasen $(L)$ bzw. Esterasen $(E)$ aus folgenden Organismen: PCL: Pseudomonas cepacia (F-62309), PPL: Schwein, Pankreas (Chirazyme L-7), MJL: Mucor javanicus (F-62304), RML: Rhizomucor miehei (F-62291), PRL: Penicillium roqueforti (F-62308), HPL: Schwein (hog), Pankreas (F-62300), WGL: Weizenkeim (F-62306), MML: Mucor miehei (F-62298), L9: Mucor miehei (Chirazyme L-9), ANL1: Aspergillus niger (F-62294), E2: Schweineleber, Esterase Fraktion 2 (Chirazyme E-2), HRLE: Schweineleber, E1: Schweineleber, Esterase Fraktion 1 (Chirazyme E-1), L8: Thermomyces lanuginosa (Chirazyme L-8), RNL: Rhizopus niveus (F62310), CLE: Candida lipolytica (F-46056), CaL: Candida antarctica (F-62299), CCL: Candida cylindracea (F-62316), L6: Pseudomonas sp. (Chirazyme L-6), L3: Candida rugosa (Chirazyme L-3), EstA3: Metagenomesterase (Schmeißer, 2004), PSL: Pseudomonas sp. (F-62335), L5: Candida antarctica, Lipase Fraktion A (Chirazyme L-5), L3p: Candida rugosa, gereinigt, L2: Candida antarctica, Lipase Fraktion B (Chirazyme L-2), CVL: Chromobacterium viscosum (F62333). Chirazyme-Enzyme wurden von Roche bezogen, F-markierte Enzyme von Fluka. 


\subsubsection{Enzymkinetik von EstCE}

Mit dem Substrat pNP-Butyrat wurden bei verschiedenen Substratkonzentrationen zwischen 0 und $2 \mathrm{mM}$ und einer Testtemperatur von $40^{\circ} \mathrm{C}$ die Anfangsgeschwindigkeiten der Reaktion bestimmt [II.9.2.1]. Es zeigte sich bei der Auswertung, dass EstCE hierbei einer klassischen Michaelis-Menten-Kinetik folgte und keine Interphasenaktivierung wie für einige Lipasen typisch (vgl. Kinetik LipCE, III.4.6.11) stattfand. Die Daten sind in einer Michaelis-Menten-Auswertung sowie einer Lineweaver-Burke-Auftragung graphisch in Abbildung 27 dargestellt. Hieraus ließen sich für EstCE und pNP-Buytrat als Substrat ein $V_{\max }$-Wert von 55,2 $\mu \mathrm{mol} \cdot \mathrm{I}^{-1} \cdot \mathrm{min}^{-1}$ und ein $K_{\mathrm{m}}$-Wert von $0,35 \mathrm{mM}$ errechnen.
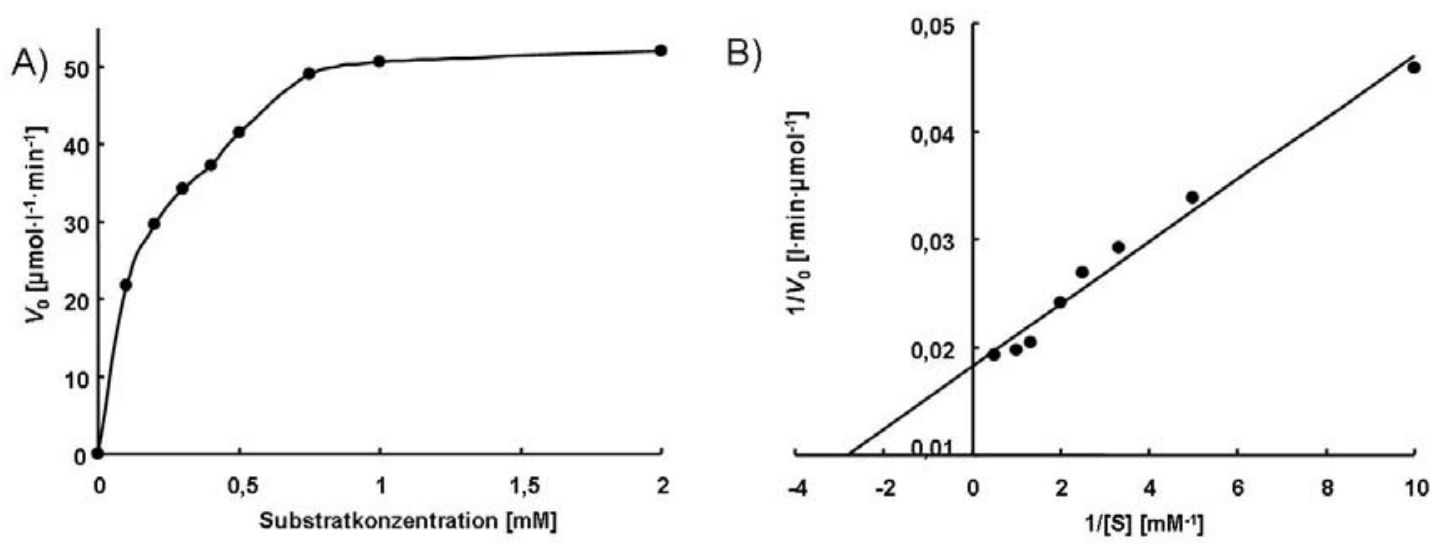

Abb. 27: Enzymkinetik von EstCE mit pNP-Butyrat als Substrat Auftragung der Anfangsgeschwindigkeit $V_{0}$ in Abhängigkeit von der Substratkonzentration [S] nach Michaelis-Menten (A) und doppelt-reziprok nach Lineweaver-Burke (B) zur Bestimmung der Parameter $K_{\mathrm{m}}$ und $V_{\text {max }}$.

\subsubsection{Untersuchungen auf $\beta$-Laktamase-Aktivität von EstCE}

Da die blastp-Vergleiche für EstCE hohe Ähnlichkeiten zu $\beta$-Laktamasen zeigten, sollte überprüft werden, ob EstCE in der Lage ist, Resistenz gegenüber einer Auswahl an $\beta$-Laktam-Antibiotika zu vermitteln. Hierzu wurde das estCE-Gen mit BamHI und HindIII aus dem Vektor pQE30::estCE herausgeschnitten und in den ebenso linearisierten Vektor pET24c umkloniert, es wurde pET24c::estCE erhalten (Abb. 28). Dadurch ging zwar der His-Tag verloren, da aber sowohl pQE30 als auch pET19b selbst $\beta$-Laktamase-Aktivität als Resistenzmarker aufwiesen, musste für diesen Versuch ein Vektor gewählt werden, der Resistenz gegenüber einer anderen Antibiotikaklasse vermittelt. In diesem Falle war das Resistenz gegenüber Kanamycin, einem Aminoglykosidantibiotikum, welches in die Proteinbiosynthese eingreift, statt in die Zellwandbiosynthese wie die $\beta$-Laktam-Antibiotika. Die vorhandene Esteraseaktivität wurde, nach Transformation von pET24c::estCE in E. coli BL21(DE3), 
durch Hofbildung auf Tributyrinindikatorplatten sichergestellt. Anschließend wurde dieser Klon in Flüssigmedium angezogen, auf LB-Platten mit 0,1 mM IPTG ausplattiert, um die Expression des inserierten Gens sicherzustellen. Nach Zugabe von 15 verschiedenen Antibiotikatestplättchen (Oxoid, Wesel) wurde nach Inkubation über Nacht der entstandene Hemmhofdurchmesser bestimmt und verglichen mit $E$. coli BL21(DE3)/pET24c als Referenz. Die getesteten Antiobiotika waren Amoxicillin, Ampicillin, Cefaclor, Cefixime, Ceftibuten, Ceftriaxone, Ceftazidime, Cefoxitin, Cefadroxil, Cefotaxime, Cefamandole, Loracarbef, Meropenem, Mezlocillin und Penicillin. In keinem der getesteten Fälle war eine signifikante Abweichung nach oben oder unten $(\leq 5 \%)$ zu beobachten, so dass eine $\beta$-Laktamase-Aktivität von EstCE gegenüber den getesteten Antibiotika unwahrscheinlich scheint. Die Funktionalität dieses Testsystems konnte am ORF6/SST1 (vgl. Kapitel III.3.2) gezeigt werden, der hohe Ähnlichkeit zu einer funktionellen $\beta$-Laktamase aus Serratia marcescens zeigte (Matsumura et al., 1998).

Des Weiteren wurden Antibiotikalösungen von Ampicillin und Penicillin $(1 \mathrm{mg} / \mathrm{ml})$ für 2 Stunden mit gereinigtem EstCE-Protein inkubiert und anschließend je $20 \mu \mathrm{g}$ auf leere, sterile Testplättchen geträufelt. Diese wurden über Nacht ebenfalls mit einem E. coliStamm auf LB-Platten inkubiert, auch dort war jedoch keine Abnahme des Hemmhofes verglichen mit unbehandelten Antibiotika als Negativkontrolle sichtbar. Durch Kontrollversuche mit kommerzieller $\beta$-Laktamase und Penicillinase (beide Sigma) konnte gezeigt werden, dass dieses System prinzipiell funktioniert (ohne Abbildung).

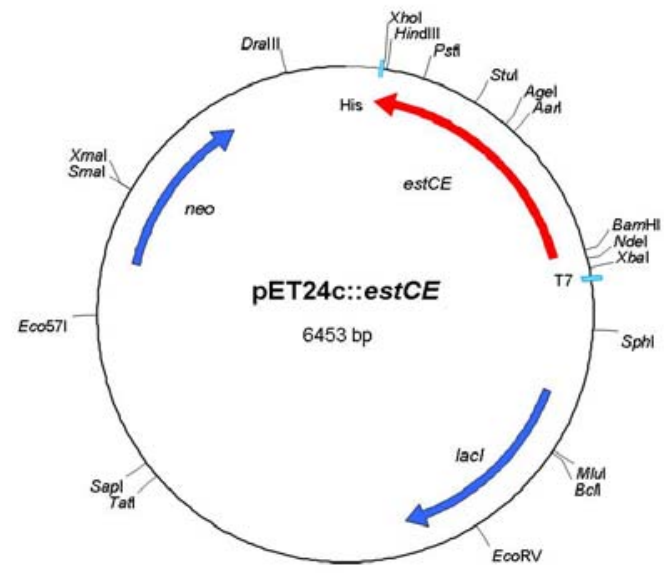

Abb. 28: Restriktionskarte des Expressionsvektors pET24c::estCE

Das estCE-Gen ist rot gekennzeichnet, Vektorgene in blau. neo: Neomycinphosphotransferase $\left(\operatorname{Kan}^{\mathrm{R}}\right)$, lacl: Lac-Repressor, T7: T7-Promotor, His: 6xHis-Tag (in diesem Fall nicht transkribiert). 


\subsubsection{Ortsspezifische Mutagenese im katalytischen Zentrum}

Um den mittels Datenbankvergleichen als katalytisches Nukleophil identifizierten Serinrest an Position 65 auch biochemisch zu bestätigen, wurde durch ortsgerichtete Mutagenese mit den Primern S65A_for und S65A_rev (Tab. 4) und dem „Quik Change Site-Directed Mutagenesis Kit" (Stratagene, Heidelberg) das codierende Triplet TCG durch Einfügen einer Punktmutation in ein GCG mutiert [II.4.8.2]. Als Vorlage für die PCR diente hierbei der Vektor pQE30::estCE. Somit wurde im Protein an dieser Stelle das Serin durch ein unreaktives Alanin ersetzt und die Mutante EstCE_S65A erhalten. Der korrekte Austausch an bp-Position 193 wurde durch Sequenzieren des Inserts mit Standardprimern verifiziert. Nach Transformation des Expressionsvektors in E.coli M15 wurden $750 \mu$ g Protein in einem Schritt durch Reinigung über eine Protino ${ }^{\circledR} 1000-S a ̈ u l e$ (Macherey\&Nagel) aus $250 \mathrm{ml}$ Kultur erhalten (Abbildung 29).

Der E. coli-Klon zeigte auf Tributyrinindikatorplatten keine hydrolytische Aktivität mehr. Anschließende Aktivitätstests mit gereinigtem Protein unter Verwendung der Substrate pNP-Butyrat, pNP-Valerat und pNP-Caproat [II.9.2.1] bei Temperaturen von $20^{\circ} \mathrm{C}$ und $45^{\circ} \mathrm{C}$ sowie Zugabe von bis zu 7,5 $\mu$ g Protein pro Ansatz und einer verlängerten Inkubation auf $1 \mathrm{~h}$ zeigten unter keiner der getesteten Bedingungen Esteraseaktivität für das mutierte Protein, so dass Ser65 als katalytisches Nukleophil identifiziert werden konnte.

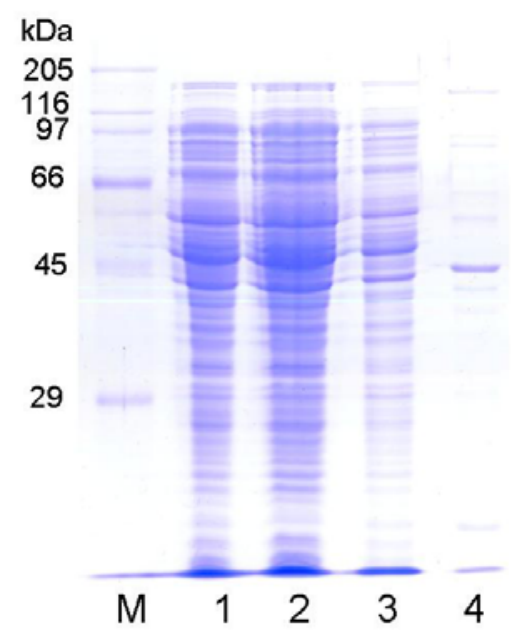

Abb. 29: SDS-PAGE der Reinigung von EstCE_S65A

Spur M: „High Molecular Weight Marker“ (Sigma), Spur 1: Rohextrakt, Spur 2: Durchlauf Protino ${ }^{\circledR} 1000$, Spur 3: Waschfraktion, Spur 4: EstCE_S65A nach Elution, 4 rg. 


\subsubsection{Kristallisierung von EstCE}

Um nähere Einblicke in die Reaktionsmechanismen der Enzyme der Lipase-Familie VIII zu bekommen, sollte EstCE kristallisiert werden. Bislang existiert nur eine Struktur von EstB aus B. gladioli (Wagner et. al., 2002) für Enzyme aus dieser Familie. EstCE wurde hierfür auf eine Konzentration von $14 \mathrm{mg} / \mathrm{ml}$ Protein eingeengt und für Kristallisationsansätze nach der Methode des „sitzenden Tropfens“ verwendet. Bei der Durchmusterung mehrerer kommerzieller Kits wurde eine geeignete Präzipitationslösung gefunden (JB Classic Screen 1 - Lösung C2 (Jena Bioscience), 25\% PEG550 MME, 0,01 $\mathrm{M} \mathrm{ZnSO}_{4}, 0,1 \mathrm{M} \mathrm{NaMES,} \mathrm{pH} \mathrm{6,5).} \mathrm{EstCE} \mathrm{bildete} \mathrm{unter} \mathrm{diesen}$ Bedingungen nach zwei Tagen bei $20^{\circ} \mathrm{C}$ sternförmige Kristalle (Abb. 30). Für eine Datenerhebung reichten diese initialen Kristalle jedoch noch nicht, so dass die Bedingungen weiter verfeinert werden müssen.
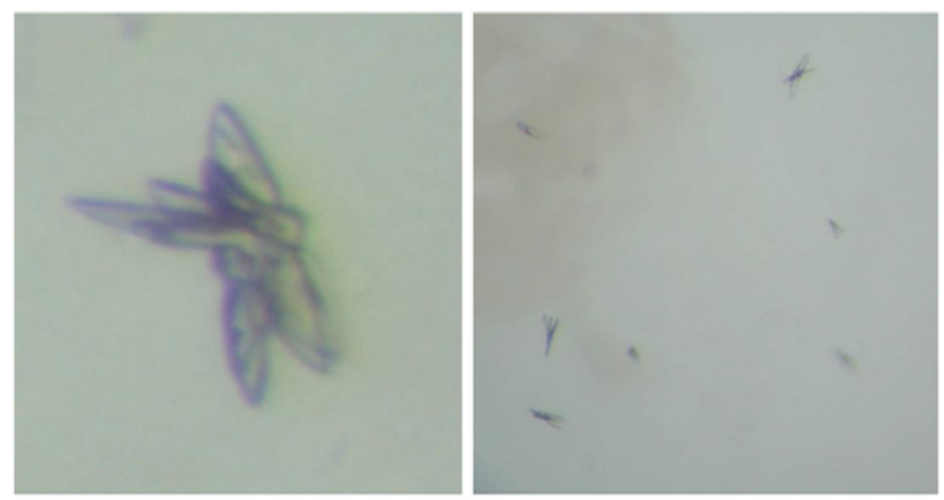

Abb. 30: Proteinkristalle von EstCE

Kristallisationsbedingungen: 25\% PEG550 MME, 0,01 $\mathrm{M} \mathrm{ZnSO}_{4}, 0,1 \mathrm{M}$ NaMES, pH 6,5, Inkubation $20^{\circ} \mathrm{C}, 2$ Tage.

\section{3. $\beta$-Laktamase-Aktivität des ORFs SST1}

\subsection{Klonierung von SST1}

Da für den ORF6 auf dem Subklon pSK::RV1 eine Identität von 79\% zu einer funktionellen $\beta$-Laktamase aus einem klinischen Serratia marcescens-Isolat (Matsumura et al., 1998) gefunden wurde, sollte dieses Genprodukt auf seine $\beta$ Laktamase-Aktivität hin überprüft werden. Hierfür wurde es mit den Primern SST1_for und SST1_rev (Tab. 4) amplifiziert, wobei eine 5'-BamHI- und eine 3'-HindIIISchnittstelle eingefügt wurden. Das Pfu-amplifizierte Genprodukt wurde zunächst in den mit EcoRV linearisierten Vektor pSK+ kloniert, mit BamHI und HindIII herausgeschnitten und in den ebenso präparierten Vektor pET24c kloniert. Der so entstandene Expressionsvektor pET24c::SST1 ist in Abb. 31 dargestellt. 


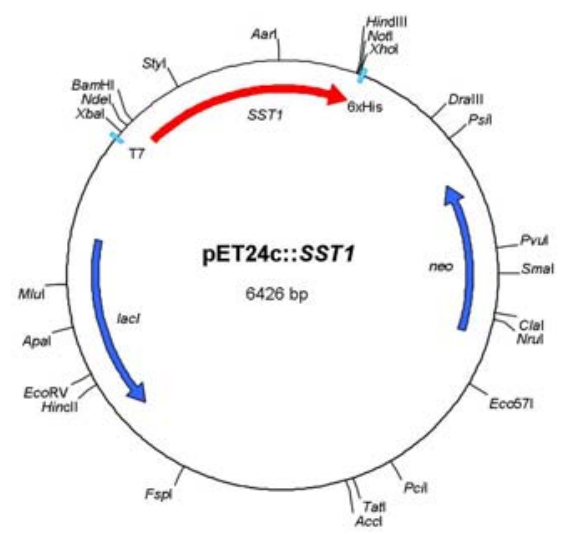

Abb. 31: Restriktionskarte des Plasmides pET24c::SST1

Das SST1-Gen ist in rot gekennzeichnet, Vektorgene in blau, lacl=Lac-Repressor, $n e o=$ Neomycinphosphotransferase $\left(\operatorname{Kan}^{\mathrm{R}}\right), \mathrm{T} 7=\mathrm{T} 7$ Promotor, $6 \mathrm{xHis}=\mathrm{His}-\mathrm{Tag}$ kodierende Region

\subsection{Antibiotikasensitivitätstests}

Nach Transformation in E. coli BL21(DE3) wurde der Klon bei $37^{\circ} \mathrm{C}$ üN inkubiert und auf LB-Platten mit 0,1 mM IPTG ausplattiert. Anschließend wurden Antibiotikatestplättchen mit verschiedenen $\beta$-Laktam-Antibiotika in unterschiedlichen Konzentrationen (Oxoid, Wesel) hinzugegeben und über Nacht inkubiert. Gegenüber den Cephalosporinen Loracarbef und Cefadroxil (je $30 \mu \mathrm{g} /$ Plättchen) konnte eine durch SST1 vermittelte Resistenz beobachtet werden, es kam zu keiner Hemmhofbildung mehr. Bei Cefamandol $(30 \mu \mathrm{g})$ konnte eine starke, aber nicht vollständige Reduzierung des Hemmhofes von 28 auf $11 \mathrm{~mm}$ (Abb. 32) beobachtet werden. Bei allen weiteren Antibiotika war keine Resistenz festzustellen.

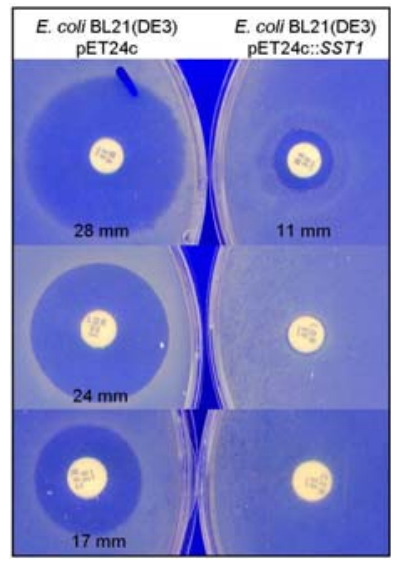

Abb. 32: Antibiotikasensitivitätstests mit E. coli BL21(DE3) pET24c::SST1

Durch SST1 vermittelte Resistenz gegenüber Cefamandol (MA, oben), Loracarbef (LOR, mitte) und Cefadroxil (CFR, unten) (je $30 \mu \mathrm{g}$ ). Links befindet sich als Negativkontrolle ein E. coliStamm mit dem leeren Vektor pET24c. Die jeweiligen Hemmhofdurchmesser sind als Durchschnittswerte in $\mathrm{mm}$ angegeben. 


\section{Identifizierung und Charakterisierung der Lipase LipCE}

\subsection{Isolation des Cosmides pCosCE2}

Die Durchmusterung von weiteren ca. 3.000 Klonen der Cosmidbank, welche aus der Anreicherungskultur „Wietze 2“ erstellt wurde, lieferte bei einem Aktivitätstest auf Tributyrinindikatorplatten einen Klon mit lipolytischer Aktivität. Von diesem wurde nach erneutem Ausstreichen auf tributyrinhaltigem Selektivmedium und Erhalten eines stabilen Phänotyps die Cosmid-DNA isoliert und das Cosmid mit pCosCE2 bezeichnet. Durch Restriktionsanalysen mit verschiedenen Restriktionsenzymen konnte eine Insertgröße von $13 \mathrm{~kb}$ ermittelt werden.

Durch Subklonierung des gesamten Cosmides mit EcoRV und Ligation in den identisch geschnittenen Vektor pSK+ wurde ein aktiver Subklon erhalten, von welchem die Plasmid-DNA isoliert und unter Erhalt eines stabilen Phänotyps retransformiert werden konnte. Restriktionsanalysen zeigten, dass dieser Klon, welcher mit pSK::RV8 bezeichnet wurde, zwei Fragmente der Größe 7,4 und 0,9 kb enthielt. Zur weiteren Charakterisierung wurde dieser Klon zusätzlich auf Triolein-RhodaminB-haltigem Medium ausgestrichen und zeigte unter UV-Licht auch dort hohe Aktivität (Abb. 33).
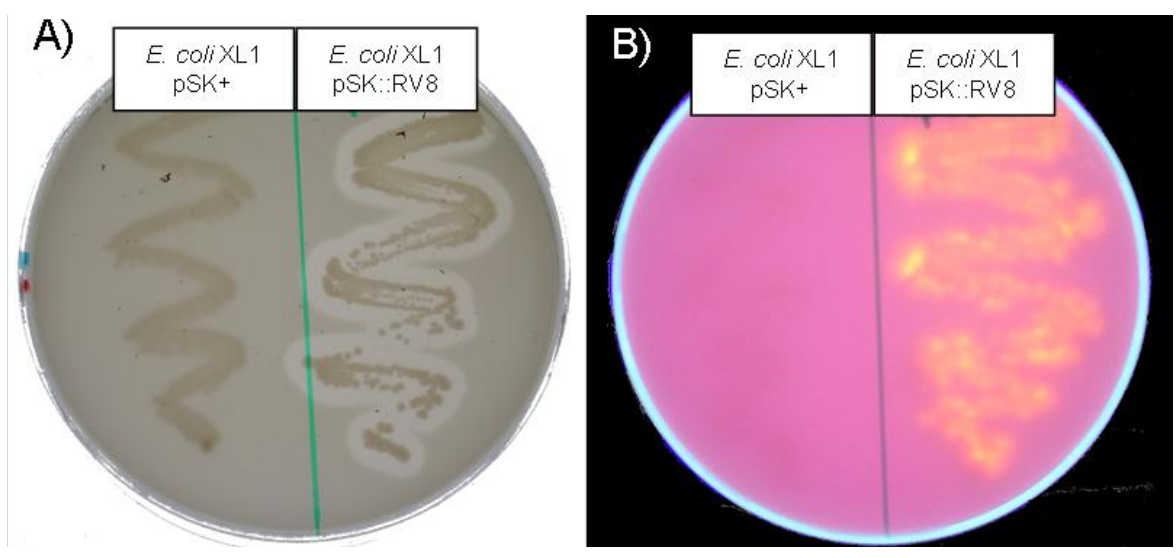

Abb. 33: Lipolytische Aktivität des aktiven Subklons pSK::RV8 auf TributyrinIndikatorplatten $(A)$ und Triolein-RhodaminB-Indikatorplatten (B).

Auf der jeweils linken Seite der Platte ist ein E. coli-Klon mit leerem Vektor als Negativkontrolle dargestellt. Die Triolein-RhodaminB-Platte in Abbildung B wurde während der Bestrahlung mit UV-Licht fotografiert.

\subsection{Identifizierung des lipolytischen ORFs mittels Transposonmutagenese}

Die isolierte Plasmid-DNA des lipolytisch aktiven Klons pSK::RV8 wurde einer in vitroTransposonmutagenese mit dem EZ-TN $\left.{ }^{\mathrm{TM}}<\mathrm{TET}-1\right\rangle$ Transposon-Kit [II.4.8.1] unterzogen. Hierdurch konnten Kolonien, welche das Transposon enthielten, durch ihre Tetracyclinresistenz selektiert werden. Von einem Klon, der auf Tributyrin-Tetracyclin- 
Selektivmedium keine lipolytische Aktitvität mehr zeigte, wurde die Plasmid-DNA isoliert und diese mittels dem Kit zugehörigen Standardprimern TET-1 RP-1 und TET-1 FP-1 (Tab. 6) sequenziert. Aus den erhaltenen Sequenzen wurden Oligonukleotide abgeleitet, die für einen weiteren „primer walking“-Schritt verwendet wurden. Insgesamt konnte so ein ORF mit einer Größe von 1431 bp identifiziert werden, in welchem das Transposon zwischen den Basenpaaren 806 und 807 inseriert war. Dieser, die lipolytische Aktivität vermittelnde ORF, wurde mit lipCE bezeichnet. Die Sequenz des lipCE-Gens wurde unter der Accession-Nr. DQ925372 bei GenBank hinterlegt.

\subsection{Genetische Charakterisierung des lipCE-Gens}

Das lipCE-Gen umfasste 1431 bp mit einem GC-Gehalt von $61,1 \%$ und kodierte damit für ein Protein mit 476 AS. Das theoretisch errechnete Molekulargewicht dieses Proteins betrug 50,4 kDa und der isoelektrische Punkt lag bei 5,43 (www.expasy.org). Es fand sich in der kodierenden Sequenz ein für Lipasen typisches Aminosäuremotiv G-H-S-L-G (bp-Position 613 bis 627, Aminosäure 205 bis 209) mit dem Serin205 als katalytischem Nukleophil. Ein Datenbankvergleich mittels blastp in der NCBIDatenbank (www.ncbi.nlm.nih.gov, Release-Nummer 2.2.14, Stand 03.07.2006) ergab eine Identität von $88 \%$ auf DNA-Ebene zu einer extrazellulären Lipase aus Pseudomonas fluorescens B68 (Accession-Nr. AY694785) sowie ähnliche Treffer zu einer Vielzahl weiterer Lipasen aus verschiedenen $P$. fluorescens-Stämmen. Auf Aminosäurebene betrug die Identität jeweils $91 \%$ zu einer weiteren $P$. fluorescensLipase (Accession-Nr. ABC18240) sowie zu der Lipase aus P. fluorescens B68.

Eine Datenbanksuche in der Conserved Domain Database (Marchler-Bauer et al., 2005) identifizierte als konservierte und an der für Lipasen charakteristischen katalytischen Triade beteiligte Aminosäuren Serin, Histidin und Aspartat die Reste Ser205, Asp255 und His313. Diese sind in der in Abbildung 34 dargestellten Nukleotidund Aminosäuresequenz farbig hervorgehoben.

Des Weiteren fand sich in der Aminosäuresequenz bei einer Suche nach einem Signalpeptid mit dem Program „SignalP 3.0“ (http://www.cbs.dtu.dk/services/SignalP/) kein Signalpeptid, obwohl eine extrazelluläre Lokalisation des Enzyms vorhergesagt wurde, was sich mit den blastp-Ergebnissen der nächsten Treffer deckt. Dafür fanden sich in einem Alignment (Abb. 35) mit den nächst verwandten $P$. fluorescens-Lipasen vier typische C-terminale, glycinreiche Sekretionssignale, die jeweils sechs AS umfassen (AS 373-378, 382-387, 391-396, 411-416). Diese sind für einen ABCabhängigen Transport der Lipasen verantwortlich und in Abb. 34 farbig hervorgehoben. 
1 atgggtatct ttgactataa aaacctcggt accgagggct ccaaagcgct gtttgccgac $\begin{array}{llllllllllllllllllll}M & G & I & F & D & Y & K & N & L & G & T & E & G & S & K & A & L & F & A & D\end{array}$

61 gccttggcga tcacgctgta ttcctatcac aacctggatc acggctttgc cgtgggctac $\begin{array}{lllllllllllllllllllllllllllll}A & L & A & I & T & L & Y & S & Y & H & N & L & D & H & G & F & A & V & G & Y\end{array}$ 121 cagaaccacg gctttggcet cggcctgccg gccacactgg tcactgcagt gctgggcagt

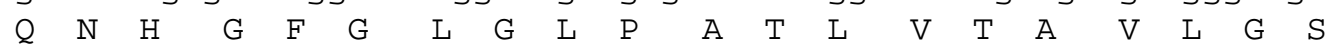
181 acggattcgc aaggcgtgat tccoggcatc ccctggaacc ctgactcgga aaaagccgcc $\begin{array}{lllllllllllllllllllllll}T & D & S & Q & G & V & I & P & G & I & P & W & N & P & D & S & E & K & A & A\end{array}$

241 cttgaagccg tgcaaaaagc cggctggacg cctatcagcg ccagcaccct gggctacggc $\begin{array}{llllllllllllllllllllllll} & L & E & A & V & Q & K & A & G & W & T & P & I & S & A & S & T & L & G & Y & G\end{array}$ 301 ggcaaagtcg atgcccgcgg cacgttcttc ggcgaaaagg ccggctacac cacggcccag

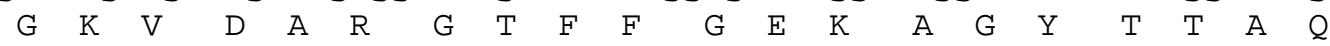

361 gtcgaggtgc tgggcaagca cgatgacacc ggtaagttgc tggaaatcgg catcagtttt

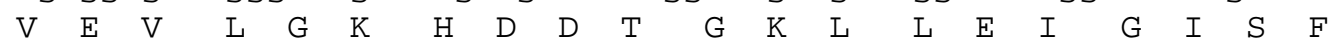

421 cgcggcacat cggggccacg ggagcacttg atcagtgact ccatcggcga cctgatcagc $\begin{array}{llllllllllllllllllll}R & G & T & S & G & P & R & E & H & L & I & S & D & S & I & G & D & L & I & S\end{array}$

481 gatctgctcg ctgccctggg acccaaggat tatgcaaaaa actacgccgg cgaagcattc $\begin{array}{llllllllllllllllllll}D & L & L & A & A & L & G & P & K & D & Y & A & K & N & Y & A & G & E & A & F\end{array}$

541 ggcagtttgc tcaagaacgt cgccgattat gccggcgccc atggcttgac gggccaggac $\begin{array}{lllllllllllllllllllllllll} & S & S & L & L & K & N & V & A & D & Y & A & G & A & H & G & L & T & G & Q & D\end{array}$ 601 gtgttggtca gcggccacag cctcggcggg ttggcggtca acagcatggc ggacctgagc $\begin{array}{llllllllllllllllllll} & V & V & S & G & H & S & L & G & G & L & A & V & N & S & M & A & D & L & S\end{array}$

661 aacagccgat gggcgggctt ctacaaggac gccaactacg tggcgtatgc ctcgccgacc $\begin{array}{llllllllllllllllllll}N & S & R & W & A & G & F & Y & K & D & A & N & Y & V & A & Y & A & S & P & T\end{array}$

721 cagagcgccg gggacaaggt gctcaatatc ggctatgaga acgacccggt gttccgtgcc $\begin{array}{llllllllllllllllllll}Q & S & A & G & D & K & V & L & N & I & G & Y & E & N & D & P & V & F & R & A\end{array}$

781 ctggacggct catccttcaa cctgtcctcc ttgggcgtgc acgacaagcc ccatgagtcg $\begin{array}{llllllllllllllllllllllllll} & D & G & S & S & F & N & L & S & S & L & G & V & H & D & K & P & H & E & S\end{array}$

841 actaccgaca atatcgtcaa cttcaacgac cattacgcct cgacgttgtg gaacgtgctg $\begin{array}{lllllllllllllllllllllllllll}T & T & D & N & I & V & N & F & N & D & H & Y & A & S & T & L & W & N & V & L\end{array}$

901 ccattctcca tcgtcaacct gccgacctgg ctctcccatt tgccettcgg ctatggcgat

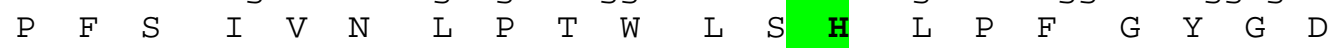

961 ggcatgaccc gcatcctcga atccggcttc tatgagcaga tgacccgcga ctctacggtg $\begin{array}{llllllllllllllllllll}G & M & T & R & I & L & E & S & G & F & Y & E & Q & M & T & R & D & S & T & V\end{array}$ 1021 atcgtcgcca atctgtccga cccggcacgg gccaacacct gggtacagga cctcaaccgc $\begin{array}{llllllllllllllllllll}I & V & A & N & L & S & D & P & A & R & A & N & T & W & V & Q & D & L & N & R\end{array}$

1081 aatgcggagg cccacaaggg caacacgttc atcatcggca gtgacggcaa cgacctgatc $\begin{array}{llllllllllllllllllll}N & A & E & A & H & K & G & N & T & F & \text { I } & \text { I } & G & \text { S } & \text { D } & \text { G } & \text { N } & \text { D } & \text { L } & \text { I }\end{array}$ 1141 cagggtggca agggcgcgga cttcatcgaa ggcggcaagg gcaatgacac cctccgtgac $\begin{array}{llllllllllllllllllll}Q & G & G & K & G & A & D & F & I & E & G & G & K & G & N & D & T & L & R & D\end{array}$

1201 aacagtgggc ataacacctt tctgttcagc ggccacttcg gcaatgaccg ggtgatcggc $\begin{array}{llllllllllllllllllll}N & S & G & H & N & T & F & L & F & S & G & H & F & G & N & D & R & V & I & G\end{array}$

1261 tatcagccca cggacaagct ggtgttcaag gacgtggaag gcagcaccga cctgcgtgac $\begin{array}{lllllllllllllllllllllll} & \mathrm{Q} & P & \mathrm{~T} & \mathrm{D} & \mathrm{K} & \mathrm{L} & \mathrm{V} & \mathrm{F} & \mathrm{K} & \mathrm{D} & \mathrm{V} & \mathrm{E} & \mathrm{G} & \mathrm{S} & \mathrm{T} & \mathrm{D} & \mathrm{L} & \mathrm{R} & \mathrm{D}\end{array}$

1321 catgccaaag tggttggcgc ggacacggtg ctcagctttg gcgccgactc ggtgaccetg $\begin{array}{llllllllllllllllllll}H & A & K & V & V & G & A & D & T & V & L & S & F & G & A & D & S & V & T & L\end{array}$ 1381 gtcggcgtcg ggcatggcgg cctatggacg gacggcgtca gcatcggctg a

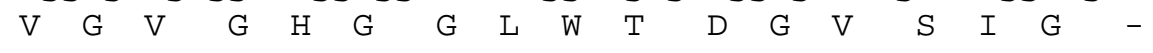

Abb. 34: Nukleotid- und und daraus abgeleitete Aminosäuresequenz des lipCE-Gens

Die Aminosäuren sind im Einbuchstabencode dargestellt, das wahrscheinliche aktive Zentrum mit der Konsensussequenz GxSxG und dem Ser205 als katalytischem Nukleophil, sowie die an der katalytischen Triade beteiligten Aminosäuren Asp255 und His313 grün unterlegt. Die wahrscheinlichen glycinreichen C-terminalen Sekretionsmotive sind gelb unterlegt und die zugehörigen Aminosäuren fettgedruckt. 
LipCE 370 FITGSDGNDLIQGGGKGADFIEGGKGNDT̈LRDNSGHNTFLFSGHFGNDRVIGYQPTDKLV

SIK 370 FIIGSDGNDLIQGGKGADFIEGKGND IRDNSGHNTFLFSHFGQR IIGYQPTDRLV

B52 370 FIIGSDGNDIIQGGNGADFIEGGKGND IRDNSGHNTFLFSGHFGNDRVIGYQPTDKLV

LS107 370 FIIGSAGNDIIQGGGGADFIEAGKGNDJIIRDSSGHNTFLFSGQFGQDRIIGYQPTDKLV

LipCE 429 FKDVEGSTDLRDHAKVVGADTVLSFGADSVTLVGVGHGGLWTb $\overline{\text { GVSIF }} 476$

SIK 429 FQGADGSTDLRDHAKAVGADTVLSFGADSVTLVGVGLGGLWSEGVLIS 476

B52 429 FKDVQGSTDLRDHAKNVGADTVLTFGADSVTLVGVGHGGLWTEGVVI 476

LS107 429 FTDVQSSGDYRDHAKVVGGDTVISFGGDSVTLVGV--VGLSGEGIVIS 474

Abb. 35: Sequenzvergleich des C-Terminus von LipCE mit den nächst verwandten Lipasen aus $P$. fluorescens SIK W1, B52 und LS107d2.

Konservierte AS sind grün hinterlegt. Die vier glycinreichen Motive sind gepunktet umrandet, die amphipatische $\alpha$-Helix mit einer durchgezogenen Linie und ein weiteres Motiv am äußersten C-Terminus gestrichelt umrandet (siehe Text).

Zudem fand sich in dem Alignment eine putative, 18 Aminosäuren umfassende amphipatische $\alpha$-Helix (Position 444-461) sowie ein am äußersten C-Terminus gelegenes Motiv, eine geladene Aminosäure (Asp471), gefolgt von vier hydrophoben Resten. Dieses ist u.a. bei Metalloproteasen von Bedeutung, die über ABC-abhängigen Transport sekretierten werden (Ghigo und Wandersmann, 1994). Allerdings war es in LipCE durch das Vorhandensein eines Serinrestes nicht so stark konserviert wie in den anderen drei Lipasen.

Beim weiteren Sequenzieren des Subklones pSK::RV8 fand sich stromaufwärts des lipCE-Gens ein weiterer ORF, der für ein Enzym mit hoher Homologie zu einer Serinprotease kodiert (2418 bp). Zudem fanden sich einige Basenpaare vom äußeren 3'-Ende eines Proteins der äußeren Membran, wie es in ABC-Transportsystemen vorkommt (Abb. 36), hier wurde das Cosmidstück jedoch bei der Erstellung der Genbank getrennt. Der restliche Teil wurde nicht komplett sequenziert. Proteaseaktivität konnte durch Tests auf Skim-Milk-Agar-Platten weder für pSK::RV8 noch für pCosCE2 nachgewiesen werden.

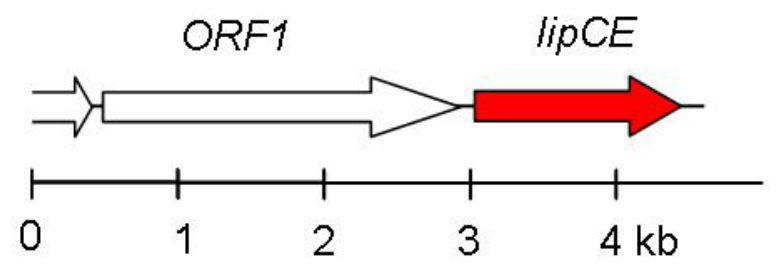

Abb. 36: Sequenziertes Cosmidteilstück mit dem lipCE-Gen

ORF1: homolog zu Serinprotease, links davon das 3'-Ende eines Gens für ein Protein der äußeren Membran, wie es in ABC-Transportsystemen zu finden ist. 


\subsection{Klonierung und heterologe Expression des lipCE-Gens}

\subsubsection{Heterologe Expression in E. coli}

Zur Expression und Reinigung des Lipaseproteins wurde das lipCE-Gen in den Expressionsvektor pET19b (Tab. 3) kloniert. Hierfür wurde es zunächst mittels der Primer LipCE_for und LipCE_rev (Tab. 4) amplifiziert, wobei eine 5'-Ndel-Schnittstelle sowie eine 3'-BamHI-Schnittstelle eingefügt wurden. Das mittels Pfu-Polymerase amplifizierte PCR-Produkt wurde zunächst in den mit EcoRV linearisierten Vektor pSK+ (Tab. 4) kloniert und anschließend mit den Enzymen Ndel und BamHI wieder herausgeschnitten und in den ebenfalls mit Ndel und BamHI linearisierten Vektor pET19b kloniert. Inserttragende Kolonien wurden durch ihre Aktivität auf Tributyrinplatten selektiert, die Plasmide isoliert und das Vorhandensein des Inserts im korrekten Leserahmen mittels Sequenzierung mit Standarprimern (T7_for/T7_rev, Tab. 4) überprüft und bestätigt.

Das LipCE-Protein wurde durch die Klonierung mit einem N-terminalen 10xHis-Tag zur späteren Aufreinigung versehen. Die Größe des rekombinanten Proteins betrug nun 499 AS mit einem theoretischen Molekulargewicht von 53,2 kDa. Das Plasmid pET19b::lipCE (Abb. 37) wurde zur Expression in E. coli BL21 (DE3) transformiert.

Die Anzucht und Expression wurde zunächst bei Wachstumstemperaturen von $37^{\circ} \mathrm{C}$ bis hin zu $12^{\circ} \mathrm{C}$ für vier Tage probiert, wobei nach Erreichen einer $\mathrm{OD}_{595}$ von 0,5 mit IPTG-Konzentrationen von $1 \mu \mathrm{M}$ bis hin zu $1 \mathrm{mM}$ die Proteinexpression induziert wurde, was unter sämtlichen getesteten Bedingungen zur Bildung von unlöslichen Einschlusskörpern (inclusion bodies) führte. Eine Sekretion des Proteins in das Periplasma bzw. in den Kulturüberstand war ebenfalls unter keiner der getesteten Bedingungen nachweisbar.

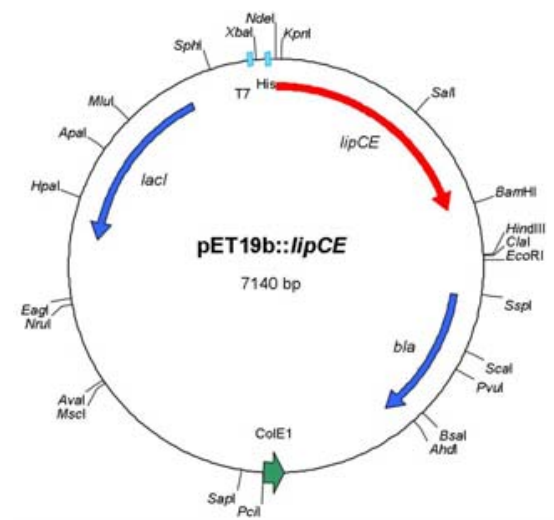

Abb. 37: Restriktionskarte des Expressionsplasmides pET19b::lipCE

Das lipCE-Gen ist als roter Pfeil dargestellt, Vektorgene in blau und der Replikationsursprung ColE1 in grün. lacl=Lac-Repressor, bla= $\beta$-Laktamase $\left(\mathrm{Amp}^{\mathrm{R}}\right), \quad$ His=10xHis-Tag, T7=T7 Promotor. 


\subsubsection{Heterologe Expression in Pseudomonas aeruginosa}

Da für eine $P$. fluorescens-Lipasen mit C-terminalem Sekretionssignal eine erfolgreiche Expression in P. aeruginosa berichtet wurde (Duong et al., 1994), wurde das lipCEGen in den Vektor pBR22b (Tab. 3) umkloniert und eine Überexpression ohne His-Tag zunächst in dem Lipase-negativen Stamm P. aeruginosa PABST7.1 getestet, der im Gegensatz zu E. coli über entsprechende Sekretionssysteme verfügt. Auch dieser Versuch führte unter Verwendung verschiedener IPTG-Konzentrationen bis zu $1 \mathrm{mM}$ und Wachstumbedingungen von $30^{\circ} \mathrm{C}$ bzw. $37^{\circ} \mathrm{C}$ zur Bildung unlöslicher Einschlusskörper (ohne Abbildung).

\subsection{Rückfaltung aus Einschlusskörpern und Reinigung von LipCE}

\subsubsection{Rückfaltung aus Einschlußkörpern}

Die Lipase LipCE wurde aus pET19b::lipCE in E. coli BL21(DE3) exprimiert, die Induktion erfolgte durch Zugabe von 0,5 mM IPTG bei Erreichen einer OD $_{595}$ von 0,5, nach weiteren fünf Stunden Wachstum bei $37^{\circ} \mathrm{C}$ erfolgte die Zellernte. Aus 1 I Kultur wurden Zellen mit einem Feuchtgewicht von 6,4 g geerntet. Anschließend erfolgte die Reinigung der inaktiven, unlöslichen Einschlusskörper unter denaturierenden Bedingungen in Gegenwart von $8 \mathrm{M}$ Harnstoff wie unter [II.8.1] beschrieben. Durch Verdünnen und anschließende Dialyse des Harnstoffs gegen 50 mM NatriumphosphatPuffer mit 5\% (v/v) Glycerin erfolgte zunächst die Rückfaltung des Proteins, unlösliche Bestandteile wurden durch Zentrifugation abgetrennt. Der Erfolg der Rückfaltung wurde vor der weiteren Reinigung durch einen Aktivitätstest auf Tributyrinplatten überprüft und anschließend mit der Reinigung fortgefahren.

\subsubsection{Reinigung mittels Ni-TED-Affinitäts-Chromatographie}

Der so gewonnenen Proteinlösung $(50 \mathrm{ml}$ ) wurde $\mathrm{NaCl}$ bis zu einer Endkonzentration von 0,3 M zugegeben, um geeignete Pufferbedingungen für ein Binden an die fertig gepackten Protino ${ }^{\circledR} 2000$-Säulen der Firma Macherey \& Nagel (Düren) zu gewährleisten. Nach Filtration (Porengröße 0,45 $\mu \mathrm{M}$ ) wurde die Lösung komplett auf die Säule gegeben und das Protein gereinigt [II.8.2]. Das Protein konnte so erfolgreich, aber noch nicht vollständig sauber, in Gegenwart von 250 mM Imidazol von der Säule eluiert werden (Abbildung 39, Spur 2).

\subsubsection{Reinigung mittels Gelfiltration}

Die insgesamt $9 \mathrm{ml}$ Eluat wurden anschließend auf 0,5 $\mathrm{ml}$ mit einer Konzentration von $7 \mathrm{mg} / \mathrm{ml}$ Protein eingeengt [II.6.6] und durch Gelfiltration [II.8.3] bis zur Homogenität gereinigt. Bei der Reinigung von LipCE mittels Gelfiltration wurde ein Elutionsvolumen 
von $77 \mathrm{ml}$ bestimmt, was anhand der Eichgerade [III.2.6.2, Abb. 8] einem Molekulargewicht von 49 kDa entspricht. Das Chromatogramm des Säulenlaufs ist in Abb. 38 dargestellt.

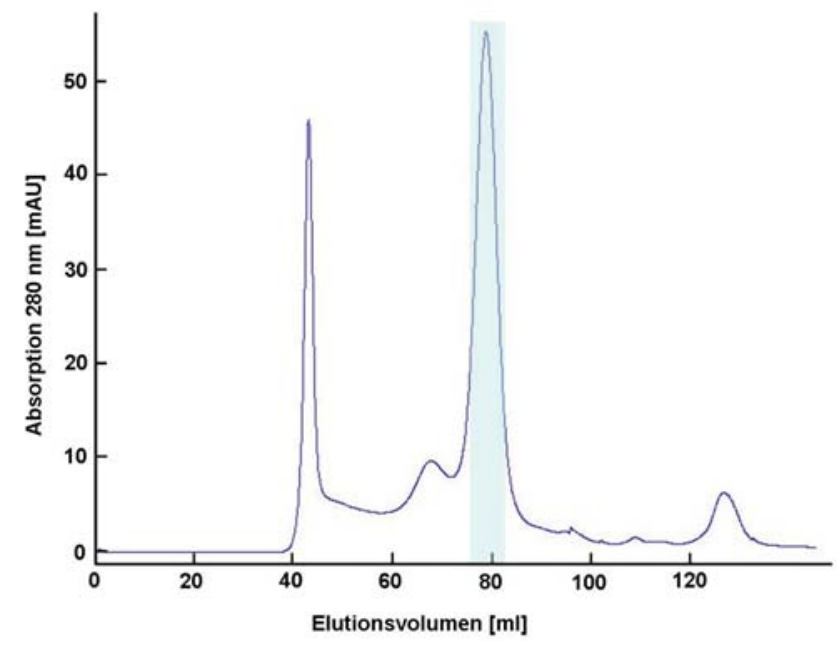

Abb. 38: Chromatogramm des Säulenlaufs der Gelfiltration von LipCE

Die lipolytisch aktiven Fraktionen sind hellblau hinterlegt, Laufparameter siehe [III.2.6.2].

Die Protein enthaltenden Fraktionen wurden mit Tributyrinindikatorplatten auf Aktivität überprüft und die Fraktionen von insgesamt 6 auf $1 \mathrm{ml}$ eingeengt. Bei einer Proteinkonzentration von $1 \mathrm{mg} / \mathrm{ml}$ wurde so insgesamt $1 \mathrm{mg}$ sauberes Protein erhalten. Der gesamte Reinigungsverlauf ist zusammenfassend in Abbildung 39 dargestellt.

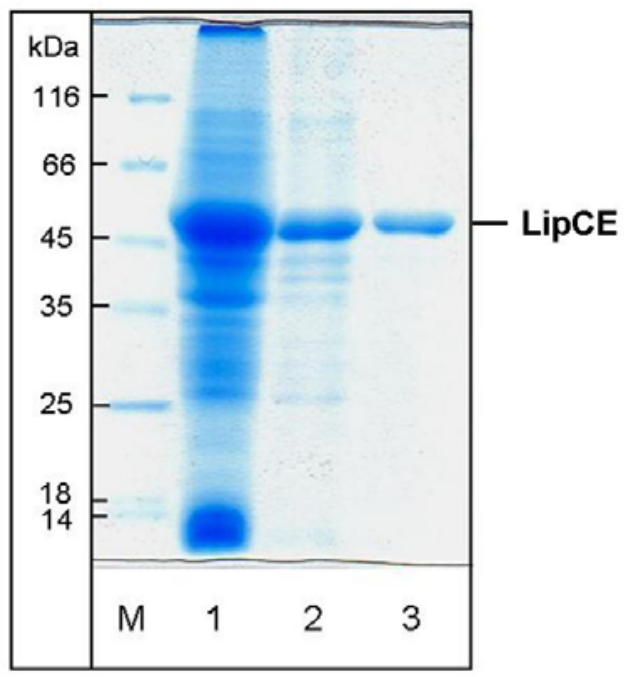

Abb. 39: SDS-PAGE (12\%) des Reinigungsverlaufs der Lipase LipCE

M: „Molecular Weight Marker“ (Fermentas), Spur 1: inaktive Einschlusskörper nach Zellaufschluß, Spur 2: nach Ni-TED-Affinitätschromatographie $(8 \mu \mathrm{g})$, Spur 3: LipCE nach Gelfiltration $(3 \mu \mathrm{g})$. 


\subsection{Biochemische Charakterisierung von LipCE}

\subsubsection{Aktivitätsbasierter Nachweis von LipCE}

Zunächst wurde die Aktivität des gereinigten LipCE-Proteins im Aktivitätsgel durch Tribuytrinhydrolyse [II.9.1] nachgewiesen (Abbildung 40). Das Protein weist unter denaturierenden Bedingungen im SDS-Gel eine Größe von etwa 52 kDa auf, was im Einklang mit der theoretisch erwarteten Größe von 53,2 kDa steht.

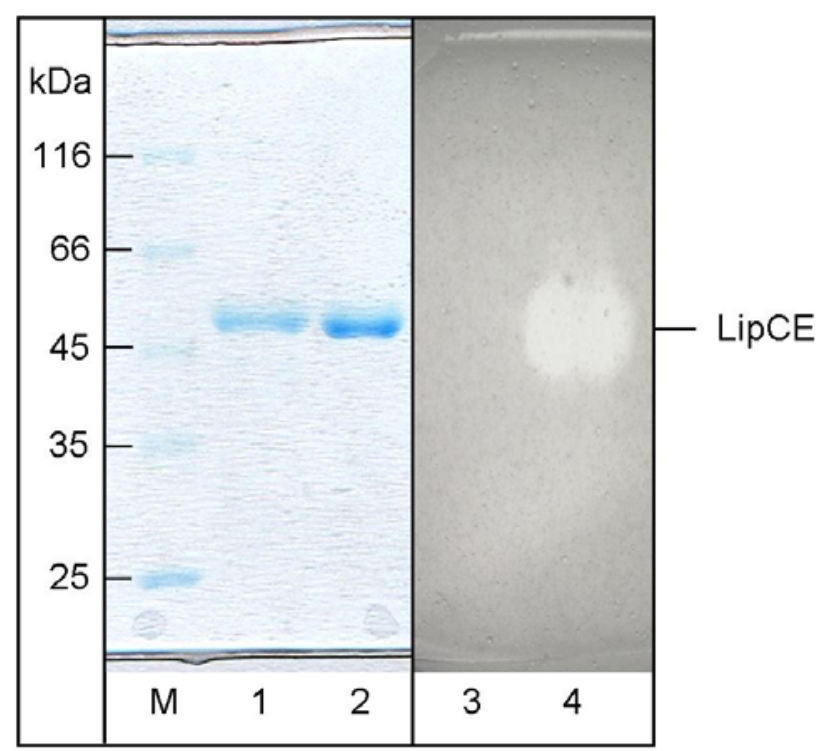

Abb. 40: Aktivitätsgel des gereinigten LipCE-Proteins

Lipolytische Aktivität ist an einer Aufklarung des Tributyrins im Testagar zu erkennen. M: „Molecular Weight Marker“ (Fermentas), Spur 1: LipCE, denaturiert (SDS-Gel), Spur 2: LipCE, nicht denaturiert in nativem Auftragspuffer (SDS-Gel), Spur 3 und 4: wie 1 und 2 (Aktivitätsgel), jeweils $3 \mu \mathrm{g}$.

\subsubsection{Temperaturabhängigkeit der Aktivität von LipCE}

Zur Ermittlung des Temperaturspektrums von LipCE wurde die Lipaseaktivität wie unter [II.9.2.2] beschrieben unter Verwendung der Substrate pNP-Laurat (Kettenlänge C12, Abbildung 41) und pNP-Palmitat (C16, Abbildung 42) bestimmt. Es zeigte sich bei beiden Substraten Aktivität über einen relativ weiten Temperaturbereich, wobei das Aktivitätsmaximum für Laurat bei $30^{\circ} \mathrm{C}$ und für Palmitat bei $25^{\circ} \mathrm{C}$ bestimmt wurde. Unter Verwendung von pNP-Laurat als Substrat konnte bei $0^{\circ} \mathrm{C}$ noch eine Restaktivität von $28 \%$ gemessen werden, selbst bei $-5^{\circ} \mathrm{C}$ wurden noch $16 \%$ Restaktivität gemessen. Der Zusatz von 10\% DMSO, in welchem das Substrat gelöst war, verhinderte bis zu dieser Temperatur das Einfrieren der Lösung. Bei Verwendung von pNP-Palmitat als Substrat konnte unterhalb $5^{\circ} \mathrm{C}$ keine Aktivität mehr gemessen werden, da diese Substratlösung unter den Bedingungen einfror. Bei Temperaturen über $50^{\circ} \mathrm{C}$ war bei beiden Substraten ein sehr rapider Abfall der Aktivität festzustellen. 

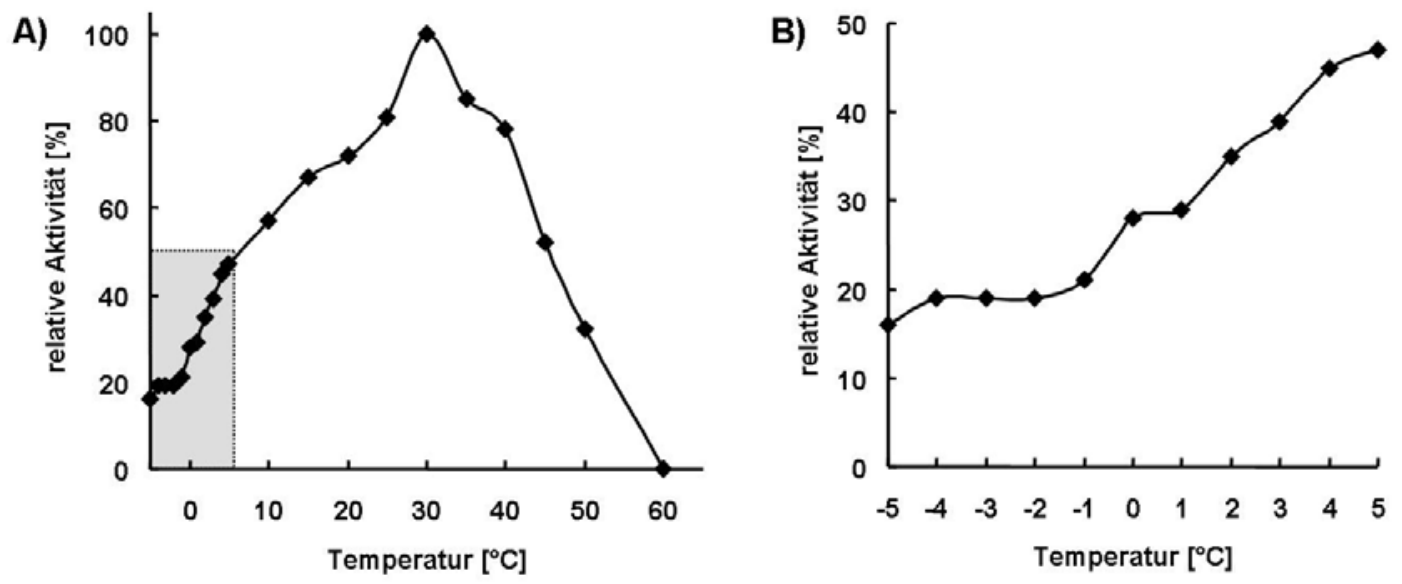

Abb. 41: Temperaturabhängigkeit der Aktivität von LipCE (Substrat pNP-Laurat)

A) Temperaturbereich von -5 bis $65^{\circ} \mathrm{C}$, B) vergrößerter Ausschnitt des in A) grau hinterlegten Bereiches von -5 bis $+5^{\circ} \mathrm{C}$. Reaktionsparameter: $100 \mu$ Substratlösung $(20 \mathrm{mM}$ pNP-Laurat in DMSO) + $900 \mu$ l Sörensenphosphatpuffer, pH 8,0; Inkubationsdauer 10 min.

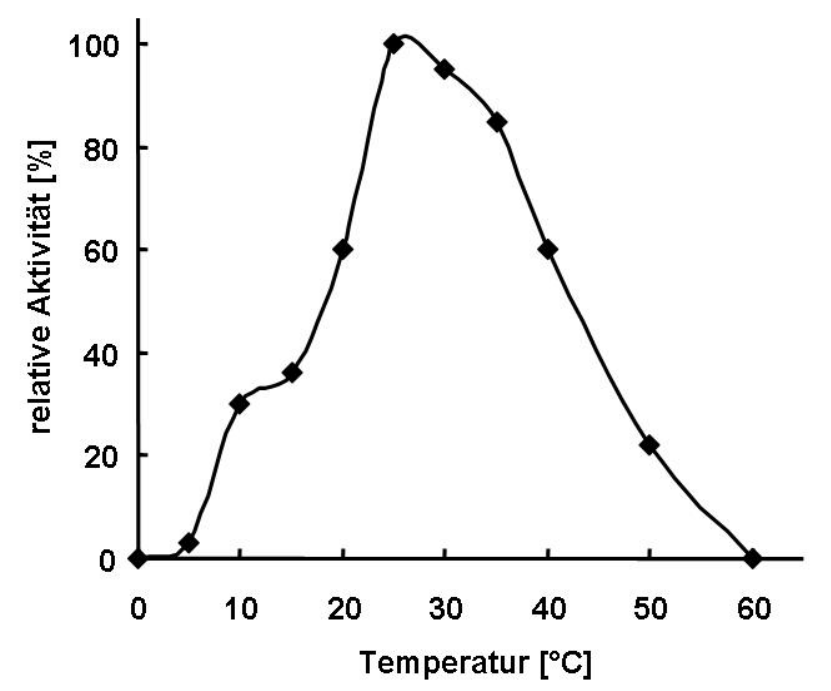

Abb. 42: Temperaturabhängigkeit der Aktivität von LipCE (Substrat pNP-Palmitat)

Reaktionsparameter: $100 \mu \mathrm{l}$ Substratlösung $(20 \mathrm{mM}$ pNP-Palmitat in DMSO $)+900 \mu \mathrm{l}$ Sörensenphosphatpuffer, $\mathrm{pH}$ 8,0; Inkubationsdauer 10 min.

\subsection{3. pH-Abhängigkeit der Aktivität von LipCE}

Unter Verwendung des Substrates pNP-Laurat wurde bei verschiedenen pH-Werten und Verwendung von drei verschiedenen Puffersystemem der optimale pH-Wert des Enzyms bei einer Temperatur von $25^{\circ} \mathrm{C}$ ermittelt [II.9.4]. Aktivität war nur in einem pHBereich von 6 bis 9 messbar mit einem Optimum bei pH 7 (Abb. 43). 


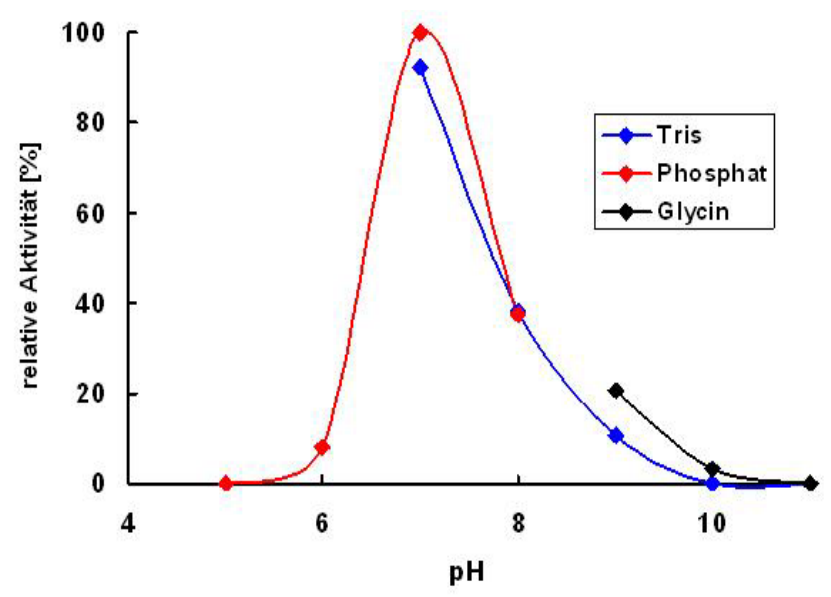

Abb. 43: pH-Anhängigkeit der Aktivität von LipCE

Die Aktivität wurde unter Verwendung von drei verschiedenen Puffersystemen (Na-Phosphat, $\mathrm{pH}$ 4-8, Tris, $\mathrm{pH}$ 7-11 und Glycin, $\mathrm{pH}$ 9-11, je 2,5 mM) und pNP-Laurat (2 mM) als Substrat bestimmt. Inkubationsdauer $10 \mathrm{~min}$, Inkubationstemperatur $25^{\circ} \mathrm{C}$. Alle Werte sind relativ zum höchsten angegeben.

\subsubsection{Aktivität von LipCE in Abhängigkeit von der Substratkettenlänge}

Die Aktivität von LipCE wurde unter Verwendung verschiedener pNP-Substrate mit Kettenlängen von $\mathrm{C} 2$ bis $\mathrm{C} 18$ bei einer Temperatur von $25^{\circ} \mathrm{C}$ wie unter [II.9.2.2] beschrieben bestimmt. Die höchste Aktivität mit 2020 U/mg Protein wurde bei einer Kettenlänge von C10 (Caprat) gemessen. Ebenfalls hohe Aktivitäten wurden bei langkettigen Substraten mit einer Kettenlänge von C12 (Laurat, 1383 U/mg), C14 (Myristat, $858 \mathrm{U} / \mathrm{mg}$ ), C16 (Palmitat, $925 \mathrm{U} / \mathrm{mg}$ ), C18 (Stearat, $686 \mathrm{U} / \mathrm{mg}$ ). Bei kürzerkettigen Fettsäureresten sank die Umsetzung dann bis hin zu C4 (Butyrat, 410 $\mathrm{U} / \mathrm{mg}$ ). pNP-Acetat (C2) wurde kaum umgesetzt, hier betrug die Aktivität nur noch 86 U/mg, was $4 \%$ der höchsten gemessenen Aktivität entspricht (Abb. 44).

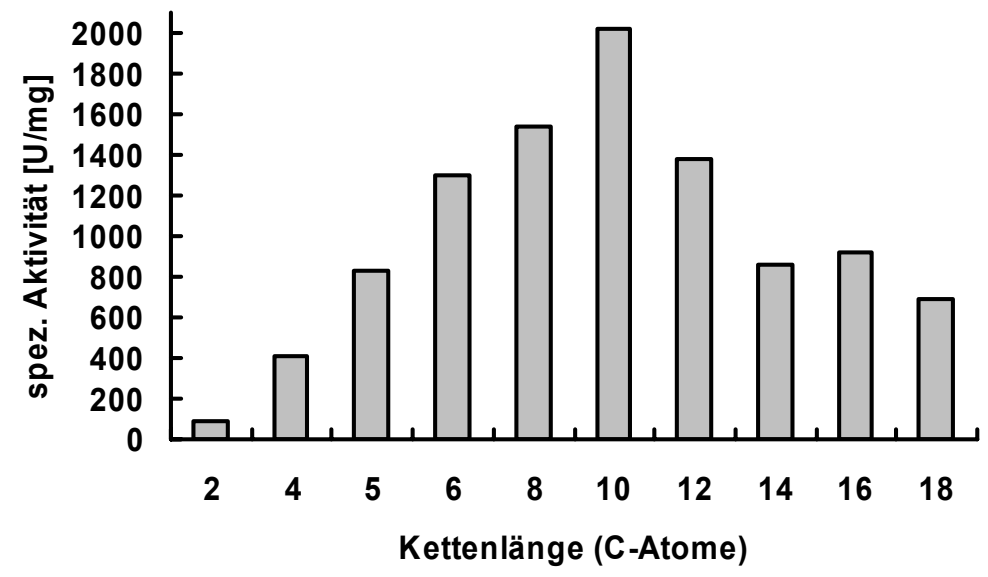

Abb. 44: Abhängigkeit der Aktivität von der Substratkettenlänge bei Verwendung geradkettiger pNP-Acylester 


\subsubsection{Temperaturstabilität von LipCE}

Zur Bestimmung der thermischen Stabilität von LipCE wurde das Enzym bei verschiedenen Temperaturen vorinkubiert und anschließend unter Verwendung von pNP-Laurat bei $25^{\circ} \mathrm{C}$ die Restaktivität ermittelt (Abb. 45). Es zeigte sich, dass das Enzym bei Temperaturen über $20^{\circ} \mathrm{C}$ sehr schnell inaktiviert wurde. Bei $50^{\circ} \mathrm{C}$ und $60^{\circ} \mathrm{C}$ waren bereits nach fünf Minuten nur noch 6\% Restaktivität bzw. gar keine Aktivität mehr nachweisbar. Bei $40^{\circ} \mathrm{C}$ sank die Restaktivität nach fünf Minuten auf $50 \%$ und war nach 30 Minuten nicht mehr nachweisbar. Bei einer Vorinkubationstemperatur von $30^{\circ} \mathrm{C}$ bzw. $20^{\circ} \mathrm{C}$ war die Restaktivität nach 10 bzw. 30 Minuten auf die Hälfte abgesunken. Nach über zwei Monaten Lagerung bei $4^{\circ} \mathrm{C}$ betrug der Aktivitätsverlust hingegen weniger als $15 \%$.

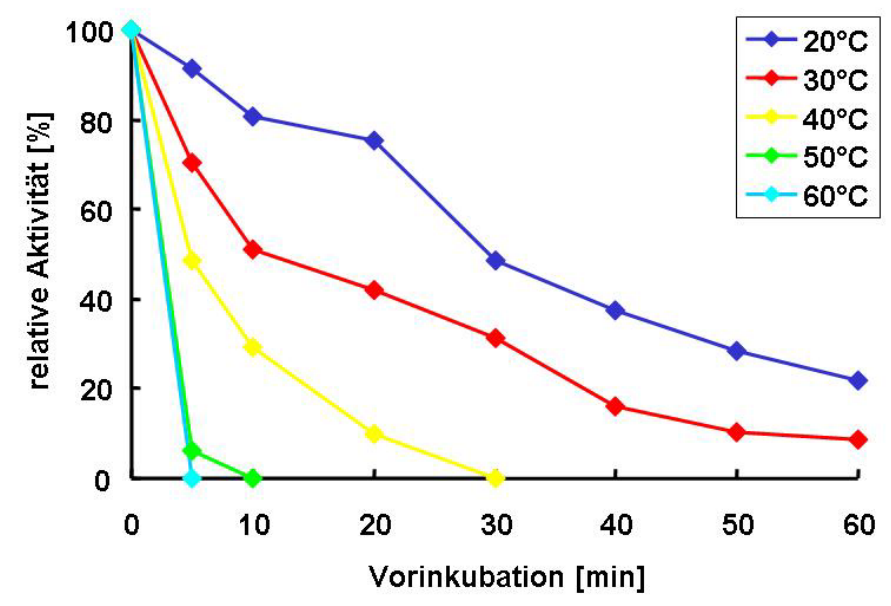

Abb. 45: Restaktivität nach Vorinkubation bei verschiedenen Temperaturen

Die restliche Aktivität wurde mit pNP-Laurat als Substrat bei einer Temperatur von $25^{\circ} \mathrm{C}$ bestimmt. Die Vorinkubation erfolgte bei den Temperaturen wie in der Legende angegeben.

\subsubsection{Einfluss von Lösungsmitteln auf die Aktivität von LipCE}

Mit pNP-Laurat als Substrat wurde der Einfluss von Lösungsmitteln in Konzentrationen von $15 \%$ bzw. $30 \%$ (v/v) auf die Aktivität von LipCE bestimmt. Die Gegenwart von $15 \%$ 2-Butanol und Chloroform inhibierte die Aktivität komplett, stark inhibierend wirkten in der Konzentration auch Acetonitril (16\% Restaktivität) und 1-Propanol (13\%), 2-Propanol reduzierte die Aktivität auf $76 \%$. Kaum Einfluss bei einer Konzentration von $15 \%$ hatten hingegen Methanol, Ethanol, Glycerin, Aceton und Dimethylformamid, wohingegen DMSO die Aktivität auf $130 \%$ steigerte. In Gegenwart von 30\% Lösungsmittel wurde die Aktivität bei 2-Butanol, Chloroform, 1-Propanol und Acetonitril komplett inhibiert, stark inhibiert wurde sie dabei von 2-Propanol (14\% Restaktivität) und Aceton (39\%), DMF reduzierte die Aktivität auf $71 \%$. Methanol und Ethanol 
beeinflussten die Aktivität kaum und DMSO (146\%) und Glycerin (131\%) steigerten die Aktivität (Tab. 14).

Tab. 14: Einfluss von Lösungsmitteln auf die Aktivität von LipCE

Die Aktivität von LipCE wurde mit pNP-Laurat in Gegenwart von 15\% bzw. $30 \%$ der angegebenen Lösungsmittel bestimmt. Die Aktivität ohne Lösungsmittel wurde hierbei als $100 \%$ gesetzt.

\begin{tabular}{lcc}
\hline Lösungsmittel & $\begin{array}{c}\text { Restaktivität [\%] } \\
15 \%(\mathrm{v} / \mathrm{v})\end{array}$ & $\begin{array}{c}\text { in } \\
\text { 2-Butanol }\end{array}$ \\
Chloroform & 0 & 0 \\
Methanol & 0 & 0 \\
Ethanol & 111 & 104 \\
Glycerin & 109 & 105 \\
DMSO & 107 & 131 \\
Acetonitril & 130 & 146 \\
Aceton & 16 & 0 \\
1-Propanol & 97 & 39 \\
2-Propanol & 13 & 0 \\
DMF & 76 & 14 \\
\hline
\end{tabular}

\subsubsection{Einfluss verschiedener Kationen, EDTA und PMSF auf die Aktivität von LipCE}

Der Einfluss verschiedener ein- und zweiwertiger Kationen sowie EDTA und PMSF in Konzentrationen von 1 bis $10 \mathrm{mM}$ auf die Aktivität wurde mit pNP-Laurat als Substrat bei $25^{\circ} \mathrm{C}$ getestet. Die meisten Salze beeinflussten die Aktivität kaum, $\mathrm{Fe}^{2+}, \mathrm{Fe}^{3+}$ sowie $\mathrm{Cu}^{2+}$ hemmten die Aktivität vollständig. Ein hemmender Einfluss wurde bei $\mathrm{Zn}^{2+}(39 \%$ Restaktivität, $10 \mathrm{mM})$ und $\mathrm{Co}^{2+}(56 \%, 10 \mathrm{mM})$ sowie EDTA $(38 \%, 10 \mathrm{mM})$ gefunden. Phenylmethansulfonylfluorid (PMSF), ein Inhibitor von Serinproteasen inhibierte die Aktivität, allerdings nicht vollständig, so dass bei $10 \mathrm{mM}$ noch $13 \%$ Restaktivität gemessen wurden. Einzig $\mathrm{Ca}^{2+}$ war in der Lage, die Aktivität um ein Vielfaches zu steigern (III.4.6.8). Sämtliche Daten sind in Tabelle 15 zusammengefaßt. 
Tab. 15: Einfluss verschiedener Salze sowie PMSF auf die Aktitvität von LipCE

Die Aktivität ist bezogen in \% auf die Aktivität ohne Zusätze $(=100 \%)$ angegeben, n.b.=nicht bestimmt. Der Einfluss von $\mathrm{Ca}^{2+}$ ist in Kapitel III.4.6.8 separat beschrieben.

\begin{tabular}{lccc}
\hline Kation & \multicolumn{3}{c}{ Konzentration } \\
& $1 \mathrm{mM}$ & $5 \mathrm{mM}$ & $10 \mathrm{mM}$ \\
\hline $\mathrm{Cd}^{2+}$ & 105 & 99 & 88 \\
$\mathrm{Na}^{+}$ & 100 & 100 & 79 \\
$\mathrm{~K}^{+}$ & 102 & 100 & 106 \\
$\mathrm{Li}^{+}$ & 104 & 95 & 102 \\
$\mathrm{Fe}^{2+}$ & 0 & 0 & 0 \\
$\mathrm{Fe}^{3+}$ & 26 & 0 & 0 \\
$\mathrm{Cu}^{2+}$ & 46 & 18 & 0 \\
$\mathrm{Mg}^{2+}$ & 97 & 99 & 105 \\
$\mathrm{Zn}^{2+}$ & 66 & 53 & 39 \\
$\mathrm{Mn}^{2+}$ & 89 & 92 & 86 \\
$\mathrm{Ba}^{2+}$ & 98 & 101 & 104 \\
$\mathrm{Co}^{2+}$ & 80 & 67 & 56 \\
$\mathrm{EDTA}$ & 57 & 41 & 38 \\
$\mathrm{PMSF}^{2+}$ & 99 & n.b. & 13 \\
\hline
\end{tabular}

\subsubsection{Einfluss von Calcium auf die Aktivität von LipCE}

Bei Zugabe von $\mathrm{Ca}^{2+}$ in Konzentrationen von $1 \mathrm{mM}$ konnte bereits ein vielfacher Anstieg der Aktivität beobachtet werden. Um diesen Effekt zu quantifizieren wurden die durchschnittlichen Reaktionsgeschwindigkeiten der Umsetzung mit pNP-Laurat als Substrat bei $25^{\circ} \mathrm{C}$ für 1 min bestimmt. $\mathrm{CaCl}_{2}$ wurde in Konzentrationen von $1 \mu \mathrm{M}$ bis 10 $\mathrm{mM}$ zugegeben. Bereits bei $\mathrm{Ca}^{2+}-$ Konzentrationen von $10 \mu \mathrm{M}$ ist eine 5,3 fache Zunahme der Reaktionsgeschwindigkeit festzustellen, die größte Steigerung ist bei einer $\mathrm{Ca}^{2+}$-Konzentration von $5 \mathrm{mM}$ um den Faktor $88 \mathrm{zu}$ beobachten, bei steigenden Konzentrationen nimmt dieser Effekt wieder leicht ab (Abb. 46). Durch EDTA-Zugabe in gleichen Konzentrationen wurde dieser Effekt wieder aufgehoben. 


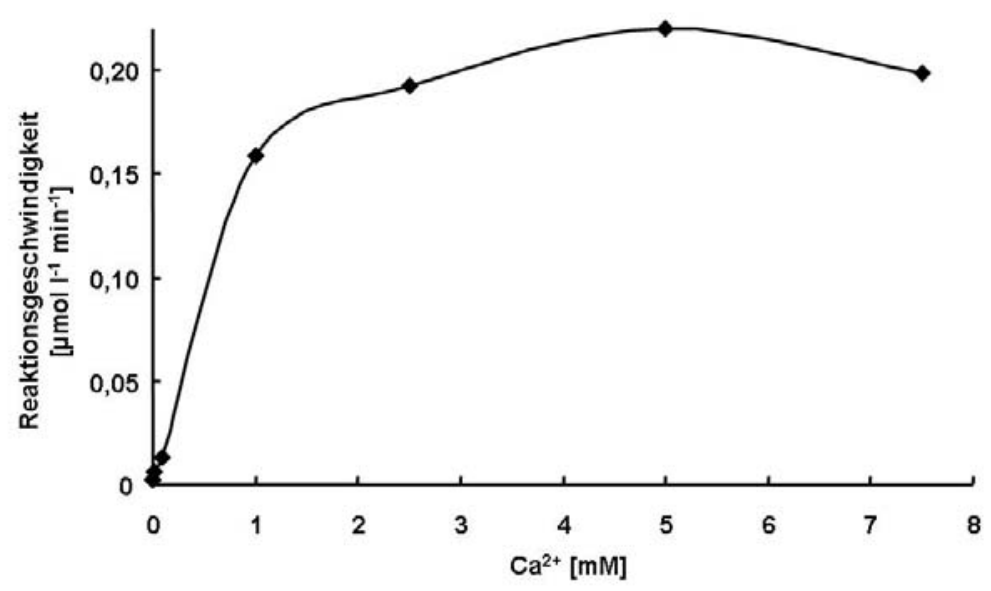

Abb. 46: Abhängig der Reaktionsgeschwindigkeit von der $\mathrm{Ca}^{2+}-$ Konzentration In Gegenwart verschiedener $\mathrm{Ca}^{2+}-$ Konzentrationen wurde die Reaktionsgeschwindigkeit von LipCE mit pNP-Laurat als Substrat ermittelt.

\subsubsection{Einfluss von Calcium auf die Stabilität von LipCE}

LipCE wurde bei Temperaturen von $40^{\circ} \mathrm{C}$ und $50^{\circ} \mathrm{C}$, bei denen das Protein relativ schnell inaktiviert wird, für eine Stunde ohne $\mathrm{Ca}^{2+}$ und in Gegenwart von $5 \mathrm{mM} \mathrm{Ca}^{2+}$ inkubiert und alle 10 min die Restaktivität mit pNP-Laurat als Substrat gemessen. Bei $50^{\circ} \mathrm{C}$ in Gegenwart von $\mathrm{Ca}^{2+}$ wurde die Aktivität erst nach 30 min komplett inaktiviert, was ohne $\mathrm{Ca}^{2+}$ bereits nach 10 min geschah (Abb.47a). Bei einer Inkubation von $40^{\circ} \mathrm{C}$ mit $\mathrm{Ca}^{2+}$ wurde über einen Zeitraum von 40 min kaum Aktivitätsverlust beobachtet (Restaktivität 86\%), erst danach war eine Inaktivierung zu beobachten, nach einer Stunde betrug die Restaktivität noch immer $35 \%$. Ohne $\mathrm{Ca}^{2+}$ war eine komplette Inaktivierung bereits nach 30 min zu beobachten (Abb 47b).
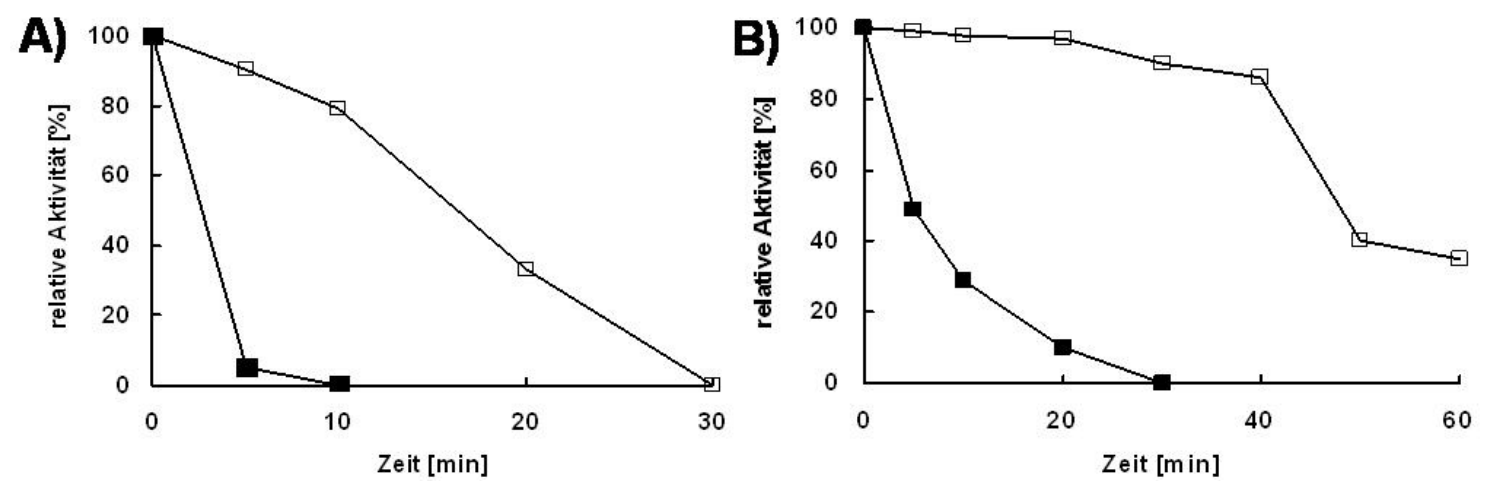

Abb. 47: Einfluss von $\mathrm{Ca}^{2+}$ auf die thermische Stabilität von LipCE

Das Protein wurde ohne $\mathrm{Ca}^{2+}(\square)$ und in Gegenwart von $5 \mathrm{mM} \mathrm{Ca}^{2+}(\square)$ bei $50^{\circ} \mathrm{C}(\mathrm{A})$ und $40^{\circ} \mathrm{C}$ (B) vorinkubiert und die restliche Aktivität mit pNP-Laurat als Substrat bestimmt. 


\subsubsection{Untersuchungen zum Einfluss von Calcium auf die Sekundärstruktur mittels CD-Spektroskopie}

Bei einer Proteinkonzentration von $0,1 \mathrm{mg} / \mathrm{ml}$ in $20 \mathrm{mM}$ Tris-Puffer, pH8 (Schichtdicke $0,1 \mathrm{~cm}$ ), wurden von LipCE Fern-UV-CD-Spektren in Abwesenheit und in Gegenwart von $5 \mathrm{mM} \mathrm{CaCl}_{2}$ aufgenommen (CD-Spectrometer 62 ADS, AVIV Biomedical Inc., USA). Die Messung der Spektren erfolgte bei Raumtemperatur. Bei Zugabe von $\mathrm{CaCl}_{2}$ veränderte sich das CD-Spektrum im Wellenlängenbereich zwischen 205 und 235 nm sichtbar (Abb. 48), was auf Änderungen in der Sekundärstruktur des Proteins hinweist. Für genauere Aussagen hinsichtlich des Anteils der jeweiligen Sekundärstrukturen bedarf es jedoch noch einer Verfeinerung. Die Messungen wurden in der AG Theoretische Chemie der Universität Duisburg-Essen (Prof. Buß) durchgeführt.

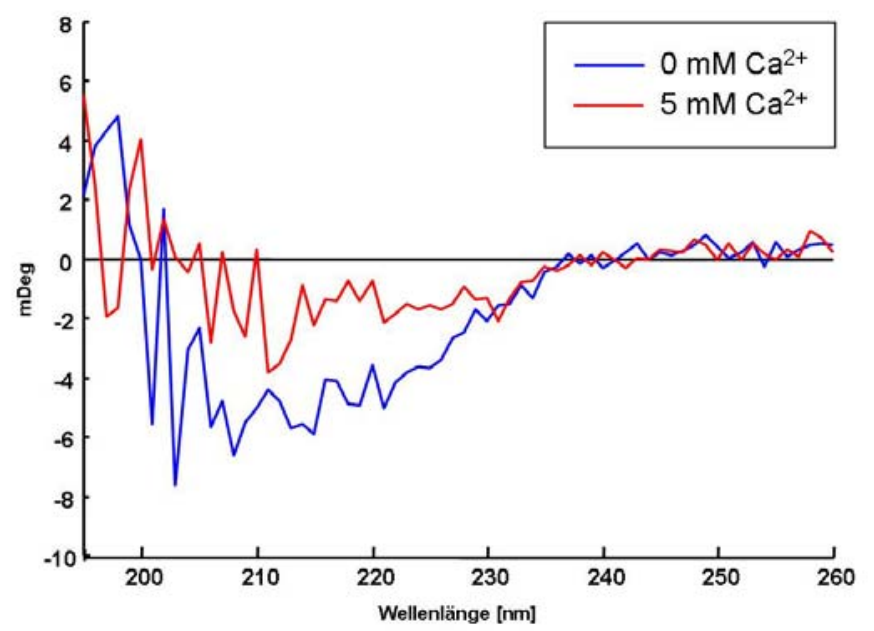

Abb. 48. Fern-UV-CD-Spektren von LipCE in Abwesenheit und Gegenwart von $\mathrm{Ca}^{2+}$

\subsubsection{Kinetische Daten}

Bedingt durch ihren Reaktionsmechanismus folgen viele Lipasen keiner klassischen Michaelis-Menten-Kinetik (Verger, 1976) wie sie bei EstCE zu beobachten war (vgl. III.2.7.10), sondern zeigen mit dem Erreichen der kritischen Mizellenkonzentration des Substrates einen sprunghaften Anstieg der Aktivität, man spricht von Grenzflächenaktivierung oder Interphasenaktivierbarkeit. Dieses Phänomen war auch bei LipCE zu beobachten. Getestet wurden die Substrate pNP-Caprat, pNP-Laurat, pNP-Myristat und pNP-Palmitat bei einer Reaktionstemperatur von $20^{\circ} \mathrm{C}$ (Abb. 49), wobei das Phänomen bei pNP-Myristat am ausgeprägtesten zu beobachten war. Hier erfolgte ein starker Anstieg der Aktivität ab einer Substratkonzentration von 0,5 mM. Bei keinem der getesteten Substrate konnte eine Sättigung bis zum getesteten Bereich von $2 \mathrm{mM}$ beobachtet werden. 


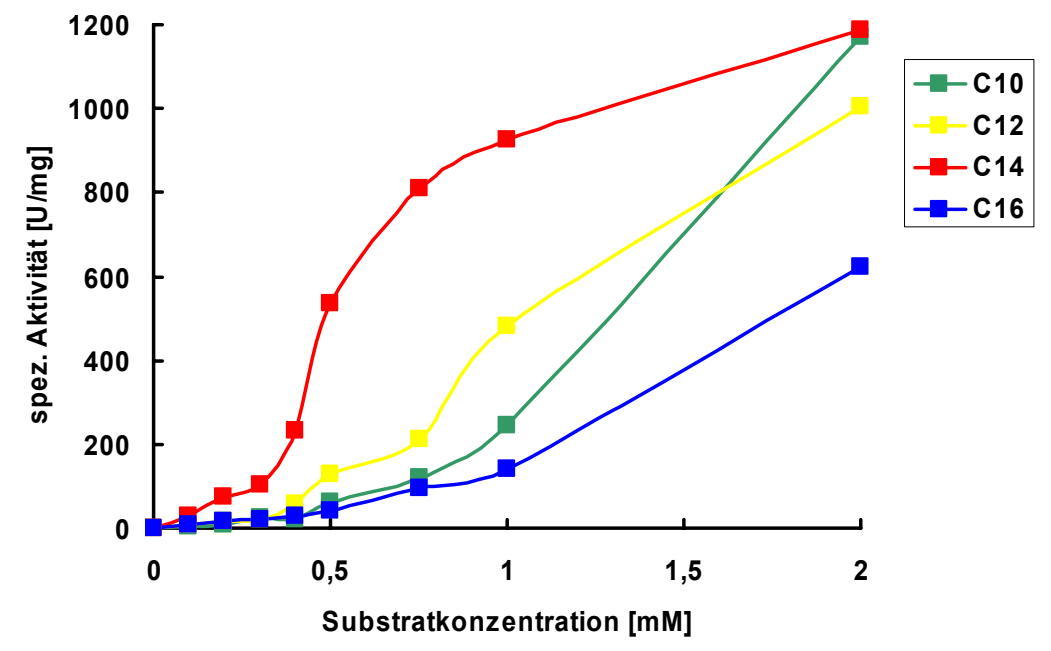

Abb. 49: Enzymkinetik der Umsetzung verschiedener pNP-Ester durch LipCE.

Die Enzymaktivität wurde bei Substratkonzentrationen von 0,1 bis $2 \mathrm{mM}$ für vier verschiedene Substrate unterschiedlicher Kettenlängen gestet. Parameter: $100 \mu \mathrm{l} \mathrm{Substrat} \mathrm{(10x} \mathrm{konz.} \mathrm{in}$ DMSO), $900 \mu$ S Sörensenphosphatpuffer pH 8, Inkubationsdauer 10 min, Temperatur $20^{\circ} \mathrm{C}$.

\subsubsection{Stereospezifische Umsetzungen biotechnologisch relevanter Substrate}

Von den 11 pNP-Estern verschiedener Säurereste (Anhang, Abb. 65) konnte LipCE die in Tab. 16 aufgelisteten pNP-Ester umsetzen, was durch spektrophotometrische Messungen bestimmt wurde. Die Umsetzung von pNP-Ibuprofen wurde detaillierter untersucht. In 4 h Reaktionszeit setzte LipCE racemisches pNP-Ibuprofen zu 47\% um [II.9.6.2]. Es wurde ein Enantiomerenüberschuß von $>91 \%$ zugunsten von $(R)$ Ibuprofen gemessen, was einem E-Wert von 55 entspricht [II.9.6.3]. Die Umsetzung von Naproxen konnte nicht detaillierter bestimmt werden, die Enantioselektivität liegt jedoch auch hier bei (R)-Naproxen, da pNP-(S)-Naproxen nicht umgesetzt wurde, racemisches pNP-Naproxen hingegen schon.

Tab. 16: Aktivität von LipCE mit pNP-Estern verschiedener Säurereste

\begin{tabular}{lc}
\hline Substrat & $\begin{array}{c}\text { Aktivität } \\
{[\mathrm{U} / \mathrm{mg}]}\end{array}$ \\
\hline pNP-Ibuprofen & 0,36 \\
pNP-2-Phenylpropanoat & 0,28 \\
pNP-3-Phenylbutanoat & 3,14 \\
pNP-Cyclohexanoat & 2,22 \\
pNP-Naproxen & 0,03 \\
pNP-(S)-Naproxen & 0 \\
\hline
\end{tabular}


Weiterhin wurden 10 Ester verschiedener Alkohole getestet (Tab. 17). Hierbei wurde durch GC-Analysen gefunden, dass LipCE spezifisch Ester primärer Alkohole umsetzt, Ester der untersuchten sekundären und tertiären Alkohole hingegen gar nicht. Enantioselektivitäten wurden bislang noch nicht bestimmt. Die Strukturfomeln sämtlicher Substrate finden sich im Anhang (Abb. 64).

Tab. 17: Umsetzung von Estern verschiedener Alkoholkomponenten durch LipCE

\begin{tabular}{|c|c|c|}
\hline \multirow[b]{2}{*}{ Substrat } & \multicolumn{2}{|c|}{ Substratumsetzung [\%] nach } \\
\hline & $3 \mathrm{~h}$ & $24 \mathrm{~h}$ \\
\hline 1-Oktylacetat & 21,2 & n.b. \\
\hline$(R, S)-2-O k t y l a c e t a t$ & 0 & 0 \\
\hline$(R, S)-3-O k t y l a c e t a t$ & 0 & 0 \\
\hline$(R, S)-1-$ Phenylacetat & 0 & 0 \\
\hline$(R, S)-1-C y c l o h e x y l e t h y l a c e t a t$ & 0 & 0 \\
\hline a-Terpinyl-Caprylat & 0 & 0 \\
\hline$(R, S)-I P G-A c e t a t$ & 0 & 2 \\
\hline 2,3-Glycerindibutylether-Acetat & 23,7 & n.b. \\
\hline$(R, S)-1-(2-$ Naphtyl)-ethylacetat & 0 & 0 \\
\hline$(R, S)$-beta-Citronollylacetat & 5,4 & 43 \\
\hline
\end{tabular}

Die GC-Untersuchungen und die Untersuchungen der Umsetzungen der Ester verschiedener Alkoholreste erfolgten am Max-Planck-Institut für Kohlenforschung (AG Prof. Reetz, Mülheim a.d.R.).

\subsubsection{3. „Enzymatischer Fingerabdruck“ von LipCE}

Für LipCE wurde analog zu EstCE (III.2.7.9) in Zusammenarbeit mit der Arbeitsgruppe Prof. J.-L. Reymond (Universität Bern) ein „enzymatischer Fingerabdruck“ erstellt. Die Anordnung der Substrate sowie die zugehörigen Strukturen entsprechen denen in Abbildung 25. Bei den Ergebnissen von EstCE (Abb. 50, links) ist zu sehen, dass Substrat Nummer 2, ein primärer Ester (4-(3-Octylcarboxy-(2-hydroxy-propyloxy))coumarine) am stärksten umgesetzt wurde, der Gesamtumsatz betrug 57\%, was am Kästchen unten rechts abzulesen ist. Drei der vier Neopentylester (mittlere Reihe) wurden ebenfalls recht stark umgesetzt, wohingegen bei den sterisch gehinderten sekundären Estern kein Umsatz gefunden wurde. Auch bei diesen Versuchen wurde der Einfluss von Calcium auf das Enzym untersucht. Dem Reaktionsansatz wurde 
$\mathrm{CaCl}_{2}$ in einer Konzentration von $10 \mathrm{mM}$ zugesetzt, was auf das Umsetzungsmuster der Substrate keinen großen Einfluss hatte (Abb. 50, rechts). Hier wurde die Reaktion allerdings nach 30 Sekunden gestoppt, der Umsatz des am stärksten umgesetzten Substrates (Substrat 2) war mit 54\% ähnlich hoch wie beim Ansatz ohne Calcium, wobei die Inkubationszeit das 30 fache betrug. Bei einer Inkubationstemperatur von $0^{\circ} \mathrm{C}$ wurde derselbe Effekt beobachtet, allerdings waren die Gesamtumsätze mit 33\% (0mM $\mathrm{Ca}^{2+}, 30$ min Inkubation) bzw. 31\% (10 $\left.\mathrm{mM} \mathrm{Ca}^{2+}, 2 \mathrm{~min}\right)$ niedriger als bei $22^{\circ} \mathrm{C}$ (ohne Abbildung).

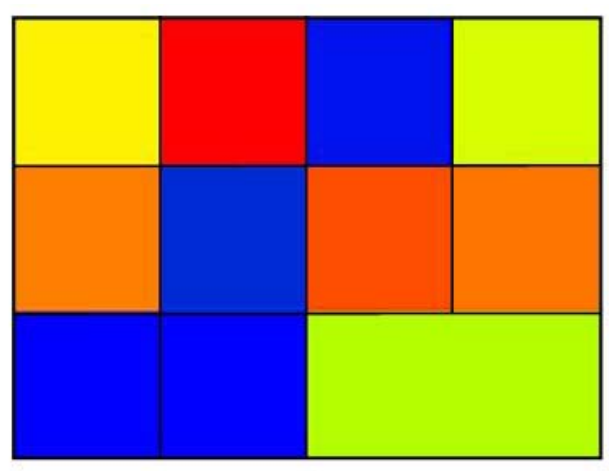

$0 \mathrm{mMCa}{ }^{2+}, 15 \mathrm{~min}$

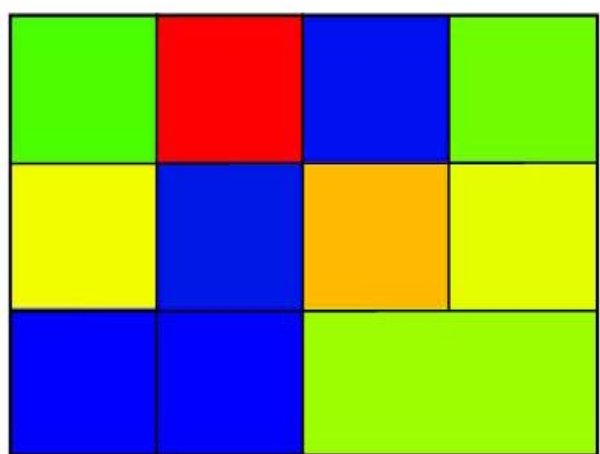

$10 \mathrm{mM} \mathrm{Ca}^{2+}, 30$ sek

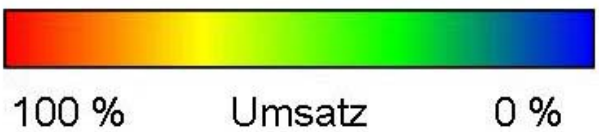

\section{Abb. 50: „Enzymatischer Fingerabdruck“ der Lipase LipCE}

Die Anordnung der Kästchen entspricht den Substraten in Abbildung 25. Die stärkste Umsetzung (Substrat 2) wurde rot gefärbt, alle anderen relativ dazu in den gezeigten Farbschattierungen der unten angegeben Farbskala. Der Fingerabdruck wurde bei $22^{\circ} \mathrm{C}$ in Gegenwart (rechts) und Abwesenheit (links) von $\mathrm{Ca}^{2+}$ erstellt. Aufgrund der höheren Aktivität in Gegenwart von $\mathrm{Ca}^{2+}$ wurden die Ansätze unterschiedlich lange inkubiert. Der Umsatz des am stärksten umgesetzten Substrates ist in den unteren beiden Kästchen wiedergegeben und lag bei $57 \%\left(\right.$ ohne $\mathrm{Ca}^{2+}$ ) bzw. 54\% (mit $\left.\mathrm{Ca}^{2+}\right)$.

Auch LipCE ließ sich anhand des Musters der Substratumsetzung mit einer Palette kommerzieller Lipasen vergleichen (vgl. III.2.7.9). Hierbei fand sich Ähnlichkeit zu Lipasen eukaryontischen Ursprungs aus Mucor javanicus (MJL) und Rhizomucor miehei (RML) (ohne Abbildung). 


\section{Sequenzbasiertes Screening nach neuen Lipasen}

\subsection{Zielsetzung und Stand der Vorarbeiten}

Neben dem aktivitätsbasierten Suchen nach neuartigen potentiellen Biokatalysatoren sollte zudem ein sequenzbasiertes Testsystem entwickelt werden, um Enzyme unabhängig von der Klonierung der metagenomischen DNA zu detektieren und isolieren zu können.

Methoden, die sich hierfür anbieten sind z. B. die Anwendung von PCR mit degenerierten Primern oder Hybridisierungen mit Sonden die komplementär zu konservierten Bereichen der gesuchten Enzyme sind. Ziel war es, für diese Suche einen DNA-Microarray zu entwickeln. Erste Versuche, dies mit Hilfe von Oligonukleotiden zu tun, welche gegen bestimmte konservierte Bereiche der Lipasen gerichtet waren, verliefen bislang nicht erfolgreich (Leggewie, 2005). Als konservierte Regionen wurden dafür das typische Lipasepentapeptid G-x-S-x-G mit dem katalytisch aktiven Serin sowie das „oxyanion hole“ gewählt, welches beim katalytischen Schritt an der Stabilisierung des Übergangszustandes beteiligt ist (Jäger et al., 1999). Hierfür wurden Oligonukleotide mit einer Länge von 18 bzw. 21 bp abgeleitet, die somit einen kodierenden Bereich von 6 bzw. 7 AS abdeckten. Auch wenn dies die am stärksten konservierten Bereiche bei Lipasen darstellen und nur vier Organismen ausgewählt wurden (E. coli, P. aeruginosa, Agrobacterium tumefaciens und Corynebacterium glutamicum) war die Varianz im GC-Gehalt dieser kurzen Oligonukleotide noch immer zu hoch. Der GC-Gehalt der einzelnen Oligos lag zwischen 56\% und 83\%, was zu Schmelztemperaturen von $58^{\circ} \mathrm{C}$ bis $70^{\circ} \mathrm{C}$ führte. Aufgrund der Kürze der Oligonukleotide war eine Varianz innerhalb der Sequenz nur sehr begrenzt möglich wodurch keine einheitliche Schmelztemperatur gefunden werden konnte. Dies wäre aber nötig gewesen, um einheitliche Temperaturbedingungen für die Hybridisierung zu schaffen, so dass selbst Hybridisierungen mit DNA von Reinkulturen als Positivkontrolle nicht immer die erwarteten Ergebnisse brachten.

Um diesem Nachteil der variierenden GC-Gehalte bei der Verwendung unterschiedlicher Organismen als Vorlage zu minimieren, wurden in diesem Ansatz PCR-Produkte mit einer mittleren Länge von etwa 500 bp gewählt. Somit sollte das Problem der Oligonukleotide umgangen werden und mehr Spielraum beim Design der Sonden-DNA zur Verfügung stehen. 


\subsection{Auswahl der Zielsequenzen}

In der ERGO-Datenbank (www.integrated-genomics.com) und der NCBI-Datenbank wurden aus den vorhandenen Genomsequenzen unter der Stichwortsuche "Lipase“ bzw. „Esterase“ insgesamt 103 verschiedene Gene ausgewählt, die als lipolytisch bzw. hydrolytisch klassifiziert wurden und deren biochemische Aktivität größtenteils nachgewiesen war. Mit Ausnahme von zwei Metagenomlipasen, die über $\beta$-Laktamasestrukturmotive verfügten, besaßen alle ausgewählten Enzyme ein Pentapapetid der Struktur G-x-S-x-G oder A-x-S-x-G, letzteres ist häufig in Lipasen aus der Gattung Bacillus zu finden. Dabei wurde darauf geachtet, ein phylogenetisch möglichst breites Spektrum an Organismen abzudecken. Den Großteil machten hierbei Eubacteria (34) aus, dazu kamen drei Archaea sowie drei Hefen. Die hierfür verwendeten Organismen sowie die ausgewählten Lipasen und Esterasen sind in Tab. 18 wiedergegeben. Insgesamt wurden 103 Lipase- und Esterasegene sowie drei Negativkontrollen (Hefegene) ausgewählt. Die Primer für das zu amplifizierende PCRProdukt wurden so gewählt, dass das jeweilige aktive Zentrum mit dem konservierten Pentapeptid mittig in dem PCR-Produkt liegt. Zudem sollten sie für die Amplifikation, soweit möglich, eine Anlagerungstemperatur von $60^{\circ} \mathrm{C}$ aufweisen, um möglichst viele Produkte simultan amplifizieren zu können.

Die durchschnittliche Größe der gewählten Fragmente lag bei 512 bp, Ausnahmen lagen bei 302 bp für das kleinste und 909 bp für das größte Fragment. 80\% der PCRProdukte wiesen eine Größe zwischen 500 und 600 bp auf (Abbildung 51A). Der GCGehalt der PCR-Produkte betrug im Durchschnitt 58,1\% (Abbildung 51B), wobei durch die große Bandbreite an Organismen die Spanne von 28,1\% (Candida albicans Gen 6695 ) bis $74 \%$ (Ralstonia eutropha Gen 1991) reichte.
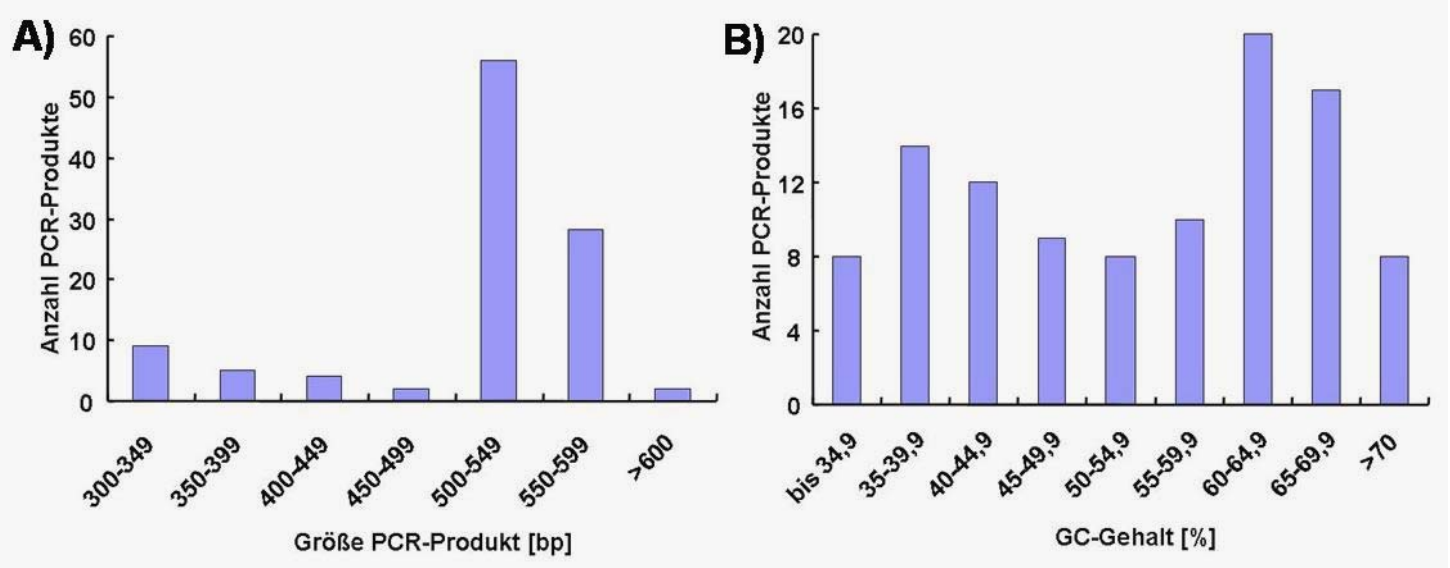

Abb. 51: Zusammensetzung des Test-Microarray hinsichtlich Größe (A) und GCGehaltes (B) der 106 PCR-Produkte (inkl. Negativkontrollen) 
Tab. 18: Auswahl der PCR-Produkte für den Microarray

\begin{tabular}{|c|c|c|c|c|c|}
\hline Organismus & Abk. $^{\top}$ & $\mathrm{Gen}^{2}$ & $\begin{array}{l}\text { Annotiert bzw. } \\
\text { charakterisiert als... }\end{array}$ & $\begin{array}{l}\text { PCR- } \\
\text { Prod. } \\
\text { [bp] }\end{array}$ & $\begin{array}{l}\mathrm{GC} \\
{[\%]}\end{array}$ \\
\hline \multirow{5}{*}{ Agrobacterium tumefaciens } & Atu & 1652 & Chlorperoxidase & 520 & 62,5 \\
\hline & Atu & 2094 & Esterase/Lipase & 519 & 61,1 \\
\hline & Atu & 3957 & lactonspez. Esterase & 554 & 62,3 \\
\hline & Atu & 5323 & Arylester Hydrolase & 571 & 59,9 \\
\hline & Atu & 5383 & Acetylhydrolase & 582 & 62,2 \\
\hline \multirow[t]{3}{*}{ Bacillus cereus } & Bce & 0714 & Esterase & 321 & 35,8 \\
\hline & Bce & 1823 & Lipase & 514 & 33,4 \\
\hline & Bce & 4017 & Lipase & 587 & 38,0 \\
\hline \multirow[t]{3}{*}{ Bacillus licheniformis } & Bli & 2142 & Lipase LipB & 507 & 46,7 \\
\hline & Bli & 3530 & mögl. Esterase/Lipase & 535 & 48,4 \\
\hline & Bli & $\left.\mathrm{NCB}\right|^{3}$ & Esterase (U35855) $)^{3}$ & 909 & 56,7 \\
\hline Bacillus pumilus & $\mathrm{Bpu}$ & $\left.\mathrm{NCB}\right|^{3}$ & Lipase (A34992) & 519 & 42,4 \\
\hline Bacillus sphaericus & Bsp & $\mathrm{NCBI}^{3}$ & Lipase (AF45371) & 530 & 44,6 \\
\hline \multirow{2}{*}{ Bacillus stearothermophilus } & Bst & $\left.\mathrm{NCB}\right|^{3}$ & Lipase (AF23762) ${ }^{3}$ & 564 & 57,2 \\
\hline & Bst & $\mathrm{NCBI}^{3}$ & Lipase $(U 78785)^{3}$ & 523 & 55,3 \\
\hline \multirow[t]{3}{*}{ Bacillus subtilus } & Bsu & 0271 & Lipase LipA & 504 & 46,8 \\
\hline & Bsu & 0835 & Lipase LipB & 520 & 42,1 \\
\hline & Bsu & 2683 & Esterase/Lipase & 508 & 44,7 \\
\hline \multirow[t]{2}{*}{ Clostridium acetobutylicum } & Cac & 1646 & Lipase/Esterase & 303 & 32,0 \\
\hline & Cac & 3363 & Lipase & 396 & 32,5 \\
\hline \multirow{3}{*}{ Candida albicans } & Cal & 0335 & extrazelluläre Lipase & 535 & 40,1 \\
\hline & Cal & 6483 & Triglycerid Lipase & 531 & 35,8 \\
\hline & Cal & 6695 & Esterase D & 594 & 28,1 \\
\hline \multirow[t]{4}{*}{ Corynebacterium glutamicum } & Cgl & 0090 & Lipase & 512 & 52,7 \\
\hline & Cgl & 0101 & Hydrolase & 536 & 52,6 \\
\hline & $\mathrm{Cgl}$ & 1343 & Paranitrobenzyl-Esterase & 521 & 56,0 \\
\hline & $\mathrm{Cgl}$ & 1805 & Lipase & 503 & 58,4 \\
\hline \multirow{2}{*}{ Clostridium tetani } & Cte & 0824 & Lipase & 557 & 33,5 \\
\hline & Cte & 1346 & Lipase & 467 & 29,6 \\
\hline \multirow[t]{3}{*}{ Deinococcus radiodurans } & Dra & 2500 & Lipase & 546 & 71,4 \\
\hline & Dra & 2961 & Lipase & 506 & 69,1 \\
\hline & Dra & 3484 & Lipase & 309 & 67,0 \\
\hline \multirow[t]{3}{*}{ Escherichia coli } & Eco & 6067 & mögliche Lipase & 557 & 51,0 \\
\hline & Eco & 6583 & Phospholipase A & 524 & 52,3 \\
\hline & Eco & 6586 & Lysophospholipase L2 & 502 & 55,0 \\
\hline \multirow[t]{3}{*}{ Enterococcus faecalis } & Efa & 2603 & Lipase/Esterase & 544 & 41,0 \\
\hline & Efa & 2766 & mögliche Esterase & 577 & 37,1 \\
\hline & Efa & 2857 & mögl. sekretierte Lipase & 586 & 45,6 \\
\hline \multirow[t]{3}{*}{ Gluconobacter oxydans } & Gox & 0534 & extrazelluläre Lipase & 504 & 67,1 \\
\hline & Gox & 0627 & Esterase D & 520 & 60,4 \\
\hline & Gox & 2345 & möliche Esterase/Lipase & 546 & 63,4 \\
\hline \multirow[t]{2}{*}{ Klebsiella pneumoniae } & Kpn & 2722 & Esterase/Lipase & 542 & 62,5 \\
\hline & $\mathrm{Kpn}$ & 9054 & Lysophopholipase L2 & 516 & 56,0 \\
\hline \multirow[t]{3}{*}{ Lactobacillus plantarum } & Lpl & 2190 & mögliche Lipase/Esterase & 512 & 47,0 \\
\hline & Lpl & 2441 & mögliche Esterase & 573 & 50,1 \\
\hline & Lpl & 2889 & Acetylesterase Est2 & 520 & 50,4 \\
\hline \multirow{3}{*}{ Mesorhizobium loti } & Mlo & 0444 & Esterase/Lipase & 348 & 67,2 \\
\hline & Mlo & 1358 & Lysophospholipase L2 & 512 & 65,2 \\
\hline & Mlo & 2950 & Lipase & 542 & 65,0 \\
\hline \multirow[t]{2}{*}{ Methanosarcina mazei } & Mma & 0044 & Phospholipase D & 376 & 33,5 \\
\hline & Mma & 0409 & Esterase & 303 & 45,2 \\
\hline \multirow[t]{5}{*}{ Pseudomonas aeruginosa } & Pae & 0308 & Lysophospholipase L2 & 386 & 70,0 \\
\hline & $\mathrm{Pae}$ & 1784 & Triacylglycerin-Lipase & 503 & 70,2 \\
\hline & $\mathrm{Pae}$ & 2889 & Lipase LipA & 570 & 66,8 \\
\hline & Pae & 3136 & Esterase/Lipase & 408 & 68,9 \\
\hline & Pae & 4874 & Lipase LipC & 566 & 68,2 \\
\hline
\end{tabular}


Tab. 18 fortgesetzt

\begin{tabular}{|c|c|c|c|c|c|}
\hline Organismus & Abk. $^{1}$ & $\mathrm{Gen}^{2}$ & $\begin{array}{l}\text { Annotiert bzw. } \\
\text { charakterisiert als... }\end{array}$ & $\begin{array}{l}\text { PCR- } \\
\text { Prod. } \\
\text { [bp] }\end{array}$ & $\begin{array}{l}\mathrm{GC} \\
{[\%]}\end{array}$ \\
\hline \multirow[t]{3}{*}{ Pseudomonas fluorescens } & $\mathrm{Pfl}$ & 2511 & Lipase & 527 & 62,1 \\
\hline & $\mathrm{Pfl}$ & 2588 & Lipase & 525 & 64,4 \\
\hline & $\mathrm{Pfl}$ & 3186 & Acetylesterase & 523 & 63,5 \\
\hline Pyrococcus furiosus & Pfu & 0493 & Lysophospholipase & 540 & 42,2 \\
\hline \multirow{3}{*}{ Petrotoga miotherma } & Pmi & 0378 & Carboxylesterase & 559 & 34,8 \\
\hline & Pmi & 0521 & Esterase/Lipase & 363 & 35,9 \\
\hline & Pmi & 0991 & Lipase & 505 & 35,3 \\
\hline \multirow[t]{3}{*}{ Pseudomonas putida } & Ppu & 3981 & Esterase & 592 & 65,5 \\
\hline & Ppu & 4789 & Lipase & 516 & 66,2 \\
\hline & Ppu & 5092 & Lysophospholipase L2 & 571 & 66,0 \\
\hline Picrophilus torridus & Pto & 0339 & Carboxylesterase & 302 & 43,5 \\
\hline \multirow[t]{4}{*}{ Ralstonia eutropha } & Reu & 1191 & Esterase/Lipase & 436 & 74,7 \\
\hline & Reu & 6034 & Esterase & 372 & 61,3 \\
\hline & Reu & 6239 & Lipase & 305 & 60,5 \\
\hline & Reu & 7991 & extrazelluläre Lipase & 525 & 64,4 \\
\hline \multirow[t]{2}{*}{ Ralstonia metallidurans } & Rme & 1482 & Esterase & 534 & 63,6 \\
\hline & Rme & 5672 & Esterase/Lipase & 577 & 66,6 \\
\hline \multirow[t]{2}{*}{ Ralstonia solanacearum } & Rso & 2535 & Esterase & 558 & 59,8 \\
\hline & Rso & 4054 & Lipase & 561 & 74,0 \\
\hline \multirow[t]{4}{*}{ Staphylococcus aureus } & Sau & 0307 & Paranitrobenzyl-Esterase & 445 & 35,7 \\
\hline & Sau & 1408 & Carboxylesterase & 531 & 37,1 \\
\hline & Sau & 1562 & Esterase/Lipase & 525 & 35,2 \\
\hline & Sau & 2525 & Lipase & 508 & 38,3 \\
\hline \multirow[t]{2}{*}{ Saccharomyces cerevisiae } & Sce & TGL1 & Lipase & 579 & 37,8 \\
\hline & Sce & TGL2 & Lipase & 524 & 39,9 \\
\hline \multirow{2}{*}{ Streptomyces coelicolor } & Sco & 7941 & extrazelluläre Lipase & 428 & 73,8 \\
\hline & Sco & 13442 & Esterase/Lipase & 796 & 74,0 \\
\hline \multirow[t]{2}{*}{ Serratia marcescens } & Sma & 0106 & Lipase LipB & 561 & 56,7 \\
\hline & Sma & 0110 & Lipase LipA & 512 & 60,7 \\
\hline \multirow[t]{3}{*}{ Sinorhizobium meliloti } & Sme & 1689 & Carboxylesterase & 596 & 60,9 \\
\hline & Sme & 3404 & Carboxylesterase & 511 & 63,2 \\
\hline & Sme & 6120 & Esterase/Lipase & 585 & 66,2 \\
\hline \multirow[t]{3}{*}{ Schizosaccharomyces pombe } & Spo & 0992 & Lipase CVT17 & 569 & 43,8 \\
\hline & Spo & 1519 & Esterase & 506 & 38,0 \\
\hline & Spo & 1766 & Lipase & 571 & 43,4 \\
\hline \multirow[t]{4}{*}{ Thermotoga maritima } & Tma & 0179 & Lipase & 570 & 46,0 \\
\hline & Tma & 0796 & Esterase/Lipase & 515 & 47,4 \\
\hline & Tma & 0839 & Carboxylesterase & 527 & 45,7 \\
\hline & Tma & 1696 & Acetylxylan-Esterase & 514 & 50,9 \\
\hline \multirow[t]{3}{*}{ Thermus thermophilus } & Tth & 0669 & Carboxylesterase & 546 & 69,8 \\
\hline & Tth & 1060 & mögliche Phospholipase & 337 & 66,1 \\
\hline & Tth & 1933 & Carboxylesterase & 305 & 70,5 \\
\hline Xanthomonas campestris & Xca & 0142 & Hydrolase (GumP) & 472 & 69,7 \\
\hline Metagenomlipase $\mathrm{u}^{4}$ & XE1 & lipA & Lipase & 513 & 60,0 \\
\hline Metagenomlipase $^{4}$ & XE1 & lipB & Lipase & 525 & 58,9 \\
\hline Metagenomesterase $^{5}$ & A3 & estA3 & Esterase & 570 & 56,1 \\
\hline Metagenomesterase $^{6}$ & CE1 & estCE & Esterase & 590 & 67,3 \\
\hline Negativkontrolle (S. cerevisiae) & $\mathrm{ACT}$ & ACT1 & Aktin (Zellgerüst) & 501 & 44,0 \\
\hline Negativkontrolle (S. cerevisiae) & RAS & RAS1 & GTP-Bindeprotein & 546 & 40,7 \\
\hline Negativkontrolle (S. cerevisiae) & STE & STE3 & Pheromonrezeptor & 531 & 38,6 \\
\hline
\end{tabular}

${ }^{1}$ Die Kurzbezeichnungen der Organismen setzen sich wie bei Restriktionsenzymen aus dem ersten Buchstaben des Gattungsnamen und den ersten zwei Buchstaben des Artnamens zusammen, ${ }^{2}$ Genbezeichnungen aus der ERGO-Datenbank, ${ }^{3}$ Daten von NCBI mit GenBankAccesion-Nummern, S. cerevisiae-Gene folgen der offiziellen Nomenklatur, ${ }^{4}$ Voget et al., 2003, ${ }^{5}$ Schmeißer, 2004, ${ }^{6}$ diese Arbeit. 


\subsection{Konstruktion des Microarrays}

Für die meisten Organismen wurde DNA mit Hilfe des „Aquapure Genomic DNA Isolation Kit" (BioRad) isoliert, für Gram-positive nach leicht modifiziertem Protokoll [II.4.4.5], bzw. es wurde DNA von anderen Arbeitsgruppen zur Verfügung gestellt. Mittels PCR unter Verwendung von Taq-Polymerase wurden die Genfragmente amplifiziert und anschließend direkt gereinigt bzw. beim Auftreten unspezifischer Banden aus dem Gel extrahiert [Il.4.4.6]. Für einige Gene musste hierbei die Analgerungstemeperatur mittels Gradienten-PCR optimiert werden, für alle anderen konnte mit $57^{\circ} \mathrm{C}$ gearbeitet werden. Nach dem Zufallsprinizip wurden 15 PCR-Produkte ausgewählt, in den Vektor pDrive (Tab. 2) kloniert und anschließend sequenziert. Es wurden hierbei keine nennenswerten Abweichungen gefunden, teilweise wich die Nukleotidsequenz etwas $a b$, da andere Stämme als die in ERGO bzw. NCBI angegebenen benutzt wurden $(<3 \%)$.

Die so gereinigten PCR-Produkte wurden nun auf Aminosilan beschichtete Glas slides gespottet [II.10.1] und mittels UV-Bestrahlung kovalent auf der Oberfläche immobilisiert. Die Spots wurden so angeordnet, dass verwandte Organismen und PCRProdukte aus einem Organismus nahe beieinander lagen. Alle Produkte wurden in vierfacher Ausfertigung in Reihen von jeweils 8 PCR-Produkten gespottet. Bei dem hier verwendeten System wären theoretisch bis zu 20.000 Spots pro Array möglich. Durch Färbung mit VistraGreen [II.10.2] welches ähnlich wie Ethidiumbromid, nur sensitiver, dem Anfärben von DNA dient, wurde die erfolgreiche Immobilisierung der PCRProdukte auf der Oberfläche nachgewiesen.

\subsection{Präparation und Markierung genomischer DNA}

Nach verschiedenen Versuchen, chromosomale DNA mit fluoreszenzgekoppelten Nukleotiden zu markieren, hat sich das unter [II.10.3] beschriebene und entwickelte Protokoll als am wirkungsvollsten herausgestellt. Zur einfacheren Handhabung und reproduzierbaren Fragmentierung wurde die DNA zunächst mit einem Restriktionsenzym mit 4er Erkennungssequenz (hier: Alul (Erkennungssequenz AGCT)) komplett verdaut und gereinigt. Der Großteil der entstandenen Fragmente war somit kleiner als 2,5 kb Anschließend wurden nach der Methode des „random prime labelling“ Cy5-markierte dCTPs durch hochkonzentriertes Klenow-Enzym (20 U/ $\mu$ l) eingebaut. Der Erfolg des Einbaus wurde anschließend durch Aufnahme eines Spektrums der Wellenlängen zwischen 550 und $700 \mathrm{~nm}$ überprüft. In die DNA eingebautes dCTP-Cy5 hat ein Absorptionsmaximum bei $650 \mathrm{~nm}$, nicht eingebautes dCTP-Cy5 wurde durch die Reinigung der Probe mittels CyScribe Purification Kit 
abgetrennt [II.10.4]. Hieraus ließ sich die Menge des eingebauten Farbstoffes feststellen. Ein Beispielspektrum ist in Abbildung 52 wiedergegeben.

Bei dem hier gezeigten Beispiel handelt es sich um Alul-verdaute, Cy5-markierte und gereinigte chromosomale $B$. licheniformis-DNA (Stamm DSM13) (60 $\mu$, 1:6 verdünnt zum Messen). Der maximale Absorptionswert betrug 0,145, woraus sich wie folgt die Menge eingebauten Farbstoffes berechnen ließ:

$$
\mathrm{n} \text { Cy5 }=(\mathrm{A} /(\mathrm{E} \cdot \mathrm{d})) \cdot \mathrm{z} \cdot \text { Verdünnungsfaktor } \cdot 10^{12}
$$

Wobei A die Absorption von Cy5 bei $650 \mathrm{~nm}$, E der Extinktionskoeffizient von Cy5 $\left(250.000 \mathrm{I} \cdot \mathrm{mol}^{-1} \cdot \mathrm{cm}^{-1}\right), \mathrm{z}$ das Volumen der Cy5-markierten DNA nach der Reinigung und d die Schichtdicke der Küvette $(1 \mathrm{~cm})$ sind. Im hier gezeigten Beispiel wurden demnach

$$
\left(0,145 /\left(250.000 \mathrm{I} \cdot \mathrm{mol}^{-1} \cdot \mathrm{cm}^{-1} \cdot 1 \mathrm{~cm}\right)\right) \cdot 60 \mu \mathrm{l} \cdot 6 \cdot 10^{12}=\underline{208,8 \mathrm{pmol}}
$$

Cy5 in die DNA eingebaut. Für verwertbare Hybridsierungen sollten wenigstens 150 pmol Farbstoff in die zu hybridisierende Probe eingebaut sein.

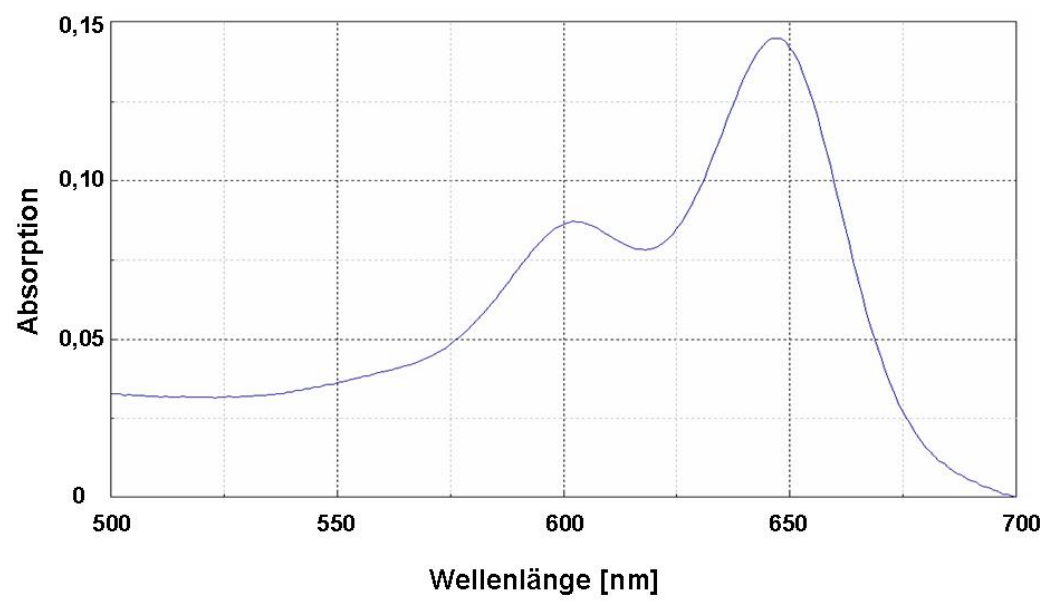

Abb. 52: Absorptionsspektrum von Cy5-makierter, chromosomaler DNA zur Bestimmung der eingebauten Farbstoffmenge

\subsection{Kontrollexperimente}

\subsubsection{Hybridisierung mit markierten PCR-Produkten}

Zur Kontrolle wurden Hybridisierungen mit markierten PCR-Produkten durchgeführt, bei denen eine 100\%ige Übereinstimmung zu ihrem jeweiligen Gegenstück auf dem Chip zu erwarten ist. Zur Amplifizierung wurden dieselben Primer benutzt, wie sie zur Generierung der gespotteten PCR-Produkte verwendet wurden. Die PCR-Produkte wurden mit Cy5-dCTP durch direkten Einbau während der PCR-Reaktion markiert. Die Menge eingebauten Farbstoffes lag i.d.R. zwischen 55 und 70 pmol. Exemplarisch ist 
dies in Abbildung 53 einmal am Beispiel des PCR-Produktes des E. coli Gens 6067 gezeigt. Dargestellt ist ein kompletter Array mit einer Vergrößerung des Abschnittes, in welchem das gefundene Signal lag. Die Signalintensität sämtlicher Spots auf dem Microarray wurde vermessen [II.10.6]. Für den beobachteten Spot lag die Signalintensität bei 1231, für die restlichen Spots in dieser Reihe lag sie zwischen 0 und 7, auch auf dem restlichen Array wurden keine Intensitäten über 10 gemessen. Dieses Experiment wurde für insgesamt fünf nach dem Zufallsprinzip ausgewählte PCR-Produkte (Eco6067, Bli3530, Pae1784, EstCE, STE3) mit ähnlichen Ergebnissen durchgeführt. Es konnten keine unspezifischen Reaktionen festgestellt werden, die Signalintensität lag jeweils wenigstens $80 f a c h$ über dem beobachteten Hintergrund.

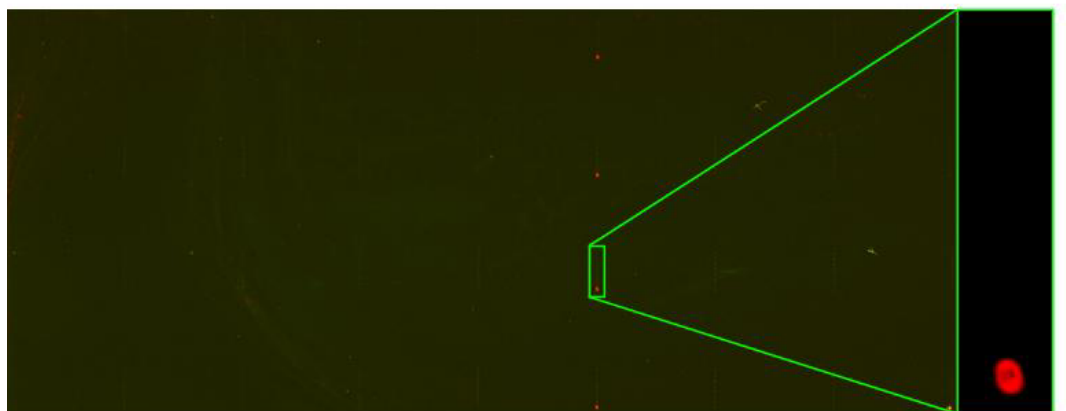

Gox0627

Gox0534

Sma0110

Sma0106

Reu7791

Eco6586

Eco6583

Eco6067

Abb. 53: Microarray nach Hybridisierung mit Cy5-markiertem PCR-Produkt Eco6067 Eine Zeile mit dem gespotteten PCR-Produkt Eco6067 ist rechts vergrößert wiedergegeben (grüne Linien). Die Beschriftung der übrigen Spots in dieser Reihe entspricht den Daten in Tabelle 1.

\subsubsection{Hybridisierung mit genomischer DNA aus Reinkulturen}

Mit genomischer DNA ausgewählter Organismen wurden weitere Kontrollexperimente unternommen, um mögliche Kreuzhybridisierungen ausschließen zu können. Aus Reinkulturen wurde hierzu DNA isoliert [II.4.4.5], diese komplett mit Alul verdaut und wie unter [II.10.3] beschrieben mit dem Farbstoff Cy5 markiert. DNA, die mit wenigstens 150 pmol Cy5 markiert war, wurde anschließend für die Hybridisierung eingesetzt. Am Beispiel B. licheniformis ist dies hier exemplarisch einmal gezeigt. Fluoreszenzmarkierte DNA wurde mit dem DNA-Microarray wie unter [II.10.5] beschrieben hybridisiert und anschließend die Intensitäten der beobachteten Spots vermessen [II.10.6]. In Abb. 54 sind exemplarisch diejenigen Reihen ausschnittweise gezeigt, die ein Signal ergeben haben. Die gemessenen Signalintensität der gezeigten Spots (Durchschnittswerte aller 4 Spots) sind in Tabelle 19 wiedergegeben. Für die Hybridisierung mit $B$. licheniformis-DNA zeigten sich die stärksten Signale für die auf dem Array befindlichen Genfragmente aus B. licheniformis mit Signalintensitäten von 
2202 und 2250. Ein weiteres relativ starkes Signal wurde für den Spot BpuA34992 beobachtet $(36,5 \%$ der Maximalintensität) sowie schwächere Signale bei Spots mit Fragmenten aus dem verwandten $B$. subtilis, die eine Stärke von $4,1 \%$ bis $6,9 \%$ der Maximalintensität zeigten, sich aber deutlich vom Hintergund abhoben. Für andere Bacillus-Arten konnten keine erhöhten Signale gemessen werden.
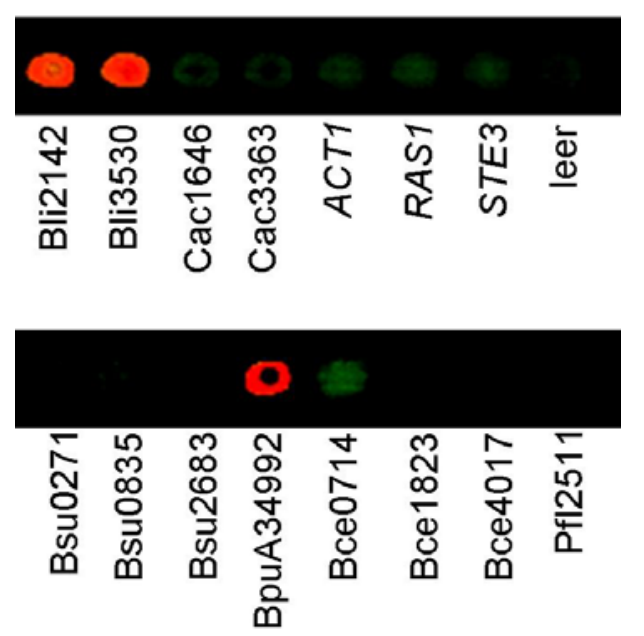

Abb. 54: Microarray nach Hybridisierung mit Cy5-markierter $B$. licheniformis-DNA

Gezeigt sind zwei Ausschnitte mit Spots mehrerer Bacillus-Spezies, die nach der Hybridisierung Signale zeigten. Die grüne Farbe bei Spot Bce0714 ist auf eine Verunreinigung im PCR-Produkt zurückzuführen, die vereinzelt auftrat. Die genauen Bezeichungen der Spots sind Tabelle $18 \mathrm{zu}$ entnehmen, die Intensitäten der Spots sind in Tabelle 19 aufgeführt.

Tab. 19: Signalintensitäten der in Abb. 54 dargestellten Microarray-Spots

Die Intensitäten sind Median-Werte der Fluoreszenz bei $635 \mathrm{~nm}$ abzüglich des Hintergrundes und stellen Mittelwerte der vierfach auf einem Array vertretenen Spots dar.

\begin{tabular}{lclc}
\hline Spot & Intensität & Spot & Intensität \\
\hline Bli2142 & 2202 & Bsu0271 & 153 \\
Bli3530 & 2190 & Bsu0835 & 89 \\
Cac1646 & 3 & Bsu2683 & 138 \\
Cac3363 & 10 & BpuA34992 & 804 \\
ACT1 & 39 & Bce0714 & 5 \\
RAS1 & 14 & Bce1823 & 6 \\
STE3 & 14 & Bce4017 & 20 \\
leer & 8 & Pfl2511 & 2 \\
\hline
\end{tabular}


Aus diesen Daten ist abzuleiten, dass eine Signalintensität bis ungefähr 50 als normale Hintergrundfluoreszenz angesehen werden konnte. Diese Versuche wurden mit chromosomaler DNA der Organismen Methanosarcina mazei, Agrobacterium tumefaciens, $P$. aeruginosa und $E$. coli als Kontrollen mit vergleichbaren Ergebnissen durchgeführt. Da es bei diesem Experiment auch noch nicht um eine quantitative Detektion von Lipasegenen in Umweltproben oder deren Expression ging, wurde im Weiteren nur auf Spots geachtet, die sich unabhängig von der Signalintensität merklich vom Hintergrund abhoben. Auf die Angabe absoluter Intensitäten wird deswegen im Folgenden verzichtet, es wurde der durchschnittliche Hintergrund der Fluoreszenz ermittelt und die Intensität der Signale relativ dazu angegeben.

\subsection{Hybridisierung mit Umwelt-DNA}

Zum Nachweis der Detektion von Lipase- bzw. Esterasegenen in Umweltproben wurde mit isolierter chromosomaler DNA aus mehreren Proben unterschiedlicher Herkunft hybridisiert. Hierfür wurden neue Anreicherungskulturen angelegt, die unter verschiedenen Bedingungen kultiviert wurden. Aus einer Bodenprobe des Standortes Wietze wurden Kulturen in Mineralmedium [II.2.2] mit 1\% Olivenöl, Mineralöl oder Glukose als einziger C-Quelle angelegt, die nach Wachstum bei $30^{\circ} \mathrm{C}$ insgesamt drei mal alle 5 Tage überimpft wurden. Um in einem einfachen Test zunächst die lipolytische Aktivität nachweisen zu können, wurden mit diesen Kulturen Aktivitätstests mit pNP-Butyrat als Substrat durchgeführt, wie sie auch als Lipasenachweis in biologischen Sanierungsprozessen im Boden genutzt werden (Margesin et al., 1999). Auffällig war bereits die unterschiedliche Färbung der Kulturen bei Verwendung unterschiedlicher Substrate. So wies die Mineralölanreicherung eine rosa Färbung auf, die Olivenölanreicherung eine gelbliche und die Glukoseanreicherung eine gräuliche. Die Aktivitätstests zeigten, dass bei der Anreicherung auf Olivenöl mit zunehmender Anreicherungsdauer die Lipaseaktivität 5,2fach anstieg, wohingegen sie bei Glukose und Mineralöl konstant niedrig blieb (Abb. 55).

Von diesen Anreicherungskulturen wurde anschließend nach jedem Anreicherungsschritt DNA isoliert [II.4.4.2], mit Cy5 markiert [II.10.3] und anschließend mit dem Microarray hybridisiert [II.10.5]. Die ersten beiden Anreicherungsschritte zeigten keine signifikanten Signale, die sich stark vom Hintergrund abhoben. Bei der dritten Anreicherungskultur fanden sich dann eindeutige Signale bei der Anreicherung auf Olivenöl. 


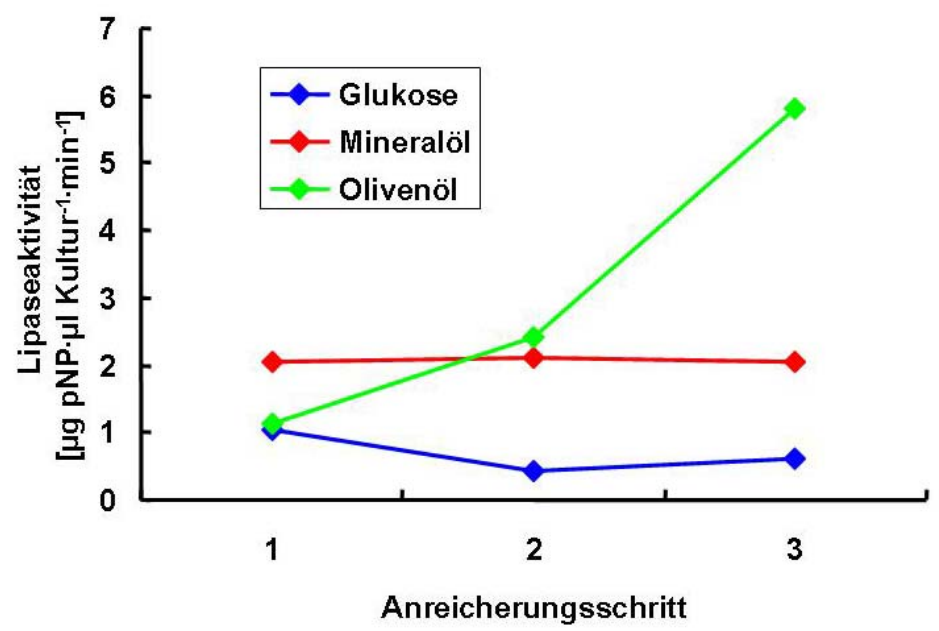

Abb. 55: Lipaseaktivität der Anreicherungskulturen auf verschiedenen C-Quellen

Die Kulturen wurden in Mineralöl mit verschiedenen C-Quellen angereichert. Die Lipaseaktivität wurde mit pNP-Butyrat als Substrat bestimmt, die direkt eingesetzten Kulturen auf eine OD595 von 1 eingestellt. Die Aktivität ist angegeben als $\mu \mathrm{g}$ freigesetztes pNP pro min und $\mu \mathrm{l}$ Kultur (nach Margesin et al., 2002).

Abb. 56 zeigt einen Spot, dessen Intensität achtfach über dem Hintergrund lag. Beim direkten Vergleich mit der DNA der Mineralölanreicherung konnte dort kein Signal beobachtet werden. Neben dem Signal Pae2889 fanden sich in der Olivenölanreicherung dann vier weitere Signale, deren Intensität wenigstens fünffach über dem Hintergrund lag (Ppu3981, Ppu4789, Atu5383, Cal6695). Bei der Mineralölanreicherung konnten zwei Spots detektiert werden (Rme5672, Cal6695), deren Intensität sich vom Hintergrund abhob, mit maximal 4fach jedoch nicht so stark war wie bei der Olivenölanreicherung.

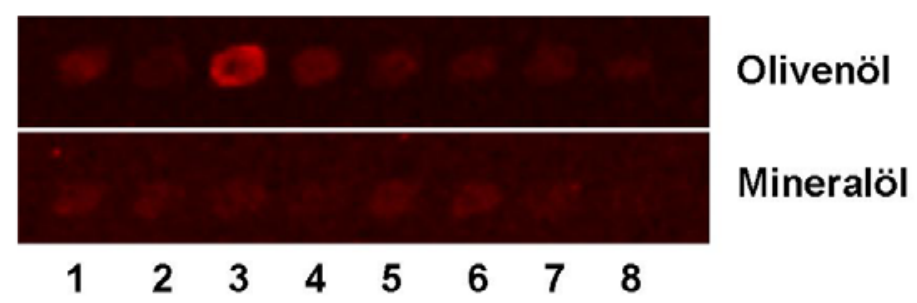

Abb. 56: Hybridisierung mit DNA aus verschiedenen Anreicherungskulturen

Die obere Reihe zeigt die Hybridisierung mit Cy5-markierter DNA aus einer Olivenölanreicherung, die untere mit DNA aus einer Mineralölanreicherung. Die Anordnung der Spots ist in beiden Reihen identisch. 1: Pae0308, 2: Pae1784, 3: Pae2889, 4: Pae3136:, 5: Pae4874, 6: Sme:1689, 7: Sme3404, 8: Sme6120. Für die genaue Zuordnung der Bezeichnungen siehe Tabelle 18. 
Hybridisiert wurde zudem mit einer Auswahl von weiteren DNA-Proben die aus verschiedenen Habitaten isoliert wurden. Es wurden hierbei Signale gefunden, die einer Vielzahl verschiedener Spots zugeordnet werden konnten. Eine Übersicht aller untersuchten Proben die Signale ergeben haben, sowie eine Angabe der gefundenen Signale ist in Tab. 20 wiedergegeben. Vier weitere Proben, bei denen es sich um direkt aus verschiedenen Böden isolierte DNA handelte, ergaben keine signifikanten Signale.

Tab. 20: Mittels Microarray identifizierte Signale aus verschiedenen Umweltproben

${ }^{1}$ : auf Treibstoffproben (Diesel) gewachsener Biofilm (Pathak, 2006), ${ }^{2}$ : Cosmidbank, erstellt aus Trinkwasserbiofilm (Schmeisser, 2004), 3: Biofilm, isoliert aus Stents klinischer Proben (B. Scheithauer, GBF Braunschweig), ${ }^{4}$ : Anreicherungskultur (Mineralmedium mit $1 \%$ Malonsäure) aus Malonsäurekontaminiertem Boden (M. Grooters, Uni Duisburg-Essen), 5: siehe Text, *Amplifizierung mittels PCR möglich (siehe III.5.7)

\begin{tabular}{|c|c|c|}
\hline Probe & Signale & \\
\hline WIWEB $^{1}$ & $\begin{array}{l}\text { Pae0308*, Pae1784*, Pae2889*, Pae3137*, } \\
\text { Sma0110, Pfl2511 }\end{array}$ & Pae4874*, \\
\hline BiollI $^{2}$ & EstA3*, Eco6586 & \\
\hline Stent-Biofilm ${ }^{3}$ & Sme3404 & \\
\hline Malonsäureanr. ${ }^{4}$ & BpuA34992 & \\
\hline W7A_Oliv ${ }^{5}$ & Ppu3981, Ppu4789, Atu5383, Cal6695, Pae2889* & \\
\hline W7A_Mineral ${ }^{5}$ & Rme5672, Cal6695 & \\
\hline
\end{tabular}

\subsection{Identifizierung der Gene in den Umweltproben mittels PCR}

Für die identifizierten Spots aus den verschiedenen Hybdridisierungen wurde versucht, homologe Genfragmente aus den Umweltproben zu amplifizieren. Dies gelang mittels PCR und Verwendung der Primerpaare die zur Erstellung des jeweiligen Spots benutzt wurden für 7 der 18 in Tabelle 20 beschriebenen Signale. Die mittels Taq-Polymerase amplifizierten PCR-Produkte der erwarteten Größe wurden gereinigt, in den Vektor pDrive kloniert und anschließend mit Standardprimern (Abi_for/Abi_rev, Tab. 3) sequenziert. Die Amplifizierung erfolgte jeweils unter identischen Bedingungen, wie sie für die Herstellung der gespotteten PCR-Produkte verwendet wurden. Die erhaltenen Sequenzen wurden anschließend mit den Ausgangssequenzen verglichen. Das Produkt, welches aus der DNA der Olivenölanreicherung amplifiziert werden konnte, wies hierbei die niedrigste Homologie zur Ausgangssequenz auf. Das PCR-Produkt war um 9 bp länger, die Identität betrug 78\% auf Nukleotidebene und $77 \%$ bei der zugehörigen Aminosäuresequenz. Bei allen Fragmenten, die amplifiziert und sequenziert werden konnten, fand sich ein Lipasestrukturmotiv der Form $G-x-S-x-G$ in 
der übersetzten Aminosäuresequenz. Die Daten für alle amplifizierten Produkte sind in Tab. 21 zusammengefaßt.

Für das neue Fragment Pae2889 aus der Olivenölanreicherung wurde mittels verschiedener PCR-Techniken wie „genomic walking“-PCR (Morris et al., 1995) oder inverser PCR (Triglia et al., 1988) versucht, die in 5'- und 3'-Richtung des bekannten Fragmentes liegenden Abschnitte unbekannter Sequenz zu ermitteln, um so das vollständige Lipasegen aus der Umweltprobe isolieren zu können. Diese Techniken beruhen darauf, aus einer bekannten Sequenz heraus mit einem spezifischen Primer und einem anligierten Primer außerhalb der bekannten Sequenz die flankierenden Regionen mittels PCR amplifizieren zu können (siehe auch IV.6.2), was bislang jedoch nicht gelungen ist.

Tab. 21: Übersicht der Identität der neu amplifizierten Produkte der Umweltproben zu den Ausgangssequenzen

${ }^{1}$ Das estA3-Gen stammt aus der Cosmidbank Biolll des Trinkwasserbiofilms

\begin{tabular}{llccc}
\hline Probe & Signal & $\begin{array}{c}\text { Ursprungs- } \\
\text { sequenz (bp) }\end{array}$ & $\begin{array}{c}\text { neue } \\
\text { Sequenz (bp) }\end{array}$ & $\begin{array}{c}\text { Identität } \\
{[\%]}\end{array}$ \\
\hline Biolll & EstA3 & 570 & 570 & $100^{1}$ \\
WIWEB & Pae0308 & 386 & 386 & 98 \\
WIWEB & Pae1784 & 503 & 503 & 98 \\
WIWEB & Pae2889 & 570 & 570 & 98 \\
WIWEB & Pae3137 & 408 & 408 & 99 \\
WIWEB & Pae4874 & 566 & 566 & 99 \\
W7A_Oliv & Pae2889 & 570 & 579 & 78 \\
\hline
\end{tabular}




\section{Diskussion}

Durch die Technik des Klonierens von DNA nach direkter Isolierung aus Umweltproben unterschiedlichster Habitate ohne Kultivierung der Organismen, wurden in den letzten Jahren komplett neue Einblicke sowohl in die mikrobielle Ökologie als auch Enzymvielfalt gewonnen (Steele und Streit, 2005). Ausgehend davon, dass die große Mehrheit der Organismen bis heute nicht kultiviert werden kann, wurde mit dem Metagenomansatz bislang erfolgreich eine Menge neuartiger Enzyme für Anwendungen in der „weißen Biotechnologie“ gewonnen (Lorenz und Eck, 2005).

Unter den Hydrolasen bilden Lipasen eine wichtige Gruppe für biotechnologische Anwendungen, aufgrund ihrer Fähigkeit eine Vielzahl an Reaktionen stereospezifisch durchzuführen, häufig unabhängig von Co-Faktoren und mit hoher Toleranz gegenüber Lösungsmitteln (Jäger und Eggert, 2002).

Ziel dieser Arbeit war es, aus Metagenomproben neuartige lipolytische Enzyme mit interessanten Eigenschaften $\mathrm{zu}$ isolieren und diese insbesondere hinsichtlich enantioselektiver Umsetzungen biotechnologisch relevanter Substrate zu untersuchen.

\section{Phylogenetische Charakterisierung des Standortes}

Boden stellt eins der diversesten Habitate prokaryotischer Organismen dar. Schätzungen gehen davon aus, dass die Zellzahlen im Boden im Bereich von $10^{9}$ bis $10^{10}$ Zellen pro Gramm Boden liegen können (Whitman et al., 1998; Øvreås und Torsvik, 1998). Auch wenn über die Diversität im Boden nach wie vor nur Schätzungen vorliegen (Curtis und Sloan, 2004), ergaben erste Untersuchungen eine Zahl von 4.600 verschiedenen Genomen je Gramm Boden (Torsvik et al., 1990) und auch heutige Studien liegen mit Werten von 3.000 bis 11.000 verschiedenen Spezies (Curtis et al., 2002; Torsvik et al., 2002; Fierer und Jackson, 2006) in derselben Größenordnung. Erst kürzlich wurden neue Berechnungen alter Daten (Sandaa et al., 1999) publiziert, welche die Diversität in unkontaminiertem Boden auf $8,3 \times 10^{6}$ verschiedene Spezies in $10^{10}$ Zellen (oder 10 Gramm Boden) schätzen (Gans et al., 2005). Berechnungen zeigen, dass für einen Boden mit 4.000 verschiedenen Spezies etwa 285.400 16SrDNA-Klone untersucht werden müssten, um alleine das Vorkommen der 2.000 häufigsten Spezies zufriedenstellend dokumentieren zu können (Dunbar et al., 2002). Die meisten Veröffentlichungen beschäftigen sich hingegen nur mit ein paar hundert Klonen, wie es auch in dieser Arbeit der Fall war. Vor diesem Hintergrund ist das Auffinden der 128 verschiedenen Spezies anhand von 480 untersuchten Klonen nur 
als ein sehr oberflächlicher Einblick in die Diversität des untersuchten Bodens zu betrachten.

Der kultivierungsunabhängige Gebrauch des $16 \mathrm{~S}$ rRNA-Gens als phylogenetischen Marker auf molekularer Ebene hat sich seit der ersten Beschreibung im Jahre 1987 als eines der am häufigsten verwendeten Merkmale durchgesetzt (Woese, 1987). Aber auch andere konservierte Gene (u.a. Hitzeschockproteine, ATPasen, Topoisomerasen) finden Verwendung (Marsh, 1999), insbesondere vor dem Hintergrund, dass die alleinige Betrachtung der 16S rRNA-Gene das metabolische Potenzial der Organismen außer Acht lässt (Achenbach und Coates, 2000; Kent und Triplett, 2005). Die Anzahl von 16S-rRNA Sequenzen in den Datenbanken hat in den letzten Jahren sprunghaft zugenommen (Rappé und Giovannoni, 2003), es finden sich inzwischen fast viermal so viele Einträge zu nicht-kultivierten als zu kultivierten Organismen (Stand Oktober 2005: 132.320 gegenüber 33.138 (Voget, 2006)).

Bei den in dieser Arbeit gefunden Sequenzen fanden sich überwiegend verwandte Spezies zu bis heute unkultivierten Vertretern, was sich mit den Schätzungen deckt, dass $99 \%$ aller Mikroorganismen bis heute nicht kultiviert wurden bzw. werden können (Amann et al., 1995). Zudem ist zu beachten, dass die gefundenen Zusammensetzungen der mikrobiellen Bodengemeinschaften bei ähnlichen kultivierungsunabhängigen Untersuchungen in Abhängigkeit von der jeweiligen DNAExtraktionsmethode stark variieren (Niemi et al., 2001). So ist die Tatsache, dass weder eukaryotische noch archaelle rRNA-Gene nachgewiesen werden konnten sicherlich auf die verwendete DNA-Extraktionsmethode und nicht auf deren Abwesenheit zurückzuführen.

Die Einträge von Rohöl in die Umwelt durch natürliche Vorkommen wie im Habitat Wietze oder anthropogene Einflüsse belaufen sich weltweit auf mehrere 100 Millionen Liter pro Jahr (Head et al., 2006). Rohöl kann aus bis zu 17.000 verschiedenen Komponenten bestehen (Marshall und Rogers, 2003), wobei die Hauptkomponenten aus gesättigten, aliphatischen und aromatischen Kohlenwasserstoffen (KW) sowie Resinen und Asphaltenen als Nicht-KW-Bestandteilen bestehen (Head et al., 2006). Dieses Rohöl kann trotz seiner ökologischen Toxizität von vielen Organismen als Kohlenstoff- und Energiequelle genutzt werden, womit diese wesentlich zur biologischen Regeneration kontaminierter Habitate beitragen. Es sind bislang 88 bakterielle (inkl. Cyanobacteria) sowie 103 Pilz- und 14 Algengattungen beschrieben, die in der Lage sind, KW abzubauen (Prince, 2005).

Es fanden sich im Wietzer Boden nahe verwandte Organismen zu Spezies, die am Kohlenwasserstoffabbau in verschiedenen Habitaten beschrieben sind. Häufig fanden 
sich Gram-positive, Mycobacterium-ähnliche Klone, die oft im Zusammenhang mit dem Abbau von polycyclischen, aromatischen KW auftreten (Leys et al., 2005b; Uyttebroek et al., 2006). Zudem wird diese Gattung mit langzeitkontaminierten Habitaten in Verbindung gebracht, wie es am Standort Wietze der Fall ist (Uyttebroek et al., 2006). Weitere typische KW-Abbauer fanden sich in nahe Verwandten zu Rhodanobacter lindaniclasticus (Nalin et al., 1999), aus der Gattung Actinobacter (Lai und Khanna, 1996) oder Sphingomonas (Thomassin-Lacroix et al., 2001; Leys et al. 2005a), die auch am Abbau polycyclischer, aromatischer KW beteiligt sind. Einige PseudomonasArten wurden zudem gefunden, aus deren Gattung ebenfalls KW-Abbauer bekannt sind (Stach und Burns, 2002; van Hamme et al., 2003; Röling et al., 2004) und die sich als solche auch häufig in kalten Habitaten finden (Margesin et al., 2003a/b).

Zuletzt fanden sich einige nahe Verwandte zu sulfatreduzierenden Bakterien der Gattung Desulfotomaculum und Desulfobacterium. Diesen wird als Bewohner von Ölvorkommen und Anlagen der petrochemischen Industrie besondere Aufmerksamkeit gewidmet (Cord-Ruwich et al., 1987), da durch die $\mathrm{H}_{2} \mathrm{~S}$-Produktion die Qualität des Öls gemindert wird und Korrosionsschäden an den Anlagen entstehen (Magot et al., 2000).

\section{Isolierung neuer Biokatalysatoren}

\subsection{Neue Lipasen aus dem Metagenom}

In den letzten zwei Jahren ist die Zahl aus dem Metagenom isolierter Lipasen sprunghaft gestiegen (Tabelle 22). Bis heute finden sich 51 neuartige Gene, die für Enzyme mit lipolytischer Aktivität kodieren (berücksichtigt wurden nur Lipasen und Esterasen, deren Gene aus Metagenomproben stammen und deren Funktionalität nachgewiesen ist). Von denen ist allerdings nur ein kleiner Teil ausgiebig charakterisiert, was für eventuelle spätere Anwendungen zwingend nötig wäre. Häufig beschränkte sich die Arbeit auf das Auffinden lipolytisch aktiver Klone und anschließendem Identifizieren der zugehörigen ORFs. Die korrespondierenden Proteine wurden erst in neueren Arbeiten exprimiert, gereinigt und charakterisiert. Eine detaillierte Charakterisierung wie sie für die beiden in dieser Arbeit gefundenen Enzyme vorlag, bildete abgesehen von den Arbeiten von Ferrer et al (2005a), Rhee et al., (2005) und Kim et al. (2006) bislang die Ausnahme. Interessanterweise zeigen alle Enzyme, sobald sie näher untersucht werden auch interessante Charakteristika wie Stereospezifität gegenüber Substraten wie Menthylacetat (EstCE), Ibuprofen (LipCE), Ketoprofen (Kim et al., 2006) oder Solketalacetat (Ferrer et al., 2005a). Weitere interessante Eigenschaften dieser Enzyme sind Thermophilie (Rhee et al., 2005) und Stabilität bei hohen Drücken (Ferrer at al., 2005a), die sich mit der Herkunft dieser 
Metagenomenzyme aus extremen Standorten wie heißen Quellen oder aus über 3.500 m Wassertiefe erklären lassen. Dies zeigt, wie interessant diese Enzymklasse insbesondere für biokatalytische Anwendung sein kann und welchen wertvollen Beitrag die Metagenomik dazu leistet. Die Charakterisierung der in dieser Arbeit gefundenen Enzyme (pH-Optimum 10 bei EstCE, Kälteaktivität bei LipCE) zeigt aber auch, dass man gar keine extremen Standorte aufsuchen muß, um Enzyme mit Fähigkeiten im Extrembereich zu finden.

\subsection{Sequenzneuheit der gefundenen Metagenomenzyme}

Bei Betrachtung der in Tab. 22 aufgeführten Enzyme und auch der hier beschriebenen Esterase EstCE wird deutlich, dass das aktivitätsbasierte Suchen nach neuen Enzymen dem sequenzbasierten überlegen ist. Häufig finden sich Enzyme, die bei reinen Sequenzierungsprojekten wohl durch das Raster gefallen wären, da keine Ähnlichkeit zu bekannten lipolytischen Enzymen gegeben ist. EstCE wäre durch die hohe Ähnlichkeit zu $\beta$-Laktamasen ebenso wie die multimere Esterase EstA3 (Schmeißer, 2004) nicht zwangsläufig detektiert wurden. So fanden Ferrer und Mitarbeiter (2005b) bei der Erstellung einer Metagenombank aus Kuhpansen elf lipolytische Klone. Vier der identifzierten ORFs wurden hypothetischen Proteinen zugeordnet deren Identität teilweise nur bei 31\% zu bekannten Proteinen lag. Ebenso fanden sich Enzyme deren Ähnlichkeit zu bekannten Lipasen bzw. Esterasen nur bei $26 \%$ lag. Bei EstCE lag die gefundenen Identität von $51 \%$ zu einer bereits beschriebenen $\beta$-Laktamase aus $B$. pseudomallei ebenfalls recht niedrig, auf Nukleotidebene betrug die Identität $60 \%$ zu einer Protocatechuate-3,4-dioxygenase aus B. gladioli (Petersen et al., 1996). Hinsichtlich einer möglichen späteren Verwertung dieser Enzyme ist dieser Punkt von Bedeutung, da nur eine ausreichend hohe Sequenzneuheit eine Patentierung ermöglicht und man in der Anwendung keinen Einschränkungen unterlegen wäre (Lorenz, 2006).

Für lipCE andererseits ist der Neuheitswert bedingt durch die hohe Identität von $88 \%$ zu bereits beschriebenen Genen nicht gegeben, was eine Patentierung sicherlich erschweren würde. 
Tab. 22: Übersicht über aus Metagenomen isolierte lipolytische Enzyme

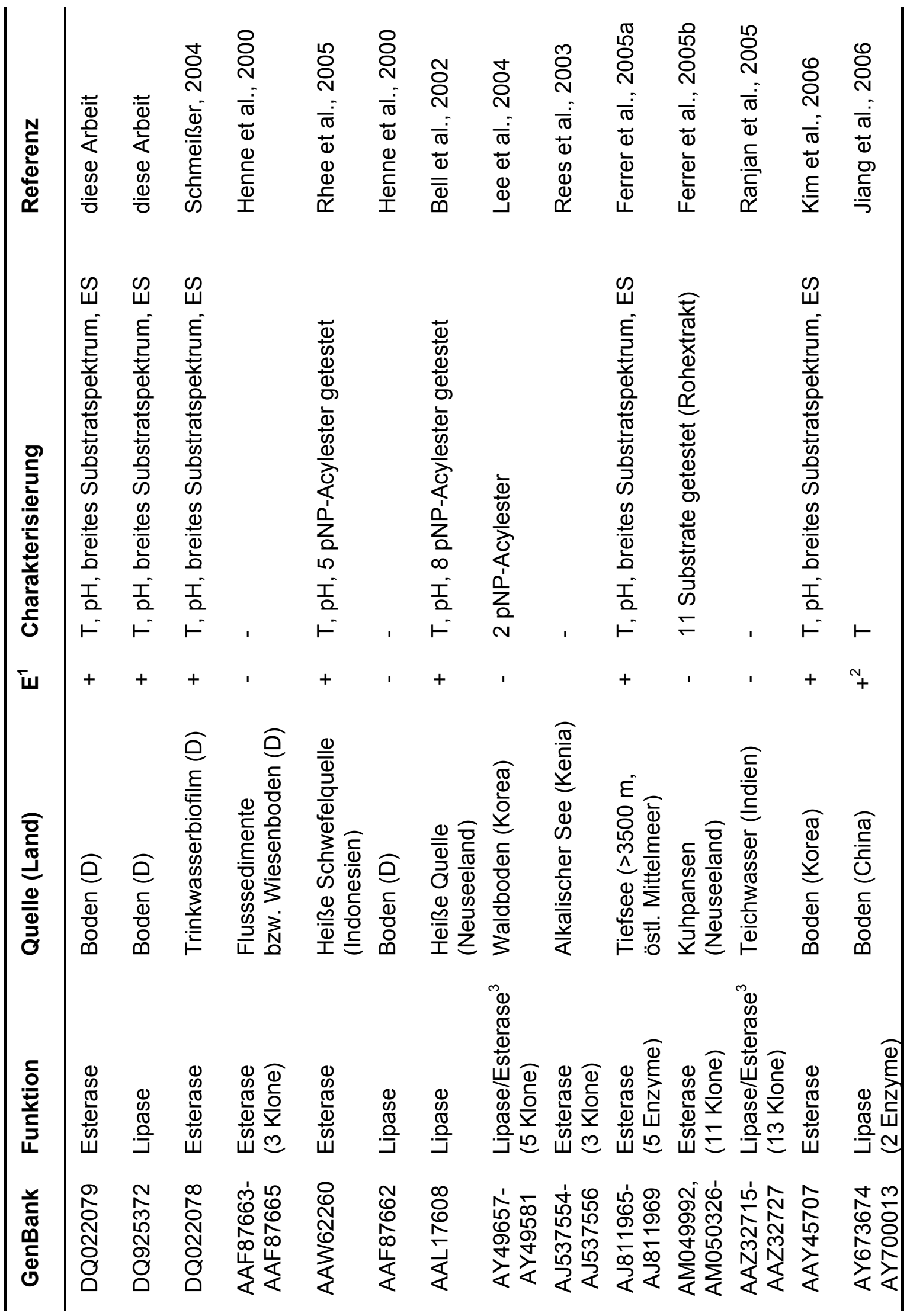

${ }^{1}$ : Enzym exprimiert und gereinigt, $(+)$ ja, $(-)$ nein, ${ }^{2}$ : Expression in Pichia pastoris (sonst E. coli),

3: Annotierung nur sequenzbasiert, T: Temperaturoptimum ermittelt, $\mathrm{pH}$ : $\mathrm{pH}-\mathrm{Optimum}$ ermittelt, ES: Enantioselektivität bei wenigstens einem der getesteten Substrate gefunden 


\subsection{Erweiterung der Familie VIII durch Metagenomlipasen}

Lipolytische Enzyme werden nach Arpigny und Jäger (1999) in acht Familien unterteilt, von denen die „echten Lipasen“ der Familie I den größten Anteil ausmachen. Enzyme der Familie VIII machen nur einen sehr kleinen Teil aus. Charakteristika dieser Familie sind eine Proteingröße von etwa 380 AS sowie hohe Ähnlichkeit zu $\beta$-Laktamasen mit einem S-x-x-K-Strukturmotiv. Das typische Lipase-Strukturmotiv G-x-S-x-G ist nicht zwingend vorhanden, das katalytische Serin liegt in dem $\beta$-Laktamase-Motiv. Zum damaligen Zeitpunkt waren für diese Familie nur drei Esterasen beschrieben. Seit dieser Beschreibung wurden zudem Esterasen B. gladioli (Petersen et al., 2001), Brevibacterium linens (Sakai et al., 1999) und $P$. aeruginosa (Ogino et al., 2004) isoliert, die in diese Familie einzugliedern sind. Das Anlegen und Durchmustern von Metagenombanken in den letzten Jahren hat weitere neue Mitglieder dieser Familie identifiziert. Die in dieser Arbeit charakterisierte Esterase EstCE ist zweifelsfrei als Mitglied der Familie VIII zu betrachten. In der Arbeit von Schmeißer (2004) fanden sich zwei weitere Esterasen in der Metagenombank eines Trinkwasserbiofilms, Ferrer und Mitarbeiter (2005b) konnten eine weitere Esterase im Metagenom aus Kuhpansen ausmachen und Ranjan und Mitarbeiter (2005) fanden im Teichwasser-Metagenom eine Esterase der Familie VIII. Diese vielen isolierten Esterasen der Familie VIII aus verschiedenen Metagenomproben lassen den Schluss zu, dass diese Familie deutlich weiter verbreitet ist, als ursprünglich angenommen. Im Gegensatz zu den meisten Lipasen, deren Funktion für die Zelle geklärt ist, bleibt die physiologische Rolle der Familie VIII-Enzyme hingegen weiterhin unbekannt.

\section{Probleme der Metagenomik}

\subsection{Heterologe Expression der gefundenen Metagenomenzyme}

Bei beiden in dieser Arbeit beschriebenen Enzymen traten Probleme auf, wie sie bei der heterologen Expression von Metagenomenzymen häufig zu Tage treten. Es kam in beiden Fällen zur Bildung von unlöslichen Einschlusskörpern, was jedoch kein spezifisches Problem von Metagenomenzymen ist, sondern bei heterologer Expression in Wirten wie E. coli häufig auftritt (Baneyx und Mujacic, 2004). Während sich das Problem bei EstCE durch die Wahl eines anderen Expressionssystemes leicht beheben ließ, war dies bei der Lipase LipCE nicht der Fall.

Von extrazellulären Pseudomonas-Lipasen ist bekannt, dass sie spezielle Faltungshelfer und Sektretionssysteme benötigen. Die Sekretion in P. aeruginosa beispielweise erfolgt über einen Typll-Sekretionsmechanismus. Signalpeptidabhängig erfolgt der Export dort durch die Xcp-Maschinerie, welche aus insgesamt zwölf 
Komponenten besteht (Filloux et al., 1998). Zudem sind spezielle Faltungshelfer (Foldasen) nötig (Jäger et al., 1994). Gleiches gilt zum Beispiel für Lipasen aus B. glumae (Frenken et al., 1993) oder P. alcaligenes (Gerritse et al., 1998).

Ein zweites System ist der ABC-abhängige Transport, die Typl-Sekretion (Binet et al., 1997). Dies besteht nur aus drei Komponenten, einer ATPase (ABC-Protein), einem Membranfusionsprotein und einem Protein in der äußeren Membran. Im Gegenteil zu den N-terminalen Signalpeptiden der Typ-II-Sekretion, weisen auf diesem Weg exportierte Proteine C-terminale Erkennungssequenzen auf. Die meisten Lipasen der Famile I.3, zu denen viele $P$. fluorescens-Lipasen zählen, werden auf diesem Wege sekretiert (Arpigny und Jäger, 1999). Auch LipCE lässt sich aufgrund der Sequenzhomolgie und des Vorhandenseins dieser C-terminalen Sekretionssignale (III.4.1.3) zweifelsfrei in die Familie I.3 eingruppieren. Von mehreren P. fluorescensLipasen ist bekannt, dass sowohl Lipase als auch die drei Komponenten des ABCTransporters in einem Operon organisiert vorliegen. Der Transporter ist sehr spezifisch für diese Lipase, z.T. werden auch Proteasen (Duong et al., 1994) oder Komponenten des S-Layers (Kawai et al., 1998) hierdurch sekretiert. Es existieren verschiedene Operonstrukturen, denen gemeinsam ist dass sich die Lipase stromabwärts des ABCTransporters befindet. Stromaufwärts davon finden sich in der Regel eine alkalische Protease, die ebenfalls von diesem System sekretiert wird, sowie deren Inhibitor. In verschiedenen $P$. fluorescens-Isolaten unterscheidet sich dieses Operon dadurch, dass bis zu zwei weitere Gene mit Homologie zu Serinproteasen zwischen Lipase und ABCTransporter liegen. In keinem der gezeigten Fälle (Abb. 57) konnte diesen Genen jedoch eine Aktivität nachgewiesen werden. Auch auf pCosCE2 fand sich eins dieser Gene, jedoch ebenfalls ohne Protease-Aktivität. Die Operonstrukturen der Gene in verschiedenen $P$. fluorescens-Stämmen ist in Abbildung 57 gezeigt. Abweichend davon ist die Anordnung in Serratia marcescens, wo sowohl Lipasegene als auch der zugehörige ABC-Transporter hohe Homologie zu P. fluorescens aufweisen, jedoch auf dem Chromosom voneinander getrennt sind (Akatsuka et al., 1995). Die hohe Sequenzhomolgie von LipCE zu den P. fluorescens-Lipasen aus SIK W1, B52 oder no. 33 spricht dafür, dass diese Operonstruktur auch in diesem Fall vorliegt, bei der Cosmidbankerstellung wurde dieser in 5'-Richtung liegende Teil jedoch getrennt. 


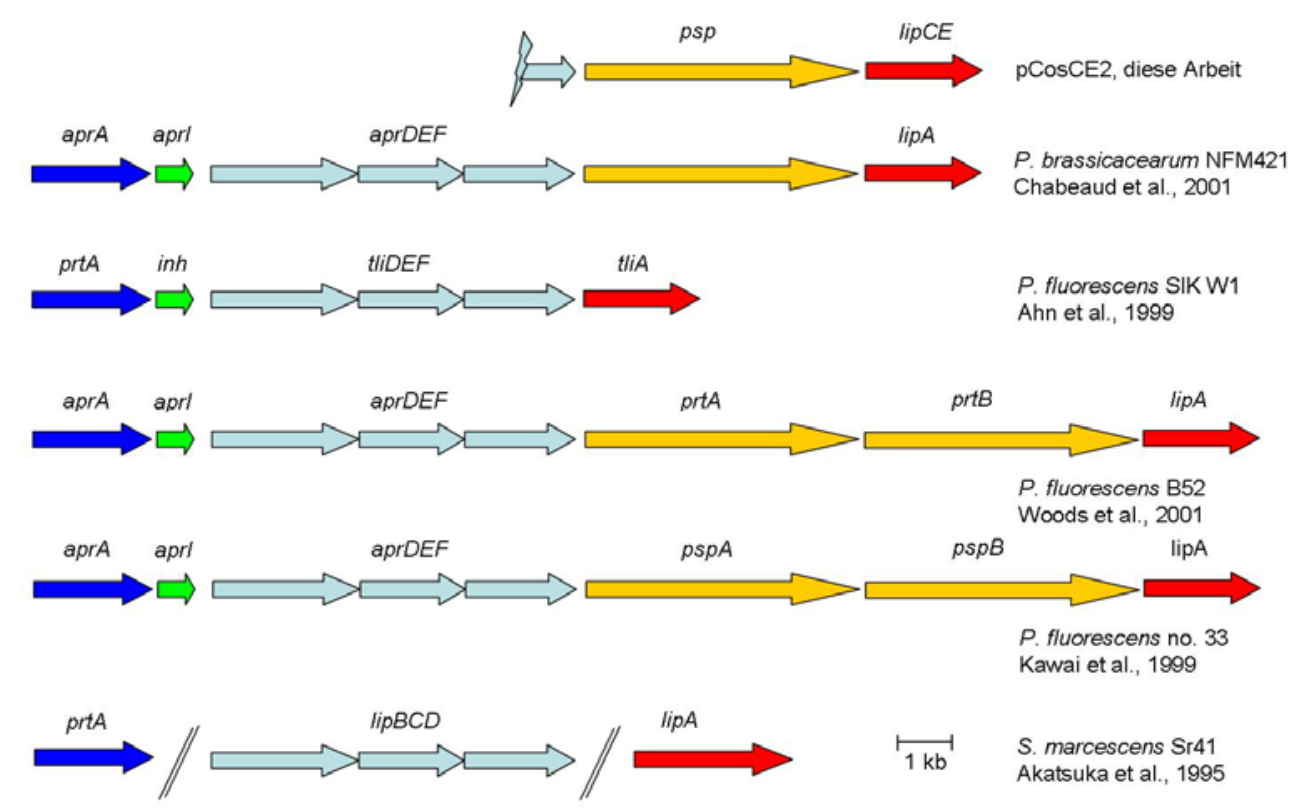

Abb. 57: Operonstrukturen von Familie I.3-Lipasen und deren spezifischen ABCTransportern in verschiedenen $P$. fluorescens-Stämmen sowie S. marcescens.

Homologe Gene sind identisch gefärbt, die verschiedenen Namen für die jeweiligen Stämme übernommen. Dunkelblau: alkalische Protease, hellgrün: Proteaseinhibitor, hellblau: ABCTransporter (1. Gen: ABC-Protein, 2. Gen: Membranfusionsprotein, 3. Gen: Protein der äußeren Membran), gelb: Serinprotease-Homologe, rot: Lipase. pCosCE2 wurde bei Erstellung der Cosmidbank getrennt (hellblauer Pfeil).

Obwohl viele ähnliche $P$. fluorescens-Lipasen bekannt sind, gelang bei keiner dieser Lipasen die heterologe Expression in E. coli bei alleiniger Expression des Lipasegens. Stets war die Bildung unlöslicher Einschlusskörper die Folge (Chung et al., 1991; Kojima und Shimizu, 2003; Kim et al., 2005; Luo et al., 2006). Erst die gleichzeitige CoExpression der drei Gene für den ABC-Transporter ermöglichte in E. coli die Sekretion aktiven Proteins in den Kulturüberstand (Ahn et al., 1999; Kawai et al., 1999). Auch bei heterologer Expression in anderen Pseudomonas sp. gelang so die Sekretion (Ahn et al., 2001). P. aeruginosa, der ein Typl-Sekretionssystem besitzt (Stover et al., 2000) war als Wirt nicht in der Lage, LipCE zu sekretieren [III.4.4.2]. Das P. aeruginosaSystem ist scheinbar zu speziell und sekretiert nur die alkalische Protease (Guzzo et al., 1991), ein Hämbindeprotein (Letoffe et al., 1998) sowie AprX, dessen Funktion nicht bekannt ist (Duong et al., 2001).

Die Co-Expression wäre eine zukünftige Option für die Expression von LipCE, da sich die Reinigung aus dem Kulturüberstand wesentlich leichter gestaltet als die Rückfaltung aus Einschlusskörpern. Dadurch würde sich auch die Attraktivität des Enzyms hinsichtlich seiner Verwendung erhöhen, da die Zugänglichkeit eines Enzyms 
unter den Aspekten biotechnologischer Anwendbarkeit ein wichtiger Parameter ist (Lorenz und Eck, 2005).

\subsection{Alternative Expressionssysteme für die Metagenomik}

Um die oben geschilderten Probleme bei der heterologen Produktion von Exoenzymen oder auch die allgemeinen Probleme wie Transkription der Gene, fehlende Erkennung der Promotoren, korrekte Proteinfaltung oder posttranslationale Modifikationen zu umgehen, ist die Entwicklung neuer Wirts- und Expressionssysteme notwendig. Erste Ansätze mit der Expression von Metagenombanken in Wirten wie Streptomyces lividans (Wang et al., 2000) oder Pseudomonas putida (Martinez et al., 2004) zur Expression von Sekundärmetaboliten (Antibiotika) wurden bereits erfolgreich unternommen, stellen bislang jedoch die Ausnahme dar. Da jedoch davon auszugehen ist, dass in E. coli 60\% aller Fremdgene gar nicht exprimiert werden (Gabor et al., 2004), geht immer noch ein immenses Potential ungenutzt verloren.

Insbesondere für die Produktion von Exoenzymen wie z.B. der Lipase LipCE sollte verstärkt der Einsatz alternativer Wirte vorangetrieben werden, die über alternative Sekretionssysteme zu E. coli verfügen. In Frage kämen dafür Bacillus-Arten, Streptomyces-Arten oder Rhizobien, aber auch eukaryotische System wie Hefen, die über viele Lipasen verfügen. Für diese Organismen stehen meist bereits etablierte genetische Systeme zur Verfügung. Erwähnenswert ist in diesem Zusammenhang die heterologe Expression zweier Metagenomlipasen in der Hefe Pichia pastoris (Jiang et al., 2006). Beide weisen hohe Ähnlichkeit zu LipCE auf (85\%) und anderen $P$. fluorescens-Enzymen der Familie I.3 auf. Hier konnten diese Enzyme erstmalig unter Verwendung der natürlichen Systeme des Wirtes ohne Co-Enzyme aktiv heterolog exprimiert und sekretiert werden, ein für Lipasen vielversprechender Ansatz.

\section{Herkunft der klonierten metagenomischen DNA}

Ausgehend von der Tatsache, dass bislang nur ein Bruchteil aller Mikrooganismen kultiviert werden kann (Amann et al., 1995) ist es natürlich schwierig, bei metagenomischen DNA-Fragmenten Aussagen über deren Herkunft zu treffen.

Im Falle des klonierten Fragmentes, welches das lipCE-Gens und die umgebenden Gene trägt, ist davon auszugehen, dass es aufgrund der hohen Sequenzhomologie von bis zu $88 \%$ aus einer $P$. fluorescens-Art oder einem nahen Verwandten stammt. Bislang wurden deren Lipasen überwiegend auf klassischem Wege aus kultivierten Pseudomonaden isoliert. Viele $P$. fluorescens-Stämme, deren Lipasegene hohe 
Ähnlichkeit zu LipCE aufwiesen wurden aus Boden- und auch Wasserproben weltweit isoliert und in Reinkultur gewonnen (Tab. 23). Zudem sind diese Pseudomonaden bekannte Produzenten psychrophiler Enzyme, die im Zusammenhang mit dem Verderben von Milchprodukten stehen (Cousin, 1982; Rajmohan et al., 2002).

Tab. 23: Auswahl einiger lipaseproduzierender Pseudomonaden, deren Lipasen hohe Ähnlichkeit zu LipCE aufweisen.

\begin{tabular}{llll}
\hline Stamm & Herkunft & $\begin{array}{c}\text { Identität } \\
\text { lipCE }\end{array}$ & Referenz \\
\hline P. fl. B52 & Rohmilch & $87 \%$ & Tan und Miller, 1993 \\
P. fl. B68 & Bodenproben & $88 \%$ & Gao et al., 1989 \\
P. br. NFM421 & Wurzelkolonisierende Isolate, Boden & $77 \%$ & Achouak et al., 2000 \\
P. fl. LS107d2 & Ziegenmilch & $84 \%$ & Cox und MacRea, 1989 \\
P. fl. SIK W1 & Rohmilch & $84 \%$ & Anderson et al., 1979 \\
P. sp. KB700A & Wasserproben & $86 \%$ & Rashid et al., 1999 \\
\hline
\end{tabular}

(P. fl.: P. fluorescens, $P$. sp.: $P$. species, $P$. br.: $P$. brassicacearum), ${ }^{1}$ Identität des jeweiligen Lipasegens zum lipCE-Gen auf Nukleotidebene

Das komplett sequenzierte Teilstück des Cosmides pCosCE1, auf welchem das estCEGen liegt, läßt sich hingegen nicht so einfach bekannten Vertretern zuordnen. Hier fällt zum einen der stark variierende GC-Gehalt der sechs ORFs auf (Tab.8, Kapitel III.2.3). ORF3, ORF5 und estCE weisen einen GC-Gehalt von etwa 51\%, die übrigen ORFs einen GC-Gehalt von etwa 57\% auf. Die Annotierung der sechs ORFs (Tab. 8) weist zudem unterschiedlichste nächste Verwandte für die Blast-Treffer aus, die sowohl aus dem Phylum der Proteobacteria als auch dem der Firmicutes, zwei gänzlich verschiedenen Linien stammen. Beide Faktoren zusammen lassen den Schluss zu, dass dieses DNA-Fragment aus einem Organismus stammt, der zumindest in diesem Bereich Teile seines Genoms durch horizontalen Gentransfer (Gogarten und Townsend, 2005; Thomas und Nielsen, 2005) erworben hat.

Auffällig ist weiterhin, dass drei der sechs ORFs mit Antibiotikaresistenzmechanismen in Verbindung gebracht werden (III.2.3), einer der ORFs (ORF6/SST1) sogar für eine funktionelle $\beta$-Laktamase kodierte (III.3). Dies ist angesichts der Herkunft aus einer Bodenprobe, die wahrscheinlich nicht in Kontakt mit Antibiotika gekommen sein dürfte zunächst auffällig. Das Auftreten von Antibiotikaresistenzen wurde meist mit dem Auftreten pathogener Stämme und den damit verbundenen Problemen in Verbindung 
gebracht und wegen seiner großen Bedeutung für den Menschen auch wesentlich intensiver erforscht. Der Boden wurde als Reservoir von Antibiotikaresistenzen bislang nur selten erforscht (Nwosu, 2001; Séveno et al., 2002). In Anbetracht der Tatsache, dass natürliche Antibiotikaproduzenten wie Streptomyceten auch Bewohner des Bodens sind, ist das Auftreten von Resistenzen allerdings zu vermuten. Die Tatsache, dass das Auftreten antibiotikaresistenter Stämme meist mit klinischen Isolaten in Verbindung gebracht wurde, sollte also überdacht werden (Salyers und AmabileCuevas, 1997). Auch die Metagenomforschung lieferte hierzu neue Einblicke, so wurden bereits neue Resistenzgene gegen Aminoglykosidantibiotika gefunden (Stokes et al., 2001). Die meisten Metagenomstudien suchten bisher jedoch nach antimikrobiellen Aktivitäten (Gillespie et al., 2002; Courtois et al., 2003). In einer Studie konnten kürzlich zehn neue, sehr divergente Resistenzgene, vornehmlich gegen Aminoglykosidantibiotika, mit nur geringer Identität $(<60 \%)$ zu bislang bekannten Proteinen und hoher genetischer Diversität identifiziert werden (Riesenfeld et al., 2004). Das Metagenom des Bodens scheint also ein Reservoir neuer Antibiotikaresistenzgene zu sein, in dem sich noch völlig neue, bis heute unbekannte Mechanismen finden lassen.

\section{Biochemische Charakterisierung der Enzyme}

\subsection{Klassifizierung der Enzyme}

Lipolytische Enzyme lassen sich in Carboxylesterasen [EC 3.1.1.1] sowie echte Lipasen unterscheiden [3.1.1.3] (Jäger et al., 1994). Die Unterschiede beruhen im Wesentlichen auf der Fähigkeit kurzkettige, wasserlösliche Substrate (Esterasen) bzw. langkettige, wasserunlösliche Substrate (Lipasen) umzusetzen. Lipasen sind meist auch in der Lage, kürzerkettige Substrate umzusetzen, jedoch liegt die maximale Aktivität bei Substraten mit einer Kettenlänge $\geq$ C10. Anhand dieser Kriterien lassen sich EstCE (Maximumaktivität $\mathrm{C} 4$, kein Umsatz längerkettiger Substrate $\geq \mathrm{C} 8$ ) eindeutig als Esterase und LipCE eindeutig als Lipase klassifizieren. Ein weiteres Kriterium sind kinetische Daten, die allerdings nicht ausschließlich herangezogen werden können. Die meisten Lipasen, aber nicht alle, zeigen das Phänomen der Grenzflächenaktivierung (Verger, 1997), es sind aber auch Lipasen beschrieben, bei denen dieses Phänomen nicht auftritt. Esterasen hingegen folgen einer klassichen Michaelis-Menten-Kinetik, da sie nicht auf die Bildung von Substratemulsionen angewiesen sind. Bei EstCE waren sowohl mit pNP-Buytrat als Substrat (III.2.7.10) sowie Tribuytrin (Daten nicht gezeigt) keine Grenzflächenaktivierung sondern ein sigmoider Kurvenverlauf in der Kinetik zu beobachten. LipCE hingegen zeigte bei 
Verwendung von pNP-Caprat bis pNP-Palmitat (III.4.4.11) einen sprunghaften Anstieg der Aktivität bei Erreichen einer gewissen Substratkonzentration, was ebenfalls für die Einteilung von EstCE als Esterase und LipCE als Lipase spricht.

\subsection{Identifizierung des katalytischen Nukleophils in EstCE - Hinweise auf den Reaktionsmechanismus}

Der Reaktionsmechanismus „klassischer" Lipasen mit den konservierten Strukturmotiven G-x-S-x-G bzw. G-D-S-L, welche das Serin als katalytisches Nukleophil umgeben ist seit langem bekannt (siehe Einleitung). Durch die bislang relativ geringe Anzahl an Mitgliedern der Lipasefamilie VIII sind bislang kaum Kristallstrukturen und somit wenig über den Reaktionsmechanismus dieser Familie bekannt.

Nachdem sowohl für EstB von B. gladioli (Petersen et al., 2001) und die Metagenomesterase EstA3 (Schmeißer, 2004) der Serinrest innerhalb des $\beta$ Laktamase-Motives eindeutig als katalytisches Nukleophil identifiziert werden konnte, wurde dies auch für EstCE gezeigt (III.2.7.12). Trotz hoher Ähnlichkeit zu $\beta$ Laktamasen konnte für keines der drei Enzyme eine Spaltung des $\beta$-Laktam-Ringes nachgewiesen werden. Aus der Kristallstruktur von EstB (Wagner et al., 2002) ließen sich durch molekulares Modellieren und Vergleiche mit der $\beta$-Laktamase P99 aus Enterobacter cloacea Hinweise darauf finden, dass dies hauptsächlich auf sterische Gründe zurückzuführen ist. Der Zugang zum aktiven Zentrum ist in EstB durch das Vorhandensein eines Loops schmaler gestaltet als in P99 und somit hat der voluminösere $\beta$-Laktam-Ring keinen Zugang zum katalytischen Serinrest. Eine Vorhersage der Sekundärstruktur für EstCE auf dem Predict Protein Server (Rost et al., 2004) sagt auch in EstCE einen Loop an dieser Stelle vorher. Zudem unterscheiden sich $\beta$-Laktamase P99 von den Esterasen EstB und EstCE durch einige Aminosäuren, die am Katalysemechanismus beteiligt sind (Tab. 24, Abb. 58). Für EstA3 wurde die Kristallstruktur ebenfalls gelöst (unveröffentlicht), auch dort finden sich sterische Gründe, die $\beta$-Laktamase-Aktivität verhindern (Streit, W., pers. Mitteilung).

Wagner und Mitarbeiter postulieren für EstB aus Vergleichen mit der Kristallstruktur von P99 folgende an der Katalyse beteiligte Aminosäuren (Abb. 58 B). Ser75 agiert als katalytisches Nukleophil, Tyr181 als protonakzeptierende Base, Lys78 und Trp348 stabilisieren durch positive Ladungen die anionische Form von Tyr181. Tyr133 interagiert über eine Wasserstoffbrücke mit Lys78 und gleichzeitig mit dem Substrat. Die Oxyanion-Stabilisierung des Acyl-Enzym-Komplexes wird durch Wasserstoffbrücken zwischen dem Substrat-Carbonyl-Sauerstoff und Aminogruppen 
der Hauptkette von Ser75 und Val318 gewährleistet (Wagner et al., 2002). Bei einem Alignment der Primärstrukturen von EstB und EstCE (Abb. 11) fällt auf, dass alle Positionen bei EstCE mit identischen Aminosäuren besetzt sind. Auch eine 3-DVorhersage der Struktur von EstCE mit „SWISS-MODEL“ (Kopp und Schwede, 2006) anhand der Struktur von EstB (PDB-Nummer 1ci9a) weist die angesprochenen Rest an räumlich identischen Stellen aus (Abb. 58 A, Tab. 24), so dass die Katalyse in EstCE mit hoher Wahrscheinlichkeit nach demselben Muster wie in EstB ablaufen wird.
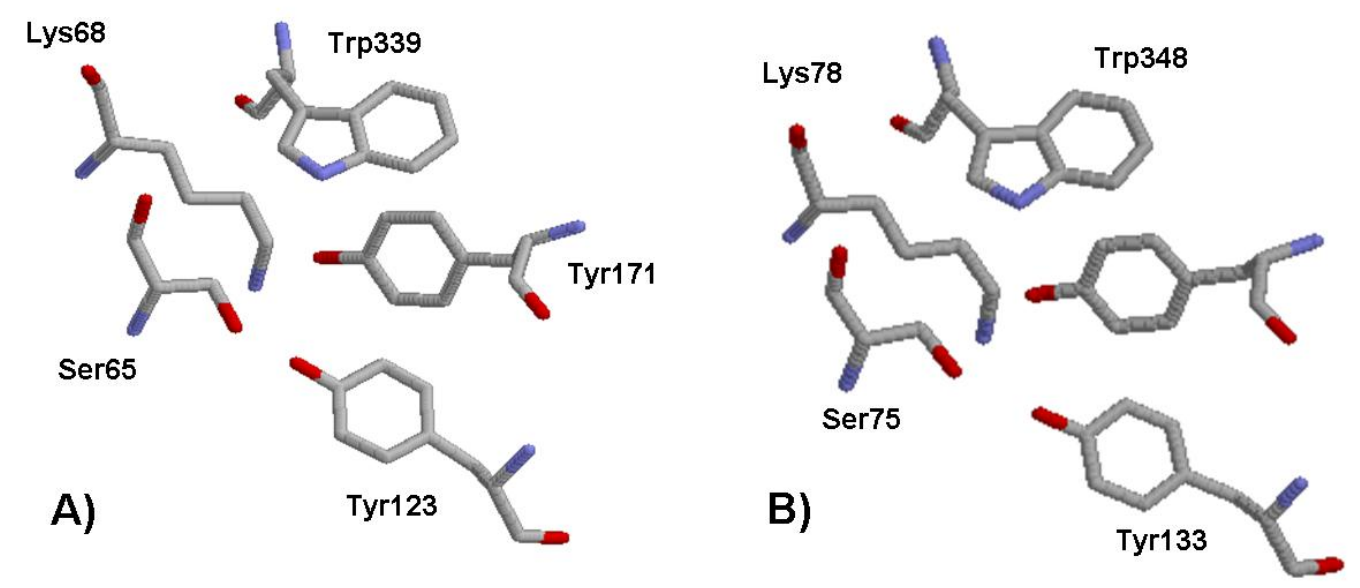

Abb. 58: Räumliche Anordnung der Aminosäuren im aktiven Zentrum

A) Vorhersage der Anordnung der Aminosäuren im aktiven Zentrum für EstCE anhand von Strukturvorhersagen mit SWISS-Model (Kopp und Schwede, 2006). B) Anordnung der Aminosäuren im aktiven Zentrum von EstB aus B. gladioli, PDB-Eintrag 1ci9a (Wagner et al., 2002). Grafiken erstellt mit RasMol (Sayle und Milnar-White, 1995).

Tab. 24: An der Katalyse beteiligte, räumlich äquivalente Reste zwischen der $\beta$ Laktamase P99 sowie den Esterasen EstB und EstCE

\begin{tabular}{l|llllllll}
\hline P99 & Ser64 & Lys67 & Asn152 & Tyr150 & Lys315 & Thr316 & Gly317 & Ser318 \\
\hline EstB & Ser75 & Lys78 & Tyr133 & Tyr181 & Trp348 & Gly349 & Gly350 & Val351 \\
\hline EstCE & Ser65 & Lys68 & Tyr123 & Tyr171 & Trp339 & Gly340 & Gly341 & Val342 \\
\hline
\end{tabular}

\subsection{Aktivität der Enzyme}

Die Lipasedatenbank „Lipase Engineering Database“ der Universität Stuttgart (Fischer und Pleiss, 2003) listet alleine 1796 Lipasegene und 1386 zugehörige Proteine auf (Stand 31.07.2006, Release-Nr. 2.3). Hierdurch stehen eine Menge Daten für Aktivitäten und Substratumsetzungen zur Verfügung. Bedauerlicherweise stehen demgegenüber eine ähnliche große Anzahl an Testsystemen, so dass sich die beschriebenen Werte selten direkt miteinander vergleichen lassen. Auf einen 
ausgiebigen Vergleich spezifischer Aktivitäten wird daher an dieser Stelle weitestgehend verzichtet, sondern nur eine relative Einordnung der ermittelten Werte gegeben.

Für EstCE wurden mit kurzkettigen Substraten (pNP-Ester, Vinylester, Triglyceride) nur sehr schwache Aktivitäten ermittelt, die von kommerziell vertriebenen Enzymen wie z.B. Lipozyme ${ }^{\circledR}$ (Novo-Nordisk, DK) weit übertroffen werden. So stehen einer Aktivität von $16 \mathrm{U} / \mathrm{mg}$ mit Vinylbutyrat $11.000 \mathrm{U} / \mathrm{mg}$ gegenüber oder $55 \mathrm{U} / \mathrm{mg}$ mit Tributyrin $2.200 \mathrm{U} / \mathrm{mg}$.

Die Aktivitäten von LipCE gegenüber pNP-Acylestern hingegen lagen wesentlich höher (pNP-Caprat $2.020 \mathrm{U} / \mathrm{mg}$, pNP-Palmitat $825 \mathrm{U} / \mathrm{mg}$ ). Die höchsten Werte, die für bakterielle Lipasen beschrieben werden liegen in ähnlichen Bereichen, teilweise auch darüber (Gupta et al., 2004).

\section{4. pH-Optimum und Stabilität der Enzyme}

Die Mehrheit der lipolytischen Enzyme weist ein pH-Optimum im neutralen bis alkalischen pH-Bereich auf (Gupta et al., 2004). Stabilität und hohe Aktivität bei sauren $\mathrm{pH}-$ Werten ist hingegen nur bei wenigen Enzymen bekannt. Beispiele für $\mathrm{pH}-O p$ tima im sauren Bereich sind die Lipase aus P. fluorescens SIK W1 ( $\mathrm{pH} \mathrm{4,8,} \mathrm{Anderson} \mathrm{et} \mathrm{al.,}$ 1979), Aspergillus nidulans ( $\mathrm{pH} 6,5$, Mayordomo et al., 2000) oder die Metagenomesterase EstE1 (pH 6, Rhee et al., 2005).

Auch die beiden in dieser Arbeit beschrieben Enzyme bilden dabei keine Ausnahme, mit pH-Optima von 7 (LipCE) bzw. 10 (EstCE). Das hohe pH-Optimum von EstCE und insbesondere die Aktivität von wenigstens $50 \%$ über einen sehr breiten $\mathrm{pH}$-Bereich von 6 bis 11 finden sich nur bei wenigen Lipasen oder Esterasen. Aktivität und Stabilität über einen ähnlich breiten pH-Bereich wird zum Beispiel für die Lipasen aus P. fluorescens NS2W (stabil von pH 3-11, Kulkarni und Gadre, 2002), P. cepacia DSM50181 (stabil von pH 2-12, Dunhaupt et al., 1991) und die Esterasen aus Archaeoglobus fulgidus DSM4304 (pH 6-12, Rusnak et al., 2005) oder Bacillus subtilis 168 ( $\mathrm{pH}$ 5-12, Eggert et al., 2000) berichtet. Attraktiv sind solche Eigenschaften hinsichtlich Stabilität und Aktivität wie sie EstCE aufweist, für Anwendungen unter stark alkalischen Bedingungen in der Waschmittelindustrie (Jäger und Reetz, 1998).

Ein pH-Optimum wie es LipCE aufweist, sowie der enge Aktivitätsbereich von $\mathrm{pH}$ 6-9 sind hingegen Charakteristika, wie sie für viele Lipasen bekannt sind (Gupta et al., 2004). 


\subsection{Thermische Eigenschaften von EstCE und LipCE}

\subsubsection{EstCE, eine Esterase mit mesophilen Eigenschaften}

Hinsichtlich des Aktivitätsmaximums der Reaktionstemperatur $\left(47^{\circ} \mathrm{C}\right)$ sowie der moderaten thermischen Stabiliät weist EstCE Merkmale eines klassischen mesophilen Enzyms auf, wie es für die Mehrheit der beschriebenen Lipasen zu finden ist (Gupta et al., 2004). Die in Tabelle 22 aufgelisteten Metagenomenzyme zeigen sehr ähnliche Charakteristika mit Ausnahme der Esterase EstE1, die aus einer heißen Quelle isoliert wurde und ein Maximum an Aktivität bei $95^{\circ} \mathrm{C}$ besitzt (Rhee et al., 2005).

\subsubsection{LipCE, eine neue kälteaktive Lipase}

LipCE hingegen wies Aktivitätsmaxima bei niedrigen Temperaturen $\left(25^{\circ} \mathrm{C}\right.$ mit pNPLaurat als Substrat) und hohe Restaktivität $(28 \%)$ bei $0^{\circ} \mathrm{C}$ auf. Unter den nahe verwandten $P$. fluorescens-Lipasen der Familie 1.3 finden sich viele kälteaktive Enzyme, was darauf zurückzuführen ist, dass viele $P$. fluorescens-Stämme als psychrophil beschrieben sind (Cox und MacRea, 1989; Dieckelmann, et al., 1998; Rajmohan et al., 2002). Mit der Mehrheit dieser Lipasen hat LipCE die hohe Thermolabilität und niedrige Temperaturoptima gemeinsam. Ein niedrigereres Temperaturoptimum wird hierbei nur für die Lipase aus $P$. fluorescens B68 $(91 \%$ Identität zu LipCE) beschrieben. Deren Optimum liegt bei $20^{\circ} \mathrm{C}$ mit pNP-Caprat als Substrat, die Restaktivität beträgt bei $0^{\circ} \mathrm{C}$ noch immer 50\% (Luo et al., 2006). Zudem ist aus Acinetobacter sp. No. 6 eine Lipase mit Optimum bei $20^{\circ} \mathrm{C}$ und $57 \%$ Restaktivität bei $4^{\circ} \mathrm{C}$ beschrieben (Suzuki et al., 2001).

\subsubsection{Molekulare Gründe für die Kälteaktivität}

Bei einem direkten Vergleich mit einem weiteren Mitglied der Lipasefamilie I.3, der Lipase TliA aus $P$. fluorescens SIK W1 fällt hingegen auf, dass dieses Enzym wesentlich thermostabiler ist und ein Aktivitätsmaximum zwischen $45^{\circ} \mathrm{C}$ und $55^{\circ} \mathrm{C}$ aufweist (Lee et al., 1993). Dies ist insofern überraschend, da es sich in der Primärstruktur von LipCE und vielen weiteren psychrophilen $P$. fluorescens-Lipasen mit einer Größe von 474 AS bzw. 476 AS und fast 90\%iger Identität kaum unterscheidet (u.a. Johnson et al., 1992; Rashid et al., 2001; Woods et al., 2001). Alle anderen Enzyme besitzen Temperaturoptima zwischen $20^{\circ} \mathrm{C}$ und $30^{\circ} \mathrm{C}$ und werden bei Temperaturen über $30^{\circ} \mathrm{C}$ sehr schnell inaktiviert.

Die strukturellen Mechanismen der Kälteadaption von Proteinen sind bei weitem noch nicht verstanden, zumal erst wenige Kristallstrukturen existieren (Feller, 2003). Ein Erklärungsansatz liegt in einer höheren Flexibilität der Proteine, wodurch strukturelle 
Veränderungen im aktiven Zentrum eine niedrigere Aktivierungsenergie benötigen (D'Amico et al., 2003; Feller, 2003). Darin beruht auch eines der wesentlichen Merkmale von kälteadaptierten Enzymen, ihre höhere spezifische Aktivität bei niedrigen Temperaturen, verglichen mit mesophilen Enzymen gleichen Reaktionstyps (Gerday et al., 2000). Dies ist jedoch gleichzeitig mit thermischer Instabilität verbunden (Marx et al., 2004), wie es auch bei LipCE zu beobachten war. Mögliche Erklärungen liegen in der Aminosäurezusammensetzung der Proteine. Kälteaktive Proteine exponieren häufig mehr geladene Aminosäuren an der Oberfläche, der Anteil an Prolin und Arginiresten sinkt, der Anteil an Glycinresten kann steigen, um mehr Flexibilität zu gewährleisten (Gerday et al., 2000). Oft lässt sich dies auch am Verhältnis Arg/(Arg+Lys) festmachen, welches häufig mit größerer Proteinflexibilität korreliert (Feller et al., 1996). Dies ist jedoch nicht immer im direkten Vergleich mit mesophilen Enzymen der Fall (Lanes et al., 2002; Coker et al., 2003; Luo et al., 2006). Betrachtet man das Verhältnis der Aminosäuren in den Lipasen LipCE, LipB68 und TliA sowie der mesophilen S. marcesens-Lipase der Familie I.3 (Abb. 59) sieht man, dass dies als Erklärung für die ungewöhnlich hohen Aktivitäts- und Stabilitätsunterschiede nicht in Frage kommt. TliA unterscheidet sich von LipCE nur in 54 AS, wobei nur in 13 Fällen polare gegen hydrophobe Aminosäuren ausgetauscht wurden. Diese Beobachtungen decken sich mit den Vergleichen zwischen KB-Lip (Rashid et al., 2001) und TliA und sollten diese Aminosäuren zu Zielen von möglichen Mutagenesestudien machen. Im Verhältnis polarer zu unpolarer Aminosäuren sowie Arg/(Arg+Lys)-Verhältnis unterscheiden sie die Enzyme ebenfalls kaum. Disulfidbrücken, deren Rolle in der Kälteadaption hinsichtlich der Stabilität ebenfalls diskutiert werden (Russel, 2000; Siddiqui et al., 2005), kommen für mögliche Erklärungen nicht in Betracht, da weder LipCE noch LipB68 oder TliA Cysteinreste besitzen.

Im Vergleich zu thermostabilen Lipasen aus P. cepacia (Guo et al., 2006) oder den thermophilen Esterasen EstE1 (Rhee et al., 2005) und EstPC (Hotta et al., 2002) treffen die Aussagen hinsichtlich Kälteadaption jedoch zu. Hier zeigt LipCE einen höheren Anteil polarer Aminosäuren, weniger Glycin-, Prolin und Argininreste, ein niedrigereres $\mathrm{Arg} /(\mathrm{Arg}+\mathrm{Lys})$-Verhältnis sowie einen niedrigereren isoelektrischen Punkt. Leider fehlen bis heute Kristallstrukturen für Enzyme dieser Familie, um die Unterschiede auf molekularer Ebene erklären zu können. 


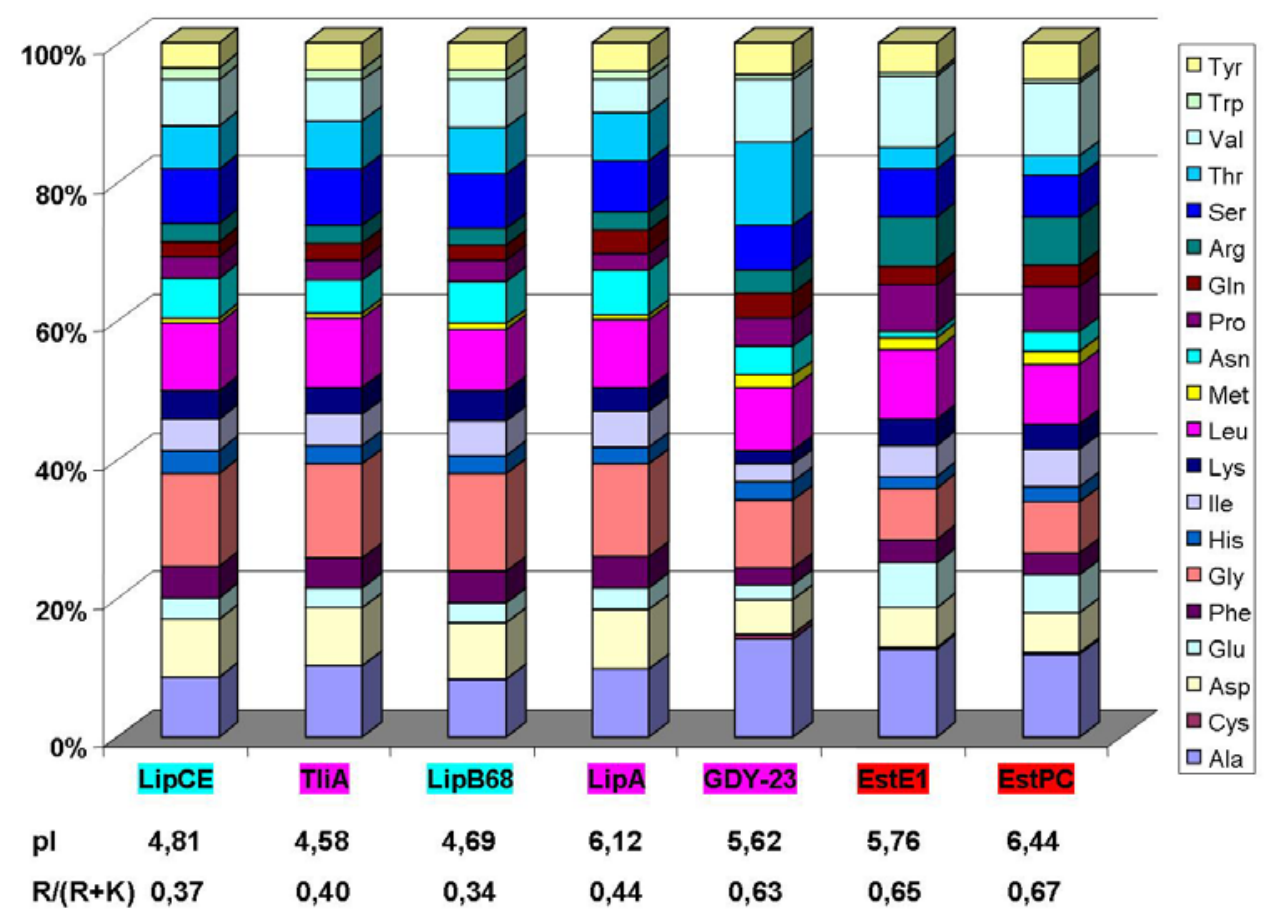

Abb. 59: Aminosäurezusammensetzung verschiedener Lipasen und Esterasen

Kälteaktive Enzyme sind blau hinterlegt, moderat thermostabile Enzyme sind rosa hinterlegt und thermophile Enzyme rot. Darunter sind der isoelektrische Punkt (pl) sowie das Verhältnis Arg/(Arg+Lys) angegeben. LipCE, diese Arbeit; TliA, Lipase aus P. fluorescens SIK W1; LipB68, Lipase aus P. fluorescens B68; LipA: Lipase aus S. marcescens; GDY-23: Lipase aus $P$. cepacia GDY-23, EstE1: Metagenomesterase; EstPC: Esterase aus Pyrobaculum calidifontis.

\subsubsection{Kälteaktive Enzyme aus dem Metagenom}

Unabhängig vom Metagenomansatz wurde in der Erforschung der Extremophilen bislang wesentlich mehr Aufmerksamkeit den Thermophilen als den Psychrophilen gewidmet (Marx et al., 2004). Doch gerade kälteaktive Enzyme bieten hinsichtlich biotechnologischer Anwendungen eine Menge Vorteile, wie niedrigen Energiebedarf, was für die Wasch- und Nahrungsmittelindustrie interessant ist (Gerday et al., 2000).

Die Isolierung kälteaktiver Enzyme ging bislang klassich einher mit der Kultivierung psychrophiler Organismen, meist Bakterien (Groudieva et al., 2004) oder Hefen (Birgisson et al., 2003). Der Metagenomansatz hat bis heute fast gar nicht zur Entdeckung neuer Enzyme in diesem Feld beigetragen. Erst kürzlich wurde als erstes psychrophiles Metagenomenzym eine kälteaktive Xylanase mit einem Temperaturoptimum von $20^{\circ} \mathrm{C}$ aus Molkereiabwässern isoliert (Lee et al., 2006). Somit ist LipCE das zweite kälteaktive Enzym metagenomischen Ursprungs. Die psychrophilen Eigenschaften dieses Enzyms lassen sich durch dessen Herkunft und anhand des Zeitpunkts der Probennahme im Winter aus teilweise gefrorenem Boden erklären. 


\subsection{Substratspezifität der beiden Enzyme}

Ein wesentlicher Punkt, der Lipasen und Esterasen zu interessanten Enzymen für biokatalytische Zwecke macht, ist ihre hohe Enantioselektivität und damit ihre Anwendung in der Synthese chiraler Produkte (Jäger und Eggert, 2002).

\subsubsection{Enantioselektive Umsetzungen durch EstCE}

Für EstCE wurde durch GC-Analysen gefunden, dass enantioselektiv die Substrate Menthylacetat, cis-3,5-Diacetoxy-1-Cyclopenten sowie der Essigsäureester von trans1,2-Cyclohexandiol umgesetzt wurden (III.2.7.8), wobei für die letzten beiden Substanzen nicht genauer ermittelt werden konnte, welches Enantiomer bevorzugt wurde. Zudem war bei beiden Substraten eine Umsetzung beider Enantiomere festzustellen (ee von 66\% bzw. 33\%). Von racemischen Menthylacetat wurde hingegen nur das (+)-Enantiomer umgesetzt, d.h. es wurde ausschließlich (+)-Menthol gebildet.

Menthol kommt in der Natur als Geschmackstoff der Pfefferminze sowohl in (+)- als auch (-)-Konfiguration vor, wobei für die industrielle Verarbeitung nur das (-)Enantiomer benötigt wird. Während (+)-Menthol einen eher ungenießbaren Geschmack aufweist, findet (-)-Menthol als erfrischender Aromastoff (der typische Pfefferminzgeschmack) Anwendung in Zahnpasta, Pfefferminzölen, Kaugummis, Kosmetika und anderen Produkten (Athawale et al., 2001; Wang et al., 2002). Im industriellen Maßstab wird (-)-Menthol durch fraktionierte Destillation aus racemischem Menthylbenzoat gewonnen (Bornscheuer, 2002). Weitere Anwendungsfelder finden sich in der Polymerindustrie. Mithilfe der Lipase aus B. cepacia wird beispielsweise Menthylmethacrylat aus ( \pm )-Menthol und Oximmethacrylat hergestellt, welches ein Grundstoff für die Parfümherstellung ist. Unter Verwendung geeigneter Lösungsmittel wird für die B. cepacia-Lipase ein ee-Wert von 98,2\% berichtet (Athawale et al., 2001).

Ein neues Anwendungsgebiet für (-)-Mentholderivate fand sich zudem als Fungizid zur Bekämpfung des Schneefäulepilzes Micronectriella nivalis (Miyazawa et al., 2003).

Die in der Literatur beschriebenen Enzyme weisen bislang meist eine Stereospezifität für (-)-Menthol auf. Dazu gehören z.B. auch die Esterasen aus $B$. subtilis und $B$. stearothermophilus (Henke und Bornscheuer, 2002) oder Candida rugosa (Wang et al., 2002), die Enantiomerenüberschüsse von 95-99\% aufweisen. Bei diesen Enzymen finden sich jedoch relativ geringe Umsatzraten (B. subtilis-Esterase $10 \%$ nach $5 \mathrm{~h}$ ), ebenso bei kommerziellen Enzymen von Aspergillus niger bzw. der Schweinepankreaslipase, die 2-3\% in $120 \mathrm{~h}$ umsetzen (Wang et al., 2002). EstCE hingegen setzte in $24 \mathrm{~h} \mathrm{(+)-Menthylacetat} \mathrm{komplett} \mathrm{um.} \mathrm{Ähnlich} \mathrm{hohe} \mathrm{Umsatzraten} \mathrm{wurden} \mathrm{bei}$ 
entgegengesetzter Enantioselektiviät für Candida rugosa-Lipasen berichtet, allerdings bei Reaktionszeiten von 120 h (Cardenas et al., 2001; Wang et al., 2002).

EstCE ist soweit bekannt die erste Esterase mit so hohen ee-Werten hinsichtlich des $(+)$-Enantiomers. Bestimmt wurde dies in der Hydrolyse von ( \pm )-Menthylacetat, da aber davon auszugehen ist, dass ebenso die Rückreaktion katalysiert wird, bietet sich zur Darstellung reinen (-)-Menthols beispielsweise die Veresterung von ( \pm )-Menthol mit einer Säure an, wodurch (+)-Menthylester und leicht zu trennendes (-)-Menthol entstünden. Am Beispiel der Veresterung mit Essigsäure in Anlehnung an die Hydrolyse von Menthylacetat ist dies in Abb. 60 dargestellt. Auf jeden Fall steht mit EstCE ein Enzym für alternative Anwendungen zur Verfügung, die nicht primär auf die Umsetzung von (-)-Menthol ausgerichtet sind.

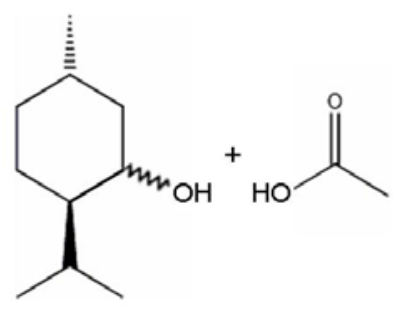

( \pm -Menthol Essigsäure

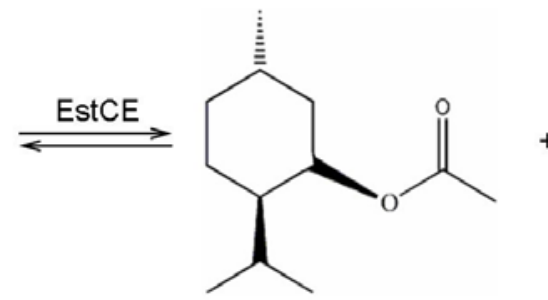

(+)-Menthylacetat

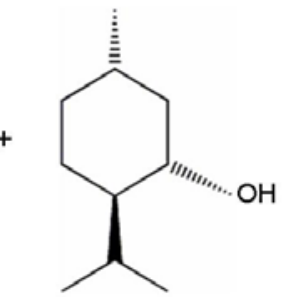

(-)-Menthol

Abb. 60. Enantioselektive Umsetzung von ( \pm )-Menthol durch EstCE zur Darstellung optisch reinen (-)-Menthols.

Zwei weitere Substrate, welche von EstCE umgesetzt wurden, waren die Essigsäureester von cis- und trans-1,2-Cyclohexandiol. Hier fielen insbesondere die hohen Umsatzraten auf. Die Enantiomere des cis-Isomers wurden beide bereits nach $12 \mathrm{~h}$ vollständig umgesetzt, wobei jedoch keine Stereospezifität beobachtet werden konnte. B. subtilis-Lipasen, welche stereospezifisch trans-1,2-Cyclohexandiol umsetzen, waren im Vergleich dazu gar nicht in der Lage cis-1,2-Cyclohexandiol umzusetzen (Detry et al., 2006). Stereospezifisch war dagegen die Umsetzung von trans-1,2-Cyclohexandiol durch EstCE, hier wurde bevorzugt das (S,S)-Enantiomer umgesetzt. Entgegengesetzte Stereospezifitäten wurden für Lipasen aus Pseudomonas sp. (Seemayer und Schneider, 1991), P. cepacia (Caron und Kazlauskas, 1991) oder B. subtilis (Lipase A und B) (Detry et al., 2006) beschrieben, die ausgehend von racemischem trans-1,2-Cyclohexandiol jeweils das $(R, R)$ Enantiomer verschieden stark bevorzugt umsetzten und sowohl Diole ( $P$. cepacia) als auch monoacetylierte Produkte produzierten (P. sp., B. subtilis, EstCE). Im Gegensatz zu EstCE betrugen bei diesen Enzymen die Reaktionszeiten teilweise bis zu 7 Tage. 
Kommerzielle Lipasen (Proteus Esterase No. 7 (Proteus, Frankreich), Schweineleberesterase (Fluka F-46058) und Acetylcholinesterase (Fluka F01022) bevorzugten das $(R, R)$-Enantiomer und waren im Gegensatz zu EstCE nicht in der Lage, (S,S)-trans-1,2-Cyclohexandiol zu spalten (Wahler et al., 2004).

Die auffallend hohen Umsätze einiger anderer in Abschnitt III.2.7.8 beschriebenen Substrate durch EstCE liegen wesentlich höher als bei den $B$. subtilis Lipasen A und B. (Detry et al., 2006). In Tabelle 25 sind diese gegenübergestellt.

Tab. 25: Substratumsatz künstlicher Substrate durch $B$. subtilis-Lipasen und EstCE (BSLA/BSLB: B. subtilis Lipase A und B, Detry et al., 2006), ' Substratumsatz nach $12 \mathrm{~h}$, ansonsten Substratumsatz nach $24 \mathrm{~h}$ Inkubation bei RT

\begin{tabular}{lccc}
\hline & \multicolumn{3}{c}{ Umsatz [\%] durch } \\
Essigsäureester von... & BSLA & BSLB & EstCE \\
\hline (rac)-1-Octin-3-ol & 46 & 28 & 62 \\
(R)-3-Chlor-1-Phenyl-1-Propanol & 75 & 67 & 100 \\
(rac)-Trimethylsilylbutinol & 41 & 5 & 100 \\
cis-1,2-Cyclohexandiol & 0 & 0 & $100^{1}$ \\
(R,R)-trans-1,2-Cyclohexandiol & 90 & 54 & 45 \\
(S,S)-trans-1,2-Cyclohexandiol & 0 & 0 & 100 \\
\hline
\end{tabular}

\subsubsection{Enantioselektive Umsetzungen durch LipCE}

Optisch reine Derivate der 2-Arylpropionsäure spielen eine wesentlich Rolle in der Herstellung nichtsteroidaler Antirheumatika, welche gegen Schmerzen, Fieber und Entzündungen eingesetzt werden. Sie entfalten ihre Wirkung durch Hemmung der Cyclooxygenasen I und II und inhibieren somit die Bildung entzündungsvermittelnder Prostaglandine (Alcántara et al., 2000). Zu dieser Gruppe gehören die Wirkstoffe Ibuprofen und Naproxen. Hierbei ist die optische Reinheit von besonderer Bedeutung, da nur eins der beiden Enantiomere schmerzstillende Wirkung entfaltet. Die Wirkung liegt jeweils beim (S)-Enantiomer, welches bei Naproxen 28fach (Roszokowski et al., 1973) und bei Ibuprofen 160fach (Hutt und Caldwell, 1984) wirkungsvoller ist. Die (R)Enantiomere sind praktisch wirkungslos (Caldwell et al., 1988).

Die chemoenzymatische Synthese, d.h. die Kombination aus chemischen und enzymatischen Prozessen gehört seit langem zum Standard. Zum Einsatz kommen hierbei Lipasen, vornehmlich aus der Gattung Pseudomonas (Alcántara et al., 2000; Liese et al., 2005) oder verschiedene Candida-Lipasen (Mustranta et al., 1992; Henke 
et al., 2000). Alternativ werden neben Lipasen aus Hefen oder Bakterien seit kurzem auch pflanzliche Lipasen aus Carica papaya (Papaya) mit hoher Enantioselektivität zur Darstellung von (S)-Naproxen eingesetzt ( $\mathrm{Ng}$ und Tsai, 2005). In der industriellen Synthese der Firma Pfizer Inc. (USA) wird mittels immobilisierter C. cylindraceaeLipase optisch reines (S)-Ibuprofen durch Hydrolyse aus $(R, S)$ Ibuprofenmethoxyethylester (ee 96\%) dargestellt (Liese et al., 2005).

Für die Umsetzung von racemischem Ibuprofen-pNP-Ester durch LipCE wurde eine ungewöhnlich hohe Stereospezifität gegenüber dem $(R)$-Enantiomer gefunden $(>91 \%$ ee, III.4.4.12). Abhängig von den jeweiligen Reaktionsbedingungen (Lösungsmittel, Temperatur, Druck) und dem Reaktionstyp (Esterbildung bzw. -hydrolyse) werden für die meisten Lipasen hohe Stereospezifitäten gegenüber dem (S)-Enantiomer berichtet. Die $(R)$-Stereospezifität könnte man sich zunutze machen durch eine Veresterung racemischen Ibuprofens beispielsweise mit 1-Propanol wie es für die Aspergillus niger Lipase berichtet wird (Carvalho et al., 2006). Dadurch bleibt optisch reines (S)Ibuprofen zurück, welches vom Ester leicht zu trennen ist (Abb. 61).

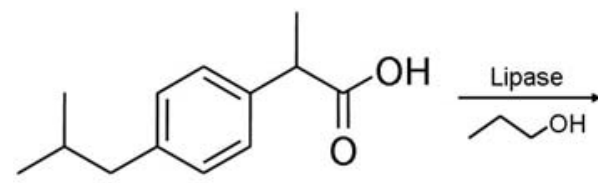

$(R, S)$-lbuprofen

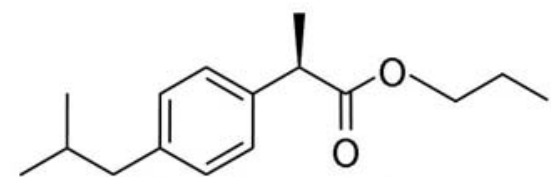

(R)-Ibuprofenpropylester

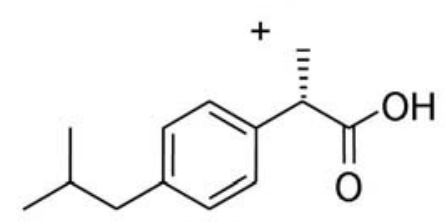

(S)-lbuprofen

Abb. 61: Trennung racemischen Ibuprofens durch Veresterung mit 1-Propanol

Für die Hydrolyse von Naproxenmethylester unter Bildung von $(R)$-Naproxen analog der Hydrolyse von pNP-Naproxen durch LipCE sind hohe Enantiomerenüberschüsse für kommerzielle Lipasen von Mucor miehei (95\% ee), Rhizopus arrhizus ( $97 \%$ ee), Rhizopus sp. (92\% ee) (alle Gu et al., 1986) und Rhizomucor miehei (95\% ee) (Botta et al., 1997) beschrieben. Lipasen aus C. cylindracea und C. rugosa weisen eine gegenteilige Stereospezifität auf, hier werden ee-Werte von über $98 \%$ zugunsten des (S)-Esters beschrieben (Botta et al., 1997; del Campo et al., 1993).

Ähnlich stellt sich die Situation bei der Hydrolyse von Ibuprofenestern dar, es finden sich Lipasen, die spezifisch nur einen der beiden Ester umsetzen (Alcántara et al., 2000; Madhav und Ching, 2001). 
Alle diese Werte variieren jedoch stark, abhängig davon welche Lösungsmittel für die Reaktion verwendet werden, welcher Rest als Estergruppe fungiert, welcher Reaktionstyp gewählt wird und ob freie oder immobilisierte Lipasen verwendet werden (Chen und Tsai, 2000; Cardenas et al., 2001; Hongwei et al., 2005; Carvalho et al., 2006; Fazlena et al., 2006). Dies sind Faktoren, die für LipCE noch zu untersuchen wären, zumal für Lösungsmittel wie Glycerin, DMSO, Methanol und Ethanol aktivitätssteigernde Einflüsse gefunden wurden (III.4.4.6).

Für potentielle Anwendungen sollte in diesem Zusammenhang auch eine Immobilisierung des Enzyms LipCE in Betracht gezogen werden, da viele der oben beschriebenen Reaktionen mit immobilisierten Enzymen durchgeführt wurden (Liese et al., 2005). Dies erhöht sowohl die Langlebigkeit als auch die Aktivität der Enzyme (Reetz et al., 1995; Bornscheuer, 2003).

\subsection{Einfluss von Co-Faktoren}

Ein klassisches Merkmal von Lipasen und Esterasen ist deren Unabhängigkeit von CoFaktoren. Die meisten Enzyme weisen unabhängig von Co-Faktoren optimale Aktivitäten auf. Steigernde Effekte wurden in der Regel mit bivalenten Kationen wie Calcium und Magnesium beobachtet, wobei Calcium die wichtigste und häufig eine stabilisierende Rolle spielt (Jäger et al., 1999; Gupta et al., 2004).

Für EstCE gilt in diesem Zusammenhang, dass es wie viele Lipasen von Kationen als auch Detergenzien kaum beeinflusst wird [III.2.7.7]. Einzig EDTA wirkte etwas stimulierend mit einer Aktivitätszunahme von $20 \%$, während $\mathrm{Ca}^{2+}$ oder $\mathrm{Mg}^{2+}$ keinen nennenswerten Einfluss hatten. $\mathrm{Fe}^{3+}, \mathrm{Fe}^{2+}$ und $\mathrm{Cu}^{2+}$ inhibierten die Enzymaktivität, was auf deren stark oxidierende Wirkung zurückzuführen sein wird, die eine Vielzahl an Enzymen unspezifisch hemmen.

\subsubsection{LipCE und der Einfluss von Calcium}

Von den getesteten Kationen bewirkte einzig $\mathrm{Ca}^{2+}$ einen stimulierenden Effekt. Wie bei EstCE wurde LipCE durch $\mathrm{Fe}^{3+}, \mathrm{Fe}^{2+}$ und $\mathrm{Cu}^{2+}$ inhibiert und tolerierte viele der getesteten Lösungsmittel in Konzentrationen von 15\% (v/v) [III.4.4.7]. In Gegenwart von $1 \mathrm{mM} \mathrm{Ca}^{2+}$ wurde ein stark stimulierender und stabilisierender Effekt beobachtet [III.4.4.8]. Bei initialen Messungen mit Rohextrakten wurde ein 6facher Anstieg der Aktivität in Gegenwart von $5 \mathrm{mM} \mathrm{Ca}^{2+}$ gefunden, während der Effekt bei reinem Protein wesentlich drastischer ausfiel. Bei $20^{\circ} \mathrm{C}$ konnte die Reaktionsgeschwindigkeit in Gegenwart von $\mathrm{Ca}^{2+}$ bis zu 88fach gesteigert werden, während der Effekt bei $0^{\circ} \mathrm{C}$ noch etwa 20fach war [III.4.4.8]. Ähnliche Abhängigkeiten sind für die Lipasen PML aus Pseudomonas sp. MIS38, ebenfalls eine Lipase der Familie I.3 (Amada et al., 2001) 
und die Lipase SHL aus Staphylococcus hyicus (Simons et al., 1999) bekannt. Hier zeigen geringere Konzentrationen von $\mathrm{Ca}^{2+}$ bereits wesentliche Steigerungen der Aktivität bzw. der Reaktionsgeschwindigkeit, während bei LipCE erst ab einer Konzentration von $1 \mathrm{mM}$ ein sprunghafter Anstieg der Reaktionsgeschwindigkeit zu beobachten war (Abb. 62).

Andere Beispiele zeigen hingegen weniger starke Einflüsse von $\mathrm{Ca}^{2+}$ auf die Lipaseaktivitäten. 6fache Steigerungen werden für die nahe verwandten $P$. fluorescens-Lipasen aus SIK W1 (Lee et al., 1993) und KB700A (Rashid et al., 2001) berichtet. Stabilisierende Effekte von $\mathrm{Ca}^{2+}$ auf das Enzym werden auch für die SIK W1Lipase berichtet, wo die Stabilität gegenüber Guanidin-HCI, DMSO und Trifluorethanol zunimmt (Kim et al., 2005). LipCE zeigte in Gegenwart von $\mathrm{Ca}^{2+}$ eine gesteigerte Stabilität gegenüber Hitzedenaturierung, was auch von Lipasen aus Acinetobacter sp. RAG-1 (Snellman et al., 2002), A. calcoaceticus AAC323-1 (Bompensieri et al., 1996), P. fluorescens M50 (Swaisgood und Bozoglu, 1984) oder Staphylcoccus hyicus (Simons et al., 1999) bekannt ist.

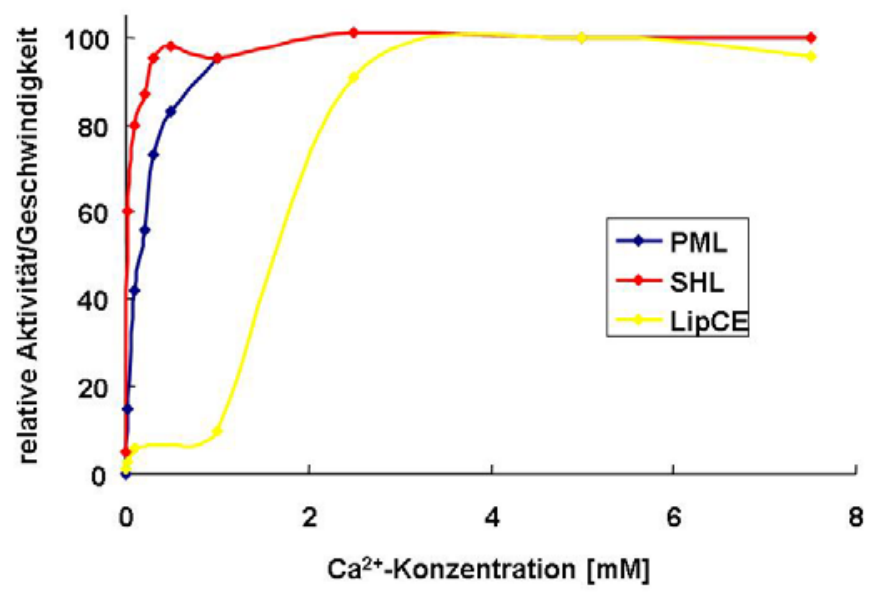

Abb. 62: Abhängigkeit verschiedener Lipaseaktivitäten von der $\mathrm{Ca}^{2+}-$ Konzentration

Für die Lipase PML aus $P$. sp. MIS38 ist die Aktivität angegeben, für SHL aus Staphylococcus hyicus und LipCE wurden $\mathrm{v}_{\max }$ bzw. $\mathrm{v}_{0}$ in Anhängigkeit von der $\mathrm{Ca}^{2+}-$ Konzentration ermittelt. Die Werte für PML (Amada et al., 2001) wurden nur bis $1 \mathrm{mM}$ angegeben.

Zurückzuführen ist dieses Phänomen auf eine Stabilisierung des Enzyms, die mit Veränderungen in der Sekundärstruktur einhergehen. Für LipCE konnte dies anhand CD-spektroskopischer Untersuchungen gezeigt werden [III.4.4.10].

Dies gilt auch für die SIK W1-Lipase. Hier halbierte sich in Anwesenheit von $\mathrm{Ca}^{2+}$ der Anteil ungeordneter Strukturen (random coil) von 66,8\% auf 32,5\%, während der Anteil von $\beta$-Faltblättern und $\alpha$-Helices stark zunahm (Kim et al., 2005). Für LipCE lässt sich 
ähnliches vermuten, allerdings stehen Verfeinerungen der CD-Spektren noch aus, so dass der Anteil an Sekundärstrukturelementen genauer bestimmt werden kann.

Für die Bindung des Calciums werden in den Familie I.3-Lipasen C-terminal gelegene, glycinreiche $\mathrm{Ca}^{2+}$-Bindemotive verantwortlich gemacht. Dies wurde zunächst durch Deletionsstudien an den Lipasen aus P. fluorescens HU380 (Kojima et al., 2003) und $P$. sp. MIS38 (Amada et al., 2001) gezeigt. Diese $\mathrm{Ca}^{2+}$-Bindemotive der allgemeinen Sequenz GGxGxDxux ( $x$, beliebige AS, u hydrophobe AS) finden sich auch in LipCE (AS 382-399). Zudem sind diese Motive auch als Erkennungssignale in den ABCabhängigen Typl-Sekretionsmechanismus involviert (Kwon et al., 2002). Aus der Kristallstruktur der alkalischen Protease aus $P$. aeruginosa, die über einen TyplSekretionsmechanismus sekretiert wird und auch über $\mathrm{Ca}^{2+}$-Bindemotive verfügt, ist bekannt, dass die $\mathrm{Ca}^{2+}$-Bindung in einer sogenannten $\beta$-Rolle stattfindet (Baumann et al., 1993). Hierbei bilden wenigstens fünf repetitive Sequenzen aus neun AS eine Rolle, in der die jeweils ersten sechs AS einen Loop und die nächsten drei ein $\beta$ Faltblatt bilden. In den äußeren Enden dieser Rolle werden die $\mathrm{Ca}^{2+}{ }^{2}$-Ionen gebunden und bewirken damit auch die stabile Struktur dieses C-terminalen Teils (Abb. 63A). Aufgrund der hohen Ähnlichkeit dieser Sequenz zwischen LipCE, MIS38 und auch der alkalischen Protease ist es wahrscheinlich, dass diese Struktur sich auch am Cterminalen Ende von LipCE findet, wie es bereits für das MIS38-Protein postuliert wurde (Angkawidjaja et al., 2005). Durch ein Modellieren der C-terminalen 108 Reste von LipCE mittels SWISS-Model (Kopp und Schwede, 2006) wird für LipCE ebenfalls eine Rollenstruktur hervorgesagt (Abb. 63B, C). Die Vorhersage wurde aufgrund hoher Ähnlichkeit zu der Struktur des C-Terminus einer sekretierten, $\mathrm{Ca}^{2+}$-abhängigen Mannuronan-C-5-Epimerase aus Azotobacter vinelandii erstellt (Pdb-Eintrag 2agm), welche an bekannten Strukturen die größte Ähnlichkeit für den untersuchten Bereich aufwies (Aachmann et al., 2006). Auch in diesem Modell würde das $\mathrm{Ca}^{2+}{ }^{2+}$ Ion von nach innen ragenden Aspartatresten komplexiert werden können. Am Beispiel der MIS38Lipase konnte durch Mutagense der Reste Asp387 und Asp396, die auch in LipCE konserviert sind, deren Bedeutung für die $\mathrm{Ca}^{2+}$-Bindung nachgewiesen werden (Angkawidjaja et al., 2005). 

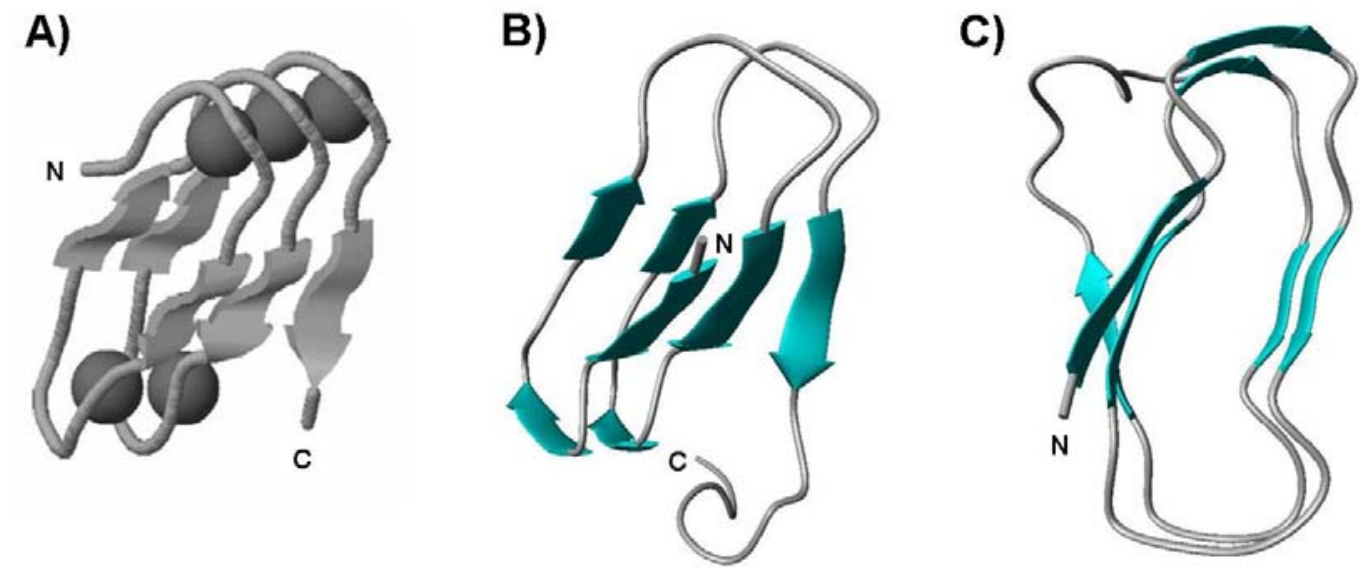

Abb. 63: Struktur der C-terminalen $\beta$-Rolle der alkalischen Protease aus $P$. aeruginosa und vorhergesagte Struktur für LipCE

A) Seitenansicht der Struktur der $\beta$-Rolle der alkalischen Protease aus $P$. aeruginosa mit gebundenen $\mathrm{Ca}^{2+}$-Ionen (aus Angkawidjaja et al., 2005). B) Vorhersage der Struktur des Cterminalen Bereichs (AS371-476) von LipCE anhand von Vergleichen mit dem C-Terminus der Mannuronan-C-5-Epimerase aus A. vinelandii (Aachmann et al., 2006). $\beta$-Faltblätter sind als Pfeile dargestellt. C) Seitenansicht in die $\beta$-Rollenstruktur von LipCE. Ansicht B und C erstellt mittels SWISS-Model (Kopp und Schwede, 2006) und RasMol (Sayle und Milnar-White, 1995).

\section{Microarray-Entwicklung zur Detektion neuer Lipasen}

\subsection{Microarrays in der Metagenomik}

Seit Einführung der Microarray-Technologie (Shena et al., 1995) wurde diese zunächst bevorzugt für Untersuchungen in der Genexpression eingesetzt, z.B. für Expressionsstudien von Organismen unter verschiedenen Umweltbedingungen (Khodursky et al., 2000; Wei et al, 2001; Conway und Schoolnik, 2003).

Nach Etablierung dieser Technik fanden Microarrays auch zunehmend Einzug in Felder der mikrobiellen Ökologie und somit auch in die Metagenomik (Cook und Sayler, 2003; Sebat et al., 2003; Zhou, 2003; Gentry et al., 2006; Xu, 2006). Etablierte Techniken sind der Einsatz von Oligonukleotidarrays zur Detektion bestimmter Spezies in Umweltproben (Small et al., 2001; Lehner et al., 2005; Loy et al., 2005) oder der Nachweis bestimmter Gene, zum Beispiel des Schadstoffabbaus (Rhee et al., 2004), Gene des Stickstoffzyklus (Taroncher-Oldenburg et al., 2003) oder Virulenzgene (Bruant et al., 2006; Hamelin et al., 2006). Auch PCR-Produktarrays wie sie in dieser Arbeit verwendet wurden, konnten zur Detektion von Genen des Stickstoffkreislaufs (Wu et al., 2001) und antimikrobiellen Resistenzgenen (Call et al., 2003) erfolgreich eingesetzt werden. Jedoch wurde bei diesen Arbeiten nur das Vorhandensein der Zielgene nachgewiesen, niemals die kompletten Gene aus Umweltproben isoliert. 
Zur Isolierung neuartiger Gene wie in dieser Arbeit wurden Microarrays bislang noch nicht verwendet. Bei der Detektion neuartiger Gene aus komplexen Habitaten wie dem Boden traten jedoch noch vermehrt Probleme auf. Zunächst sollte prinzipiell über eine Erhöhung der Zielgene auf dem Array nachgedacht werden, was in der Konstellation jedoch durch das Vorhandensein ausreichender DNA-Proben bzw. Klone für die Amplifzierung limitiert sein dürfte (Gentry et al., 2006). Hier sollte in Zukunft stärker versucht werden, auf längere Oligonukleotide zu setzen, da diese unabhängig vom Vorhandensein des Wirtsorganismus synthetisiert werden können und somit unlimitiert zur Verfügung stehen. Bei einem Oligonukleotidarray zur Detektion von Genen des Kohlenwasserstoffabbaus und der Schwermetallresistenz wurden bereits 1662 Oligonukleotide auf einem Spot erfolgreich benutzt (Rhee et al., 2004).

Bei der Verwendung von Oligonukleotiden sind jedoch Lipasegene zunächst nicht die optimale Zielgruppe, da die Enzyme dieser Gruppe, abgesehen von den Bereichen des oxyanion holes und des katalytischen Pentapeptides kaum konserviert sind (Jäger et al., 1999), wodurch die Varietät im GC-Gehalt enorm hoch ist. Dies bereitete bereits bei Versuchen mit kurzen Oligonukleotiden (18-21 bp) Probleme (Leggewie, 2005).

Auffallend war im Rahmen dieser Arbeit auch die niedrige Frequenz von detektierten Genen, im Boden direkt konnten gar keine Gene detektiert werden. Aus Anreicherungskulturen, die nach drei Anreichungsschritten nur noch aus wenigen Individuen bestanden und Mischungen von fünf Isolaten aus einem Diesel-Biofilm (Pathak, 2006) konnten am verlässlichsten vorhandene Gene detektiert werden. Dies ist wahrscheinlich auf das schlechte Detektionslimit von Microarrays im Zusammenhang mit Anwendungen in komplexen mikrobiellen Habitaten zurückzuführen (Cook und Sayler, 2004). Für die Verwendung von DNA aus Bodenproben wurden $50 \mathrm{ng}$ DNA eines einzelnen Genoms als Minimalmenge gefunden, um mittels PCR-Produktarrays spezifische Gene detektieren zu können (Cho und Tiedje, 2002). Die in dieser Arbeit eingesetzten DNA-Mengen beliefen sich auf etwa 2-4 $\mathrm{\mu g}$ markierte DNA pro Ansatz, so dass ein einzelner Organismus wenigstens $1 / 40$ bis $1 / 80$ der untersuchten Population ausmachen müsste, um zuverlässig detektiert zu werden. Die Tatsache, dass in Mischkulturen somit nur die Gene mit der höchsten Verbreitung detektiert werden können, deckt sich auch mit anderen Untersuchungen (Sebat et al., 2003). Insbesondere für Untersuchungen in Bodenproben, die aus bis zu mehreren tausend verschiedenen Organismen bestehen können (Torsvik et al., 2002), sind Microarrays momentan also noch nicht das Mittel der Wahl (Zhou und Thompson, 2002). Das Detektionslimit membranbasierter Systeme kann in diesem Zusammenhang bis zu 100fach sensitiver sein (Voordouw et al., 1993). 
Dies wird auf das Bindeverhalten der PCR-Produkte an den benutzten Glasoberflächen der Microarrays gegenüber porösen Membranen (Zhou und Thompson, 2002) und die generell höhere Probenmenge, die auf Membranen aufgetragen werden kann, zurückgeführt (Membran >1 $\mathrm{gg} / \mathrm{Spot}$, Chip 10-20 pg/Spot) (Cho und Tiedje, 2002). Verglichen mit glasbasierten Microarrays können PCR-Reaktionen teilweise sogar 100 bis 10.000fach sensitiver sein (Zhou et al., 1997).

Vor diesem Hintergrund könnte bei der Verwendung einer geringen Anzahl an PCRProdukten wie in diesem Fall die Verwendung membranbasierter Systeme für initiale Erprobungen zunächst wieder in Erwägung gezogen werden, zumal die Kosten hierbei niedriger sind als bei der Verwendung von Microarrays (Lucchini et al., 2001). Die Kosten für eine Hybridisierungsreaktion belaufen sich inklusive Slide und Markierungsfarbstoffen auf etwa 150-200 €. Membranbasierte Systeme könnten im Gegensatz zu Microarrayslides zudem mehrmals verwendet werden (Lucchini et al., 2001).

\subsection{Identifizierung neuartiger Lipasegene}

Im Rahmen dieser Arbeit wurden neuartige Genfragmente aus Umweltproben isoliert, deren niedrigste Sequenzähnlichkeit bei $78 \%$ zur Zielsequenz lag. Abhängig von den Hybridisierungsbedingungen kann die Grenze zur verlässlichen Detektion und Unterscheidung bei niedriger Stringenz bei $60-70 \%$ Ähnlichkeit liegen, bei höherer Stringenz bei $80-85 \%$ (Wu et al., 2001). Dies weist zwar einen brauchbaren Neuartigkeitswert zur Detektion neuartiger Enzyme auf, bereitet dann aber auch Probleme, diese aufgrund der niedrigen Sequenzhomologie nach der Detektion verlässlich amplifizieren zu können. Dies war auch bei einigen dektektierten Spots dieser Arbeit zu beobachten, wobei zwischen Signalstärke und Erfolg der Amplifizierung kein direkter Zusammenhang gefunden wurde. Hierbei ist auch zu bedenken, dass aufgrund des sehr hohen Anteils unbekannter Sequenzen in der hybridisierten Metagenom-DNA nicht immer verlässliche Rückschlüsse vom schwachen Aufleuchten eines Spots zum Vorhandensein eines Gens mit gleicher Funktion gezogen werden können (Zhou und Thompson, 2002; Gentry et al., 2006).

Für die amplifizierten Genfragmente sollten sich mittels Techniken wie inverser PCR (Triglia et al., 1988) oder linkerabhängiger Techniken (Yuanxin et al., 2003; Tan et al., 2005; Guo und Xiong, 2006) prinzipiell bei Kenntnis des inneren Sequenzbereiches die flankierenden Regionen isolieren lassen. Für Lipasen (Bradner et al., 2003; Luo et al., 2006) und andere Enzyme (Morris et al., 1995) aus Einzelorganismen wurde die genomic walking PCR erfolgreich zur Isolierung kompletter Gene eingesetzt. Nach Amplifikation eines Teilbereiches mit Hilfe degenerierter Primer konnte auch eine 
Lipase aus metagenomischer DNA erfolgreich gewonnen werden, ohne diese über ein aktivitätsbasiertes Durchmustern einer Genbank zu finden (Bell et al., 2002). Für den hier gefundenen neuartigen Sequenzbereich [III.5.6] mit Homologie zur $P$. aeruginosaLipase LipA gelang dies jedoch nicht, was auf die allgemeinen Probleme der niedrigen Reinheitsqualität metagenomischer DNA zurückzuführen sein kann. Dies kann die Microarray-Hybridisierungen an sich bereits stören (Cook und Sayler, 2003), aber auch generell enzymatische Modifikationen behindern (Streit und Schmitz, 2004). Da die isolierten Fragmente aus den Dieselbiofilmisolaten alle Identitäten von über $98 \%$ zur Zielsequenz aufwiesen, wurde aufgrund mangelnder Sequenzneuheit darauf verzichtet, das komplette Gen zu amplifizieren. 


\section{Zusammenfassung}

Zielsetzung dieser Arbeit war die Isolierung, biochemische Charakterisierung und Verwertungsprüfung von stereoselektiven lipolytischen Enzymen aus Metagenomen.

Dazu wurde im Rahmen der hier vorgelegten Arbeit eine Cosmidbank aus metagenomischer DNA angelegt und nach Klonen durchmustert.

Insgesamt wurden zwei viel versprechende lipolytische Klone gefunden, die für eine Lipase und eine Esterase kodierten. Auf pCosCE1 wurde ein Gen (1167 bp) gefunden, welches für eine Esterase mit $51 \%$ Identität zu $\beta$-Laktamasen der Gattung Burkholderia kodierte. Typische Lipase-Strukturmotive wie G-D-S-L oder G-x-S-x-G wies das Protein nicht auf. Das 388 AS große Protein EstCE wurde heterolog in Escherichia coli überexprimiert und mittels Ni-TEDAffinitätschromatographie und Gelfiltration gereinigt. Die biochemische Charakterisierung ergab ein Temperaturoptimum von $47^{\circ} \mathrm{C}$ und ein $\mathrm{pH}-$ Optimum von pH 10. Es wurden ausschließlich Ester kurzkettiger Fettsäuren (bis C8) umgesetzt, was für pNP-Ester, Vinylsäureester und Triglyceride bestimmt wurde. Zudem wurde ein Umsatz ringförmiger und aromatischer Reste (pNP-Benzoat, -Cyclohexanoat, -3-Phenylbutanoat) und verschiedener primärer und sekundärer Alkoholreste) gefunden. Mit pNP-Butyrat als Substrat wurden kinetische Daten von $55,2 \mu \mathrm{mol} \cdot I^{-1} \cdot \mathrm{min}^{-1}$ für $V_{\max }$ und $0,35 \mathrm{mM}$ für $K_{\mathrm{m}}$ bestimmt. Durch GC-Analysen konnte eine stereospezifische Umsetzung des Essigsäureesters von Menthylacetat gefunden werden, wobei nur (+)Menthylacetat, nicht aber (-)-Menthylacetat umgesetzt wurde. Die Aktivität wurde durch Cofaktoren nicht wesentlich beeinflusst, lediglich $\mathrm{Fe}^{2+}, \mathrm{Fe}^{3+}, \mathrm{Cu}^{2+}$, $\mathrm{Zn}^{2+}, \mathrm{Ni}^{2+}$ und $\mathrm{Cd}^{2+}$ hemmten die Aktivität. Durch Aminosäureaustausche konnte der Serinrest $65 \mathrm{im} \beta$-Laktamase-Strukturmotiv als katalytisches Nukleophil identifiziert werden. $\beta$-Laktamase-Aktivität von EstCE gegenüber einer Reihe Antibiotika konnte nicht gefunden werden. Die Erstellung eines "enzymatischen Fingerabdruckes" lieferte zudem Ähnlichkeiten vom Substratspektrum zu eukaryontischen Lipasen der Gattung Candida (Kooperation mit der AG Prof. Reymond, Universität Bern).

Auf dem Cosmid pCosCE2 wurde ein Gen (1431 bp) gefunden, welches für eine Lipase mit hoher Ähnlichkeit (88\%) zu extrazellulären Lipasen aus 
Pseudomonas fluorescens kodiert. Das 476 AS große Protein LipCE wurde heterolog in $E$. coli überexprimiert, wo es zur Bildung von unlöslichen Einschlusskörpern kam. Aus diesen wurde das Protein nach Denaturierung und anschließender Rückfaltung gereinigt. Die biochemische Charakterisierung zeigte, dass es sich um eine kälteaktive Lipase handelt, die bei $0^{\circ} \mathrm{C}$ noch eine Restaktivität von $28 \%$ und selbst bei $-5^{\circ}$ noch $16 \%$ Aktivität aufwies. Das Temperaturoptimum lag bei $30^{\circ} \mathrm{C}$, bei höheren Temperaturen erfolgte eine sehr rasche Inaktivierung. Bevorzugte Substrate waren mittel- und langkettige Fettsäureester, die höchste Aktivität wurde mit pNP-Caprat (C10) als Substrat gemessen (2020 U/mg). Das pH-Optimum lag mit pH 7 im neutralen Bereich. Die Aktivität wurde stark durch die Gegenwart von $\mathrm{Ca}^{2+}$ beeinflusst. Die Enzymaktivität konnte um ein Vielfaches gesteigert werden, zudem erhöhte sich die thermische Stabilität des Proteins. CD-Spektroskopische Untersuchungen zeigten Änderungen der Sekundärstruktur des Proteins in Gegenwart von $\mathrm{Ca}^{2+}$. Zudem wurden am C-Terminus durch Sequenzvergleiche und molekulares Modellieren mögliche $\mathrm{Ca}^{2+}$-Bindestellen identifiziert. Diese dienen womöglich gleichzeitig als Sekretionssignale für einen Typl-Sekretionsmechanismus, wie er für viele ähnliche $P$. fluorescens-Lipasen beschrieben ist.

Es wurde weiterhin eine stereospezifische Umsetzung pharmazeutisch wichtiger Substrate wie Ibuprofen (als pNP-Ester) gefunden, mit einem Enantiomerenüberschuss von $>91 \%$ zugunsten des $(R)$-Enantiomers. Zudem zeigte LipCE eine hohe Selektivität für die Umsetzung von Estern primärer Alkohole was dieses Enzym zusammen mit der hohen Aktivität bei niedrigen Temperaturen interessant für biotechnologische Anwendungen macht.

Zur Entwicklung neuer Technologien bei der sequenzbasierten Suche nach neuartigen Lipasen in Metagenomen wurde zudem ein DNA-Microarray konstruiert. Auf diesem wurden PCR-Fragmente von Lipasen und Esterasen aus 37 verschiedenen Organismen immobilisiert. Dieser Microarray wurde erfolgreich zur Detektion neuer Gene aus Umweltproben, wie Anreicherungskulturen oder verschiedenen Biofilmen eingesetzt. 


\section{Literaturverzeichnis}

Aachmann, F. L., Svanem, B. I., Guntert, P., Petersen, S. B., Valla, S., and Wimmer, R. (2006). NMR structure of the R-module: a parallel beta-roll subunit from an Azotobacter vinelandii mannuronan C-5 epimerase. J Biol Chem 281, 7350-7356.

Achenbach, L. A., and Coates, J. D. (2000). Disparity between bacterial phylogeny and physiology. Am Soc Microbiol News 66, 714-715.

Achouak, W., Soutra, L., Heulin, T., Meyer, J. M., Fromin, N., Degraeve, S., Christen, R., and Gardan, L. (2000). Pseudomonas brassicacearum sp. nov. and Pseudomonas thiveralensis sp. nov., two root-associated bacteria isolated from Arabidopsa thaliana and Brassica napus. Int J Syst Bacteriol 50, 9-18.

Ahn, J. H., Pan, J. G., and Rhee, J. S. (1999). Identification of the tliDEF ABC transporter specific for lipase in Pseudomonas fluorescens SIK W1. J Bacteriol 181, 1847-1852.

Ahn, J. H., Pan, J. G., and Rhee, J. S. (2001). Homologous expression of the lipase and $A B C$ transporter gene cluster, tliDEF, enhances lipase secretion in Pseudomonas spp. Appl Environ Microbiol 67, 5506-5511.

Akatsuka, H., Kawai, E., Omori, K., Komatsubara, S., Shibatani, T., and Tosa, T. (1995). The lipA gene of Serratia marcescens which encodes an extracellular lipase having no N-terminal signal peptide. J Bacteriol 176, 1949-1956.

Alcántara, A. R., Sánchez-Montero, J. M., and Sinisterra, J. V. (2000). Chemoenzymatic preparation of enantiomerically pure $\mathrm{S}(+)$-2-arylpropionic acids with anti-inflammatory activity. In Patel, R. N. (Ed.) "Stereoselective biocatalysis", Marcel New York, Dekker Inc., 659-702

Amada, K., Kwon, H. J., Haruki, M., Morikawa, M., and Kanaya, S. (2001). $\mathrm{Ca}^{2+}-$ induced folding of a family $\mathrm{I} .3$ lipase with repetitive $\mathrm{Ca}^{2+}$ binding motifs at the Cterminus. FEBS Lett 501, 17-21.

Amann, R. I., Ludwig, W., and Schleifer, K. H. (1995). Phylogenetic identification and in situ detection of individual microbial cells without cultivation. Microbiol Rev 59, 143169.

Anderson, R. E., Hedlund, C. B., and Jonsson, U. (1979). Thermal inactivation of a heat-resistant lipase produced by the psychrotrophic bacterium Pseudomonas fluorescens. J Dairy Sci 62, 361-367.

Angkawidjaja, C., Paul, A., Koga, Y., Takano, K., and Kanaya, S. (2005). Importance of a repetitive nine-residue sequence motif for intracellular stability and functional structure of a familiy I.3 lipase. FEBS Lett 579, 4707-4712.

Arpigny, J. L., and Jäger, K. E. (1999). Bacterial lipolytic enzymes: classification and properties. Biochem J 343, 177-183.

Athawale, V., Manjrekdar, N., and Athawale, M. (2001). Enzymatic synthesis of chiral menthyl methacrylate monomer by Pseudomonas cepacia lipase catalysed resolution of ( \pm )-menthol. J Mol Catal B: Enzymatic 16, 169-173.

Bachmann, B. J. (1987). Lincage map of Escherichia coli K12., Vol 2 (Washington D.C., USA: American Society for Microbiology (ASM)). 
Bachmann, R., Budde, F., and Riese, J. (2004). The third wave - biotechnology conquers the chemical industry. Chem Ing Techn 76, 1155-1158.

Baneyx, F., and Mujacic, M. (2004). Recombinant protein folding and misfolding in Escherichia coli. Nat Biotechnol 22, 1399-1408.

Baumann, U., Wu, S., Flaherty, K. M., and McKay, D. B. (1993). Three-dimensional structure of the alkaline protease of Pseudomonas aeruginosa: a two-domain protein with a calcium binding parallel beta roll motif. EMBO J 12, 3357-3364.

Bell, P. J., Sunna, A., Gibbs, M. D., Curach, N. C., Nevalainen, H., and Bergquist, P. L. (2002). Prospecting for novel lipase genes using PCR. Microbiology 148, 22832291.

Beja, O., Aravind, L., Koonin, E. V., Suzuki, M. T., Hadd, A., Nguyen, L. P., Jovanovich, J. P., Gates, C. M., Feldmann, R. A., Spudich, J. L., Spudich, E. N., and DeLong, E. F. (2000). Bacterial rhodopsin: evidence for a new type of phototrophy in the sea. Science 289, 1902-1906.

Binet, R., Létoffé, S., Ghigo, J. M., Delepelaire, P., and Wandersman, C. (1997). Protein secretion by Gram-negative bacterial ABC exporters - a review. Gene 192, 711.

Birgisson, H., Delgado, O., Garcia-Arroyo, L., Hatti-Kaul, R., and Mattiasson, B. (2003). Cold-adapted yeasts as producers of cold-active polygalacturonases. Extremophiles 7, 185-193.

Bodrossy, L., and Sessitsch, A. (2004). Oligonucleotide microarrays in microbial diagnostics. Curr Opin Microbiol 7, 245-254.

Bompensieri, S., Gonzalez, R., Kok, R., Miranda, M. V., Nutgeren-Roodzant, I., Hellingwerf, K. J., Cascone, O., and Nudel, B. C. (1996). Purification of a lipase from Acinetobacter calcoaceticus AAC323-1 by hydrophobic-interaction methods. Biotechnol Appl Biochem 23, 77-81.

Boone, D. R., Castenholtz, R. W., Garrity, G. M. (eds.) (2001). Bergey's manual of systematic bacteriology, Vol. 1, New York, Springer.

Bornscheuer, U. T. (2002). Microbial carboxyl esterases: classification, properties and application in biocatalysis. FEMS Microbiol Rev 26, 73-81.

Bornscheuer, U. T. (2003). Immobilizing enzymes: How to create more suitable biocatalysts. Angew Chem Int Ed 42, 3336-3337.

Botta, M., Cernia, E., Corelli, F., Manetti, F., and Soro, S. (1997). Probing the substrate specificity for lipases. II. Kinetic and modelling studies on the molecular recognition of 2-arylpropionic esters by Candida rugosa and Rhizomucor miehei lipases. Biochim Biophy Acta 1337, 302-310.

Bradford, M. M. (1976). A rapid and sensitive method for the quantitation of microgram quantities of protein utilizing the principle of protein dye-binding. Anal Biochem 72, 248254.

Bradner, J. R., Bell, P. J., Te'o, V. S. J., and Nevalainen, K. M. H. (2003). The application of PCR for the isolation of a lipase gene from the genomic DNA of an Antarctic microfungus. Curr Genet 44, 224-230. 
Brady, L., Brzozowski, A. M., Derewenda, Z. S., Dodson, E., Dodson, G., Tolley, S., Turkenburg, J. P., Christiansen, L., Huge-Jensen, B., Norskov, L., Thim, L., and Menge, U. (1990). A serine protease triad forms the catalytic center of a triacylglycerol lipase. Nature 343, 767-770.

Brosius, J., Dull, T. J., Sleeter, D. D., and Noller, H. F. (1981). Gene organization and primary structure of a ribosomal RNA operon from Escherichia coli. J Mol Biol 148, 107-127.

Bruant, G., Maynard, C., Bekal., S., Gaucher, I., Masson, L., Brousseau, R., and Harel, J. (2006). Development and validation of an oligonucleotide microarray for detection of multiple virulence and antimicrobial resistance genes in Escherichia coli. Appl Environ Microbiol 72, 3780-3784.

Bullock, W. O., Fernandez, J. M., Short, J. M. (1987). XL1-blue: a high efficiency plasmid transforming recA Escherichia coli strain with beta-galactosidase selection. Bio Techniques 5, 376-378.

Call, D. R., Bakko, M. K., Krug, M. J., and Roberts, M. C. (2003). Identifying antimicrobial resistance genes with DNA microarrays. Antimicrob Agents Chemother 47, 3290-3295.

Cardenas, F., Alvarez, E., de Castro-Alvarez, M. S., Sanchez-Montero, J. M., Valmaseda, M., Elson, S. W., and Sinisterra, J. V. (2001). Screening and catalytic activity in organic synthesis of novel fungal and yeast lipases. J Mol Catal B: Enzymatic 14, 111-123.

Caron, G., and Kazlauskas, R. J. (1991). An optimized sequential kinetic resolution of trans-1,2-cyclohexanediol. J Org Chem 56, 7251-7256.

Carvalho, P. O., Contesini, F. J., Bizaco, R., Calafatti, S. A., and Macedo, G. A. (2006). Optimization of enantioselective resolution of racemic ibuprofen by native lipase from Aspergillus niger. J Ind Microbiol Biotechnol 33, 713-718.

Chabeaud, P., de Groot, A., Bitter, W., Tommassen, J., Heulin, T., and Achouak, W. (2001). Phase-variable expression of an operon encoding extracellular alkaline protease, a serine protease homolog, and lipase in Pseudomonas brassicacearum. J Bacteriol 183, 2117-2120.

Chahinian, H., Ali, Y. B., Abousalham, A., Petry, S., Mandrich, L., Manco, G., Canaan, S., and Sarda, L. (2005). Substrate specificity and kinetic properties of enzymes belonging to the hormone-sensitive lipase familiy: Comparison with nonlipolytic and lipolytic carboxylesterases. Biochim Biophys Acta 1783, 29-36.

Chen, C. S., Fujimoto, Y., Girdaukas, G., and Sih, C. J. (1982). Quantitative analyses of biochemical kinetic resolutions of enantiomers. J Am Chem Soc 104, 72947299 .

Chen, C. S., Wu, S., Girdaukas, G., and Sih, C.J. (1987). Quantitative analyses of the biochemical kinetic resolutions of enantiomers 2: Enzyme catalysed esterification in water-organic solvents biphasic systems. J Am Chem Soc 109, 2812-2817.

Chen, J. C., and Tsai, S. W. (2000). Enantioselective synthesis of (S)-ibuprofen ester prodrug in cyclohexane by Candida rugosa lipase immobilized on Accurel MP1000. Biotechnol Prog 16, 986-992. 
Cho, J. C., and Tiedje, J. M. (2002). Quantitative detection of microbial genes by using DNA microarrays. Appl Environ Microbiol 68, 1425-1430.

Chung, G. H., Lee, Y. P., Yoo, O. J., and Rhee, J. S. (1991). Cloning and nucleotide sequence of a thermostable lipase from Pseudomonas fluorescens SIK W1. Appl Microbiol Biotechnol 35, 237-241.

Coker, J. A., Sheridan, P. P., Loveland-Curtze, J., Gutshall, K. R., Aumann, A. J., and Brenchley, J. E. (2003). Biochemical characterization of a $\beta$-galactosidase with a low temperature optimum obtained from an Antarctic Arthrobacter isolate. J Bacteriol $185,5473-5483$.

Cole, J. R., Chai, B., Farris, R. J., Wang, Q., Kulam, S. A., McGarrell, D. M., Garrity, G. M., and Tiedje, J. M. (2005). The ribosomal database project (RDP-II): sequences and tools for high-throughput rRNA analysis. Nucleic Acids Res 33, 294-296.

Conway, T., and Schoolnik, G. K. (2003). Microarray expression profiling: capturing a genome-wide portrait of the transcriptome. Mol Microbiol 47, 879-889.

Cook, K. L., and Sayler, G. S. (2003). Environmental application of array technology: promise, problems and practicalities. Curr Opin Biotechnol 14, 311-318.

Cord-Ruwich, R., Kleinitz, W., and Widdel, F. (1987). Sulphate-reducing bacteria and their activities in oil production. J Petrol Technol 1, 97-106.

Courtois, S., Cappellano, C. M., Ball, M., Francou, F. X., Normand, P., Helynck, G., Martinez, A., Kolvek, S. J., Hopke, J., Osburne, M. S., August, P. R., Nalin, R., Guérineau, R., Jeannin, P., Simonet, P., and Pernodet, J. L. (2003). Recombinant environmental libraries provide access to microbial diversity for drug discovery from natural products. Appl Environ Microbiol 69, 49-55.

Cousin, M. A. (1982). Presence and activity of psychrotrophic microorganisms in milk and dairy products. J Food Protect 45, 172-207.

Cowan, D., Meyer, Q., Stafford, W., Muyanga, S., Cameron, R., and Wittwer, P. (2005). Metagenomic gene discovery: past, present and future. Trends Biotechnol 23, 321-328.

Cox, J., and MacRea, I. C. (1989). A numerical taxonomic study of proteolytic and lipolytic psychrotrophs from caprine milk. J Appl Bacteriol 66, 137-152.

Curtis, T. P., Sloan, W., and Scannell, J. (2002). Estimating prokaryotic diversity and its limits. Proc Natl Acad Sci 99, 10494-10499.

Curtis, T. P., and Sloan, W. T. (2004). Prokaryotic diversity and its limits: microbial community structure in nature and implications for microbial ecology. Curr Opin Microbiol 7, 221-226.

D'Amico, S., Marx, J. C., Gerday, C., and Feller, G. (2003). Activity - stability relationship in extremophilic enzymes. J Biol Chem 278, 7891-7896.

del Campo, C., Garcia, M., Gradillas, A., Llama, E. F., Salazar, L., SánchezMontero, J. M., and Sinisterra, J. V. (1993). Enantiospecific hydrolysis of esters of nonsteroidal antiinflammatory drugs using lipase of Candida cylindracea. J Mol Catal 84, 399-405. 
Dennis, P., Edwards, E. A., Liss, S. N., and Fulthorpe, R. (2003). Monitoring gene expression in mixed microbial communities by using DNA microarrays. Appl Environ Microbiol 69, 769-778.

DeSantis, G., Zhu,Z., Greenberg, W. A., Wong, K., Chaplin, J., Hanson, S. R., Farwell, B., Nicholson, L. W., Rand, C. L., Weiner, D. P., Robertson, D. E., and Burk, M. J. (2002). An enzyme library approach to biocatalysis: development of nitrilases for enantioselective production of carboxylic acid derivatives. J Am Chem Soc 124, 9024-9025.

Detry, J., Rosenbaum, T., Lütz, S., Hahn, D., Jäger, K. E., Müller, M., and Eggert, T. (2006). Biocatalytic production of enantiopure cyclohexane-trans-1,2-diol using extracellular lipases from Bacillus subtilis. Appl Microbiol Biotechnol 72, 1107-1116.

Devon, R. S., Porteous, D. J., and Brooks, A. J. (1995). Splinkerettes--improved vectorettes for greater efficency in PCR walking. Nucleic Acids Res 23, 1644-1645.

Dieckelmann, M., Johnson, L. A., and Bachman, I. R. (1998). The diversity of lipases from psychrotrophic strains of Pseudomonas: a novel lipase from a highly lipolytic strain of Pseudomonas fluorescens. J Appl Microbiol 85, 527-536.

Dunbar, J., Barns, S. M., Ticknor, L. O., and Kuske, C. R. (2002). Empirical and theoretical bacterial diversity in four arizona soils. Appl Environ Microbiol 68, 30353045.

Dunhaupt, A., Lang, S., and Wagner, F. (1991). Properties and partial purification of a Pseudomonas cepacia lipase. In: Alberghina, L., Schmid, R. D., Verger, R. (eds) Lipases: structure, mechanism and genetic engineering. (GBF monographs, Vol. 16), VCH Weinheim, 389-392.

Duong, F., Soscia, C., Lazdunski, A., and Murgier, M. (1994). The Pseudomonas fluorescens lipase has a C-terminal secretion signal and is secreted by a threecomponent bacterial ABC-exporter system. Mol Microbiol 11, 1117-1126.

Duong, F., Bonnet, E., Geli, V., Lazdunski, A., Murgier, M., and Filloux A. (2001). The AprX protein of Pseudomonas aeruginosa: a new substrate for the Apr type I secretion system. Gene 262, 147-153.

Eggert, T., Penchreac'h, G., Docuhet, I., Verger, R., and Jäger, K. E. (2000). A novel extracellular esterase from Bacillus subtilis and its conversion to a monoacylglycerol hydrolase. Eur J Biochem 267, 6459-6469.

Elend, C., Schmeisser, C., Leggewie, C., Babiak, P., Carballeira, J. D., Steele, H. L., Reymond, J. L., Jäger, K. E., and Streit, W. R. (2006). Isolation and biochemical characterization of two novel metagenome-derived esterases. Appl Environ Microbiol 72, 3637-3645.

Entcheva, P., Liebl, W., Johann, A., Hartsch, T., and Streit, W. R. (2001). Direct cloning from enrichment cultures, a reliable strategy for isolation of complete operons and genes from microbial consortia. Appl Environ Microbiol 67, 89-99.

Fazlena, H. Kamaruddin, A. H., and Zulkali, M. M. D. (2006). Dynamic kinetic resolution: alternative approach in optimizing S-ibuprofen production. Bioprocess Biosyst Eng 28, 227-233. 
Feller, G., Narinx, E., Arpigny, J. L., Aittaleb, M., Baise, E., Genicot, S., and Gerday, C. (1996). Enzymes from psychrophilic organisms. FEMS Microbiol Rev 18, 189-202.

Feller, G. (2003). Molecular adaptions to cold in psychrophilic enzymes. Cell Mol Life Sci 60, 648-662.

Ferrer, M., Golyshina, O. V., Chernikova, T. N., Khachane, A. N., Martins Dos Santos, V. A., Yakimov, M. M., Timmis, K. N., and Golyshin, P. N. (2005a). Microbial enzymes mined from Urania deep-sea hypersaline anoxic basin. Chem Biol 8, 895-904.

Ferrer, M., Golyshina, O. V., Chernikova, T. N., Khachane, A. N., Reyes-Duarte, D., Martins Dos Santos, V. A., Strompl, C., Elborough, K., Jarvis, G., Neef, A., Yakimov, M. M., Timmis, K. N., and Golyshin, P. N. (2005b). Novel hydrolase diversity retrieved from a metagenome library of bovine rumen microflora. Environ Microbiol 7, 1996-2010.

Fierrer, N., and Jackson, R. B. (2006). The diversity and biogeography of soil bacterial communities. PNAS 103, 626-631.

Filloux, A., Michel, G., and Bally, M. (1998). GSP-dependent protein secretion in Gram-negative bacteria: The Xcp system of Pseudomonas aeruginosa. FEMS Microbiol Rev 22, 177-198.

Fischer, M., and Pleiss, J. (2003). The lipase engineering database: a navigation and analysis tool for protein families. Nucleic Acids Res 31, 319-321.

Flaschel, E., und Sell, D. (1996). Charme und Chancen der Weißen Biotechnologie. Chem Ing Tech 77, 1298-1312.

Frazzetto, G. (2003). White biotechnology. EMBO Reports 4, 835-837.

Frenken, L. G., de Groot, A., Tomassen, J., and Verrips, C. T. (1993). Role of the lipB gene product in the folding of the secreted lipase of Pseudomonas glumae. Mol Microbiol 9, 591-599.

Fukuda, H., Kondo, A., and Noda, H. (2001). Biodiesel fuel production by transesterification of oils. J Biosci Bioeng 92, 405-416.

Gabor, E. M., Alkema, W. B. L., and Janssen, D. B. (2004). Quantifying the accessibility of the metagenome by random expression cloning techniques. Environ Microbiol 6, 879-886.

Gans, J., Wolinsky, M., and Dunbar, J. (2005). Computational improvements reveal great bacterial diversity and high metal toxicity in soil. Science 309, 1397-1390.

Gao, X. G., Zhang, K. C., Cao, S. G. (1998). Isolation of a lipase producing Pseudomonas strain and optimization of its fermentation conditions. Acta Microbiol Sin 38, 313-317.

Gentry, T. J., Wickham, G. S., Schadt, C. W., He, Z., and Zhou, J. (2006). Microarray applications in microbial ecology research. Microb Ecol 52, 159-175.

Gerday, C., Attaleb, M., Bentahir, M., Chessa, J. P., Claviere, P., Collins, T., D'Amico, S., Dumont, J., Garsoux, G., Georlette, D., Hoyoux, A., Lonhienne, T., 
Meuwis, M. A., and Feller, G. (2000). Cold-adapted enzymes: from fundamentals to biotechnology. Trends Biotechnol 18, 103-107.

Gerritse, G., Ure, R., Bizzoulier, F., and Quax, W. J. (1998). The phenotype enhancement method identifies the Xcp outer membrane secretion machinery from Pseudomonas alcaligenes as a bottleneck for lipase production. J Biotechnol 64, 2338.

Ghanem, A., and Aboul-Enein, H. Y. (2005). Application of lipases in kinetic resolution of racemates. Chirality $17,1-15$.

Ghigo, J. M., and Wandersman, C. (1994). A carboxy-terminal four-amino acid motif is required for secretion of the metalloprotease PrtG through the Erwinia chrysanthemi protease secretion pathway. J Biol Chem 269, 8979-8985.

Gillespie, D. E., Brady, S. F., Bettermann, A. D., Cianciotto, N. P., Liles, M. R., Rondon, M. R., Clardy, J., Goodman, R. M., and Handelsman, J. (2002). Isolation of antibiotics turbomycin $A$ and $B$ from a metagenomic library of soil microbial DNA. Appl Environ Microbiol 68, 4301-4306.

Goddard, J. P., and Reymond, J. L. (2004). Enzyme activity fingerprinting with substrate cocktails. J Am Chem Soc 126, 11116-11117.

Gogarten, J. P., and Townsend, J. P. (2005). Horizontal gene transfer, genome innovation and evolution. Nature Rev Microbiol 3, 679-687.

Grochulski, P., Li, Y., Schrag, J. D., Bouthillier, F., Smith, P., Harrison, D., Rubin, B., and Cygler, M. (1993). Insights into interfacial activation from an open structure of Candida rugosa lipase. J Biol Chem 268, 12843-12847.

Groudieva, T., Kambourova, M., Yusef, H., Royter, M., Grote, R., Trinks, H., and Antranikian, G. (2004). Diversity and cold-active hydrolytic enzymes of culturable bacteria associated with Arctic sea ice, Spitzbergen. Extremophiles 8, 475-488.

Guo, D., Yang, J., and Yan, Y. (2006). Production and cloning of a novel short-chain alcohol tolerant and thermostable lipase from Pseudomonas cepacia GDY-23 (unveröffentlicht, Accession-Nr. DQ075249).

Guo, H., and Xiong, J. (2006). A specific and versatile genomic walking technique. Gene 381, 18-23.

Gupta, R., Beg, Q. K., and Lorenz, P. (2002). Bacterial alkaline proteases: molecular approaches and industrial applications. Appl Microbiol Biotech 59, 15-32.

Gupta, R., Gupta, N., and Rathi, P. (2004). Bacterial lipases: an overview of production, purification and biochemical properties. Appl Microbiol Biotechnol 64, 763781.

Guzzo, J., Pages, J. M., Duong, F., Lazdunski, A., and Murgier, M. (1991). Pseudomonas aeruginosa alkaline protease: Evidence for secretion genes and study of secretion mechanism. J Bacteriol 173, 5290-5297.

Hamelin, K., Bruant, G., El-Shaarawi, A., Hill, S., Edge, T. A., Bekal, S., Fairbrother, J. M., Harel, J., Maynard, C., Masson, L., and Brousseau, R. (2006). A virulence and antimicrobial resistance DNA microarray detects a high frequency of 
virulence genes in Escherichia coli isolates from Great Lakes recreational waters. Appl Environ Microbiol 72, 4200-4206.

Handelsman, J., Rondon, M. R., Brady, S. F., Clardy, J., and Goodman, R. M. (1998). Molecular biological access to the chemistry of unknown soil microbes: a new frontier for natural products. Chem Biol 5, R245-R249.

Head, I. M., Jones, D. M., and Röling, W. F. M. (2006). Marine microorganisms make a meal of oil. Nature Rev Microbiol 4, 173-182.

Healy, F. G., Ray, R. M., Aldrich, H. C., Wilkie, A. C., Ingram, L. O., and Shanmugam, K. T. (1995). Direct isolation of functional genes encoding cellulases from the microbial consortia in a thermophilic, anaerobic digester maintained on lignocellulose. Appl Microbiol Biotechnol 43, 667-674.

Henke, E., Schuster, S., Yang, H., and Bornscheuer, U. T. (2000). Lipase-catalyzed resolution of ibuprofen. Monatshefte Chemie 131, 633-638.

Henke, E., and Bornscheuer, U. T. (2002). Esterases from Bacillus subtilis and $B$. stearothermophilus share high sequence homology but differ substantially in their properties. Appl Microbiol Biotechnol 60, 320-326.

Henne, A., Schmitz, R. A., Bomeke, M., Gottschalk, G., and Daniel, R. (2000). Screening of environmental DNA libraries for the presence of genes conferring lipolytic activity on Escherichia coli. Appl Environ Microbiol 66, 3113-3116.

Herrera, S. (2004). Industrial biotechnology. A chance at redemption. Nat Biotechnol 22, 671-675.

Hongwei, Y., Jinchuan, W., and Bun, C. C. (2005). Kinetic resolution of ibuprofen catalyzed by Candida rugosa lipase in ionic liquids. Chirality 17, 16-21.

Hotta, Y., Ezaki, S., Atomi, H., and Imanaka, T. (2002). Extrem stable and versatile carboxylesterase from a hyperthermophilic archaeon. Appl Environ Microbiol 68, 39253931.

Hutt, A. J., and Caldwell, J. (1984). The importance of stereochemistry in the clinical pharmacokinetics of the 2-arylpropionic acid nonsteroidal anti-inflammatory drugs. Clin Pharmacokin 9, 371-373.

Jäger, K. E., Ransac, S., Dijkstra, B. W., Colson, C., van Heuvel, M., and Misset, O. (1994). Bacterial lipases. FEMS Microbiol Rev 15, 29-63.

Jäger, K. E., Schneidinger, B., Rosenau, F., Werner, M., Lang, D., Dijkstra, B. W., Schimossek, K., Zonta, A., and Reetz, M. T. (1997). Bacterial lipases for biotechnological applications. J Mol Catal B: Enzym 3, 3-12.

Jäger, K. E., and Reetz, T. M. (1998). Microbial lipases form versatile tools for biotechnology. Trends Biotechnol 16, 396-403.

Jäger, K. E., Dijkstra, B. W., and Reetz, M. T. (1999). Bacterial biocatalysts: Molecular biology, three-dimensional structures, and biotechnological applications of lipases. Annu Rev Microbiol 53, 515-551.

Jäger, K. E., and Eggert, T. (2002). Lipases for biotechnology. Curr Opin Biotechnol 13, 390-397. 
Jiang, Z., Wang, H., Ma, Y., and Wei, D. (2006). Characterization of two novel lipase genes isolated directly from environmental sample. Appl Microbiol Biotechnol 70, 327332.

Johnson, L. A., Beacham, I. R., MacRae, I. C., and Free, M. L. (1992). Degradation of triglycerides by a pseudomonad isolated from milk: Molecular analysis of a lipaseencoding gene and its expression in Escherichia coli. Appl Environ Microbiol 58, 17761779 .

Käberlein, T., Lewis, K., and Epstein, S. S. (2002). Isolating 'uncultivable' microorganisms in pure culture in a simulated natural environment. Science 296, 11271129.

Kane, M. D., Poulsen, L. K., and Stahl, D. A. (1993). Monitoring the enrichment and isolation of sulfate-reducing bacteria by using oligonucleotide hybridization probes designed from environmentally derived 16S rRNA sequences. Appl Environ Microbiol $59,682-686$.

Kawai, E., Akatsuka, H., Idei, A., Shibatani, T., and Omori, K. (1998). Serratia marcescens S-layer protein is secreted extracellularly via an ATP-binding cassette exporter, the Lip system. Mol Microbiol 27, 941-952.

Kawai, E., Idei, A.,Kumura, H., Shimazaki K. I., Akatsuka, H., and Omori, K. (1999). The ABC-exporter genes involved in the lipase secretion are clustered with the genes for lipase, alkaline protease, and serine protease homologues in Pseudomonas fluorescens no. 33. Biochim Biophys Acta 1446, 377-382.

Khodursky, A. B., Peter, B. J., Cozzarelli, N. R., Botstein, D., Brown, P. O., and Yanofsky, C. (2000). DNA microarray analysis of gene expression in response to physiological and genetic changes that affect tryptophan metabolism in Escherichia coli. Proc Natl Acad Sci 97, 12170-12175.

Kent, A. D., and Triplett, E. W. (2002). Microbial communities and their interactions in soil and rhizosphere ecosystems. Annu Rev Microbiol 56, 211-236.

Kim, K. R., Kwon, D. Y., Yoon, S. H., Kim, W. Y., and Kim, K. H. (2005). Purification, refolding, and characterization of recombinant Pseudomonas fluorescens lipase. Prot Expr Purif 39, 124-129.

Kim, Y. J., Choi, G. S., Kim, S. B., Yoon, G. S., Kim, Y. S., and Ryu, Y. W. (2006). Screening and characterization of a novel esterase from a metagenomic library. Protein Expr Purif 45, 315-23.

Kojima, Y., Kobayashi, M., and Shimizu, S. (2003). A novel lipase from Pseudomonas fluorescens HU380: Gene cloning, overproduction, renaturationactivation, two-step purification, and characterization. J Biosc Bioeng 96, 242-249.

Kojima, Y., and Shimizu, S. (2003). Purification and characterization of the lipase from Pseudomonas fluorescens HU380. J Biosc Bioeng 96, 219-226.

Kopp, J., and Schwede, T. (2006). The SWISS-MODEL repository: new features and functionalities. Nucleic Acids Res 34, D315-D318.

Kulkarni, N., and Gadre, R. V. (2002). Production and properties of an alkaline, thermophilic lipase from Pseudomonas fluorescens NS2W. J Int Food Microbiol 28, 344-348. 
Kwon, H. J., Haruki, M., Morikawa, M., and Kanaya, S. (2002). Role of repetitive nine-residue sequence motifs in secretion, enzymatic activity, and protein conformation of a family I.3 lipase. J Biosci Bioeng 93, 157-164.

Laemmli, U. K. (1970). Cleavage of structural proteins during the assembly of the head of bacteriophage T4. Nature 227, 680-685.

Lai, B., and Khanna, S. (1996). Degradation of crude oil by Actinobacter calcoaceticus and Alcaligenes oderans. J Appl Bacteriol 81, 355-362.

Lanes, O., Leiros, I., Smalås, A. O., and Willassen, N. P. (2002). Identification, cloning, and expression of uracil-DNA glycosylase from Atlantic cod (Gadus morhua): characterization and homology modelling of the cold-active catalytic domain. Extremophiles 6, 73-86.

Lawrence, R. C., Freyer, T. F., Reiter, B. (1967). Rapid method for the quantitative estimation of microbial lipases. Nature 213, 1264-1265.

Lee, Y. P., Chung, G. H., Rhee, J. S. (1993). Purification and characterization of Pseudomonas fluorescens SIK W1 lipase expressed in Escherichia coli. Biochim Biophys Acta 1169, 156-164.

Lee, S. W., Won, K., Lim, H. K., Kim, J. C., Choi, G. J., and Cho, K. Y. (2004). Screening for novel lipolytic enzymes from uncultured soil microorganisms. Appl Microbiol Biotechnol 65, 720-726

Lee, C. C., Kibblewhite-Accinelli, R. E., Wagschal, K., Robertson, G. H., and Wong, D. W. (2006). Cloning and characterization of a cold-active xylanase enzyme from an environmental DNA library. Extremophiles 10, 295-300.

Leggewie, C. (2005). Neue Biokatalysatoren aus dem Metagenom: Expression, Identifizierung und biochemische Eigenschaften. Dissertation, Heinrich-HeineUniversität Düsseldorf.

Lehner, A., Loy, A., Behr, T., Gänge, H., Ludwig, W., Wagner, M., and Schleifer, K. H. (2005). Oligonucleotide microarray for identification of Enterococcus species. FEMS Microbiol Let 246, 133-142.

Letoffe, S., Redeker, V., and Wandersman, C. (1998). Isolation and characterization of an extracellular haem-binding protein from Pseudomonas aeruginosa that shares function and sequence similarities with the Serratia marcescens HasA haemophore. Mol Microbiol 28, 1223-1234.

Leys, N. M., Ryngaert, A., Bastiaens, L., Verstraete, W., Top, E. M., Springael, D. (2005a). Occurrence and phylogenetic diversity of Sphingomonas strains in soils contaminated with polycyclic aromatic hydrocarbons. Appl Environ Microbiol 70, 19441955.

Leys, N. M., Ryngaert, A., Bastiaens, L., Wattiau, P., Top, E. M., Verstraete, W., Springael, D. (2005b). Occurrence and community composition of fast-growing Mycobacterium in soils with polycyclic aromatic hydrocarbons. FEMS Microbiol Ecol 51, 375-388.

Liebeton, K., and Eck, J. (2004). Identification and expression in E. coli of novel nitrile hydratases from the metagenome. Eng Life Sci 4, 557-562. 
Liese, A., Seelbach, K., and Wandrey, C. (2005). Industrial biotransformations, $2^{\text {nd }}$ ed. Wiley-VCH, Weinheim.

Lorenz, P., Liebeton, K., Niehaus, F., and Eck, J. (2002). Screening for novel enzymes for biocatalytic processes: accessing the metagenome as a resource of novel functional sequence space. Curr Opin Biotechnol 13, 572-577.

Lorenz, P., and Eck, J. (2005). Metagenomics and industrial applications. Nature Rev Microbiol 3, 510.

Lorenz, P. (2006). Metagenomics für die Weiße Biotechnologie. Chem Ing Techn 78, 461-468.

Loy, A., Schulz, C., Lucker, S., Schopfer-Wendels, A., Stöcker, K., Baranyi, C., Lehner, A., and Wagner, M. (2005). 16S rRNA gene-based oligonucleotide microarray for environmental monitoring of the betaproteobacterial order 'Rhodocyclales'. Appl Environ Microbiol 71, 1373-1386.

Luccini, S., Thompson, A., and Hinton, J. C. (2001). Microarrays for microbiologists. Microbiol 147, 1403-1414.

Luo, Y., Zheng, Y., Jiang, Z., Ma, Y., and Wei, D. (2006). A novel psychrophilic lipase from Pseudomonas fluorescens with unique property in chiral resolution and biodiesel production via transesterification. Appl Microbiol Biotechnol 73, 349-355.

Madhav, M. V., and Ching, C. B. (2001). Study on the enzymatic hydrolysis of racemic methyl ibuprofen ester. J Chem Technol Biotechnol 76, 941-948.

Magot, M., Ollivier, B., and Patel, B. K. C. (2000). Microbiology of petroleum reservoirs. Ant Leuwenh 77, 103-116.

Marchler-Bauer, A., Anderson, J. B., Cherukuri, P. F., DeWeese-Scott, C., Geer, L. Y., Gwadz, M., He, S., Hurwitz, D. I., Jackson, J. D., Ke, Z., Lanczycki, C. J., Liebert, C. A., Liu, C., Lu, F., Yamashita, R. A., Yin, J. J., Zhang, D., and Bryant, S. H. (2005). CDD: a Conserved Domain Database for protein classification. Nucleic Acids Res 33, D192-196.

Margesin, R., Zimmerbauer, A., and Schinner, F. (1999). Soil lipase activity - a useful indicator of oil biodegradation. Biotechnol Techniques 13, 859-863.

Margesin, R., Gander, S., Zacke, G., Gounot, A. M., and Schinner, F. (2003a). Hydrocarbon degradation and enzyme activities of cold-adapted bacteria and yeasts. Extremophiles 7, 451-458.

Margesin, R., Labbé, D., Schinner, F., Greer, C. W., and Whyte, L. G. (2003b). Characterization of hydrocarbon-degrading microbial populations in contaminated and pristine Alpine soils. Appl Environ Microbiol 69, 3085-3092.

Marsh, T. (1999). Terminal restriction fragment length polymorphism (T-RFLP): an emerging method for characterizing diversity among homologous populations of amplification products. Curr Opin Microbiol 2, 323-327.

Marshal, A. G., and Rogers, R. P. (2003). Petroleomics: the next grand challenge for chemical analysis. Acc Chem Res 37, 53-59. 
Martinez, A., Kolvek, S. J., Yip, C. L., Hopke, J., Brown, K. A., MacNeil, I. A., and Osburne, M. S. (2004). Genetically modified bacterial strains and novel bacterial artificial chromosome shuttle vectors for constructing environmental libraries and detecting heterologous natural products in multiple expression hosts. Appl Environ Microbiol 70, 2452-2463.

Marx, J. C., Blaise, V., Collins, T., D’Amico, S., Delille, D., Gratia, E., Hoyoux, A., Huston, A. L., Sonan, G., Feller, G., and Gerday, C. (2004). A perspective on cold enzymes: current knowledge and frequently asked questions. Cell Mol Biol 50, 643655.

Matsumura, N., Minami, S., and Mitsuhasi, S. (1998). Sequences of homologous $\beta-$ lactamases from clinical isolates of Serratia marcescens with different substrate specificities. Antimicrob Agents Chemother 42, 176-179.

Mayordomo, I., Randez-Gil, F., and Prieto, J. A. (2000). Isolation, purification and characterization of a cold-active lipase from Aspergillus nidulans. J Agric Food Chem $48,105-109$.

Meyerhans, A., Vartanian, J. P., and Wain-Hobson, S. (1990). DNA recombination during PCR. Nucleic Acids Res 18, 1687-1691.

Miyazawa, M., Kawazoe, H., Sumi, Y., and Hyakumachi, M. (2003). Lytic activity of /menthol derivatives against the snow blight disease fungus, Micronectriella nivalis. $\mathrm{J}$ Agric Food Chem 51, 1880-1883.

Morris, D. D., Reeves, R. A., Gibbs, M. D., Saul, D. J., and Bergquist, P. L. (1995). Correction of the $\beta$-mannanase domain of the celC pseudogene from Caldocellulosiruptor saccharolyticus and activity of the gene product on kraft pulp. Appl Environ Microbiol 61, 2262-2269.

Mustranta, A. (1992). Use of lipases in the resolution of racemic ibuprofen. Appl Microbiol Biotechnol 38, 61-66.

Muyzer, G., de Waal, E. C., and Uitterlinden, A. G. (1993). Profiling of complex microbial populations by denaturing gradient gel electrophoresis analysis of polymerase chain reaction-amplified genes coding for 16S rRNA. Appl Environ Microbiol 59, 695-700.

Nalin, R., Simonet, P., Vogel, T. M., and Normand, P. (1999). Rhodanobacter lindaniclasticus gen. nov., sp. nov., a lindane-degrading bacterium. Int J Syst Bacteriol 49, 19-23.

Neefs, J. M., van de Peer, L. H., and de Wachter, R. (1990). Compilation of small ribosomal subunit RNA sequences. Nucleic Acids Res 18, 2237-2317.

Ng, I. S., and Tsai, S. W. (2005). Hydrolytic resolution of $(R, S)$-Naproxen 2,2,2trifluoroethyl thioester by Carica papaya lipase in water-saturated organic solvents. Biotechnol Bioeng 89, 88-95.

Niemi, R. M., Heiskanen, I., Wallenius, K., and Lindstrom, K. (2001). Extraction and purification of DNA in rhizosphere soil samples for PCR-DGGE analysis of bacterial consortia. J Microbiol Methods 45, 155-65. 
Nini, L., Sarda, L., Comeau, L. C., Boitard, E., Dubès, J. P., and Chahinian, H. (2001). Lipase-catalysed hydrolysis of short-chain substrates in solution and in emulsion: a kinetic study. Biochim Biophys Acta 1534, 34-44.

Nwosu, V. C. (2001). Antibiotic resistance genes with particular reference to soil microorganisms. Res Microbiol 152, 421-430.

Ogino, H., Mimitsuka, T., Muto, T., Matsumura, M., Yasuda, M., Ishimi, K., and Ishikawa, H. (2004). Cloning, expression, and characterization of a lipolytic enzyme gene (lip8) from Pseudomonas aeruginosa LST-03. J Mol Microbiol Biotechnol 7, 212223.

Ollis, D. L., Cheah, E., Cygler, M., Dijkstra, B., Frolow, F., Franken, S. M., Harel, M., Remington, S. J., Silman, I., Schrag, J., Sussman, J. L., Verschueren, K. H. G., and Goldman, A. (1992). The $\alpha / \beta$ hydrolase fold. Prot Eng 5, 197-211.

Øvreås, L., and Torsvik, V. (1998). Microbial diversity and community structure in two different agricultural soil communities. Micob Ecol 36, 303-315.

Pathak, G. P. (2006). Phenotypic characterisation of diesel biofilm isolates and isolation of novel bioctalysts using metagenomic approaches. Master-Thesis, Universität Duisburg-Essen.

Petersen, E. I., Valinger, G., Bolkner, S., Stubenrauch, G., and Schwab, H. (2001). A novel esterase from Burkholderia gladioli which shows high deacetylation activity on cephalosporins is related to beta-lactamases and DD-peptidases. J Biotechnol 89, 1125.

Petersen, E., Zuegg, J., Ribbons, D. W., and Schwab, H. (1996). Molecular cloning and homology modeling of protocatechuate 3,4-dioxygenase from Pseudomonas marginata. Microbiol Res 151, 359-370.

Piel, J. (2002). A polyketide synthase-peptide synthetase gene cluster from an uncultured bacterial symbiont of Paederus beetles. Proc Natl Acad Sci 99, 1400214007 .

Prince, R. C. (2005). Petroleum microbiology (eds. Ollivier, B., and Magot, M.) S. 317336. ASM Press, Washington D.C., USA.

Rajmohan, S., Dodd, C. E. R., and Waites, W. M. (2002). Enzymes from isolates of Pseudomonas fluorescens involved in food spoilage. J Appl Microbiol 93, 205-213.

Ranjan, R., Grover, A., Kapardar, R. K., and Sharma, R. (2005). Isolation of novel lipolytic genes from uncultured bacteria of pond water. Biochem Biophys Res Commun $335,57-65$.

Rappé, M. S., and Giovannoni, S. J. (2003). The uncultured microbial majority. Annu Rev Microbiol 57, 369-394.

Rashid, N., Kikuchi, H., Ezaki, S., Atomi, H., and Imanaka, T. (1999). Isolation and characterization of psychotrophs from subterran environments. J Biosci Bioeng 87, 746-751.

Rashid, N., Shimada, Y., Ezaki, S., Atomi, H., and Imanaka, T. (2001). Lowtemperature lipase from psychrotrophic Pseudomonas sp. strain KB700A. Appl Environ Microbiol 67, 4064-4069. 
Rees, H., Grant, S., Jones, B., Grant, W., and Heaphy, S. (2003). Detecting cellulase and esterase enzyme activities encoded by novel genes present in environmental DNA libraries. Extremophiles 7, 415.

Reetz, M., Zonta, A., and Simpelkamp, J. (1995). Efficient heterogeneous biocatalysts by entrapment of lipases in hydrophobic sol-gel materials. Ang Chem Int Ed Eng 34, 301-303.

Rhee, S. K., Liu, X., Wu, L., Chong, S. C., Wan, X., and Zhou, J. (2004). Detection of genes involved in biodegradation and biotransformation in microbial communities by using 50-mer oligonucleotide microarrays. Appl Environ Microbiol 70, 4303-4317.

Rhee, J. K., Ahn, D. G., Kim, Y. G., and Oh, J. W. (2005). New thermophilic and thermostable esterase with sequence similarity to the hormone-sensitive lipase family, cloned from a metagenomic library. Appl Environ Microbiol 71, 817-825.

Riesenfeld, C. S., Goodman, R. M., and Handelsman, J. (2004). Uncultured soil bacteria are a reservoir of new antibiotic resistance genes. Environ Microbiol 6, 981989.

Röling, W. F. M., Milner, M. G., Jones, D. M., Fratepietro, F., Swannell, R. P. J., Daniel, F., and Head, I. M. (2004). Bacterial community dynamics and hydrocarbon degradation during a field-scale evaluation of bioremediation on a mudflat beach contaminated with buried oil. Appl Environ Microbiol 70, 2603-2613.

Rosenau, F., and Jäger, K. E. (2003). Overexpression of biocatalysts in Pseudomonas. In A. Svendsen (ed.), Enzyme functionality: Design, engineering and screening. Marcel Decker, New York, USA.

Rost, B., Yachdav, G., and Lin, J. (2004). The predict protein server. Nucleic Acids Res 32, 321-326.

Roszkowski, A. P., Rooks, W., Tomolonis, A., Miller, L., and Pelczarska, A. B. (1973). Pharmacological properties of naproxen. Scand J Rheumatol 2, 12-19.

Rusnak, M., Nieveler, J., Schmid, R. D., and Petri, R. (2005). The putative lipase, AF1763, from Archaeoglobus fulgidus is a carboxylesterase with a very high $\mathrm{pH}$ optimum. Biotechnol Let 27, 743-748.

Sakai, Y., Ishikawa, J., Fukasaka, S., Yurimoto, H., Mitsui, R., Yanase, H., and Kato, N. (1999). A new carboxylesterase from Brevibacterium linens IFO 12171 responsible for the conversion of 1,4-butanediol diacrylate to 4-hydroxybutyl acrylate: Purification, characterization, gene cloning, and gene expresion in Escherichia coli. Biosci Biotechnol Biochem 63, 688-697.

Salyers, A. A., and Amabile-Cuevas, C. F. (1997). Why are antibiotic resistance genes so resistant to elimination? Antimicrob Agents Chemother 41, 2321-2325.

Sambrook, J., Fritsch, E., and Maniatis, T. (1989). Molecular cloning, a laboratory manual. Cold Spring Harbor Laboratory Press, Cold Spring Harbor.

Sandaa, R., Torsvik, V., Enger, Ø., Daae, F. L., Castberg, C., and Hahn, D. (1999). Analysis of bacterial communities in heavy-metal contaminated soils at different levels of resolution. FEMS Microbiol Ecol 30, 237-251. 
Santosa, D. A. (2001). Rapid extraction and purification of environmental DNA for molecular cloning applications and molecular diversity studies. Mol Biotechnol 17, 5964.

Sarda, L., and Desnuelle, P. (1958). Action de la lipase pancréatique sur les esters en émulsion. Biochim Biophys Acta 30, 513-521.

Sayle, R. A., and Milnar-White, E. J. (1995). RasMol: biomolecular graphics for all. Trends Biochem Sci 20, 374.

Schloss, P. D., and Handelsman, J. (2005). Metagenomics for studying unculturable microorganisms: cutting the Gordian knot. Genome Biol 6, 229.

Schmeisser, C., Stöckigt, C., Raasch, C., Wingender, J., Timmis, K. N., Wenderoth, D. F., Flemming, H. C., Liesegang, H., Schmitz, R. A., Jäger, K. E., and Streit, W. R. (2003). Metagenome survey of biofilms in drinking-water networks. Appl Environ Microbiol 69, 7298-7309.

Schmeisser, C. (2004). Metagenomanalyse eines Multispezies-Biofilms: Biochemische Charakterisierung und Kristallisierung der ersten multimeren Esterase aus einem bisher nicht kultivierten Mikroorganismus. Dissertation, Georg-AugustUniversität Göttingen.

Schmid, A., Dordick, J. S., Hauer, B., Kiener, A., Wubbolts, M., and Witholt, B. (2001). Industrial biocatalysis today and tomorrow. Nature 409, 258-268.

Sebat, J. L., Colwell, F. S., and Crawford, R. L. (2003). Metagenomic profiling: Microarray analysis of an environmental genomic library. Appl Environ Microbiol 69, 4927-4934.

Seemayer, R., and Schneider, M. P. (1991). Enzymatic preparation of optically pure trans-1,2-cycloalkanediols. J Chem Soc Chem Commun 1, 49-50.

Séveno, N. A., Kallifidas, D., Smalla, K., van Elsas, J. D., Collard, J. M., Karagouni, A. D., and Wellington, E. M. H. (2002). Occurrence and reservoirs of antibiotic resistance genes in the environment. Rev Med Microbiol 13, 15-27.

Shena, M., Shalon, D., Davis, R. W., and Brown, P. O. (1995). Quantitative monitoring of gene expression patterns with a complementary DNA microarray. Science 270, 467-470.

Siddiqui, K. S., Poljak, A., Guilhaus, M., Feller, G., D’Amico, S., Gerday, C., and Cavicchioli, R. (2005). Role of disulfide bridges in the activity and stability of a coldactive $\alpha$-amylase. J Bacteriol 187, 6206-6212.

Sijbesma, F. (2003). White biotechnology: Gateway to a more sustainable future. Quelle: www.europabio.org oder www.mckinsey.com.

Simons, J. W., van Kampen, M. D., Ubarretxena-Belandia, I., Cox, R. C., Alves dos Santos, C. M. A., Egmond, M. R., and Verheij, H. M. (1999). Identification of a calcium binding site in Staphylococcus hyicus lipase: Generation of calciumindependent variants. Biochemistry 38, 2-10.

Small, J., Call, D. R., Brockman, F. J., Straub, T. M., and Chandler, D. P. (2001). Direct detection of 16S rRNA in soil extracts by using oligonucleotide microarrays. Appl Environ Microbiol 67, 4708-4716. 
Snellman, E. A., Sullivan, E. R., and Colwell, R. R. (2002). Purification and properties of the extracellular lipase, LipA, from Acinetobacter sp. RAG-1. Eur J Biochem 269, 5771-5779.

Sommer, P., Bormann, C., and Götz F. (1997). Genetic and biochemical characterization of a new extracellular lipase from Streptomyces cinnamomeus. Appl Environ Microbiol 63, 3553-3560.

Stach, J. E. M., and Burns, R. G. (2002). Enrichment versus biofilm culture: a functional and phylogenetic comparison of polycyclic aromatic hydrocarbon-degrading microbial communities. Environ Microbiol 4, 169-182.

Steele, H. L., and Streit, W. R. (2005). Metagenomics: Advances in ecology and biotechnology. FEMS Microbiol Lett 247, 105-111.

Stokes, H. W., Holmes, A. J., Nield, B. S., Holley, M. P., Nevalainen, K. M., Mabbutt, B. C., and Gillings, G. R. (2001). Gene cassette PCR: sequenceindependent recovery of entire genes from environmental DNA. Appl Environ Microbiol $67,5240-5246$

Stover, C. K., Pham, X. Q., Erwin, A. L., Mizoguchi, S. D., Warrener, P., Hickey, M. J., Brinkman, F. S. L., Hufnagle, W. O., Kowalik, D. J., Lagrou, M., Garber, R. L., Goltry, L., Tolentino, E., Westbrock-Wadman, S., Yuan, Y., Brody, L. L., Coulter, S. N., Folger, K. R., Kas, A., Larbig, K., Lim, R., Smith, K., Spencer, D., Wong, G. K., Wu, Z., Paulsen, I. T., Reizer, J., Saier, H. M., Hancock, R. E. W, Lory, S., and Olson, M. V. (2000). Complete genome sequence of Pseudomonas aeruginosa PAO1, an opportunistic pathogen. Nature 406, 959-964.

Straathof, A. J. J., Panke, S., and Schmid, A. (2002). The production of fine chemicals by biotransformations. Curr Opin Biotechnol 13, 548-556.

Streit, W., Bjourson, A. J., Cooper, J. E., and Werner, D. (1993). Application of subtraction hybridization for the development of a Rhizobium legominosarum biovar phaseoli and Rhizobium tropici group-specific DNA-probe. FEMS Microbiol Ecol 13, 5968.

Streit, W. R., Daniel, R., and Jäger, K. E. (2004). Prospecting for biocatalysts and drugs in the genomes of non-cultured microorganisms. Curr Opin Biotechnol 15, 285290.

Streit, W. R., and Schmitz, R. A. (2004). Metagenomics - the key to the uncultured microbes. Curr Opin Microbiol 7, 492-498.

Suzuki, T., Nakayama, T., Kurihara, T., Nishino, T., and Esaki, N. (2001). Coldactive lipolytic activity of psychrotrophic Acinetobacter sp. strain no. 6. J Biosc Bioeng $92,144-148$.

Swaisgood, H. E., and Bozoglu, F. (1984). Heat inactivation of the extracellular lipase from Pseudomonas fluorescens. J Agric Food Chem 32, 7-10.

Tan, G., Gao, Y., Shi, M., Zhang, X., He, S., Chen, Z., and An, C. (2005). SiteFindingPCR: a simple and efficient PCR method for chromosome walking. Nucleic Acids Res 33, e122. 
Tan, Y., and Miller, K. J. (1993). Cloning, expression, and nucleotide sequence of a lipase gene from Pseudomonas fluorescens B52. Appl Environ Microbiol 58, 14021407.

Taroncher-Oldenburg, G., Griner, E. M., Francis, C. A., and Ward, B. B. (2003). Oligonucleotide microarray for the study of functional gene diversity in the nitrogen cycle in the environment. Appl Environ Microbiol 69, 1159-1171.

Thomas, C. M., and Nielsen, K. M. (2005). Mechanisms of, and barriers to, horizontal gene transfer between bacteria. Nature Rev Microbiol 3, 711-721.

Thomassin-Lacroix, E. J. M., Yu, Z., Eriksson, M., Reimer, K. J., and Mohn, W. W. (2001). DNA-based and culture-based characterization of a hydrocarbon-degrading consortium enriched from Arctic soil. Can J Microbiol 47, 1107-1115.

Torsvik, V., Salte, K., Sorheim, R., and Goksoyr, J. (1990). Comparison of phenotypic diversity and DNA heterogeneity in a population of soil bacteria. Appl Environ Microbiol 56, 776-81.

Torsvik, V., Øvreås, L., and Thingstad, T. F. (2002). Prokaryotic diversity magnitude, dynamics, and controlling factors. Science 296, 1064-1066.

Triglia, T., Peterson, M. G., and Kemp, D. J. (1988). A procedure for in vitro amplification of DNA segments that lie outside the boundaries of known sequences. Nucleic Acids Res 16, 8186.

Tyson, G. W., Chapman, J., Hugenholtz, P., Allen, E. E., Ram, R. J., Richardson, P. M., Solovyev, V. V., Rubin, E. M., Rokhsar, D. S., and Banfield, J. F. (2004). Community structure and metabolism through reconstruction of microbial genomes from the environment. Nature 428, 37-43.

Uyttebroek, M., Breugelmans, P., Jansse, M., Wattiau, P., Joffe, B., Karlson, U., Ortega-Calvo, J. J., Bastiaens, L., Ryngaert, A., Hausner, M., and Springael, D. (2006). Distribution of the Mycobacterium community and polycyclic aromatic hydrocarbons (PAHs) among different size fractions of a long-term PAH contaminated soil. Environ Microbiol 8, 836-847.

van Hamme, J. D., Singh, A., and Ward, O. P. (2003). Recent advances in petroleum microbiology. Microbiol Mol Biol Rev 67, 503-549.

Venter, J. C., Remington, K., Heidelberg, J. F., Halpern, A. L., Rusch, D., Eisen, J. A., Wu, D., Paulsen, I., Nelson, K. E., Nelson, W., Fouts, D. E., Levy, S., Knap, A. H., Lomas, M. W., Nealson, K., White, O., Peterson, J., Hoffman, J., Parsons, R., Baden-Tillson, H., Pfannkoch, C., Rogers, Y. H., and Smith, H. O. (2004). Environmental genome shotgun sequencing of the Sargasso Sea. Science 304, 66-74.

Verger, R. (1997). 'Interfacial activation' of lipases: Facts and artifacts. Trends Biotechnol 15, 32-38.

Voget, S., Leggewie, C., Uesbeck, A., Raasch, C., Jäger, K. E., and Streit, W. R. (2003). Prospecting for novel biocatalysts in a soil metagenome. Appl Environ Microbiol $69,6235-6242$.

Voget, S. (2006). Metagenomanalyse eines hydrolytischen Konsortiums: Identifizierung und biochemische Charakterisierung von Polysaccharid-abbauenden 
Biokatalysatoren aus nicht kultivierten Mikroorganismen. Dissertation, Georg-AugustUniversität, Göttingen.

Voget, S., Steele, H. L., and Streit, W. R. (2006). Characterization of a metagenome derived halotolerant cellulase. J Biotechnol 126, 26-36.

Voordouw, G., Shen, Y., Harrington, C. S., Telang, A. J., Jack, T. R., and Westlake, D. W. S. (1993). Quantitative reverse sample genome probing of microbial communities and its application to oil field production waters. Appl Environ Microbiol $59,4101-4114$.

Wagner, U. G., Petersen, E. I., Schwab, H., and Kratky, C. (2002). EstB from Burkholderia gladioli: A novel esterase with a $\beta$-lactamase fold reveals steric factors to discriminate between esterolytic and $\beta$-lactam cleaving activity. Protein Sci 11, 467478.

Wahler, D., Boujard, O., Lefevre, F., and Reymond, J. L. (2004). Adrenaline profiling of lipases and esterases with 1,2-diol and carbohydrate acetates. Tetrahedron 60, 703-710.

Wang, D. L., Nag, A., Lee, G. C., and Shaw, J. F. (2002). Factors affecting the resolution of $d l$-menthol by immobilized lipase-catalyzed esterification in organic solvent. J Agric Food Chem 50, 262-265.

Wang, G. Y., Graziani, E., Waters, B., Pan, W., Li, X., McDermott, J., Meurer, G., Saxena, G., Andersen, R. J., and J. Davies (2000). Novel natural products from soil DNA libraries in a streptomycete host. Org Lett 2, 2401-2404.

Wei, Y., Schottel, J. L., Derewenda, U., Swenson, L., Patkar, S., Derewenda, Z. S. (1995). A novel variant of the catalytic triad in the Streptomyces scabies esterase. Nat Struct Biol 2, 218-223.

Wei, Y., Lee, J. M., Richmond, C., Blattner, R., Rafalski, J. A., and LaRossa, R. A. (2001). High-density microarray mediated gene expression profiling of Escherichia coli. J Bacteriol 183, 545-556.

Whitman, W. B., Coleman, D. C., and Wiebe, W. J. (1998). Prokaryotes: The unseen majority. Proc Natl Acad Sci 95, 6578-6583.

Winkler, U. K., and Stuckmann, M. (1979). Glycogen, hyaluronate, and some other polysaccharides greatly enhance the formation of exolipase by Serratia marcescens. J Bacteriol 138, 663-670.

Woese, C. R. (1987). Bacterial evolution. Microbiol Rev 51, 221-271.

Woods, R. G., Burger, M., Beven, C. A., and Beacham, I. R. (2001). The aprX-lipA operon of Pseudomonas fluorescens B52: a molecular analysis of metalloprotease and lipase production. Microbiol 117, 345-354.

Wu, L., Thompson, D. K., Li, G., Hurt, R. A., Tiedje, J. M., and Zhou, J. (2001). Development and evaluation of functional gene arrays for detection of selected genes in the environment. Appl Environ Microbiol 67, 5780-5790.

Xu, J. (2006). Microbial ecology in the age of genomics and metagenomics: concepts, tools, and recent advances. Molec Ecol 15, 1713-1731. 
Yuanxin, Y., Chengcai, A., Li, L., Jiayu, G., Guihong, T., and Zhangliang, C. (2003). T-linker-specific ligation PCR (T-linker PCR): an advanced PCR technique for chromosome walking or for isolation of tagged DNA ends. Nucleic Acids Res 31, e68.

Yun, J., Kang, S., Park, S., Yoon, H., Kim, M.-J., Heu, S., and Ryu, S. (2004). Characterization of a novel amylolytic enzyme encoded by a gene from a soil-derived metagenomic library. Appl Environ Microbiol 70, 7229.

Zengler, K., Toledo, G., Rappé, M, Elkins, J., Mathur, E. J., Short, J. M., and Keller, M. (2002). Cultivating the uncultured. Proc Natl Acad Sci 99, 15681-15686.

Zhou, J., Bruns, M. A., and Tiedje, J. M. (1996). DNA recovery from soils of diverse composition. Appl Environ Microbiol 62, 316-322.

Zhou, J., Davey, M. E., Figueras, J. B., Rivkina, E., Glichinsky, D., Tiedje, J. M. (1997). Phylogenetic diversity of a bacterial community determined from Siberian tundra soil DNA. Microbiol 143, 3913-3919.

Zhou, J., and Thompson, D. K. (2002). Challenges in applying microarrays to environmental studies. Curr Opin Biotechnol 13, 204-207.

Zhou, J. (2003). Microarrays for bacterial detection and microbial community analysis. Curr Opin Microbiol 6, 288-294.

Zinke, H. (2004). Weiße Biotechnologie: Neue Produkte, gesellschaftlicher Nutzen und Wertschöpfungspotentiale. Zeitschrift für Biopolitik 2, 31-41. 


\section{Anhang}

\begin{tabular}{|c|c|c|c|}
\hline & Substrat & & Substrat \\
\hline 1 & ${ }_{1-O k t y l a c e t a t} ل_{\mathrm{CH}_{3}}$ & 10 & $\underset{\alpha-T e r p i n y l-A c e t a t}{\mathrm{H}_{3} \mathrm{C}} \succ \underbrace{\mathrm{CH}_{3} \mathrm{CH}_{\mathrm{CH}_{3}}}_{\mathrm{CH}_{3}}$ \\
\hline 2 & (RS)-2-Oktylacetat & 11 & $\underset{\alpha \text {-Terpinyl-Caprylat }}{\mathrm{H}_{3} \mathrm{C}}$ \\
\hline 3 & $\begin{array}{l}\mathrm{H}_{3} \mathrm{C} \\
\text { (RS)-3-Oktylacetat }\end{array}$ & 12 & $\langle\underbrace{>}_{\text {2,3-Glycerindibutylether-Acetat }}\langle\underbrace{\mathrm{H}_{3} \mathrm{C}}_{\mathrm{CH}_{3}}$ \\
\hline 4 & (RS)-1-Phenylethylacetat & 13 & (RS)-IPG-Acetat \\
\hline 5 & (RS)-1-(2-Naphtyl)-ethylacetat & 14 & Methyl-Caprylat \\
\hline 6 & (RS)-1-Cyclohexylethylacetat & 15 & ${ }_{\text {Ethyl-Caprylat }}$ \\
\hline 7 & Phenylacetat & 16 & Isopropyl-Caprylat \\
\hline 8 & Cyclohexylacetat & 17 & Tert-Butyl-Caprylat \\
\hline 9 & (RS)-beta-Citronollylacetat & & \\
\hline
\end{tabular}

Abb. 64: Strukturformeln der Estersubstrate mit unterschiedlichen Alkoholresten (AG Prof. Reetz, MPI für Kohlenforschung, Mülheim a.d. Ruhr). 


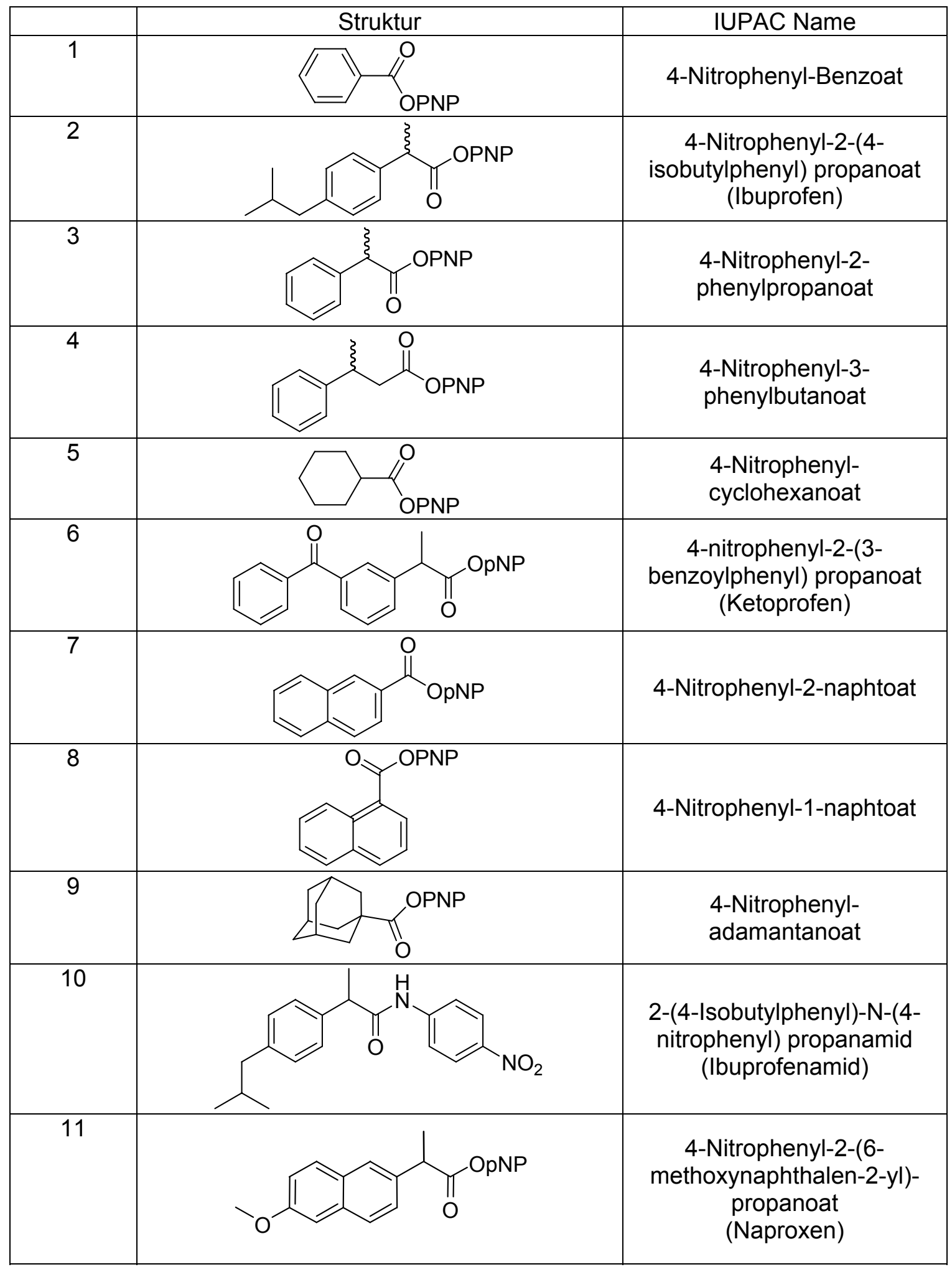

Abb. 65: Strukturformeln der pNP-Ester mit verschiedenen Säureresten, Trivialnamen sind in Klammen angegeben (AG Prof. Reetz, MPI für Kohlenforschung, Mülheim a.d. Ruhr). 


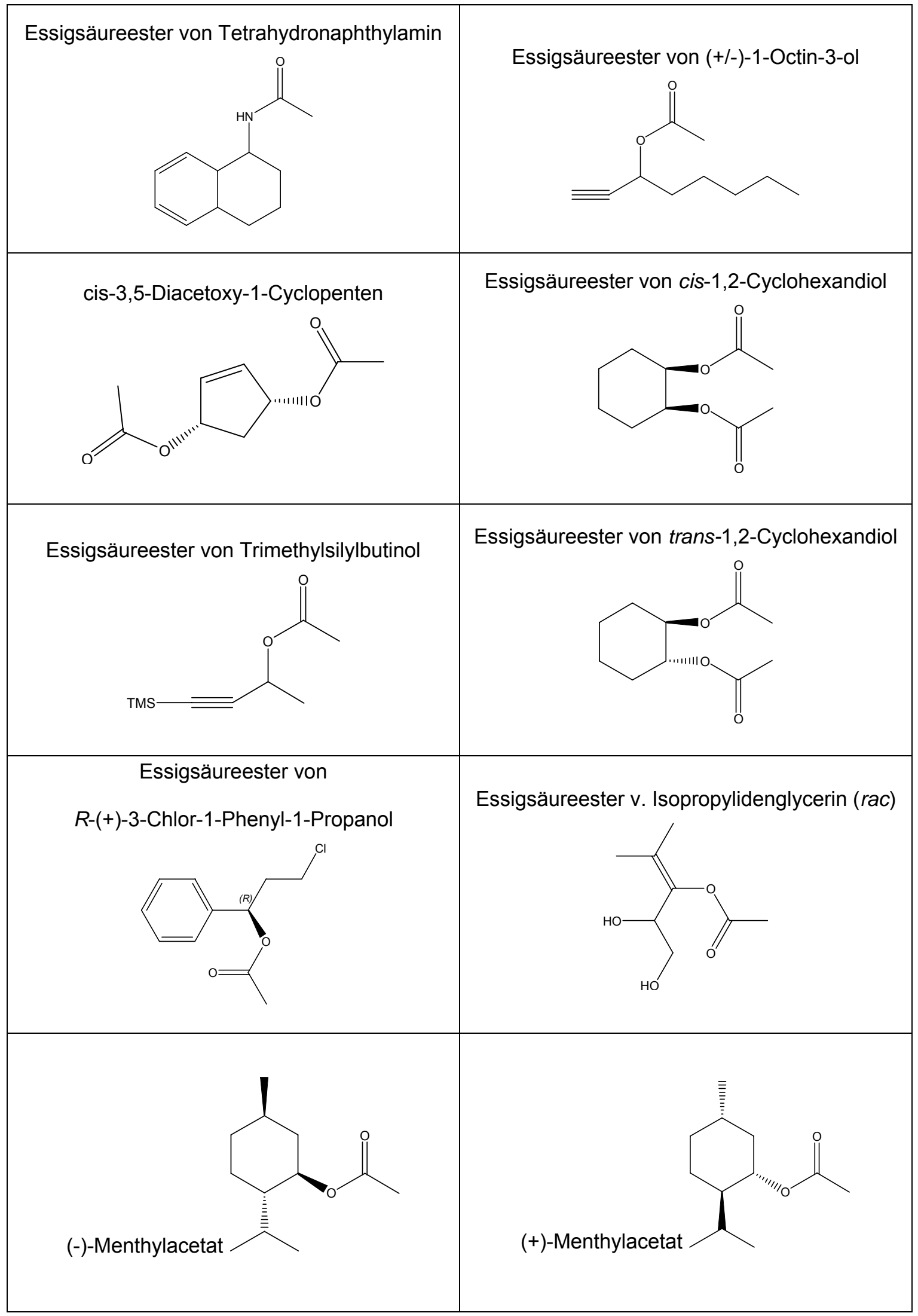

Abb. 66: Strukturformeln der verschiedenen Modellsubstrate, die durch EstCE umgesetzt wurden (Kapitel III.2.7.8) (AG Prof. Jäger, FZ Jülich). 
Tab. 26: Übersicht über die nächsten Verwandten der aus den Bodenproben isolierten 16S rRNA-Klone (128 Klone)

\begin{tabular}{|c|c|c|c|}
\hline $\mathrm{Nr}^{1}$ & nächster Verwandter in der RDP-Datenbank & $\begin{array}{l}\text { Ähn- } \\
\text { lich- } \\
\text { keits- } \\
\text { wert }^{2}\end{array}$ & $\begin{array}{l}\text { GenBank } \\
\text { Accession } \\
\text { Nummer }\end{array}$ \\
\hline \multicolumn{4}{|c|}{$\underline{\alpha-P r o t e o b a c t e r i a ~}$} \\
\hline 115 & unidentified proteobacterium; from $1200 \mathrm{mbsl}$ of lake Baikal & 0,937 & X99983 \\
\hline 139 & uncultured Caulobacteraceae bacterium from PCB-biofilm 1 & 0,810 & AJ966829 \\
\hline 191 & uncultured alpha proteobacterium Kmlps0-27 & 0,722 & AF289877 \\
\hline 196 & Roseobacter sp. SKA26 & 0,177 & AF261048 \\
\hline 204 & uncultured alpha proteobacterium; BPC2_G05 & 0,899 & AY689976 \\
\hline 207 & uncultured Caulobacter sp.; SSCP Band from PCB-biofilm 1 & 0,714 & AJ966820 \\
\hline 215 & Gluconacetobacter sp. 291101 & 0,858 & AY072698 \\
\hline 218 & uncultured bacterium; VE1-98 & 0,793 & AJ507496 \\
\hline 220 & uncultured eubacterium WD2108 & 0,915 & AJ292611 \\
\hline 230 & uncultured eubacterium WD271 & 0,986 & AJ292602 \\
\hline 233 & Sphingomonas sp. PC5.28; DSM 9259 & 0,943 & X89909 \\
\hline 254 & Acidisphaera sp. NO-15 & 0,965 & AF376024 \\
\hline 286 & uncultured eubacterium WD297 & 0,915 & AJ292607 \\
\hline 311 & uncultured Acidiphilium sp.; C-2 & 1,000 & AY270161 \\
\hline 317 & Sphingomonas sp. Enf2 & 0,862 & DQ339610 \\
\hline 319 & Acidiphilium angustum & 0,983 & M79365 \\
\hline 329 & Sphingomonas sp. BF14; DSM 9257 & 0,961 & Z23157 \\
\hline 338 & eubacterial soil DNA clone S-18 & 0,965 & AF016733 \\
\hline 351 & uncultured Acidiphilium sp.; C-2 & 0,469 & AY270161 \\
\hline 371 & Agrobacterium rhizogenes; A94 & 0,848 & DQ335113 \\
\hline 372 & uncultured alpha proteobacterium; DGGE band BDPM28 & 0,847 & AJ831517 \\
\hline 374 & uncultured soil bacterium; F57_Pitesti & 0,971 & DQ378219 \\
\hline 386 & uncultured Bradyrhizobium sp.; SSCP Band 09 & 0,844 & AM267488 \\
\hline 387 & uncultured alpha proteobacterium; ACK-DH13 & 0,869 & U85153 \\
\hline 388 & uncultured bacterium; C-CF-28 & 0,854 & AF443569 \\
\hline 389 & uncultured soil bacterium; G6-13 & 0,816 & AY846164 \\
\hline 402 & uncultured eubacterium WD295 & 0,911 & AJ292606 \\
\hline 416 & uncultured alpha proteobacterium; ACK-W10 & 0,844 & U85158 \\
\hline 421 & uncultured bacterium; DGGE gel band 7 & 0,659 & AY509582 \\
\hline 423 & bacterium Ellin5086 & 0,874 & AY234503 \\
\hline 445 & uncultured bacterium; DR550SWSAEE41 & 0,892 & DQ354729 \\
\hline 460 & uncultured alpha proteobacterium; ACK-M37 & 0,900 & U85157 \\
\hline 461 & uncultured alpha proteobacterium; ACK-DE34 & 0,751 & U85151 \\
\hline 471 & uncultured eubacterium WD233 & 0,971 & AJ292595 \\
\hline 472 & Sphingomonas sp. CHNTR37 & 0,935 & DQ337575 \\
\hline 476 & uncultured bacterium; $\mathrm{S} 13$ & 0,954 & AY055069 \\
\hline 478 & uncultured soil bacterium; S0215 & 0,882 & AF507572 \\
\hline 504 & Gluconacetobacter hansenii; LMG 1529 & 0,312 & AJ012544 \\
\hline 510 & uncultured bacterium; AKIW916 & 0,915 & DQ129276 \\
\hline 525 & uncultured eubacterium WD2119 & 0,969 & AJ292613 \\
\hline 526 & Rhodopila globiformis; 15740 & 0,912 & AY229979 \\
\hline 527 & uncultured eubacterium WD238 & 0,836 & AJ292597 \\
\hline 549 & uncultured bacterium; 1174-901-15 & 0,911 & AB128887 \\
\hline
\end{tabular}




\begin{tabular}{|c|c|c|c|}
\hline 560 & uncultured atmospheric bacterium RM3C-1 & 0,921 & AF240481 \\
\hline 566 & uncultured alpha proteobacterium; BPC3_C08 & 0,889 & AY690057 \\
\hline 586 & uncultured bacterium; DGGE band YNPRH-B5 & 0,814 & AF465664 \\
\hline 591 & uncultured Afipia sp.; SSCP Band 22-B2C from PCB-biofilm 2 & 0,821 & AJ966832 \\
\hline 594 & uncultured bacterium; DGGE band $\mathrm{RH} 2-4$ & 0,874 & AY817743 \\
\hline \multicolumn{4}{|c|}{$\beta$-Proteobacteria } \\
\hline 186 & uncultured Burkholderia sp.; SBS2w58 & 0,964 & AY556534 \\
\hline 231 & Burkholderia sp. CD9 & 0,978 & AY178076 \\
\hline 235 & Burkholderia sp. CK68 & 0,940 & DQ195918 \\
\hline 259 & uncultured beta proteobacterium; F03_Pitesti & 0,979 & DQ378169 \\
\hline 352 & Burkholderia sp. PB1 & 0,920 & AJ971346 \\
\hline 422 & Herbaspirillum sp. Chnp3-5 & 0,948 & AY367037 \\
\hline 564 & uncultured beta proteobacterium; NEC11006 & 0,985 & AY911464 \\
\hline 573 & uncultured beta proteobacterium; 44a-U1-9 & 0,838 & AY082479 \\
\hline 581 & uncultured bacterium; SM-OTU74 & 0,764 & AY321247 \\
\hline \multicolumn{4}{|c|}{$\underline{\gamma \text {-Proteobacteria }}$} \\
\hline 189 & uncultured gamma proteobacterium; ACK-SA1 & 0,551 & U85137 \\
\hline 229 & uncultured bacterium; DR550SWSAEE45 & 0,917 & DQ354732 \\
\hline 234 & uncultured gamma proteobacterium; cEV18 & 0,987 & AY357961 \\
\hline 294 & uncultured bacterium; AS17 & 0,987 & AJ631208 \\
\hline 336 & uncultured bacterium; U8_18p1 & 0,990 & AY547899 \\
\hline 438 & uncultured gamma proteobacterium; BPM2_C11 & 0,925 & AY689643 \\
\hline 448 & uncultured bacterium; HPG-SRK-1 & 0,984 & DQ159121 \\
\hline 470 & uncultured gamma proteobacterium; BPM1SE05 & 0,955 & AY689857 \\
\hline 533 & uncultured gamma proteobacterium; BPM2_B02 & 0,959 & AY689644 \\
\hline 583 & uncultured proteobacterium; MAH15 & 1,000 & AJ629856 \\
\hline \multicolumn{4}{|c|}{$\underline{\delta \text {-Proteobacteria }}$} \\
\hline 116 & eubacterial soil DNA clone S-27 & 0,680 & AF016740 \\
\hline \multicolumn{4}{|c|}{ Acidobacteria } \\
\hline 104 & uncultured soil bacterium; G10-23 & 0,909 & AY845991 \\
\hline 114 & uncultured Acidobacteria bacterium; BSR2SA02 & 0,931 & AY689683 \\
\hline 122 & bacterium Ellin337 & 0,842 & AF498719 \\
\hline 142 & uncultured eubacterium; ACK-C84 & 0,647 & U85142 \\
\hline 162 & Acidobacteriaceae bacterium TAA43 & 0,872 & AY587228 \\
\hline 202 & uncultured eubacterium WD277 & 0,951 & AJ292587 \\
\hline 208 & uncultured Acidobacteria bacterium; BDC3SE10 & 0,944 & AY689605 \\
\hline 225 & uncultured eubacterium WD243 & 0,934 & AJ292579 \\
\hline 240 & Acidobacteriaceae bacterium Gsoil 969 & 0,933 & AB245337 \\
\hline 245 & uncultured Acidobacteria bacterium; BPM2_F06 & 0,930 & AY689641 \\
\hline 253 & uncultured Acidobacterium sp.; C-8 & 0,971 & AY270167 \\
\hline 282 & uncultured Acidobacteria bacterium; BPM2_E01 & 0,923 & AY689658 \\
\hline 346 & uncultured Acidobacteria bacterium; BDC3SC07 & 0,865 & AY689585 \\
\hline 348 & uncultured bacterium; 655940 & 0,911 & DQ404812 \\
\hline 364 & uncultured Acidobacteria bacterium; BSR3SB05 & 0,905 & AY690189 \\
\hline 418 & uncultured bacterium; BI6 & 0,859 & AY092384 \\
\hline 427 & bacterium Ellin351 & 0,837 & AF498733 \\
\hline 458 & uncultured bacterium; MNM13.2 & 0,906 & DQ202228 \\
\hline 479 & uncultured Acidobacteriales bacterium; DGGE band B1 & 0,603 & AY523608 \\
\hline 509 & uncultured soil bacterium; G10-15 & 0,916 & AY845982 \\
\hline 518 & uncultured Acidobacteria bacterium; BPM3_B12 & 0,850 & AY689921 \\
\hline
\end{tabular}


521 uncultured eubacterium WD257

$0,767 \quad$ AJ292583

538 uncultured eubacterium WD228

$0,910 \quad$ AJ292578

587 unidentified bacterium; FA2

0,911

$\mathrm{AB} 005821$

\section{$\underline{\text { Cyanobacteria }}$}

126 chlorophyte isolate CMS93

185 uncultured phototrophic eukaryote; BPM3_B10

0,964 AJ880281

0,629 AY689896

CFB-Gruppe

181

uncultured Bacteroidetes bacterium; BPC3_F06

$0,862 \quad$ AY690048

250 uncultured bacterium; JE39

0,877 DQ004776

377 uncultured Bacteroidetes bacterium; SW63

0,839 AJ575724

382 uncultured Bacteroidetes bacterium; JG35+U2A-AG9

0,868 AM114441

434 uncultured Bacteroidetes bacterium; BSR3SE12

0,932

0,887

AY690193

531

uncultured bacterium FukuN23; FukuS23

\section{Gram-positive}

140 unidentified eubacterium 190R6

0,206 U35516

203 Mycobacterium triplex; NITBRL171101

0,875

0,911

Subtercola boreus ( $\mathrm{T}$ )

248 uncultured bacterium; $\mathrm{AH} 28$

0,862

uncultured soil bacterium; S0230

0,239

0,808

0,602

0,784

0,778

1,000

0,997

0,853

0,885

AY062938

AF224722

AY963321

AF507581

335 Rubrobacterales bacterium Pa33

DQ533685

493 uncultured soil bacterium; S0161

AY250896

517 uncultured eubacterium 2112

537 uncultured Mycobacterium sp.; A6

AF507535

547

552

uncultured Mycobacterium sp.; M1

AJ292683

bacterium Ellin5111

AJ488923

553

uncultured actinobacterium; BPM3_G08

unklassifizierte Organismen

unidentified bacterium; 4511

0,169

0,740

0,603

0,490

0,705

0,761

0,708

0,205

0,787

0,793

0,808

0,713

0,682

0,821
AJ488914

AY234528

AY689887

X89318

AJ884743

DQ385039

AJ318764

DQ340277

AJ966851

AY913563

AF507563

AJ874226

AY917804

AM269456

AY917329

AF228145

AJ292686

${ }^{1}$ Die Nummern geben die Nummern der 480 ursprünglichen Klone in den Mikrotiterplatten (101196, 201-296, usw.) wieder. ${ }^{2}$ Zur Berechnung des Ähnlichkeitswertes wird die Sequenz in Oligonukleotide zu 7 bp zerlegt. Der Ähnlichkeitswert berechnet sich aus der Anzahl der gemeinsamen (einzigartigen) Oligonukleotide zwischen zwei Sequenzen, dividiert durch die niedrigste Anzahl an einzigartigen Oligonukleotide einer der beiden Sequenzen. 


\section{Danksagung}

Mein besonderer Dank gilt Herrn Prof. Dr. Wolfgang Streit für die Überlassung des interessanten Themas, die Möglichkeit selbstständigen wissenschaftlichen Arbeitens und die Unterstützung während der Arbeit.

Herrn Prof. Dr. Wolfgang Liebl danke ich für die Übernahme des Korreferates der Arbeit.

Für die angenehme Arbeitsatmosphäre gilt mein besonderer Dank den Laboren 37/44 der AG LiebI/Streit an der Universität Göttingen mit sämtlichen ehemaligen Mitarbeitern und Mitarbeiterinnen. Da ich niemanden vergessen will, verzichte ich lieber auf die Aufzählung sämtlicher Namen, da es doch einige waren im Laufe der Zeit.

Gleiches gilt selbstverständlich für das Biofilm Centre mit der neu aufgebauten AG Molekulare Enzymtechnologie an der Universität Duisburg-Essen mit allen Mitarbeiterinnen und Mitarbeitern sowie die AG Flemming. Ein besonderer Dank geht dabei an Helen für die Mithilfe am ersten Paper.

Für das Korrekturlesen von Teilen der Arbeit und die konstruktiven Anmerkungen danke ich Armin, Christel, Sonja, Meike, Katrin und Helen.

Den Mitarbeitern der AG Prof. Reetz am Pax-Planck-Institut für Kohlenforschung in Mülheim an der Ruhr, Horst Höbenreich und Dr. José Daniel Carballeira Rodriguez, danke ich für das zur Verfügung stellen der synthetisierten Substrate und die durchgeführten GC-Analysen.

Für die Einarbeitung in die Micorarray-Technologie und sämtliche weitere Zusammenarbeit danke ich Dr. Armin Ehrenreich, für die Zusammenarbeit mit den EstCE-Kristallen Dr. Oliver Einsle (beide Universität Göttingen).

Für die Messungen der verschiedenen Modellsubstrate für EstCE und die Möglichkeit, selber pH-Messungen vor Ort durchzuführen, sowie sämtliche anderen LipaseZusammenarbeiten gilt mein Dank Dr. Christian Leggewie (AG Prof. Jäger, FZ Jülich).

Weiterhin gilt mein Dank für die Erstellung der enzymatischen Fingerabdrücke Peter Babiak aus der AG Prof. Reymond (Universität Bern) und Robert Knierim (Theoretische Chemie, Uni Duisburg-Essen) für die Messungen der CD-Spektren.

Zu guter Letzt geht mein Dank natürlich an meine Familie für die Unterstützung während des gesamten Studiums und der Promotionszeit. 


\section{Lebenslauf}

\begin{tabular}{|c|c|}
\hline 02.05.1977 & $\begin{array}{l}\text { geboren in Göttingen } \\
\text { deutsche Staatsbürgerschaft }\end{array}$ \\
\hline 1984-1988 & Besuch der Grundschule Friedland \\
\hline $1988-1990$ & Besuch der Orientierungsstufe Groß Schneen \\
\hline $1990-1996$ & Besuch des Felix-Klein-Gymnasiums, Göttingen \\
\hline 05/1996 & Abitur \\
\hline 09/1996-06/1997 & Grundwehrdienst in Hamm/Westfalen \\
\hline 10/1997 & $\begin{array}{l}\text { Immatrikulation im Fach Biologie an der Georg-August- } \\
\text { Universität Göttingen }\end{array}$ \\
\hline 10/1999 & $\begin{array}{l}\text { Vordiplom in den Fächern Zoologie, Mikrobiologie, Chemie } \\
\text { und Physikalische Chemie }\end{array}$ \\
\hline $02 / 2002$ & $\begin{array}{l}\text { Diplomprüfung in den Fächern Mikrobiologie, Genetik und } \\
\text { Organische Chemie }\end{array}$ \\
\hline $03 / 2002-01 / 2003$ & $\begin{array}{l}\text { Anfertigung der experimentellen Diplomarbeit unter Anleitung } \\
\text { von Prof. Dr. W. Liebl mit dem Titel: „Chromosomale } \\
\text { Inaktivierung eines Corynebacterium glutamicum } \\
\text { Restriktionssystems“ }\end{array}$ \\
\hline $02 / 2003$ & $\begin{array}{l}\text { Beginn der experimentellen Arbeiten zur vorliegenden } \\
\text { Dissertation am Institut für Mikrobiologie und Genetik der } \\
\text { Georg-August-Universität Göttingen }\end{array}$ \\
\hline seit $05 / 2005$ & $\begin{array}{l}\text { Fortsetzung der Arbeiten am Biofilm Centre der Universität } \\
\text { Duisburg-Essen }\end{array}$ \\
\hline
\end{tabular}

